\title{
Process Modeling and Techno-Economic Analysis of Thermo- Catalytic Dimethyl Ether Synthesis and Microwave-Based Aromatics Production Technologies from Shale Gas
}

\author{
Chirag Mevawala \\ West Virginia University, chmevawala@mix.wvu.edu
}

Follow this and additional works at: https://researchrepository.wvu.edu/etd

Part of the Catalysis and Reaction Engineering Commons, Other Chemical Engineering Commons, Thermodynamics Commons, and the Transport Phenomena Commons

\section{Recommended Citation}

Mevawala, Chirag, "Process Modeling and Techno-Economic Analysis of Thermo-Catalytic Dimethyl Ether Synthesis and Microwave-Based Aromatics Production Technologies from Shale Gas" (2020). Graduate Theses, Dissertations, and Problem Reports. 7963.

https://researchrepository.wvu.edu/etd/7963

This Dissertation is protected by copyright and/or related rights. It has been brought to you by the The Research Repository @ WVU with permission from the rights-holder(s). You are free to use this Dissertation in any way that is permitted by the copyright and related rights legislation that applies to your use. For other uses you must obtain permission from the rights-holder(s) directly, unless additional rights are indicated by a Creative Commons license in the record and/ or on the work itself. This Dissertation has been accepted for inclusion in WVU Graduate Theses, Dissertations, and Problem Reports collection by an authorized administrator of The Research Repository @ WVU.

For more information, please contact researchrepository@mail.wvu.edu. 


\title{
Process Modeling and Techno-Economic Analysis of Thermo-Catalytic Dimethyl Ether Synthesis and Microwave-Based Aromatics Production Technologies from Shale Gas
}

\author{
Chirag Mevawala \\ Dissertation submitted \\ to the Benjamin M. Statler College of Engineering and Mineral Resources \\ at West Virginia University \\ in partial fulfillment of the requirements for the degree of \\ Doctor of Philosophy \\ in \\ Chemical Engineering
}

Debangsu Bhattacharyya, Ph.D., Chair

Jinali $\mathrm{Hu}$, Ph.D.

Richard Turton, Ph.D.

Stephen E. Zitney, Ph.D.

Xingbo Liu, Ph.D.

Jingxin Wang, Ph.D.

Department of Chemical and Biomedical Engineering

Morgantown, West Virginia

2020

Keywords: shale gas, dimethyl ether (DME), methane dehydro-aromatization (DHA), microwave (MW), modeling, techno-economic analysis, parameter estimation

Copyright 2020 Chirag Mevawala 


\title{
Abstract \\ Process Modeling and Techno-Economic Analysis of Thermo-Catalytic Dimethyl Ether Synthesis and Microwave-Based Aromatics Production Technologies from Shale Gas
}

\author{
Chirag Mevawala
}

Production of majority of the transportation fuels and other value-added chemicals, such as aromatics and olefins, has been heavily dependent on petroleum based resources. These fuel resources have resulted in increase in global greenhouse gases. Moreover, the conventional oil production is expected to reach its peak from early 2020s to the 2040s, followed by a terminal decline in oil production [1]. As a result, it is necessary to develop cleaner and more carbon efficient non-petroleum based transportation fuels and value-added chemicals. The goal of this research is to develop plant-wide process models and perform techno-economic analysis and optimization to identify the economic feasibility of the shale-gas utilization processes. The focus of this work is the development of plant-wide models for production of dimethyl ether (DME) from shale gas via direct and indirect synthesis route, and development of reactor and plant-wide process models for direct non-oxidative methane dehydro-aromatization (DHA) to aromatics via conventional and microwave (MW) heating.

Plant-wide models of the shale gas to dimethyl ether (DME) process with integrated $\mathrm{CO}_{2}$ capture via direct and indirect synthesis routes has been developed in Aspen Plus V8.4®. Models of the pre-reforming reactor, autothermal reforming (ATR) reactor and DME synthesis reactors using kinetic data have been developed. For $\mathrm{CO}_{2}$ capture, Rectisol and methyl diethanolamine (MDEA)/piperazine (PZ) technologies have been evaluated and results have been compared with the experimental data. A novel DME separation process has been developed and evaluated for efficient separation of DME, syngas, and $\mathrm{CO}_{2}$. Binary interaction parameters for the vapor-liquid equilibrium (VLE) model of the methanol-DME-CO- $\mathrm{CO}_{2}-\mathrm{H}_{2} \mathrm{O}-\mathrm{H}_{2}$ system are regressed using the

experimental data. Effects of the key parameters like $\mathrm{CO}_{2}$ recycle ratio and $\mathrm{H}_{2} / \mathrm{CO}$ ratio on the 
utility consumption in the syngas synthesis unit, acid gas removal (AGR) unit, DME synthesis unit and DME separation unit are studied. In addition, plant-wide techno-economic optimization is performed in Aspen Plus Equation Oriented Environment with a modified formulation for net present value (NPV), which considers both capital cost (CAPEX) and operating cost (OPEX), as the objective function. Effects of key design parameters as well as investment parameters on the process economics have been evaluated.

In the direct non-oxidative methane DHA process, dynamic data reconciliation, parameter estimation, and multi-scale fixed-bed reactor model development for the direct non-oxidative methane dehydroaromatization (DHA) process has been performed. Due to rapid coke formation, catalysts in the non-oxidative methane DHA reactors get deactivated. A model for deactivation is required for designing the cycle conditions and to calculate the number of reactors for a fixed-bed DHA process. Therefore, a model for the catalyst deactivation is developed along with rate models for other DHA reactions and validated with experimental data. Due to the very fast coke formation rate on the fresh catalyst, there is coke formation during the induction period. Extent of catalyst deactivation at the end of the induction period is desired for estimation of reaction rate parameters, but it cannot be measured in real time. Therefore, an algorithm is developed for estimation of the initial state of the reactor and the kinetic parameters by coupling an iterative direct substitution approach with an optimization approach. Experimental data from an in-house reactor are used for developing the kinetic model. Using the rate model, a dynamic, heterogeneous, multi-scale reactor model, with embedded heating is developed for conventional heating reactor, and effect of key variables on the reactor performance has been evaluated. For microwave-assisted heating reactor, amount of MW power absorbed at a specific catalyst site is modeled using Maxwell's equation. For integrating the Maxwell's equation with process model, a reduced order model is developed. The reduced order model is a function of temperature, dielectric properties, and input power. A 2D multi-scale heterogeneous industrial scale MW reactor model has been developed coupling catalyst pellet level and reactor level model. The reduced order MW propagation model has been coupled with heat and mass transfer equations to study the effect the MW on heat, mass, and reaction limitation. Temperature difference between the metal particles sites and catalyst support sites have also been investigated. 


\section{Dedicated to}

My Grandparents, Parents, and Sister 


\section{Acknowledgements}

I would like to extend my deepest gratitude to Dr. Debangsu Bhattacharyya, my advisor, for giving me an opportunity to further my education as PhD student in his research lab. I would also like to thank him for his support, patience, and mentorship in my development as researcher. His knowledge, advice, and expertise were extremely valuable and helpful to me in tackling research problems throughout my career as a PhD student. I am also very thankful to Dr. Jinali Hu, with whom I collaborated extensively on the methane DHA project. Dr. Hu's expertise in microwave catalysis, and his industrial experience gave me a unique perspective in my research work. I would also like to thank Dr. Hu for always willing to prioritize experiments that were useful in my estimation work. I also extend my deepest gratitude to my committee members, Dr. Richard Turton, Dr. Stephen E. Zitney, Dr. Xingbo Liu, and Dr. Jingxin Wang for their keen insight, advice, and guidance in this research work.

I would like to thank Dr. Yuan Jiang for her mentorship during my first two years at West Virginia University. I would also like to thank Goutham Kotamreddy for sharing his knowledge and key insights on ACM, and for his support as a friend. Thanks to Xinwei Bai for performing all the experiments for me and sharing his knowledge on catalysis. Also, thanks to all the members from Dr. Debangsu's research group for making this journey a memorable one.

Most importantly, I would like to thank my mom and dad for their sacrifice and support. To my sister, for always being there for me and giving me the confidence to pursue this, and to my wife for always lifting up my spirit during difficult times.

I would like to gratefully acknowledge financial support from the West Virginia University through STEM Mountains of Excellence fellowship. I would also like to acknowledge financial support from RAPID Manufacturing Institute under project no. DE-EE0007888-06-07. 


\section{Table of Contents}

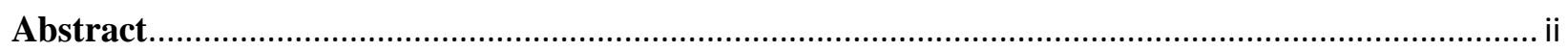

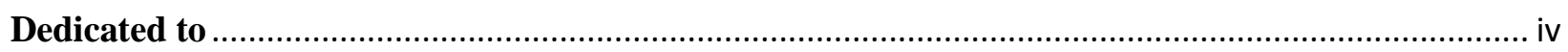

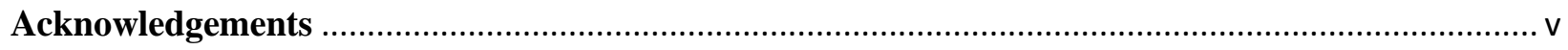

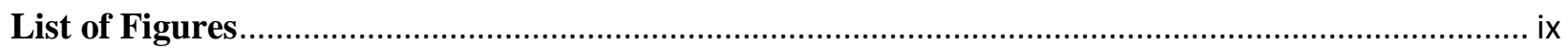

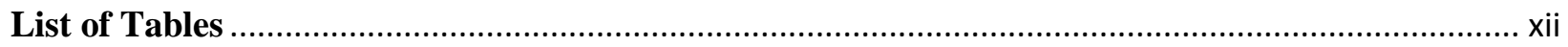

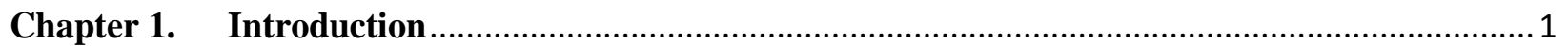

1.1. Dimethyl Ether (DME) Production Process ........................................................... 1

1.2. Aromatics Production Process ................................................................................... 2

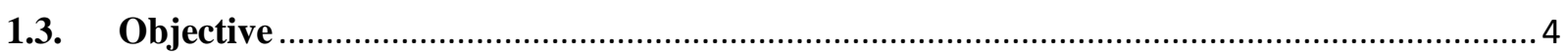

Chapter 2. Plant-Wide Modeling of Shale-gas Conversion to DME via Direct and Indirect

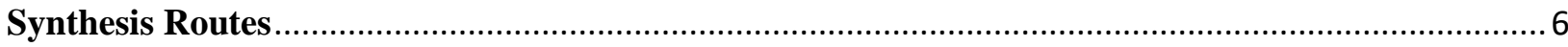

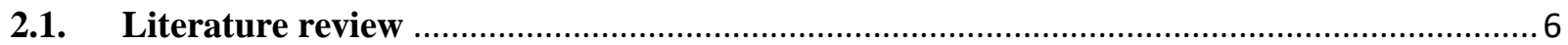

2.2. Steady-State Modeling of Shale-gas to DME Production Process via Direct and Indirect

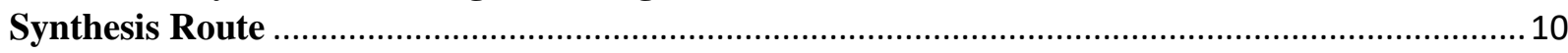

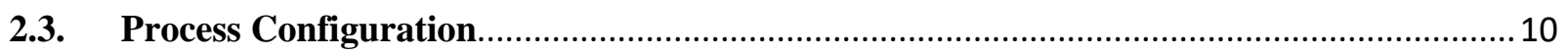

2.4. Heat Integration and Heat Exchanger Design........................................................ 13

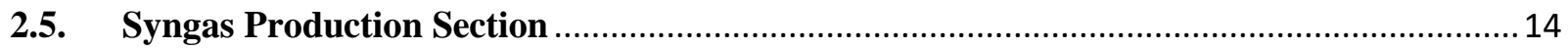

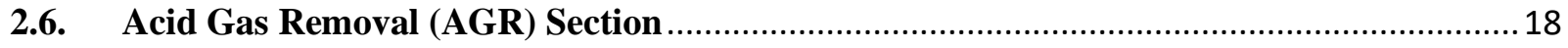

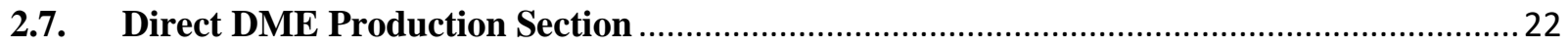

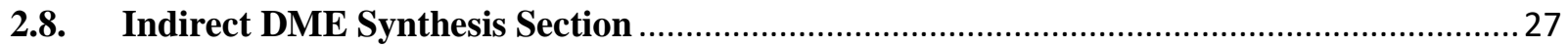

2.9. Heat Recovery Steam Generation (HRSG) and Steam Cycle ..........................................30

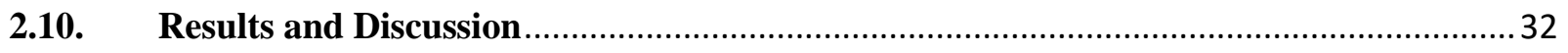

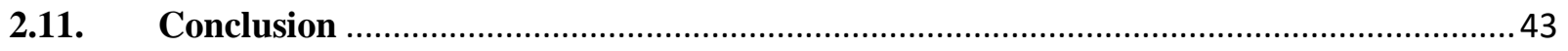

Chapter 3. Techno-Economic Optimization of Shale gas to DME Production Process via Direct

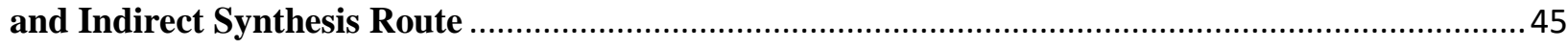

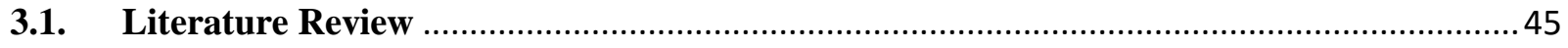

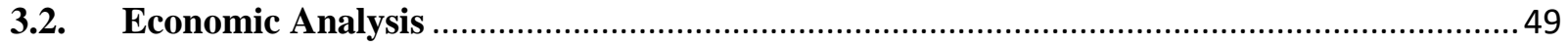

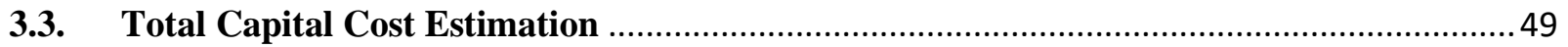

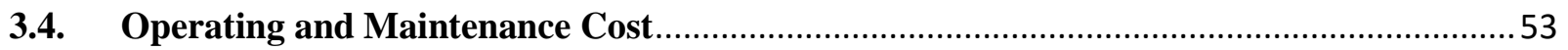

3.5. Optimization in Aspen Plus Equation Oriented Environment …..................................54

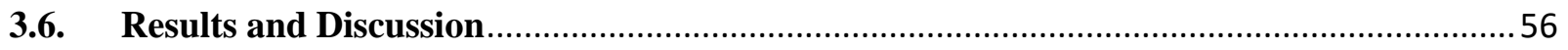

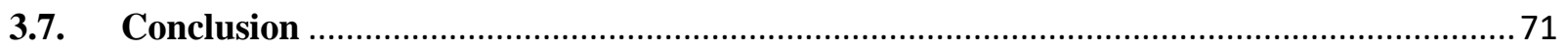


Chapter 4. Dynamic Data Reconciliation, Parameter Estimation, and Multi-Scale Reactor Modeling of the Direct Non-Oxidative Methane Dehydroaromatization Process

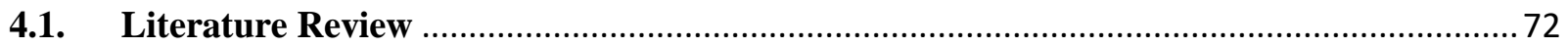

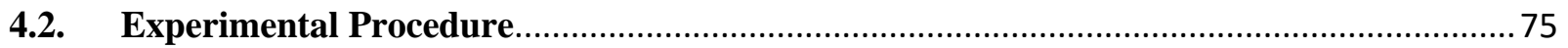

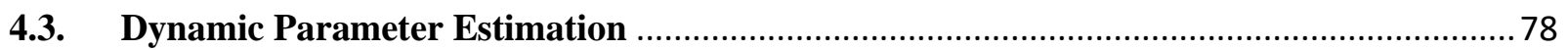

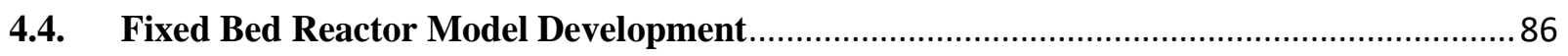

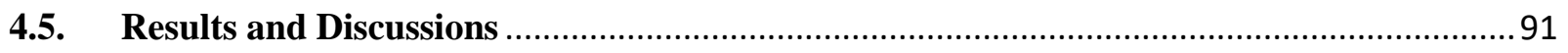

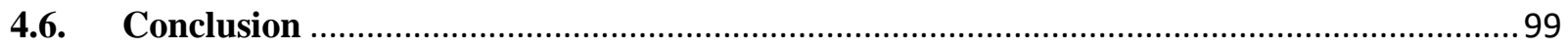

Chapter 5. Dynamic Data Reconciliation, Parameter Estimation, and Multi-Scale Modeling of the Microwave-Assisted Methane Dehydroaromatization Process ..............................................100

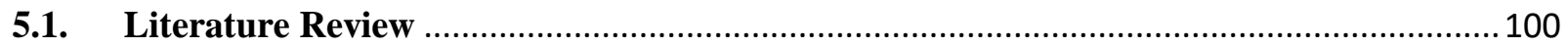

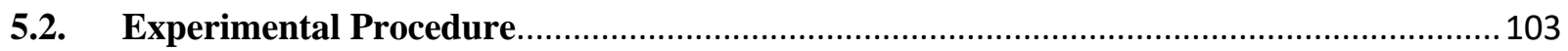

5.3. Reaction Model, Dynamic Data Reconciliation, and Parameter Estimation.....................105

5.4. Microwave Power Absorption and Reduced Order Model Development ....................... 113

5.5. Microwave Reactor Model Development........................................................................119

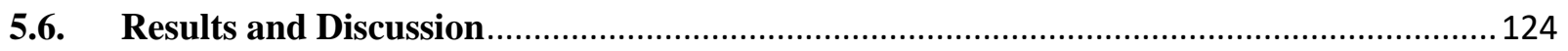

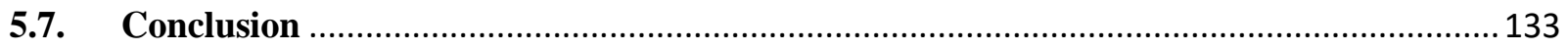

Chapter 6. Plant-Wide Modeling and Techno-Economic Analysis of Direct Non-Oxidative Methane DHA Via Conventional and MW Catalysis ................................................................ 135

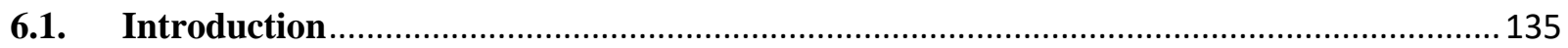

6.2. Direct Non-oxidative Methane DHA Plant-Wide Model................................................136

6.3. Shale Gas Conversion to Aromatics Via Methanol Synthesis Plant-Wide Model ............141

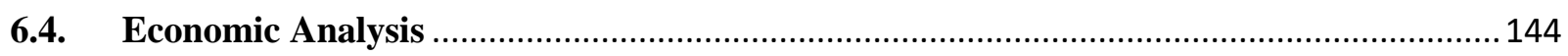

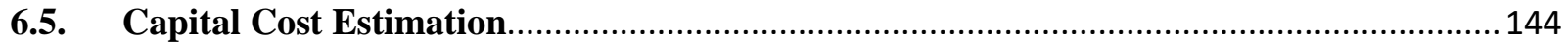

6.6. Operating \& Maintenance Cost Estimation ................................................................ 146

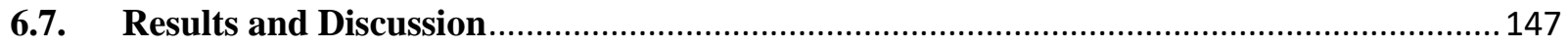

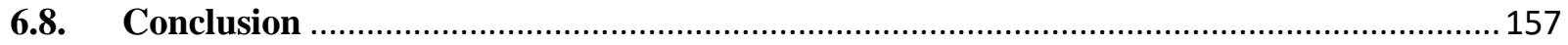

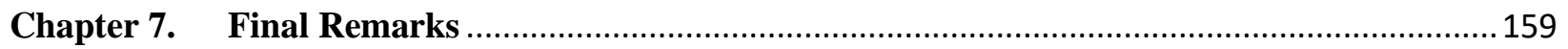

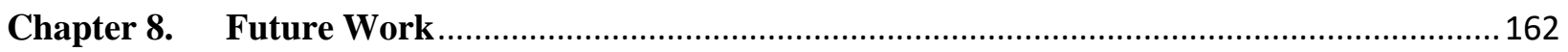

Appendix A: Equilibrium Constant Coefficient and Estimated Kinetic Parameters for Direct DME

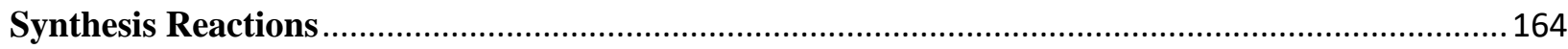

Appendix B: Regressed Binary Interaction Parameters for ${\mathrm{DME}-\mathrm{CO}_{2}, \text { Methanol-CO}}_{2}, \mathrm{DME}-\mathrm{H}_{2} \mathrm{O}$,

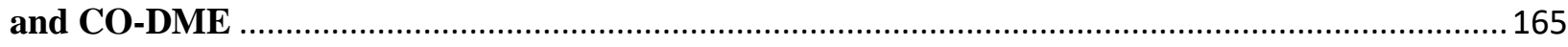

Appendix C: Validation of Methanol Dehydration Reactor Model ..............................................166

Appendix D: Equipment Details for Direct and Indirect DME Production Process.......................168 
Appendix E: Bare Module Cost Correlation between APEA and Cost Equations.....

Appendix F: Temperature Profile TGA Experiments.

Appendix G: Methane DHA Conventional Heating- Data Reconciliation Plots for $725^{\circ} \mathrm{C}$ and $750^{\circ} \mathrm{C}$

Appendix H: Methane DHA Conventional Heating- Model Comparison with Experiment for $\mathbf{8 0 0}^{\circ} \mathrm{C}$ .

Appendix I: Gantt Chart for 2-parallel Reactor Cyclic Operation ..............................................173

Appendix J: Derivation of Radiation Boundary Condition ......................................................... 174

Appendix K: Estimated Constants for Reduced Order Microwave Power Absorption Model and

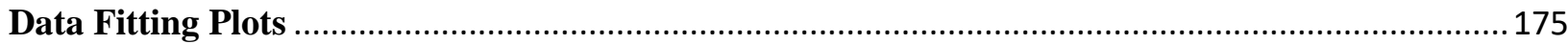

Appendix L: Reactor Performance for 915 MHz Frequency .................................................... 177

Appendix M: Time-Varying Profiles for Methane DHA Conventional Heating Reactor at $7_{00}^{\circ} \mathrm{C}$,

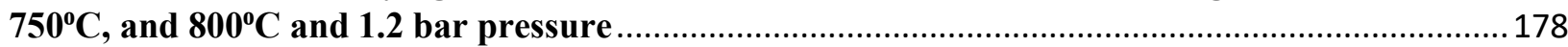

Appendix N: Shale Gas to Aromatics Via Methanol Synthesis Process- Products Throughput .....179

Appendix O: Publications and Presentations ........................................................................... 180

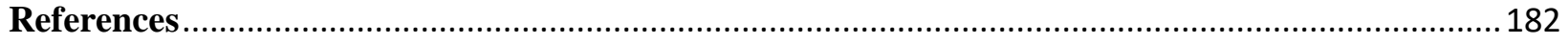




\section{List of Figures}

Figure 2.1: Block flow diagram of DME production process via direct synthesis route ..................11

Figure 2.2: Block flow diagram of DME production process via indirect DME synthesis route ......112

Figure 2.3: Configuration of the Syngas Synthesis Section........................................................ 15

Figure 2.4: Schematic of the Rectisol Process .............................................................................20

Figure 2.5: Schematic of the MDEA/PZ-Based Absorption Process for $\mathrm{CO}_{2}$ Removal ...................22

Figure 2.6: Configuration of the DME Synthesis Unit ............................................................23

Figure 2.7: Comparison of the Estimated Mole Fractions with the Experimental Data from Nie et

al. [74]

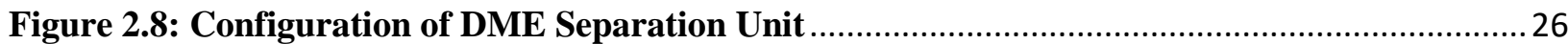

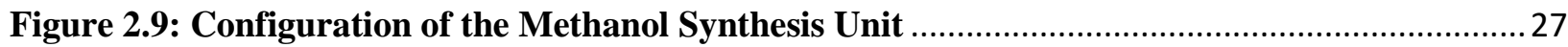

Figure 2.10: Concentration and Temperature Profile of the Methanol Synthesis Reactor ..............28

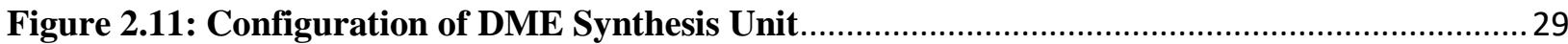

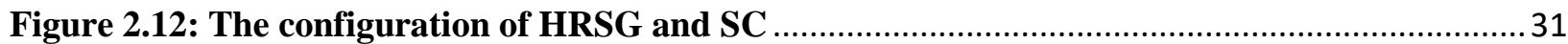

Figure 2.13: Sensitivity of $\mathrm{H}_{2} / \mathrm{CO}$ Ratio to the $\mathrm{CO}_{2}$ Recycle Ratio..............................................34

Figure 2.14: Effect of the $\mathrm{H}_{2} / \mathrm{CO}$ ratio on DME Productivity at $260^{\circ} \mathrm{C}, 50 \mathrm{bar}, 1.35 \mathrm{~h}-1 \mathrm{WHSV} \ldots . .38$

Figure 2.15: Effect of the $\mathrm{CO}_{2}$ Content on DME Productivity ......................................................39

Figure 2.16: Effect of Methanol Content on DME and $\mathrm{CO}_{2}$ Captured in the Absorber ................... 41

Figure 2.17: Effect of the Methanol Content on Reboiler Duty ..................................................42

Figure 2.18: Effect of Syngas Module on Methanol Production at $250{ }^{\circ} \mathbf{C}, 60$ bar and................... 42

Figure 3.1: Breakdown of plant total direct cost by section (10\% IRR, 5,000 MTPD DME) ..........63

Figure 3.2: Feasibility envelop for direct DME synthesis process (Rectisol Technology; 5,000 MTPD

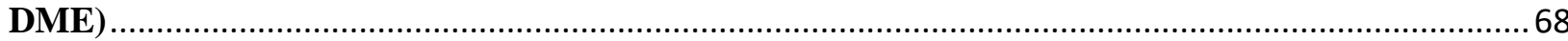

Figure 3.3: Feasibility envelop for indirect DME synthesis process (Rectisol Technology; 5,000

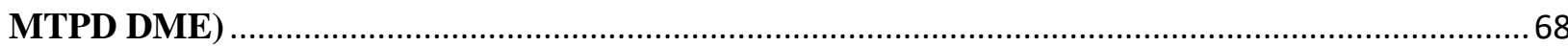

Figure 3.4: Effect of electricity price on breakeven DME price (Rectisol Technology, 20\% IRR;

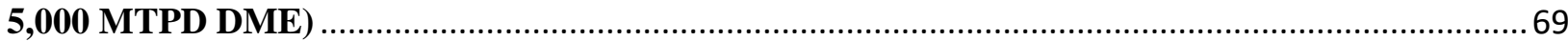

Figure 3.5: Effect of project scale on breakeven DME price, CAPEX, and OPEX (Rectisol

Technology, 20\% IRR). Direct synthesis process (circle w/ blue line); indirect synthesis process

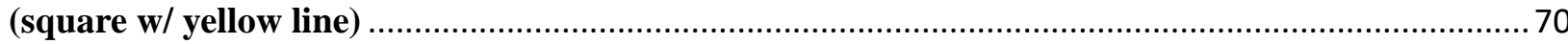

Figure 3.6: The sensitivity of breakeven DME price to plant contingency for direct DME synthesis process (Rectisol Technology; 20\% IRR; 5,000 MTPD DME) ......................................................70

Figure 4.1: Experimental setup for conducting methane DHA reactions......................................76

Figure 4.2: TGA result of the spent catalyst samples: (a): $725^{\circ} \mathrm{C} ;(\mathrm{b}): 750^{\circ} \mathrm{C} ;(\mathrm{c}): 7^{\circ} 5^{\circ} \mathrm{C} ;(\mathrm{d}): 8^{\circ 00} \mathrm{C}$

(only the step 6 in the Figure F.1. is shown here; the weight at the end of step 7 and the detailed reading can be found in Appendix $F$

Figure 4.3: Comparison of experimental and reconciled data for $775^{\circ} \mathrm{C}$. (a) methane; (b) benzene;

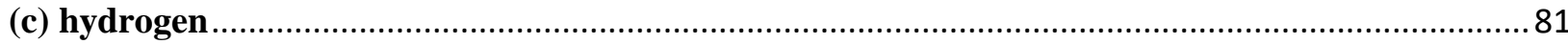

Figure 4.4: Algorithm to predict initial coke concentration for dynamic parameter estimation .......83

Figure 4.5: Comparison of model prediction with experimental data for three temperatures at 1 atmosphere. Model Prediction: Red line; Experimental Data: Blue line also includes standard

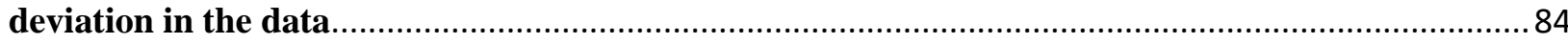

Figure 4.6: Effect of temperature on reactor performance parameters. (a) Methane conversion; (b) Benzene yield; (c) Ethylene yield; (d) Catalyst Activity ...........................................................93 
Figure 4.7: Profile of performance parameters over reactor length at different time instant for reactor operating at $700^{\circ} \mathrm{C}$ and 2.1 bar inlet pressure. (a) Bulk gas temperature; (b) Methane conversion; (c) Benzene yield; (d) Ethylene yield

Figure 4.8: Pressure drop and methane conversion for different $L / D$ ratio and inlet flowrate. (a) Methane conversion; (b) Pressure drop .95

Figure 4.9: Effect of change in catalyst activity on time average values of and standard deviation in (a) Methane Conversion; (b) Benzene Yield $\left(700^{\circ} \mathrm{C}, 2.1 \mathrm{bar}, 325 \mathrm{kmol} / \mathrm{h}(\mathrm{CH} 4-0.9, \mathrm{~N} 2-0.1 \mathrm{~mol} \%)\right.$

Figure 4.10: Sensitivity of methane standard deviation w.r.t off-set time between reactor \#1 and \#2

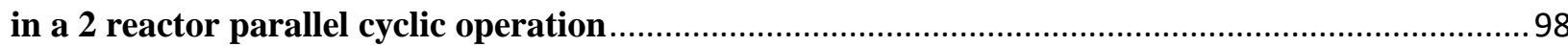

Figure 5.1: Experimental setup for variable-frequency MW reactor ...........................................104 Figure 5.2: TGA temperature profile for MW-assisted non-oxidative methane DHA reaction...... 105 Figure 5.3: Experimental and reconciled data at three experimental temperatures for methane,

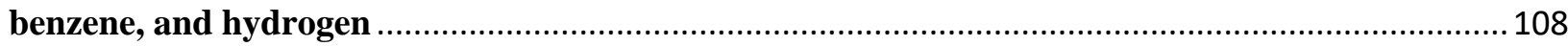
Figure 5.4: Algorithm to simultaneously predict the initial coke concentration and perform dynamic parameter estimation 110

Figure 5.5: Comparison of estimated and reconciled data after performing parameter estimation

Figure 5.6: Schematic of cylindrical MW reactor and incident MW 112

Figure 5.7: MW power absorbed modeled using Maxwell's equation and reduced order model. $550^{\circ} \mathrm{C}$ - (a) $2.45 \mathrm{GHz}$ (b) $915 \mathrm{MHz} ; 8^{\circ 00} \mathrm{C}$ - (c) $2.45 \mathrm{GHz}$ (d) $915 \mathrm{MHz}$ Figure 5.8: Impact of input $\mathrm{MW}$ power on reactor performance parameter for $2.45 \mathrm{GHz}$ operating frequency: a) methane conversion, b) benzene yield, c) ethylene yield, d) catalyst activity, e) bulk gas temperature

Figure 5.9: Sensitivity of input MW power on reactor performance

Figure 5.10: Spatial variation of area average (a) methane conversion, (b) benzene yield, (c) ethylene yield and (d) bulk gas temperature. $f=2.45 \mathrm{GHz} ; P_{\text {in }}=3.6$ mega-watts

Figure 5.11: Spatial variation of metal particle and catalyst support temperature at $t=1$ sec and $t=$ $1 \mathrm{~min}$, at the catalyst particle surface near the reactor center. MW absorption capacity of metal particle is increased by 200 times 130 Figure 5.12: Spatial variation of metal particle and catalyst support temperature at $t=1$ sec and $t=$ $1 \mathrm{~min}$, at the catalyst particle surface near the reactor center. (a)-(b) hmp $\cdot$ Acontact reduced by 95\%; (c) hmp $\cdot$ Acontact reduced by $100 \%$. MW power absorption by metal particles is 200 times higher than catalyst support 131

Figure 5.13: Spatial variation of volumetric average metal particle and catalyst support temperature at $\mathbf{t}=1 \mathrm{sec}$ and $\mathbf{t}=1 \mathrm{~min}$, at the catalyst particle surface near the reactor center. (a)-(b) $\mathrm{hmp} \cdot$ Acontact reduced by $95 \%$; (c) $\mathrm{hmp} \cdot$ Acontact reduced by $100 \%$. MW power absorption by metal particles is 200 times higher than catalyst support. Only reaction \#1 occurring on metal particle 133

Figure 6.1: Block flow diagram of direct non-oxidative methane DHA process via conventional and MW-assisted heating.....

Figure 6.2: Conventional shale gas conversion to aromatics via methanol synthesis 142 Figure 6.3: Effect of methane and hydrogen price on IRR and NPV for methane DHA processes $(19782 \mathrm{~kg} / \mathrm{h} \mathrm{CH} 4$ feed)

Figure 6.4: Effect of electricity and hydrogen price on IRR and NPV for methane DHA conventional heating process $\left(\mathrm{CH}_{4}\right.$ feed $\left.-19782 \mathrm{~kg} / \mathrm{h}, \mathrm{CH}_{4}-2.02 \$ / \mathrm{GJ}\right)$. 153 
Figure 6.5: Impact of catalyst cost and hydrogen price on IRR and NPV for methane DHA conventional heating process $\left(\mathrm{CH}_{4}\right.$ feed $-19782 \mathrm{~kg} / \mathrm{h}, \mathbf{C H}_{4}-\mathbf{2 . 0 2}$ \$/GJ, Electricity- 17.5 \$/GJ) ....154 Figure 6.6: Impact of MW reactor cost on process economics parameter for $\mathrm{MW}$-assisted process (scale - $19782 \mathrm{~kg} / \mathrm{h} \mathrm{CH}$ feed) 155

Figure 6.7: Impact of DROR on NPV of MW-assisted heating process operating at $800^{\circ} \mathrm{C}\left(\mathrm{CH}_{4}\right.$ Feed $-19782 \mathrm{~kg} / \mathrm{h})$. 156 


\section{List of Tables}

Table 2.1: Marcellus Shale Gas Composition.............................................................................. 13

Table 2.2: Reactions considered in the Kinetic Model.................................................................. 16

Table 2.3: Kinetic Parameters and Equilibrium Constants............................................................. 16

Table 2.4: Reactions considered in this Kinetic Model.................................................................. 17

Table 2.5: Validation of ATR Model with Hoang \& Chan [48] ..................................................... 17

Table 2.6: Performance of the Rectisol Process in Comparison to Gatti et al. [68] ..........................21

Table 2.7: Rate Model of the Direct Syngas to DME Synthesis Reaction [33,74] ...........................24

Table 2.8: Rate Model of the Methanol Synthesis Reaction...........................................................28

Table 2.9: Rate Model of the Methanol Dehydration Reaction ...................................................... 30

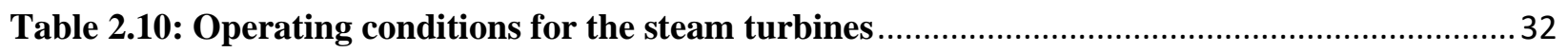

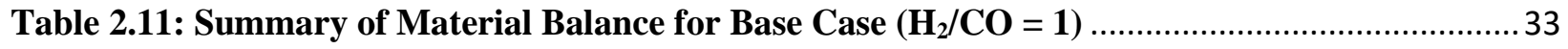

Table 2.12: Effect of the $\mathrm{CO}_{2}$ Recycle on Syngas Synthesis Unit ...................................................35

Table 2.13: Effect of $\mathrm{H}_{2} / \mathrm{CO}$ Ratio on $\mathrm{CO}_{2}$ Removal Technologies.................................................36

Table 2.14: Utility Consumption by DME Production Section when $\mathrm{H}_{2} / \mathrm{CO}=1$........................... 37

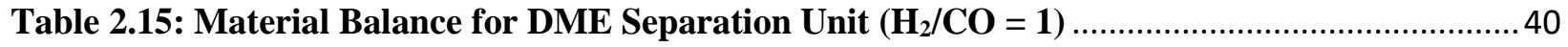

Table 2.16: Effect of $\mathrm{CO}_{2}$ Capture on Indirect DME Production Process ....................................... 43

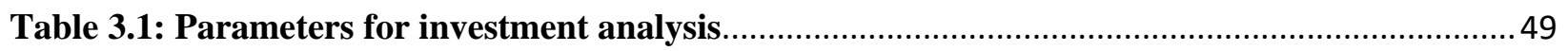

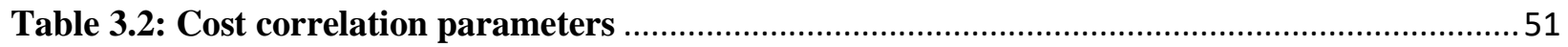

Table 3.3: Summary of equipment costing and specification for Rectisol process (Direct DME

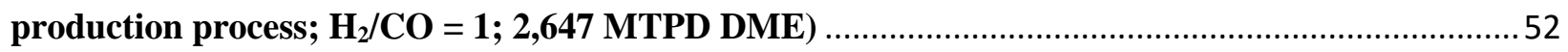

Table 3.4: Prices of raw material, product, utility, catalyst, and labor …......................................53

Table 3.5: Constraints on variables for the optimization of direct and indirect DME plant ............56

Table 3.6: Performance results for direct and indirect shale gas to DME process ............................58

Table 3.7: Comparison of AGR and DME production section cost with literature..........................60

Table 3.8: Comparison of shale to DME production process via direct synthesis $\left(\mathrm{H}_{2} / \mathrm{CO}=1 ; 5,000\right.$

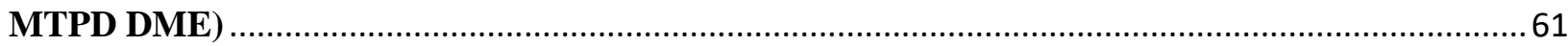

Table 3.9: Effect of $\mathrm{H}_{2} / \mathrm{CO}$ ratio on direct DME synthesis process and comparison with indirect

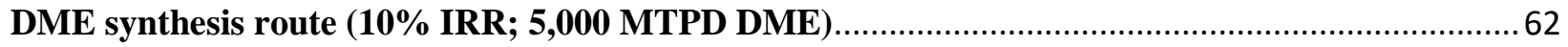

Table 3.10: Decision variable values before and after optimization ...........................................65

Table 3.11: Comparison of the economics between the base case and optimized case for 10\% IRR 66 Table 4.1: Numerical summary of the TGA result of the spent samples from different reaction

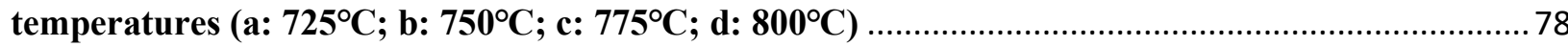

Table 4.2: Estimated values of the kinetic rate parameters and catalyst activity …......................... 85

Table 4.3: Comparison of model coke prediction with experiment ................................................ 85

Table 4.4: Values of some key parameters used for simulation.......................................................91

Table 4.5: Sensitivity study results for parallel reactor operation ............................................... 98

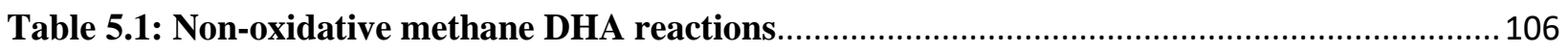

Table 5.2: Comparison of estimated kinetic parameters between MW and non-MW experimental

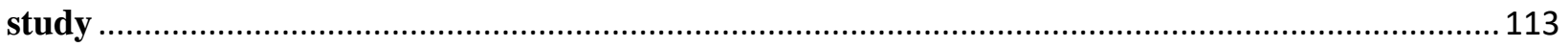

Table 5.3: Comparison of model coke prediction with experiment..............................................113

Table 5.4: Values of some key parameters used for simulation................................................. 125

Table 6.1: Production distribution and total no. of reactors for methane DHA process with

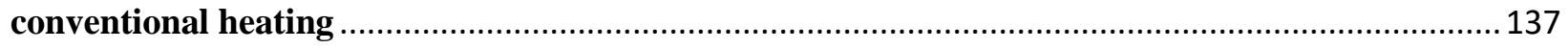


Table 6.2: Production distribution and total no. of reactors for methane DHA process with MWassisted heating.

Table 6.3: Summary of key streams for methane DHA conventional heating process operating at $7^{750} \mathrm{C}$

Table 6.4: Summary of key streams for MW-assisted methane DHA process................................141

Table 6.5: Product distribution of MTA reactor [14] ................................................................. 143

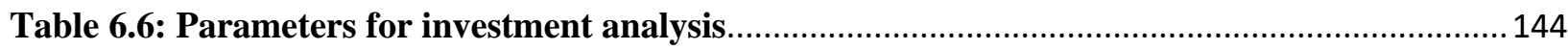

Table 6.7: Cost correlation for microwave and MTA reactor ..................................................... 145

Table 6.8: Price of raw materials, utilities, and products considered for economic analysis...........146

Table 6.9: Comparison of process performance between conventional and MW-assisted methane

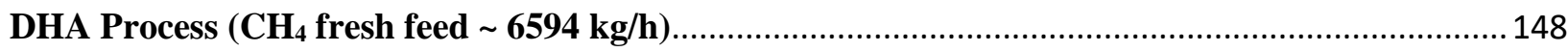

Table 6.10: Comparison of methane DHA process with large-scale shale gas to aromatics via

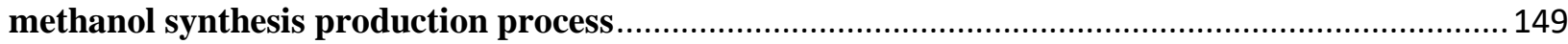

Table 6.11: Impact of plant scale on the performance of methane DHA process as compared to multi-step process......

Table 6.12: Comparison of NPV at different DROR for methane DHA cases $\left(\mathrm{CH}_{4}\right.$ Feed - 19782 $\mathrm{kg} / \mathrm{h})$. 


\section{Nomenclature}

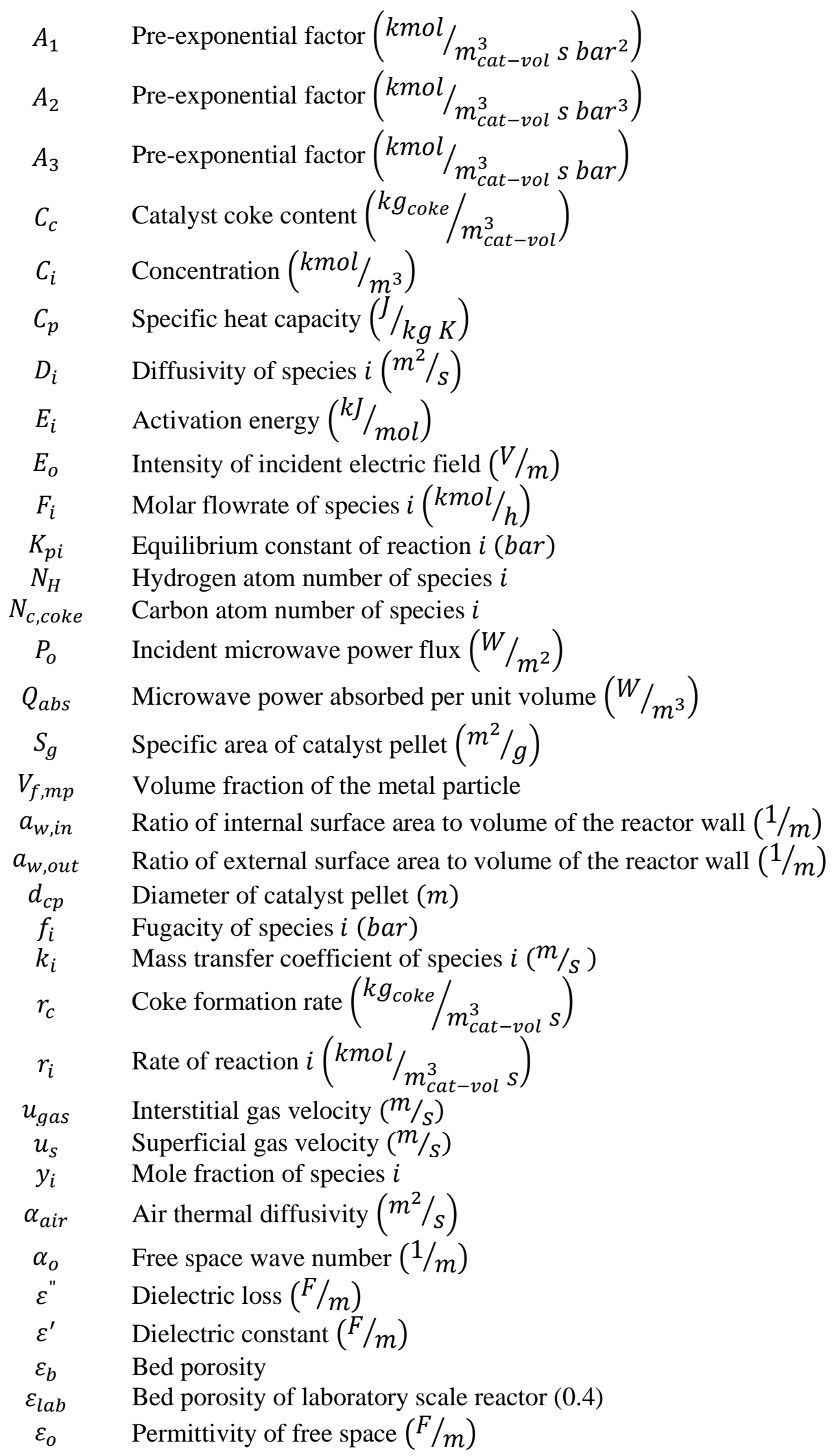




\begin{tabular}{|c|c|}
\hline$\eta_{i}$ & Extent of reaction $i(\mathrm{kmol} / \mathrm{h})$ \\
\hline$\mu_{o}$ & Permeability of free space $(\mathrm{H} / \mathrm{m})$ \\
\hline$\varphi_{C M}$ & $\begin{array}{l}\text { Coke yield from methane } \\
\text { Catalyst pellet porosity }\end{array}$ \\
\hline$h$ & Heat transfer coefficient $\left(\mathrm{W} / \mathrm{m}^{2} \mathrm{~K}\right)$ \\
\hline$A$ & Area $\left(m^{2}\right)$ \\
\hline$B$ & Magnetic induction $\left(\mathrm{Wb} / \mathrm{m}^{2}\right)$ \\
\hline$D$ & Electric displacement $\left(C / \mathrm{m}^{2}\right)$ \\
\hline$E$ & Electric field $(V / m)$ \\
\hline$H$ & Magnetic field $(\mathrm{A} / \mathrm{m})$ \\
\hline$H$ & Enthalpy $(J / m o l)$ \\
\hline$J$ & Current flux $\left(\mathrm{A} / \mathrm{m}^{2}\right)$ \\
\hline$M$ & Molecular weight $(\mathrm{kg} / \mathrm{kmol})$ \\
\hline$P$ & Pressure (bar) \\
\hline$R$ & Ideal gas constant $(\mathrm{J} / \mathrm{mol} \mathrm{K})$ \\
\hline$R$ & Radius of the reactor $(m)$ \\
\hline$T$ & Temperature $\left({ }^{\circ} \mathrm{C}\right)$ \\
\hline$c$ & Velocity of light $(\mathrm{m} / \mathrm{s})$ \\
\hline$f$ & Frequency of microwave $(1 / s)$ \\
\hline$\alpha$ & Catalyst activity parameter $\left(\mathrm{m}_{\text {cat-vol }}^{3} / \mathrm{kg}_{\text {coke }}\right)$ \\
\hline$\beta$ & Thermal expansion coefficient $(1 / K)$ \\
\hline$\varepsilon$ & Dielectric complex permittivity $(\mathrm{F} / \mathrm{m})$ \\
\hline$\lambda$ & Thermal conductivity $\left(\mathrm{W} / \mathrm{m} \mathrm{K}_{\mathrm{K}}\right)$ \\
\hline$\mu$ & Permeability $(\mathrm{H} / \mathrm{m})$ \\
\hline$\mu$ & Dynamic viscosity $(c P)$ \\
\hline$\rho$ & Density $\left(\mathrm{kmol} / \mathrm{m}^{3}\right)$ \\
\hline$\sigma$ & Electric conductivity $(\mathrm{S} / \mathrm{m})$ \\
\hline$\tau$ & Tortuosity of catalyst pellet \\
\hline$\omega$ & Angular frequency $(\mathrm{Rad} / \mathrm{s})$ \\
\hline
\end{tabular}

\section{Subscripts}

$\begin{array}{cl}\text { amb } & \text { Ambient } \\ \text { bed } & \text { Catalyst bed } \\ \text { cat } & \text { Catalyst phase } \\ \text { cat,gas } & \text { Gaseous species in catalyst phase } \\ \text { cat, surf } & \text { Catalyst pellet surface } \\ c p & \text { Catalyst pellet } \\ c s & \text { Catalyst support } \\ \text { gas, gc } & \text { Gas phase }\end{array}$




$\begin{array}{cl}\text { knud } & \text { Knudsen } \\ \text { mix } & \text { Mixture } \\ \text { mp } & \text { Metal particle } \\ \text { rec } & \text { Reactor } \\ \text { wall } & \text { Tube wall } \\ \text { htf } & \text { Heat transfer Fluid } \\ t, \text { in } & \text { Tube inside } \\ t, \text { out } & \text { Tube outside }\end{array}$




\section{Chapter 1. Introduction}

According to the International Energy Agency (IEA), the global energy demand and the $\mathrm{CO}_{2}$ emissions are expected to increase by $37 \%$ and $16 \%$ by 2040 , respectively [2]. In the United States, three main sectors contributing to $\mathrm{CO}_{2}$ emissions are industry (22\%), electricity production facilities (27\%), and transportation (28\%) mainly due to combustion of coal, and petroleumderived fuels [3]. The shale gas boom in the United States has already started replacing coal as the power source, reducing $\mathrm{CO}_{2}$ emissions. However, the production of transportation fuel and other value-added chemicals is still dependent on petroleum based feedstocks. So, there has been an increase in research efforts to develop cleaner and more carbon efficient non-petroleum based transportation fuels and value-added chemicals that can reduce the greenhouse gas emission [4].

\subsection{Dimethyl Ether (DME) Production Process}

In the transportation fuel sector, the use of dimethyl ether (DME) as an alternative liquid fuel is being strongly evaluated. DME is clean, non-toxic, environmentally friendly (with about 95\% less $\mathrm{CO}_{2}$ emission than diesel) and an excellent refrigerant [4,5]. It has properties like liquefied petroleum gas (LPG), and therefore, current transportation logistics developed for LPG can be utilized with minor modifications [4]. Likewise, DME can possibly replace diesel in transportation vehicles because of its high cetane number (55-60) $[4,6]$ and can be utilized as a part of a vaporized charge, and as a household cooking fuel [6]. DME can be produced from a variety of fossil fuels, such as coal, biomass, and natural gas. Due to the abundance of coal in most of the Asia-Pacific countries, it is being considered as the feedstock for producing DME. However, in the United States, shale gas seems to be an attractive option, for producing DME, due to its low-cost and abundant availability [7]. Commercially, DME is produced by a two-step process by a number of companies such as Toyo, MGC, Lurgi, and Udhe [4]. However, the two-step process has lower DME production due to the thermodynamic equilibrium limitation of carbon-monoxide conversion to methanol [8]. This problem can be overcome by the direct synthesis route leveraging the 
synergistic effect of the simultaneous conversion of methanol to DME which, in turn, increases syngas conversion and yield of DME [8]. A few companies have proposed the one-step process with either natural gas or coal as the feedstock [4], however a detailed system and unit-level analysis has not be undertaken. Moreover, shale gas has not been used as the feedstock of choice. The selection of feedstock is very important because syngas composition can vary widely depending on the source. Syngas derived from coal has a much lower $\mathrm{H}_{2} / \mathrm{CO}$ ratio (close to 1) compared to the syngas derived from natural gas or shale gas (usually > 2) $[9,10]$. The main difference between the syngas synthesis process using natural gas versus the shale gas is the presence of heavy hydrocarbons (such as ethane and propane) in the shale gas. These heavier hydrocarbons have faster reaction rates than methane. Moreover, they lead to coke formation in the reactor leading to deactivation of the catalyst. So, the selection of feedstock has a strong impact on the process technology. Most of the papers in the area of DME synthesis from natural gas/coal have mainly focused on catalyst development, intrinsic kinetic studies and on developing reactor technologies $[4,11,12]$. Systems level analysis of DME synthesis processes from both technical and economic perspectives is lacking in the open literature not only for shale gas but also for coal/natural gas. With this motivation, in this study several important contributions have been made as mentioned in Section 1.3 and the subsequent Chapters.

\subsection{Aromatics Production Process}

In the value-added chemicals sector, the production of aromatics namely benzene, toluene, and xylene (BTX) from non-petroleum based feedstock has been of great interest. BTX is a building block for wide variety of consumer products. For example, benzene is primarily utilized in production of phenolic resins, nylons, polystyrene, elastomers, and solvent. Majority of toluene produced is used in production of benzene and polyurethanes. Para-xylene is the most important xylene of the three, and it is used in the production of dimethyl terephthalate and terephthalic acid. Orth-xylene and meta-xylene are used in the production of phthalic anhydride and isophthalic acid, respectively $[13,14]$. Majority of the BTX production comes from either petroleum naphtha, pyrolysis gasoline by-product, and/or coal liquids from coke-oven [14]. However, the abundance availability of shale gas reserves in United States has significantly increased interest in a new approach for BTX production. For example, the Cyclar process developed by BP and UOP uses $\mathrm{C}_{3}-\mathrm{C}_{4}$ feed, on H-ZSM-5 catalyst for production of aromatics [13-15]. Other existing routes for 
converting natural gas to aromatics involve multi-step processes in which syngas is first produced from natural gas via steam reforming, partial oxidation, or autothermal reforming (ATR)- all of which lead to an energy and capital intensive process [6,16-19]. Syngas produced is then converted to aromatics via a two-step process where methanol is produced as an intermediate product $[20,21]$. These multi-step processes not only lead to high capital and operating costs, but also low carbon utilization and low selectivity of desired aromatics. In partial oxidation and ATR based processes, some amount of carbon monoxide and hydrogen gets utilized during the aromatic synthesis step for removing residual oxygen, leading to low carbon utilization efficiency and the loss of valuable hydrogen. Furthermore, in partial oxidation and ATR based processes, carbon monoxide reacts with oxygen to form carbon dioxide which needs to be captured, resulting in additional energy usage and capital cost. Therefore, a route that does not require syngas generation is preferred. An alternative process is to convert shale gas directly to hydrocarbons. However, direct conversion of methane, the main component of shale gas, is challenging because it is a very stable molecule and it cannot be easily activated. Methane has a strong $\mathrm{C}-\mathrm{H}$ bond with a first bond dissociation energy of $439.3 \mathrm{~kJ} / \mathrm{mol}$ [22], which indicates that high amount of energy would be needed in order to break the bond. Moreover, the $\mathrm{C}-\mathrm{H}$ bond of methane is stronger than higher hydrocarbons products and as a result these products are more reactive than methane [23]. Existing approaches that are being investigated for direct conversion of methane to higher hydrocarbons are oxidative coupling of methane (OCM), and non-oxidative methane dehydroaromatization (DHA) [24-28]. Drawbacks associated with the OCM route include the high cost associated with the separation of light gases like $\mathrm{CO}$ from hydrogen and hydrocarbons, $\mathrm{CO}_{2}$ capture, and production of oxygen via air separation. A promising approach is to carry out the direct conversion of methane to aromatics via non-oxidative methane DHA reaction in a conventional or MWassisted reactor packed with metal-supported catalyst [29]. In this approach, oxygen is not required and light gases such as $\mathrm{CO}$ and $\mathrm{CO}_{2}$ are not produced. So, the operating and capital costs associated with the production of oxygen, separation of $\mathrm{CO}$ from valuable product such as $\mathrm{H}_{2}$, and $\mathrm{CO}_{2}$ capture can be avoided. In non-oxidative methane DHA reaction, it has been reported that MWassisted DHA lead to high methane conversion, and $\mathrm{C}_{2}$ selectivity at a lower temperature compared to conventional heating [30]. Operating the reactor at a lower temperature can assist in reducing the operating cost of the process. In the open literature, majority of the work has been focused on the development of catalyst, catalyst regeneration strategies, and studying operating conditions for 
maximum reactor productivity. Few authors have focused on development of reaction kinetic model using steady state data, without the consideration of catalyst deactivation. In terms of reactor modeling, majority of the work has been focused on optimization of steady state isothermal membrane reactors. A comprehensive reaction rate model that accounts for catalyst deactivation, and also the development of conventional and MW-assisted industrial scale heterogenous fixedbed reactor is still lacking in open literature. Moreover, a comprehensive study on the technoeconomic feasibility of the methane DHA process comparing the conventional heating, MWassisted heating, and the multi-step shale gas conversion to aromatics via methanol synthesis is still lacking. This research aims to fill those gaps by making several important contributions as mentioned in Section 1.3 and the subsequent Chapters.

\subsection{Objective}

In this study, plant-wide modeling and techno-economic optimization is performed for thermocatalytic DME synthesis and microwave based aromatics production process. For this purpose, high-fidelity system and equipment-level process models are developed on a multi-software platform that includes Aspen Plus, Aspen Custom Modeler (ACM), Exchanger Design and Rating (EDR), MATLAB, and Excel. The objective is utilizing the modeling tools and identify the economic feasibility of the processes, and effect of key process variables on the plant overall performance. To summarize, the main contributions of this work are summarized below:

\section{Shale gas to DME Synthesis Via Direct and Indirect Route}

- Plant-wide models of the shale gas to DME process with integrated $\mathrm{CO}_{2}$ capture via direct and indirect synthesis routes have been developed.

- Optimal parameter estimation, and model validation are undertaken for various sections of the process including the pre-reforming reactor, autothermal reforming reactor, DME synthesis reactors, $\mathrm{CO}_{2}$ capture units and separation sections.

- A novel DME separation process has been developed for efficient separation of DME, syngas, and $\mathrm{CO}_{2}$.

- Plant-wide techno-economic optimization is performed in an equation-oriented environment for maximizing the net present value (NPV). Effects of key design parameters and investment parameters on the process economics have been evaluated.

\section{Direct Non-Oxidative Methane DHA Via Conventional and MW-Assisted Heating}


- Dynamic data reconciliation, parameter estimation, and multi-scale, multi-physics dynamic fixed-bed reactor model development are undertaken for methane DHA process via conventional and MW-assisted heating.

- Due to rapid coke formation, catalysts in the non-oxidative methane DHA reactors get deactivated. A model for the catalyst deactivation is proposed along with rate models for other DHA reactions. An algorithm is developed by coupling an iterative direct substitution approach with an optimization algorithm for optimal estimation of the initial state of the reactor and the kinetic parameters using the in-house experimental data.

- For the MW-assisted reactor, the amount of heat generated at specific catalyst sites has been modeled using Maxwell's equation. For integrating the Maxwell's equation within the process model, a reduced order model is developed.

- Dynamic commercial scale heterogenous multi-scale fixed bed MW reactor model and conventional heating model with embedded heating is developed where the catalyst pellet level model is coupled with reactor level model considering the electromagnetic effects, interparticle and intra-particle heat and mass transfer, and reaction rate model that includes coke formation model and catalysts deactivation model.

- Plant-wide models are developed, and techno-economic analysis of the conventional and MWassisted processes are performed and compared with a multi-step aromatics production process. 


\section{Chapter 2. Plant-Wide Modeling of Shale-gas Conversion to DME via Direct and Indirect Synthesis Routes}

A plant-wide model of the shale gas to dimethyl ether (DME) process with integrated $\mathrm{CO}_{2}$ capture via direct and indirect synthesis routes has been developed in Aspen Plus V8.4®. In this study, models of the pre-reforming reactor, autothermal reforming (ATR) reactor and DME synthesis reactors using kinetic data have been developed. For $\mathrm{CO}_{2}$ capture, Rectisol and methyl diethanolamine (MDEA)/piperazine (PZ) technologies have been evaluated and results have been compared with the experimental data. A novel DME separation process has been developed and evaluated for efficient separation of DME, syngas, and $\mathrm{CO}_{2}$. Binary interaction parameters for the vapor-liquid equilibrium (VLE) model of the methanol-DME-CO- $\mathrm{CO}_{2}-\mathrm{H}_{2} \mathrm{O}-\mathrm{H}_{2}$ system are regressed using the literature experimental data. Effects of the key parameters like $\mathrm{CO}_{2}$ recycle ratio and $\mathrm{H}_{2} / \mathrm{CO}$ ratio on the utility consumption in the syngas synthesis unit, acid gas removal (AGR) unit, DME synthesis unit and DME separation unit are studied. It is observed that the direct shale gas to DME production process operated with an optimal $\mathrm{H}_{2} / \mathrm{CO}$ ratio of 1 has a higher DME yield and overall equivalent electrical efficiency than the indirect shale gas to DME production process.

\subsection{Literature review}

Systems level analysis of DME synthesis processes from both technical and economic perspectives is lacking in the open literature not only for shale gas but also for coal/natural gas. Ohno et al. [31] have reported on the development of a $100 \mathrm{t} / \mathrm{d}$ natural gas to DME synthesis plant. In a study by Peng et al. [10], issues related to the direct DME synthesis have been discussed. Studies on DME synthesis from coal is also available in the open literature [32,33]. Han et al. [32] and Shim et al. [33], have developed kinetic models of the direct DME synthesis reactor. Chen et al. [34] have simulated the DME synthesis reactor by minimizing the Gibbs free energy. The authors have also performed pinch analysis to reduce energy consumption. Both one-dimensional model as well as 
three-dimensional CFD models of slurry and fixed bed direct DME synthesis reactors have been reported in the literature [35-37]. The first step in the shale gas to DME process is to produce syngas via autothermal reforming (ATR). Unlike natural gas, shale gas consists of not only $\mathrm{CH}_{4}$ but also heavy hydrocarbons such as ethane and propane. Reaction rates of heavy hydrocarbons is typically faster than $\mathrm{CH}_{4}$. In addition, they lead to coke formation which can significantly reduce the activity of a catalyst, as mentioned before [16,38]. This issue can be avoided by integrating an adiabatic pre-reforming reactor before the ATR reactor to convert heavier hydrocarbons into $\mathrm{CH}_{4}$ at relatively lower temperatures than the ATR reactor $[39,40]$. In addition to prevention of catalyst coking, the pre-reformer also offers several advantages such as an increase in production capacity by $10-20 \%$ and a reduction in the energy consumption in the primary reformer due to its operation at a lower steam to carbon ratio $[39,41]$. Low-temperature separation of heavy hydrocarbons in place of using a pre-reforming reactor is also an option, however the capital and utility cost associated with this separation would be higher than utilizing a pre-reforming reactor because of the ultra-low temperature requirements and increase in equipment items such a cascade refrigeration cycle, and a distillation column. Existing literature in the area of pre-reforming of higher hydrocarbons has mainly focused on the development of catalysts and modeling of the reactor $[16,42,43]$. In some studies, both the pre-reformer and ATR reactors have been modeled as equilibrium reactors [44-46]. Modeling of micro-reactors for fuel cell applications where ATR reactions take place in presence of high steam to carbon ratio has been presented $[47,48]$. Some studies have also focused on one-dimensional modeling of the ATR reactor for estimating temperature profiles of different catalysts [49,50]. Considering the key roles, a pre-reformer and ATR reactor plays in the DME process, reactor models using kinetic data rather than the equilibrium models are desired especially when an economic analysis must be undertaken. Before sending the syngas produced from the ATR reactor to the DME synthesis unit, it must be processed through an AGR unit for separation of impurities, mainly $\mathrm{CO}_{2}$, from the syngas. The choice of AGR technology strongly depends on the partial pressure of $\mathrm{CO}_{2}$ in the feed. Physical absorption is favored when the partial pressure of $\mathrm{CO}_{2}$ in the feed is relatively high, while for low $\mathrm{CO}_{2}$ partial pressure, chemical absorption such as amine based processes are preferred [51]. Final selection of the technology also depends on the impurities to be removed, capital costs, and energy requirements. There are several candidate technologies that can be evaluated. $\mathrm{CO}_{2}$ removal by the Rectisol process has been considered in a study by Ogawa et al. [52] for a similar application. In 
our study, Rectisol and MDEA/PZ technologies are evaluated as the candidate physical and chemical absorption technologies, respectively.

DME can be synthesized from the clean syngas using the indirect or direct route. In the indirect synthesis route, syngas is first converted to methanol followed by dehydration of methanol in a separate reactor to produce DME. In the direct synthesis route, syngas is directly converted to DME in a single reactor where both methanol synthesis and dehydration reactions simultaneously take place over a bi-functional catalyst such as $\mathrm{CuO} / \mathrm{ZnO} / \mathrm{Al}_{2} \mathrm{O}_{3}$ and $\gamma-\mathrm{Al}_{2} \mathrm{O}_{3}$. The indirect route is widely used commercially, but it has lower DME production rate due to the thermodynamic equilibrium limitation of $\mathrm{CO}$ conversion to methanol [8]. This problem can be overcome by the direct synthesis route leveraging the synergistic effect of the simultaneous conversion of methanol to DME which, in turn, increases syngas conversion and yield of DME [8]. In the direct synthesis route, the yield of DME is very sensitive to the $\mathrm{H}_{2} / \mathrm{CO}$ ratio and $\mathrm{CO}_{2}$ content in the feed stream. The maximum syngas conversion, i.e. the syngas conversion under equilibrium, is approximately 90\% at optimal operating conditions [52]. This unconverted syngas is captured and recycled to the DME reactor along with the fresh syngas. Since the total feed stream composition varies widely when recycle is considered, it is more appropriate to develop a reactor model using the reaction kinetic data for rigorous techno-economic analysis of the system. The $\mathrm{H}_{2} / \mathrm{CO}$ ratio in the syngas derived from coal is less than 1 and can be easily adjusted to 1 by feeding a small amount of additional steam to the ATR reactor. However, when syngas is obtained from the hydrogen rich shale gas, this is not straightforward. The $\mathrm{CO}_{2}$ recycles from the AGR unit and the DME separation unit must be integrated to feed extra $\mathrm{CO}_{2}$ to the ATR reactor to adjust the $\mathrm{H}_{2} / \mathrm{CO}$ ratio to 1 . Inclusion of the $\mathrm{CO}_{2}$ recycle from the AGR and DME separation units results in additional complexity and more utility costs. Hence, it is important to evaluate the effect of $\mathrm{CO}_{2}$ recycle on the $\mathrm{H}_{2} / \mathrm{CO}$ ratio. Peng et al. [10], Ohno et al. [31], and Ogawa et al. [52] have considered the effect of $\mathrm{CO}_{2}$ recycle to the ATR reactor, but a rigorous systems level analysis is still lacking.

Various approaches for DME separation have been proposed in the existing literature. In the study of Bhatt et al. [53], chilled methanol was used to separate unconverted syngas from $\mathrm{CO}_{2}$. Then a series of flash separators and distillation columns was used to purify DME. In some pilot plants, chilled DME is used as a solvent to capture $\mathrm{CO}_{2}$ and then physical or chemical absorption is considered to separate $\mathrm{CO}_{2}$-DME from the unconverted syngas [31]. In the study of Han et al. [32], deionized water was used as a solvent to separate DME from the unconverted syngas and $\mathrm{CO}_{2}$ 
[54]. Here, we have proposed a new separation method which does not use physical or chemical solvent, and instead uses product DME as a solvent and methanol-water mixture to achieve the desired separation. Moreover, the thermodynamic models used for DME separation technologies in the existing literature have binary interaction parameters that are estimated using UNIFAC-RQ or UNIFAC model $[32,34]$. As the DME separation unit has a large impact on the overall process technology and economics, it is important to estimate the binary interaction parameters using the experimental VLE data that can make the thermodynamic model more accurate. This, in turn, can increase the accuracy of the process model for DME, syngas, and $\mathrm{CO}_{2}$ separation system. To summarize, the following contributions have been made:

- System level energy analysis was performed for both direct and indirect DME production process with varying key design parameters and compared. In particular,

For the direct shale gas to DME production process,

- A rigorous plant-wide process model has been developed that includes a novel DME separation section to reduce the overall utility usage of the process, and reuse of $\mathrm{CO}_{2}$ produced within the process in the ATR reactor, reducing $\mathrm{CO}_{2}$ emission.

- The kinetic parameters of reactions involved in the direct DME synthesis reactor has been regressed using experimental data.

- Kinetic reactor models for the pre-reforming reactor, and ATR reactor has been developed and validated with literature.

- The binary interaction parameters for DME- $\mathrm{CO}_{2}, \mathrm{DME}-\mathrm{H}_{2} \mathrm{O}$, and DME-CO are not available in Aspen Plus or open literature. So, experimental data has been used to regress them using experimental data to increase the validity of these parameters for a wide range of operating conditions.

- Different syngas $\mathrm{H}_{2} / \mathrm{CO}$ ratio, $\mathrm{CO}_{2}$ recycle ratio, and AGR technologies have been evaluated to study effect on overall process economics.

For the indirect shale gas to DME production process,

- High-fidelity plant-wide models have been developed that includes development and validation of reactor kinetic models for methanol synthesis reactor and methanol dehydration reactor, and study of different AGR technologies. 


\subsection{Steady-State Modeling of Shale-gas to DME Production Process via Direct and Indirect Synthesis Route}

In this section, direct and indirect DME production process will be discussed with a simplified block flow diagram. This is followed by a brief description of heat integration and heat exchanger design. A detail description of syngas synthesis section, AGR section, direct DME production section, and indirect DME synthesis section. A brief description of the HRSG is also be shown. Effects of key parameters like $\mathrm{CO}_{2}$ recycle ratio and $\mathrm{H}_{2} / \mathrm{CO}$ ratio on the utility consumption of syngas synthesis unit, acid gas removal (AGR) unit, DME synthesis unit and DME separation unit are studied.

\subsection{Process Configuration}

The block flow diagram of the shale gas to DME process via direct and indirect synthesis routes is shown in Fig. 2.1 and 2.2, respectively. The entire plant can be divided into two main sectionsthe syngas production section and the DME production section. The syngas production section consists of the syngas synthesis section that includes the pre-reforming and ATR reactors, and the AGR unit. Similarly, the DME production section can be divided into the DME synthesis unit that includes the DME synthesis reactor and the DME separation unit. 


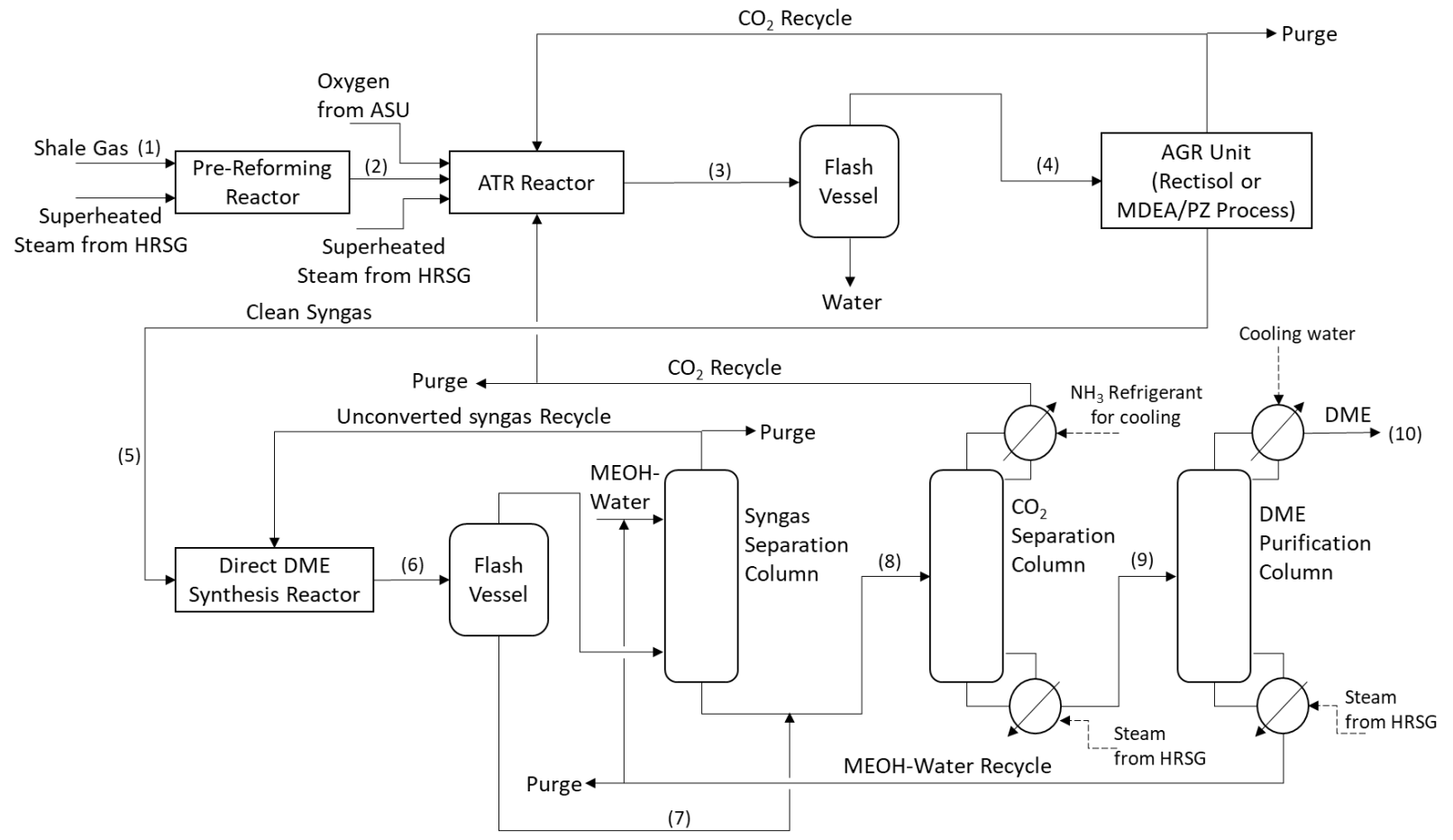

Figure 2.1: Block flow diagram of DME production process via direct synthesis route

In the syngas production section, shale gas along with the superheated steam is fed to the prereforming reactor for reforming heavy hydrocarbons $\left(>C_{2}\right)$ to methane and other components. Heavy hydrocarbons get completely converted in the pre-reformer significantly reducing coking of catalyst in the ATR reactor. The reformed shale gas is then sent to the ATR reactor, to which oxygen from the air separation unit (ASU), and superheated steam from the heat recovery steam generation (HRSG) is also fed. $\mathrm{CO}_{2}$ captured in the AGR unit and the DME separation section is also recycled to the ATR reactor to obtain a lower $\mathrm{H}_{2} / \mathrm{CO}$ ratio in the syngas. The hot raw syngas from the ATR reactor is cooled, to remove water via condensation, and then fed to the AGR unit. Two solvent-based AGR technologies, Rectisol and MDEA/PZ-based capture, are evaluated. The Rectisol process is a physical absorption technology which uses refrigerated methanol as the solvent at a high pressure, while MDEA/PZ is a chemical absorption technology. When Rectisol process is used, syngas is compressed using a multi-stage compressor before the AGR unit. When $\mathrm{MDEA} / \mathrm{PZ}$ is used as the solvent, syngas compression takes place after the AGR unit. Clean syngas from the AGR unit is sent to the DME production section where direct synthesis of syngas to DME takes place on a bi-functional catalyst. The outlet stream of the reactor, consisting of DME, methanol, water, $\mathrm{CO}_{2}$, and unconverted syngas, is processed through a flash vessel, an absorber, 
and two distillation columns to obtain the final DME product. For the direct route, $\mathrm{H}_{2} / \mathrm{CO}$ syngas ratio, 1 to 2, and two AGR technologies, Rectisol and MDEA/PZ, are evaluated, because the optimal selection of the AGR technology highly depends on the $\mathrm{CO}_{2}$ partial pressure, which varies with the $\mathrm{H}_{2} / \mathrm{CO}$ ratio. It should also be noted that the $\mathrm{CO}_{2}$ recycle, to the ATR reactor, is not required to achieve an $\mathrm{H}_{2} / \mathrm{CO}=2$ in the syngas because this ratio can be easily obtained by manipulating the $\mathrm{O}_{2} / \mathrm{C}$ and steam/C ratio within the typical operating range. Ammonia $\left(\mathrm{NH}_{3}\right)$ refrigeration cycle required for maintaining the low temperature in the Rectisol is also modeled in this work [6].

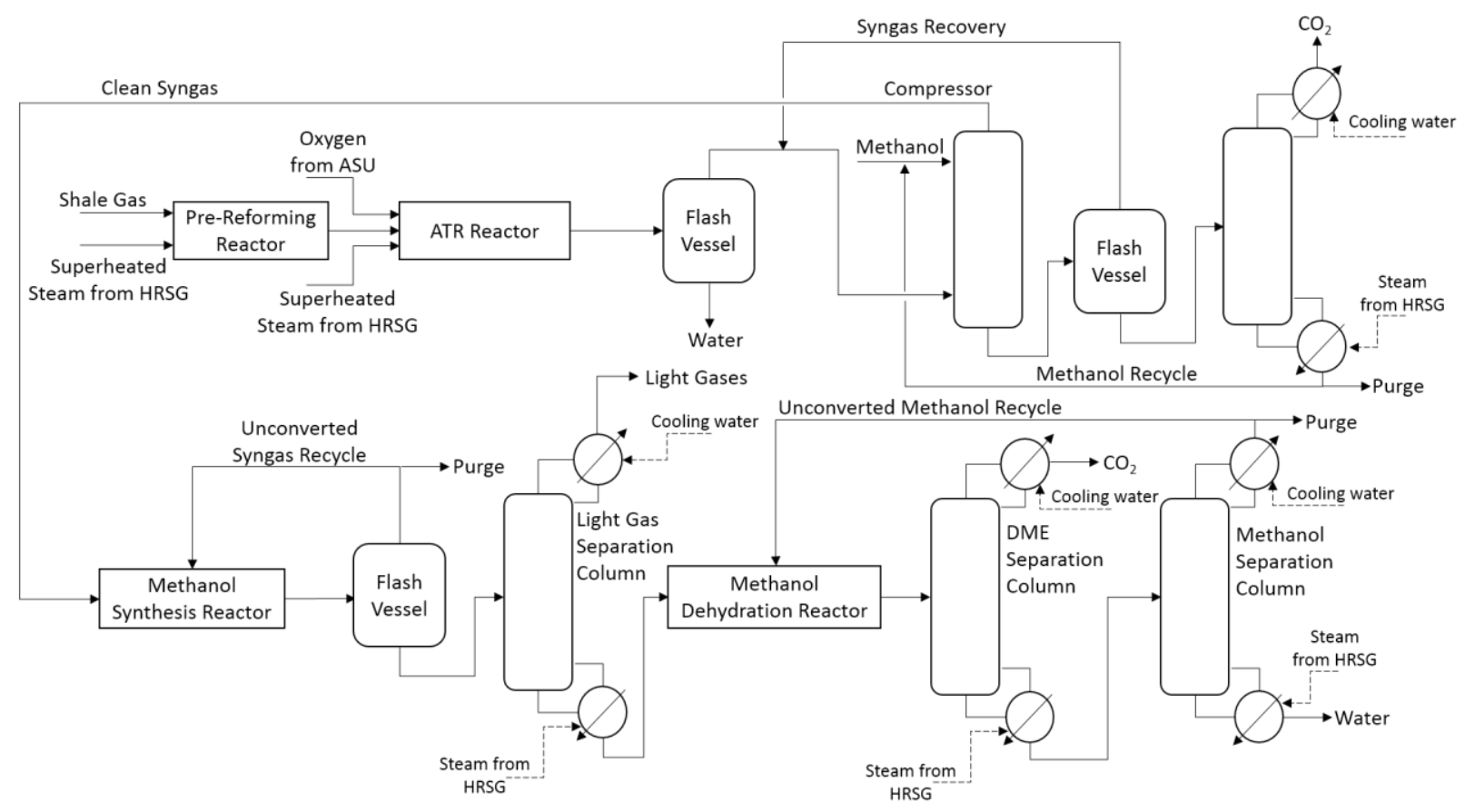

Figure 2.2: Block flow diagram of DME production process via indirect DME synthesis route

The indirect synthesis route, as shown in Fig. 2.2, is also investigated in this study as a technology basis, in which the syngas production section is like the direct DME synthesis process route shown in Fig. 2.1. The main difference between the two synthesis routes is the absence of $\mathrm{CO}_{2}$ recycle and the configuration of the DME production section. In the indirect route, the raw syngas from the ATR reactor is sent to the AGR unit for separating $\mathrm{CO}_{2}$ from syngas. The clean syngas from the AGR unit is then sent to the methanol synthesis reactor, where syngas is converted to methanol. The outlet stream of the methanol synthesis reactor is sent through a flash vessel and a distillation column to purify methanol. Clean methanol is then sent to the methanol dehydration reactor for 
DME synthesis. The outlet stream of the methanol dehydration reactor is sent through two distillation columns to obtain DME and methanol. Since the indirect DME synthesis route is already commercialized, the analysis is performed only for the process with the Rectisol as the AGR technology. Like the direct DME process, the purge streams in the indirect DME production process are sent to the HRSG and SC Island to satisfy the utility requirement in the process. Marcellus shale gas from Well 3 as described in the work of Ding [55] is considered to be the feed in this study. Its composition is shown in Table 2.1.

Table 2.1: Marcellus Shale Gas Composition

\begin{tabular}{cc}
\hline Component & Mol\% \\
\hline Methane $\left(\mathrm{CH}_{4}\right)$ & 83.8 \\
Ethane $\left(\mathrm{C}_{2} \mathrm{H}_{6}\right)$ & 12.0 \\
Propane $\left(\mathrm{C}_{3} \mathrm{H}_{8}\right)$ & 3.00 \\
Carbon Dioxide $\left(\mathrm{CO}_{2}\right)$ & 0.900 \\
Nitrogen $\left(\mathrm{N}_{2}\right)$ & 0.300 \\
\hline
\end{tabular}

\subsection{Heat Integration and Heat Exchanger Design}

Heat integration is performed using the Aspen Energy Analyzer (AEA) V8.4 [40]. The process model developed in Aspen Plus is exported to the AEA. A minimum approach temperature of $10^{\circ} \mathrm{C}$ is considered for performing heat integration. The AEA software by default gives a heat exchanger network for the process by selecting appropriate utilities and by performing heat integration between the process streams. However, the suggested heat exchanger network may not be practical especially with due consideration of operability issues. For example, in the direct shale gas to DME process, it may not be practical to have a heat exchanger between a stream in the syngas synthesis section and the DME production section because the AGR unit is located in between these two sections and any operational issues in one section can affect the other. In addition, due to the considerable time-delay between these sections, control system design becomes challenging when such heat integration is considered. After excluding similar heat exchange and declaring appropriate utilities for the process, the heat exchanger network is designed in AEA. The payback years, operating cost savings, capital investment etc. is calculated as the basis of heat exchanger network design selection. The network with the least number of years for payback is selected. There are around 18-25 heat exchangers in each of the direct and 
indirect DME production processes. Once the heat exchanger network is developed and assembled in Aspen Plus, the heat exchangers are designed using the Aspen Exchanger Design and Rating (EDR) V8.4. The heat exchangers are modeled using the HeatX block in Aspen Plus with appropriate property package and then exported to the EDR for a more rigorous design. All the heat exchangers are modeled as shell \& tube heat exchangers in EDR.

\subsection{Syngas Production Section}

The configuration of the syngas synthesis section is shown in Fig. 2.3. Reactor models using the reaction rate data for the adiabatic pre-reforming reactor and the ATR reactor are developed. These two reactors are modeled as plug flow reactor (PFR) with kinetic parameters regressed using the experimental data. Redlich-Kwong-Soave equation of state (EOS) with modified Huron-Vidal mixing rules (RKSMHV2 in Aspen Plus ${ }^{\circledR}$ ) is used to calculate the thermodynamic properties. The water gas-shift and methane steam reforming reactions both take place in the pre-reforming reactor and ATR reactor. In the literature, LHHW and power law rate model has been proposed for these two reactions by $\mathrm{Xu}$ and Froment [56] and Numaguchi and Kikuchi [57], respectively. Xu and Froment investigated the intrinsic kinetics of these reactions with considerable amount of hydrogen in the feed $\left(\mathrm{H}_{2} / \mathrm{CH}_{4}=1.25\right)$, to avoid oxidation of Ni. As shown in Table 2.4, reaction \#7 and 8 of their LHHW rate model has a negative exponent to the partial pressure of hydrogen. As a result, the reaction rates become infinity when the partial pressure of hydrogen in the feed is zero. Comparison of these two rate models was performed by C. R. H. De Smet et al. [58] for fuelcell and methanol production applications. They concluded: 1) There were temperature differences in the initial part of the reactor. However, the reactor temperature converged to the same value for both the models. 2) The mole fractions at the reactor outlet for both models are similar to the equilibrium values. The pre-reforming reactor does not have hydrogen in the feed. So, the power law model developed by Numaguchi and Kikuchi [57] is used to avoid the blow up of the reaction term. While for the ATR reactor, the model developed by Xu and Froment [56] for the similar application as here is used. 


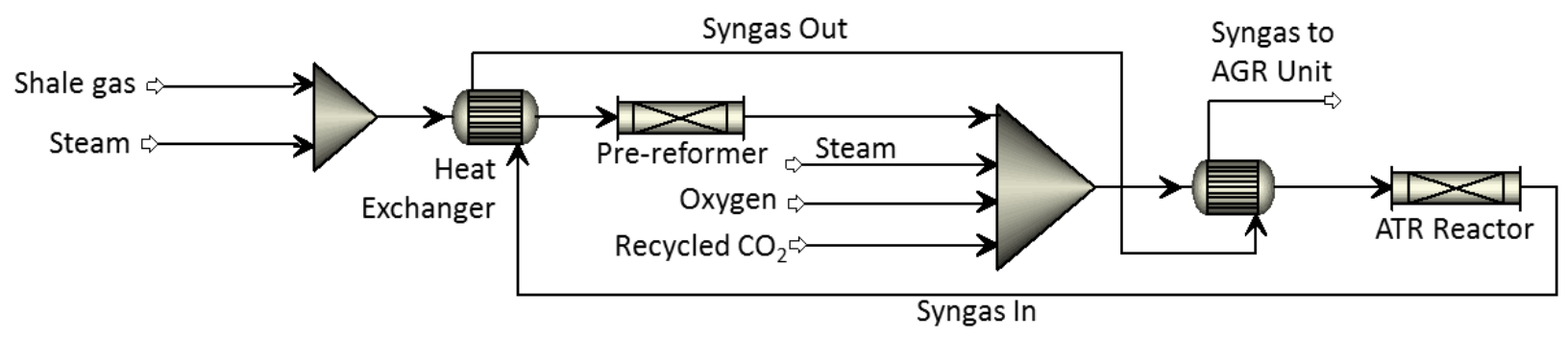

Figure 2.3: Configuration of the Syngas Synthesis Section

\subsubsection{Pre-reforming Reactor}

Reactions considered for modeling the pre-reformer are shown in Table 2.2. Kinetic studies on pre-reforming of syngas containing $\mathrm{C}_{2}-\mathrm{C}_{3}$ hydrocarbon are rare in the open literature. The kinetic model of ethane reforming is validated with the experimental data of Rostrup-Nielsen [16]. Using the same feed composition and operating conditions, ethane conversion is $22.4 \%$ from our validation model in comparison to $23 \%$ reported by Rostrup-Nielsen [16]. Ethane steam reforming reaction is also studied in presence of methanation and water gas shift (WGS) reaction, and similar ethane conversion of $22.4 \%$ is achieved. Kinetic parameters for other reactions are obtained from the open literature as shown in Table $2.3[59,60]$. It should be noted that typical industrial operating conditions achieve near-complete conversion of ethane [61,62] rather than the low conversion in the work of Rostrup-Nielsen [16]. Therefore, the reactor operating conditions are modified to make them similar to the typical industrial operating conditions [61,62] In particular, the reactor is operated adiabatically at $30 \mathrm{bar}$ pressure with a steam/C ratio of 0.4 , and a weight hourly space velocity (WHSV) of $1.67 \mathrm{~h}^{-1}$. The catalyst loading is $84,806 \mathrm{~kg}$ (particle density $=1767 \mathrm{~kg} / \mathrm{m}^{3}$ ) [63] and the bed voidage is assumed to be 0.4. It should be noted that these operating conditions result in complete conversion of higher hydrocarbons, while methane steam reforming and WGS reactions reach equilibrium [61]. 
Table 2.2: Reactions considered in the Kinetic Model

\begin{tabular}{|c|c|c|c|}
\hline No. & Reaction & Rate Equation & $\Delta H_{25^{\circ} \mathrm{C}}(\mathrm{kJ} / \mathrm{mol})$ \\
\hline 1 & $\mathrm{C}_{3} \mathrm{H}_{8}+3 \mathrm{H}_{2} \mathrm{O} \rightarrow 3 \mathrm{CO}+7 \mathrm{H}_{2}$ & $r_{1}=k_{1} C_{C_{3 H_{8}}}$ & 497,729 \\
\hline 2 & $\mathrm{C}_{2} \mathrm{H}_{6}+2 \mathrm{H}_{2} \mathrm{O} \rightarrow 2 \mathrm{CO}+5 \mathrm{H}_{2}$ & $r_{2}=k_{2} P_{C_{2} H_{6}}^{0.54} P_{H_{2} O}^{-0.33} P_{H_{2}}^{0.2}$ & 347,266 \\
\hline 3 & $\mathrm{CH}_{4}+\mathrm{H}_{2} \mathrm{O}=\mathrm{CO}+3 \mathrm{H}_{2}$ & $r_{3}=k_{3} P_{C H_{4}} P_{H_{2} O}\left(1-\frac{P_{C O} P_{H_{2}}^{3}}{K_{3} P_{C H_{4}} P_{H_{2} O}}\right)$ & 206,000 \\
\hline 4 & $\mathrm{CO}+\mathrm{H}_{2} \mathrm{O}=\mathrm{CO}_{2}+\mathrm{H}_{2}$ & $r_{4}=k_{4} P_{C O} P_{H_{2} O}\left(1-\frac{P_{C_{2}} P_{\mathrm{H}_{2}}}{K_{4} P_{C O} P_{\mathrm{H}_{2} \mathrm{O}}}\right)$ & $-41,000$ \\
\hline
\end{tabular}

Table 2.3: Kinetic Parameters and Equilibrium Constants

\begin{tabular}{cccc}
\hline No. & $\boldsymbol{k}_{\boldsymbol{j}}$ & $\boldsymbol{E}_{\boldsymbol{j}}(\mathbf{k J} / \mathbf{m o l})$ & $\boldsymbol{K}_{\boldsymbol{j}}$ \\
\hline 1 & $2.87 \cdot 10^{11} \mathrm{hr}^{-1}$ & 112 & - \\
2 & $1.68 \cdot 10^{5} \frac{\mathrm{kmol}}{\left(\mathrm{kg} \cdot \mathrm{hr} \cdot \mathrm{bar} \mathrm{r}^{-0.41}\right)}$ & 76.0 & - \\
3 & $0.151 \frac{\mathrm{kmol}}{\left(\mathrm{kg} \cdot \mathrm{hr} \cdot \mathrm{bar} \mathrm{r}^{2}\right)}$ & 29.0 & $7.26 \cdot 10^{14} \cdot \mathrm{e}^{-(31266 / \mathrm{T})} \mathrm{bar}^{2}$ \\
4 & $4.39 \cdot 10^{6} \frac{\mathrm{kmol}}{(\mathrm{kg} \cdot \mathrm{hr} \cdot \mathrm{bar})}$ & 67.1 & $2.24 \cdot 10^{-2} \mathrm{e}^{(4160 / \mathrm{T})}$ \\
\hline
\end{tabular}

\subsubsection{Autothermal Reforming (ATR) Reactor}

In the adiabatic ATR reactor, endothermic steam reforming and exothermic partial oxidation reactions occur simultaneously along with the mildly exothermic WGS reaction. The reaction scheme, LHHW kinetics, and their corresponding values used in this work have been obtained from the open literature as shown in Table $2.4[48,56]$. 
Table 2.4: Reactions considered in this Kinetic Model

\begin{tabular}{|c|c|c|c|}
\hline No. & Reaction & Rate Equation & $\Delta H_{25^{\circ} \mathrm{C}}(\mathrm{kJ} / \mathrm{mol})$ \\
\hline 5 & $\mathrm{CH}_{4}+2 \mathrm{O}_{2} \rightarrow \mathrm{CO}_{2}+2 \mathrm{H}_{2} \mathrm{O}$ & $r_{5}=\frac{k_{5} P_{C_{4}} P_{O_{2}}^{0.5}}{\left(1+K_{C_{4}} P_{C H_{4}}+K_{O_{2}} P_{O_{2}}^{0.5}\right)^{2}}$ & $-802,000$ \\
\hline 6 & $\mathrm{CH}_{4}+\mathrm{H}_{2} \mathrm{O}=\mathrm{CO}+3 \mathrm{H}_{2}$ & $r_{6}=\frac{k_{6}}{P_{H 2}^{2.5}}\left(P_{C H_{4}} P_{H_{2} O}-\frac{P_{H_{2}}^{3} P_{C O}}{K_{6}}\right) \frac{1}{A_{d}^{2}}$ & 206,000 \\
\hline 7 & $\mathrm{CO}+\mathrm{H}_{2} \mathrm{O}=\mathrm{CO}_{2}+\mathrm{H}_{2}$ & $r_{7}=\frac{k_{7}}{P_{H_{2}}}\left(P_{C O} P_{H_{2} O}-\frac{P_{H_{2}} P_{C O_{2}}}{K_{7}}\right) \frac{1}{A_{d}^{2}}$ & $-41,000$ \\
\hline 8 & $\mathrm{CH}_{4}+2 \mathrm{H}_{2} \mathrm{O}=\mathrm{CO}_{2}+4 \mathrm{H}_{2}$ & $r_{8}=\frac{k_{8}}{P_{H_{2}}^{3.5}}\left(P_{C_{H_{4}}} P_{H_{2} O}^{2}-\frac{P_{H_{2}}^{4} P_{C O_{2}}}{K_{8}}\right) \frac{1}{A_{d}^{2}}$ & 165,000 \\
\hline & $+K_{C O} P_{C O}+K_{H_{2}} P_{H_{2}}+K_{C H}$ & ${ }_{C H_{4}}+\left(K_{H_{2} O} P_{H_{2} O} / P_{H_{2}}\right)$ & \\
\hline
\end{tabular}

The model is validated using the experimental data from Hoang \& Chan [48] as shown in Table 2.5. The total inlet flow rate is $14.4 \mathrm{~kg} / \mathrm{hr}$. The temperature of the inlet stream is $126^{\circ} \mathrm{C}$, which is lower than the oxidation reaction that gets initiated at a temperature $280^{\circ} \mathrm{C}$ or so, heating up the bed temperature to $300^{\circ} \mathrm{C}$ or so $[48,49]$.

Table 2.5: Validation of ATR Model with Hoang \& Chan [48]

\begin{tabular}{ccccc}
\hline & Inlet mol \% & \multicolumn{2}{c}{ Outlet mol\% } & Error \% \\
& \multicolumn{5}{c}{ Model } & Reported \\
\hline $\mathrm{H}_{2}$ & 1.30 & 27.0 & 30.0 & 10.0 \\
$\mathrm{CO}$ & 0.400 & 7.00 & 6.50 & 7.70 \\
$\mathrm{CO}_{2}$ & 0.100 & 6.30 & 7.00 & 10.0 \\
$\mathrm{O}_{2}$ & 12.0 & 0 & 0 & 0 \\
$\mathrm{H}_{2} \mathrm{O}$ & 24.6 & 23.8 & 22.5 & 5.80 \\
$\mathrm{CH}_{4}$ & 16.4 & 0 & 0 & 0 \\
$\mathrm{~N}_{2}$ & 45.3 & 35.8 & 34.0 & 5.30 \\
Temperature $\left({ }^{\circ} \mathrm{C}\right)$ & 126 & 794 & 762 & 3.10 \\
\hline
\end{tabular}

An experimental study by Scognamiglio et al. [49] focusing on the temperature profiles of catalytic ATR reformer shows that the oxidation reaction is initiated as the gas temperature increases beyond a threshold due to heat exchange with the hot catalyst followed by the steam reforming 
reaction that occurs as the temperature exceeds a threshold due to the oxidation reactions. However, in Aspen Plus ${ }^{\circledR}$, the catalyst temperature is not available as a variable. As a workaround, heat flux between the catalyst and gas phase is calculated using their respective temperature profiles reported by Hoang \& Chan [48] with the constraint that the total heat flux should sum up to zero since the reactor operates adiabatically. This calculated heat flux profile is passed on to the ATR reactor. Operating conditions like steam/C ratio, $\mathrm{O}_{2} / \mathrm{C}$ ratio and inlet temperature depend on the exit syngas composition and its intended application. These operating conditions are designed to satisfy the desired $\mathrm{H}_{2} / \mathrm{CO}$ ratio, which ranged between 1 and 2 in this study. Because of the high hydrogen content in the shale gas, $\mathrm{CO}_{2}$ is recycled to the ATR reactor to achieve lower $\mathrm{H}_{2} / \mathrm{CO}$ ratio (<1.6). This aspect will be discussed in detail later in this Chapter. The $\mathrm{O}_{2} / \mathrm{C}$ ratio is manipulated to keep the outlet reactor temperature between $850^{\circ} \mathrm{C}$ and $1100^{\circ} \mathrm{C}$ as recommended by the industry to achieve complete conversion of hydrocarbons $[19,62]$. In this study, the ATR reactor is designed to operate adiabatically at 21 bar pressure with a WHSV of $7.23 \mathrm{~h}^{-1}$. The steam/C and $\mathrm{O}_{2} / \mathrm{C}$ ratios are varied between $0.5-0.7$ and $0.6-0.7$, respectively. The catalyst considered for this reactor is $\mathrm{Ni} / \mathrm{Al}_{2} \mathrm{O}_{3}$ with a loading of $77,713 \mathrm{~kg}$ (particle density $=1870 \mathrm{~kg} / \mathrm{m}^{3}$ ), and the bed voidage is assumed to be 0.4 [64].

\subsection{Acid Gas Removal (AGR) Section}

Presence of $\mathrm{CO}_{2}$ in the feed to the DME reactor is known to have a negative impact on the production of DME. A study by Kabir et al. [54] on production of DME from Victorian brown coal reported a three-fold increase in the DME yield when the $\mathrm{CO}_{2}$ content in the feed stream was zero. However, the utility consumption in the AGR unit can increase significantly if the partial pressure of $\mathrm{CO}_{2}$ at the inlet and outlet of the AGR unit decreases especially when a physical solvent is used. The partial pressure of $\mathrm{CO}_{2}$ in the AGR unit can be increased by considering a lower extent of $\mathrm{CO}_{2}$ capture in the AGR unit and by recycling a $\mathrm{CO}_{2}$-rich stream back to the ATR reactor. It also provides flexibility in maintaining the $\mathrm{H}_{2} / \mathrm{CO}$ ratio at the outlet of the ATR reactor. However, recycling of $\mathrm{CO}_{2}$-rich gas would require compressor(s). Therefore, the extent of $\mathrm{CO}_{2}$ capture from the syngas should be determined by considering these tradeoffs.

In this study, both physical and chemical $\mathrm{CO}_{2}$ removal technologies are evaluated for treating the raw syngas because the $\mathrm{CO}_{2}$ partial pressure changes considerably due to the consideration of different $\mathrm{H}_{2} / \mathrm{CO}$ ratio at the outlet of the ATR reactor. Rectisol, a physical solvent, is being used 
commercially for years, requiring relatively less utility consumption when operated at high pressure [54]. Therefore, it is selected as a potential technology. Jiang and Bhattacharyya [44,65] evaluated three $\mathrm{CO}_{2}$ capture technologies, namely Selexol, monoethanolamine (MEA) and MDEA/PZ, for post Fischer-Tropsch $\mathrm{CO}_{2}$ capture in an indirect coal-biomass to liquids plant. The shale-gas to DME production process has a strong similarity to the indirect coal-biomass to liquids plant in terms of the feed composition to the AGR unit and its design objective. It was observed in that study that the MDEA/PZ technology with intercooling had the lowest overall penalty. Hence, $\mathrm{MDEA} / \mathrm{PZ}$ is evaluated as a potential chemical absorption technology in this study. Advantages of the Rectisol technology over the MDEA/PZ technology are simple solvent regeneration, cheap solvent, and flexible process configuration. Some of the disadvantages of the Rectisol process are refrigeration requirement, requirement of high partial pressure in the absorber, higher solvent circulation rate for removing $\mathrm{CO}_{2}$, and absorption of hydrocarbons in the solvent.

\subsubsection{Rectisol Process}

Rectisol process uses methanol as the solvent with the absorber operating at temperatures between $-28^{\circ}$ to $-70^{\circ} \mathrm{C}$, and at a pressure of 30 to $60 \mathrm{bar}$ [51]. In this study, a rate-based absorber model available in the Aspen Plus ${ }^{\circledR}$ library with the Perturbed-Chain Statistical Associating Fluid Theory (PC-SAFT) thermodynamic package is used. The model parameters of this model have been regressed using experimental data [66]. There are several configurations available in open literature for the Rectisol process for selective removal of $\mathrm{H}_{2} \mathrm{~S}$ and $\mathrm{CO}_{2}$ [67]. However, in our study only $\mathrm{CO}_{2}$ is present, so a new process scheme is developed as shown in Fig. 2.4. 


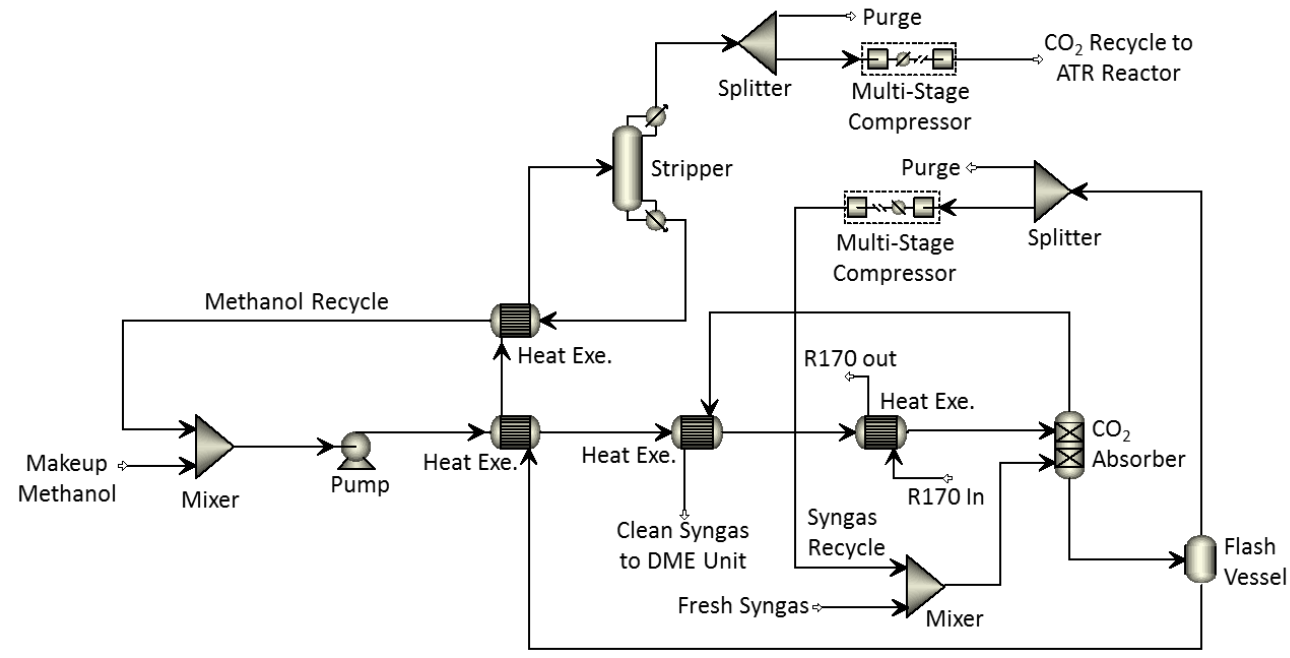

Figure 2.4: Schematic of the Rectisol Process

The $\mathrm{CO}_{2}$ absorber is operated at $50 \mathrm{bar}$, which is decided based on the operating pressure of the downstream DME synthesis unit. Fresh syngas is compressed and fed to the bottom of the absorber while the chilled methanol $\left(-28^{\circ} \mathrm{C}\right)$ is fed to the top. Clean syngas is obtained from the top of the absorber, while the $\mathrm{CO}_{2}$ loaded methanol leaves the absorber bottom. The bottom stream from the absorber is sent to a flash vessel operating at 15 bar to flash off and recycle the captured syngas. The liquid stream from the flash vessel is heated and fed to the stripper, a tray column, operating at 10 bar to regenerate the solvent which is then recycled to the absorber. A design specification is implemented to limit the concentration of $\mathrm{CO}_{2}$ in the clean syngas stream to $1 \mathrm{~mol} \%$.

An ammonia refrigeration cycle is modeled with a minimum temperature approach of $5^{\circ} \mathrm{C}$ to meet the refrigeration demand in the Rectisol process. The refrigeration cycle consists of a 4-stage compressor with inter-stage cooling, an expander, and a heat exchanger. Ammonia, at $35^{\circ} \mathrm{C}$ and $15 \mathrm{bar}$, from the multi-stage compressor is expanded to $-33.34^{\circ} \mathrm{C}$. A design specification is used to control the temperature of ammonia, after heat exchange with methanol, to ensure that the minimum temperature approach is met. The overall energy consumption of the Rectisol process is calculated using the specific equivalent electric consumption (SEEC) shown below [68].

$S E E C=\frac{E_{\text {ref }}+E_{c w}+E_{\text {process }}+E_{\text {fuel }}+E_{\text {reboiler }}}{\mathrm{CO}_{2} \text { captured }}$

In Eq. (2.1), $E_{r e f}$ is the electric power required in the refrigeration cycle compressors; $E_{c w}$ is the electric power required for cooling water circulation; $E_{\text {process }}$ is the electric power consumed by 
process pumps and compressors; $E_{f u e l}$ is the chemical exergy of the fuel species co-captured with $\mathrm{CO}_{2}$ and $E_{\text {reboiler }}$ is the electric equivalent of reboiler duty. Since, the loss of fuel species i.e. $\mathrm{H}_{2}$ and $\mathrm{CO}$ in the AGR process is very less $(<0.008) E_{f u e l}$ is ignored in the calculations. The SEEC calculated using our model is compared with the study of Gatti et al. [68] in Table 2.6. As seen, the SEEC value of the model developed in this study is reasonably close to the optimized mixed refrigerant scheme $\mathrm{B}$, considering the difference in the $\mathrm{CO}_{2}$ partial pressure.

Table 2.6: Performance of the Rectisol Process in Comparison to Gatti et al. [68]

\begin{tabular}{cccc}
\hline & Our Model & \multicolumn{2}{c}{ Reported } \\
& & $\begin{array}{c}\text { Reference } \\
\text { Scheme }\end{array}$ & $\begin{array}{c}\text { Scheme B mixed } \\
\text { refrigerant }\end{array}$ \\
\hline Absorber Temperature $\left({ }^{\circ} \mathrm{C}\right)$ & -28 & -50 & -50 \\
Absorber Pressure (bar) & 50 & 60 & 60 \\
$\mathrm{CO}_{2}$ mol\% & 21 & 30 & 30 \\
$E_{\text {ref }}(\mathrm{MW})$ & 11.4 & 21.1 & 12.1 \\
$E_{c w}(\mathrm{MW})$ & 0.9 & 1.5 & 1 \\
$E_{\text {process }}(\mathrm{MW})$ & 3.8 & 15.8 & 18.9 \\
$E_{\text {reboiler }}(\mathrm{MW})$ & 8.4 & 5 & 0.4 \\
$\mathrm{CO}_{2}$ Captured $(\mathrm{kg} / \mathrm{s})$ & 24.4 & 43.4 & 32.4 \\
$\mathrm{CO}_{2}$ capture $(\%)$ & 48.2 & 65 & 65.3 \\
$\mathrm{SEEC}\left(\mathrm{kJ} / \mathrm{kg}\right.$ of $\mathrm{CO}{ }_{2}$ captured $)$ & 93.6 & 97.5 & 98 \\
\hline
\end{tabular}

\subsubsection{MDEA/PZ Process}

The advanced amine solvent with MDEA as the base amine and PZ as an activator has a lower regeneration energy requirement compared to primary and secondary amines [69]. The rate based model of the MDEA/PZ process in Aspen Plus ${ }^{\circledR}$ previously reported by Jiang and Bhattacharyya [65] is used in this study, with some modifications in configuration as shown in Fig. 2.5. The electrolyte NRTL model with Redlich-Kwong (ENRTL-RK) EOS is used to calculate the thermodynamic properties. 


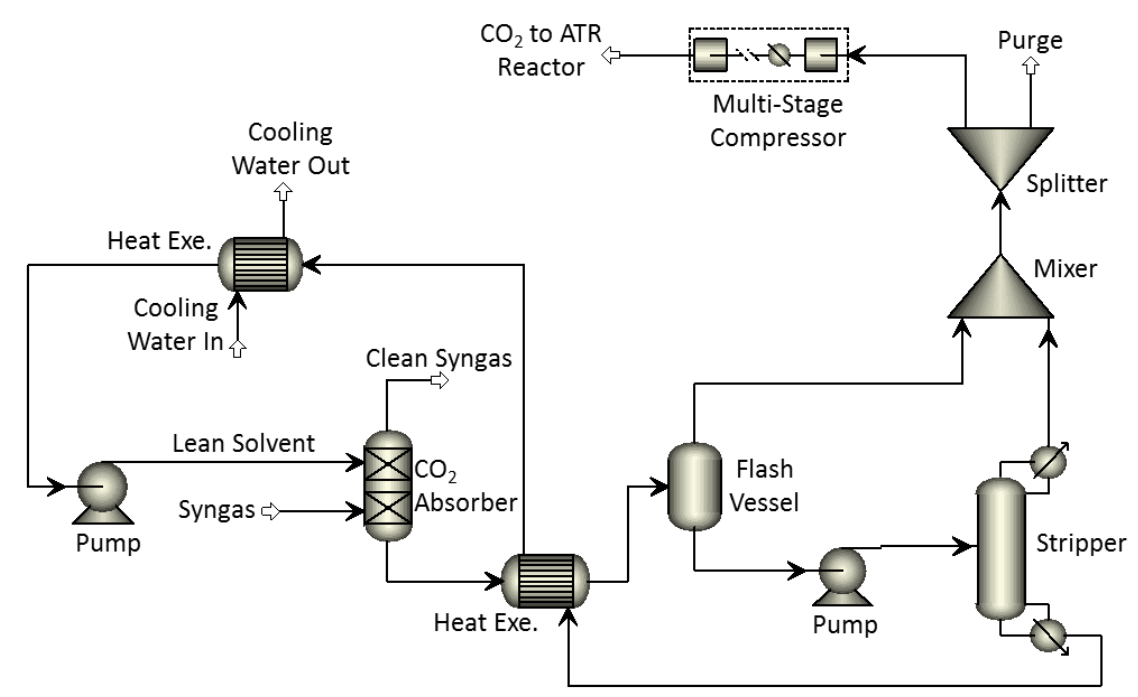

Figure 2.5: Schematic of the MDEA/PZ-Based Absorption Process for $\mathrm{CO}_{2}$ Removal

The rich solvent from the bottom of the absorber is heated by the hot stream from the stripper bottom and sent to the flash vessel where $66 \% \mathrm{CO}_{2}$ is removed. The liquid stream from the flash separator is sent to the stripper. The desired $\mathrm{CO}_{2}$ mole fraction in the clean syngas is achieved by manipulating the solvent circulation rate. Energy consumption in the process is $2.41 \mathrm{~kJ} / \mathrm{kg}$ of $\mathrm{CO}_{2}$ capture, which is similar to the results reported by Tobiesen et al. [70].

\subsection{Direct DME Production Section}

Clean syngas obtained from the syngas production section is then sent to the DME production section. The DME production section consists of DME synthesis and separation section.

\subsubsection{Direct DME Synthesis Unit}

The DME reactor is a PFR being modeled by the R-PFR block in Aspen Plus ${ }^{\circledR}$ with BWR-Lee Sterling EOS as the thermodynamic package. The configuration of the DME synthesis section is shown in Fig. 2.6. 


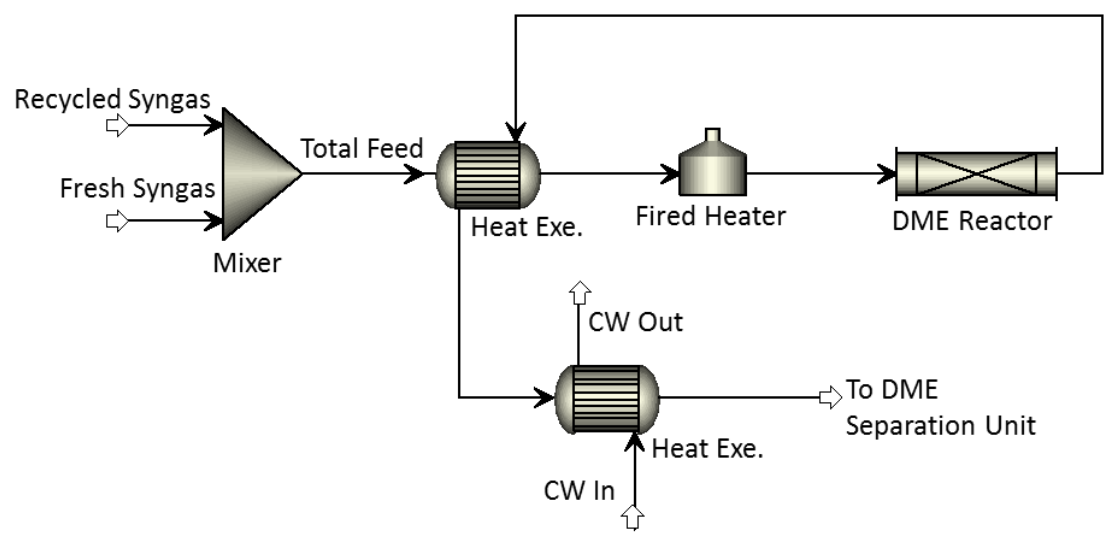

Figure 2.6: Configuration of the DME Synthesis Unit

Four possible reactions as shown in Table 2.7 are considered in the direct DME synthesis reactor. By phase rule, there are only 3 independent reactions for this reaction system [71,72]. Reactions 9, 10 and 12 are chosen as the three independent reactions in this study. These reactions take place on a bi-function catalyst, $\mathrm{CuO} / \mathrm{ZnO} / \mathrm{Al}_{2} \mathrm{O}_{3}$ and $\gamma-\mathrm{Al}_{2} \mathrm{O}_{3}$, with a loading of 201,793 $\mathrm{kg}$ (particle density $=1982.5 \mathrm{~kg} / \mathrm{m}^{3}[73]$ ), and a bed voidage of 0.4 . The reactor is designed to operate at $260^{\circ} \mathrm{C}$ and 50 bar with a WHSV of $1.35 \mathrm{~h}^{-1}$ like the pilot plant studies [5, 30]. Fugacity was calculated from the equation of state and it was close to 1 . So, partial pressure is used in place of fugacity in the reaction model. The pre-exponential factor, activation energy and adsorption constants are obtained from the open literature [74]. Zhang et al. [75] have calculated the equilibrium constants for all species using Eq. 2.2.

$\ln K_{j}=A+\frac{B}{T}+C \ln T+D T+E T^{2}+F T^{3}$

However, since only the first four terms are allowed in Aspen Plus ${ }^{\circledR}$, the parameters of the truncated equation are estimated, using the value of the equilibrium constant calculated using Eq. 2.2 and the parameters reported by Zhang et al. [75], over a temperature range of $200^{\circ} \mathrm{C}-400^{\circ} \mathrm{C}$, which is the expected feasible range of operation of the DME synthesis reactor. The updated coefficients for the equilibrium constants are reported in Appendix A. When the kinetic parameters proposed by Nie et al. [74] were used, the simulation results deviated considerably from the experimental data. 
Table 2.7: Rate Model of the Direct Syngas to DME Synthesis Reaction [33,74]

No.

Reaction

Rate Equation

$\Delta \mathrm{H}_{298}$

$(\mathbf{k J} / \mathbf{k m o l})$

\begin{tabular}{|c|c|c|c|}
\hline 9 & $\mathrm{CO}+2 \mathrm{H}_{2} \leftrightarrow \mathrm{CH}_{3} \mathrm{OH}$ & $\begin{array}{c}r_{9}=\frac{k_{9} f_{c o} f_{\mathrm{H}_{2}}^{2}\left(1-B_{9}\right)}{\left(1+K_{c o} f_{c o}+K_{\mathrm{CO}_{2}} f_{\mathrm{CO}_{2}}+K_{\mathrm{H}_{2}} f_{\mathrm{H}_{2}}\right)^{3}} \\
\text { where } B_{9}=\frac{f_{\mathrm{CH}_{3} \mathrm{OH}}}{K_{9} f_{c o} f_{\mathrm{H}_{2}}^{2}}\end{array}$ & $-90,400$ \\
\hline 10 & $\mathrm{CO}_{2}+3 \mathrm{H}_{2} \leftrightarrow \mathrm{CH}_{3} \mathrm{OH}+\mathrm{H}_{2} \mathrm{O}$ & $\begin{array}{c}r_{10}=\frac{k_{10} f_{\mathrm{CO}_{2}} f_{\mathrm{H}_{2}}^{3}\left(1-B_{10}\right)}{\left(1+K_{c o} f_{c o}+K_{\mathrm{CO}_{2}} f_{\mathrm{CO}_{2}}+K_{\mathrm{H}_{2}} f_{\mathrm{H}_{2}}\right)^{4}} \\
\text { where } B_{10}=\frac{f_{\mathrm{CH}_{3} \mathrm{OH}} f_{\mathrm{H}_{2} \mathrm{O}}}{K_{10} f_{\mathrm{CO}_{2}} f_{\mathrm{H}_{2}}^{3}}\end{array}$ & $-49,400$ \\
\hline 11 & $\mathrm{CO}+\mathrm{H}_{2} \mathrm{O} \leftrightarrow \mathrm{CO}_{2}+\mathrm{H}_{2}$ & $\begin{array}{c}r_{11}=\frac{k_{11} f_{\mathrm{H}_{2} \mathrm{O}}\left(1-B_{11}\right)}{1+K_{c o} f_{c o}+K_{\mathrm{CO}_{2}} f_{\mathrm{CO}_{2}}+\sqrt{K_{\mathrm{H}_{2}} f_{\mathrm{H}_{2}}}} \\
\text { where } B_{11}=\frac{f_{\mathrm{CO}_{2}} f_{\mathrm{H}_{2}}}{K_{11} f_{c o} f_{\mathrm{H}_{2} \mathrm{O}}}\end{array}$ & $-41,000$ \\
\hline 12 & $2 \mathrm{CH}_{3} \mathrm{OH} \leftrightarrow \mathrm{CH}_{3} \mathrm{OCH}_{3}+\mathrm{H}_{2} \mathrm{O}$ & $\begin{array}{c}r_{12}=\frac{k_{12} f_{\mathrm{CH}_{3} \mathrm{OH}}\left(1-B_{12}\right)}{\left(1+\sqrt{K_{\mathrm{CH}_{3} \mathrm{OH}} f_{\mathrm{CH}_{3} \mathrm{OH}}}\right)^{2}} \\
\text { where } B_{12}=\frac{f_{\mathrm{DME}_{\mathrm{E}} f_{\mathrm{H}_{2} \mathrm{O}}}}{K_{12} f_{\mathrm{CH}_{3} \mathrm{OH}}^{2}}\end{array}$ & $-23,000$ \\
\hline
\end{tabular}

In order to improve model accuracy, the Aspen Plus ${ }^{\circledR}$ Regression tool is used to obtain the preexponential factor and activation energy of Reactions 9, 10, and 12. The key difference in the data regression approach between this study and Nie et al. [74] is in the formulation of the objective function. While Nie et al. [74] only considered weighted output data in the objective for parameter estimation, in this work variances in both input and output data are considered. The objective function that is minimized by Nie et al. [74] is shown in Eq. 2.3.

$f=\sum_{j=1}^{N \exp }\left(\sum_{i=1}^{N}\left(y_{i}-\hat{y}_{i}\right)^{T} w_{i}^{-1}\left(y_{i}-\hat{y}_{i}\right)\right)$ 
In Eq. 2.3, $w_{i}$ represents the weights used for component $i ; y_{i}$ is the experimental mole fraction and $\hat{y}_{i}$ is the predicted mole fraction of the component $i$. The objective function that is used in this study is given by Eq. 2.4:

$f=\frac{1}{2}\left(\sum_{j=1}^{N \text { exp }}\left(\sum_{k=1}^{N r_{j}}\left(W_{j, k}-\widehat{W}_{j, k}\right)^{T} \sigma_{j, k}{ }^{-2}\left(W_{j, k}-\widehat{W}_{j, k}\right)++\sum_{n=1}^{N r r_{j}}\left(Y_{j, n}-\hat{Y}_{j, n}\right)^{T} \sigma_{j, n}{ }^{-2}\left(Y_{j, n}-\widehat{Y}_{j, n}\right)\right)\right)$

In Eq. 2.4, $N \exp , N r, W, \hat{W}, N r r, Y, \hat{Y}, \sigma$ represent the number of experiments conducted, number of input variables, measured values of the input variables, estimated values of the input variables, number of measured output variables, measured values of the output variables, estimated values of the output variables and standard deviation for the variables, respectively. Nie et al. [74] considered only three components, $\mathrm{CO}, \mathrm{CO}_{2}$ and $\mathrm{DME}$, in their objective function, while in this study, five components, namely $\mathrm{CO}, \mathrm{CO}_{2}, \mathrm{DME}, \mathrm{H}_{2} \mathrm{O}$ and $\mathrm{H}_{2}$, are taken into account. The estimated parameters are shown in Appendix A. Fig. 2.7 shows comparison between the estimated mole fractions and the experimental data [74].

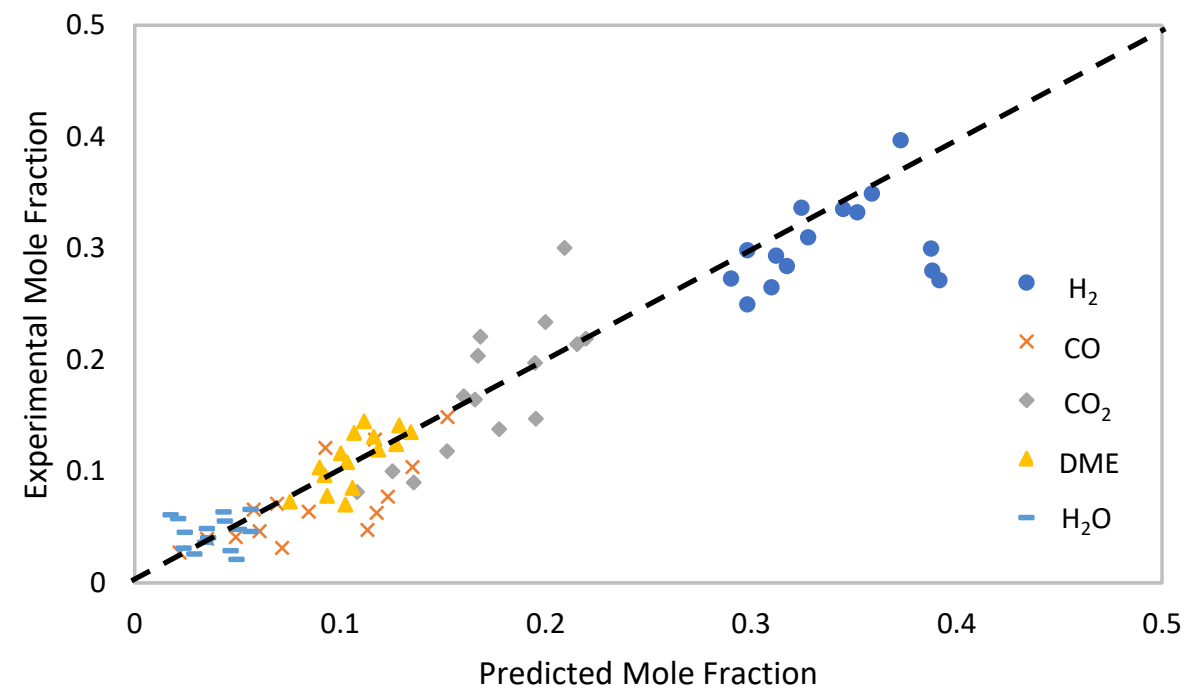

Figure 2.7: Comparison of the Estimated Mole Fractions with the Experimental Data from Nie et al. [74]

\subsubsection{DME Separation Unit}

There is hardly any work in the open literature on the separation of DME from $\mathrm{CO}_{2}$. In a conference paper on DME production [31], MDEA solvent was used to separate DME. Since MDEA is a chemical solvent, it has a high reboiler duty. In this study, a novel configuration for $\mathrm{DME}-\mathrm{CO}_{2}$ - 
syngas separation unit is proposed as shown in Fig. 2.8 by using methanol as the solvent to reduce the utility consumption. As the default NRTL-RK property method in Aspen Plus ${ }^{\circledR}$ library does not have the required binary interaction parameters for the methanol-DME- $\mathrm{CO}_{2}-\mathrm{CO}-\mathrm{H}_{2} \mathrm{O}$ system, binary interaction parameters in the NRTL-RK EOS are regressed using the experimental data available in the open literature [76-83]. The regressed binary interaction parameters and the parity plots are shown in Appendix B.

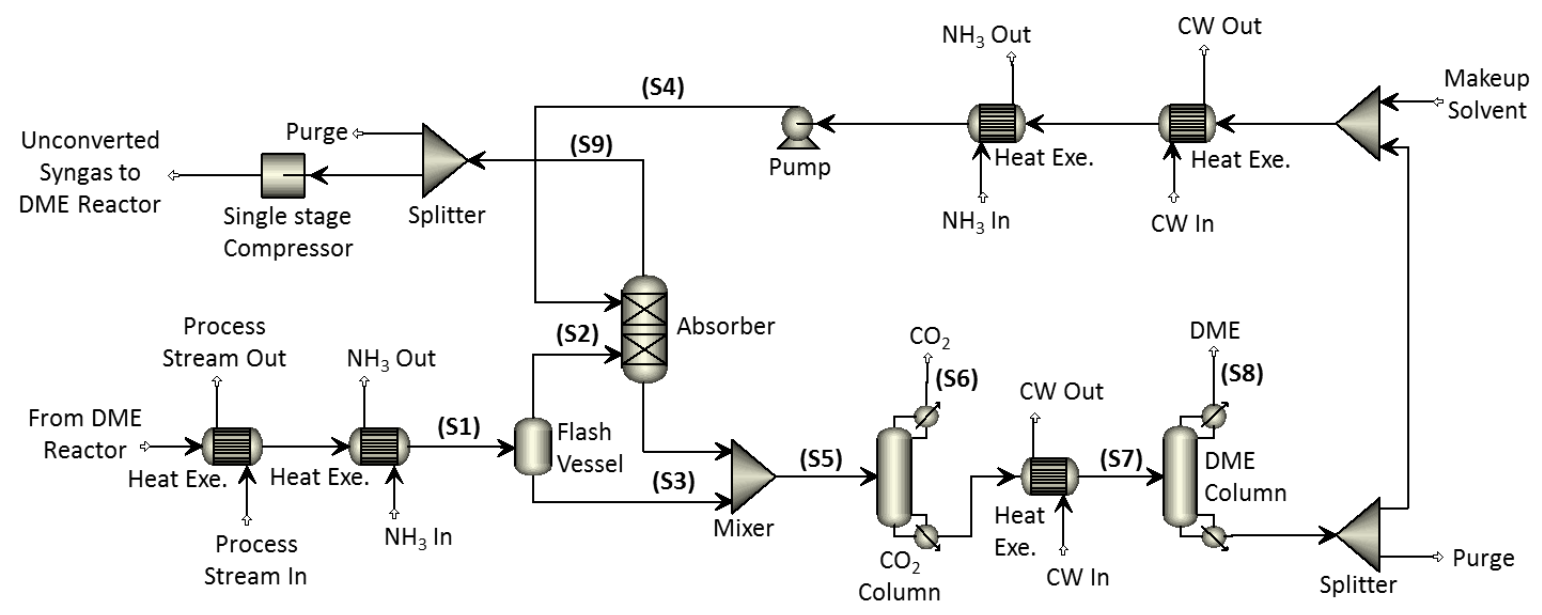

Figure 2.8: Configuration of DME Separation Unit

$\mathrm{CO}_{2}$ has good solubility in DME at elevated pressure and low temperature [76]. In this study, the outlet stream from the DME reactor is chilled to $0^{\circ} \mathrm{C}$ and fed to a flash vessel operating at 45 bar, where more than $50 \% \mathrm{CO}_{2}$ remains dissolved in the liquid stream that contains about $86 \%$ DME. The vapor stream from the flash vessel is fed to the bottom of the high pressure absorber, where a methanol-water mixture is used as the solvent and fed to the absorber top to separate the unconverted syngas from other components. The absorber uses Glitsch Grid EF25A structured packing [32]. It is designed for a maximum fractional capacity of $80 \%$ flooding. The top stream from the absorber is recycled to the DME reactor. The flow rate of the solvent is manipulated to keep the $\mathrm{CO}_{2}$ concentration in the total feed to the DME reactor to be less than $3 \mathrm{~mol} \%$. The bottoms stream is fed to a distillation column. Design parameters such as the number of stages, reflux ratio and feed tray of the distillation column are used to obtain the desired $\mathrm{CO}_{2}$ release from the solvent [32]. The released $\mathrm{CO}_{2}$ is recycled to the ATR reactor and the bottoms stream is fed to the DME column. This distillation column is designed to produce DME with more than $99.8 \mathrm{~mol} \%$ purity at the top. The bottom from the DME column containing mainly water and methanol is 
recycled back to the absorber for syngas separation. The desired DME purity is obtained by manipulating the reflux ratio.

\subsection{Indirect DME Synthesis Section}

In this section, details of the kinetic reactor models of the methanol synthesis reactor and the methanol dehydration reactor are discussed. In addition, design of the product recovery unit is also discussed. As mentioned before, in the indirect DME synthesis section, syngas is first converted to methanol and then methanol is converted to DME.

\subsubsection{Methanol Synthesis Unit}

The methanol synthesis unit consists of the methanol synthesis reactor and the syngas separation column. The configuration of the methanol synthesis unit is shown in Fig. 2.9. RKSMHV2 and PC-SAFT EOS are used as the property methods for the reactor and the separation column, respectively. Fresh syngas from the syngas production unit is compressed to 60 bar and heated to $250^{\circ} \mathrm{C}$ in a series of heat exchangers followed by a fired heater. After pre-heating the reactor inlet stream, the effluent from the methanol synthesis reactor is further cooled to $60^{\circ} \mathrm{C}$ and fed to a flash vessel for methanol separation. About $85 \%$ of the vapor stream from the flash vessel is recycled to the methanol synthesis reactor and the remaining is purged to avoid $\mathrm{CO}_{2}$ buildup. The liquid stream is sent to a distillation column operating at 12 bar for methanol purification. The bottom stream from the distillation column containing $99.5 \mathrm{~mol} \%$ methanol is then sent to the methanol dehydration reactor.

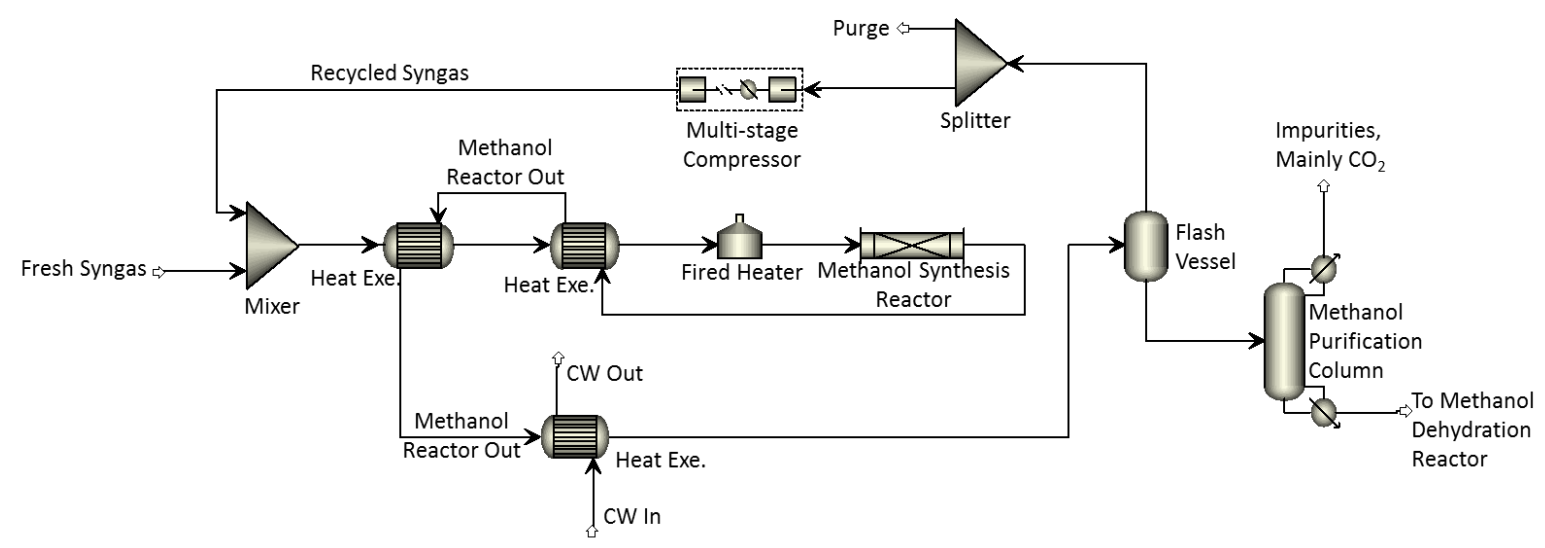

Figure 2.9: Configuration of the Methanol Synthesis Unit

The methanol synthesis reaction takes place on a commercial $\mathrm{Cu} / \mathrm{ZnO} / \mathrm{Al}_{2} \mathrm{O}_{3}$ catalyst with a loading of $96,609 \mathrm{~kg}$ (particle density $=1775 \mathrm{~kg} / \mathrm{m}^{3}$; bed voidage $=0.5$ ). These reactions occur 
under isothermal condition typically at $210-270^{\circ} \mathrm{C}$, and $50-100$ bar pressure $[84,85]$. Three possible reactions in this reactor are $\mathrm{CO}$ hydrogenation, $\mathrm{CO}_{2}$ hydrogenation and reverse water gas shift (RWGS). Only two reactions out of these three reactions are independent. In this work, the $\mathrm{CO}_{2}$ hydrogenation and RWGS reactions are considered to be the independent reactions with the kinetic models as shown in Table 2.8 [86].

Table 2.8: Rate Model of the Methanol Synthesis Reaction

\begin{tabular}{|c|c|c|c|}
\hline No. & Reaction & Rate Equation & $\Delta \mathrm{H}_{298}(\mathrm{~kJ} / \mathrm{kmol})$ \\
\hline 13 & $\mathrm{CO}_{2}+3 \mathrm{H}_{2} \leftrightarrow \mathrm{CH}_{3} \mathrm{OH}+\mathrm{H}_{2} \mathrm{O}$ & $r_{13}=\frac{k_{13} P_{\mathrm{CO}_{2}} P_{\mathrm{H}_{2}}\left(1-\frac{P_{\mathrm{H}_{2} \mathrm{O}} P_{\mathrm{CH}_{3} \mathrm{OH}}}{K_{13} P_{\mathrm{H}_{2}}^{3} P_{\mathrm{CO}_{2}}}\right)}{A B S^{3}}$ & $-49,400$ \\
\hline 14 & $\mathrm{CO}_{2}+\mathrm{H}_{2} \leftrightarrow \mathrm{CO}+\mathrm{H}_{2} \mathrm{O}$ & $r_{14}=\frac{k_{14} P_{C_{2}}\left(1-\frac{K_{14} P_{\mathrm{H}_{2} \mathrm{O}} P_{\mathrm{CO}}}{P_{\mathrm{H}_{2}} P_{\mathrm{CO}_{2}}}\right)}{A B S}$ & 41,000 \\
\hline \multicolumn{4}{|c|}{$\mathrm{ABS}=1+\left(K_{\mathrm{H}_{2} \mathrm{O}, \mathrm{H}_{2}} P_{\mathrm{H}_{2} \mathrm{O}} / P_{\mathrm{H}_{2}}\right)+K_{\mathrm{H}_{2}}^{0.5} P_{\mathrm{H}_{2}}^{0.5}+K_{\mathrm{H}_{2} \mathrm{O}} P_{\mathrm{H}_{2} \mathrm{O}}$} \\
\hline
\end{tabular}

The readjusted parameters for the model are obtained from Van-Dal and Bouallou [84]. Model validation is performed using the experimental data given by Vanden Bussche and Froment [86]. The concentration and temperature profiles shown in Fig. 2.10 closely matches the experimental data of Bussche and Froment [86].

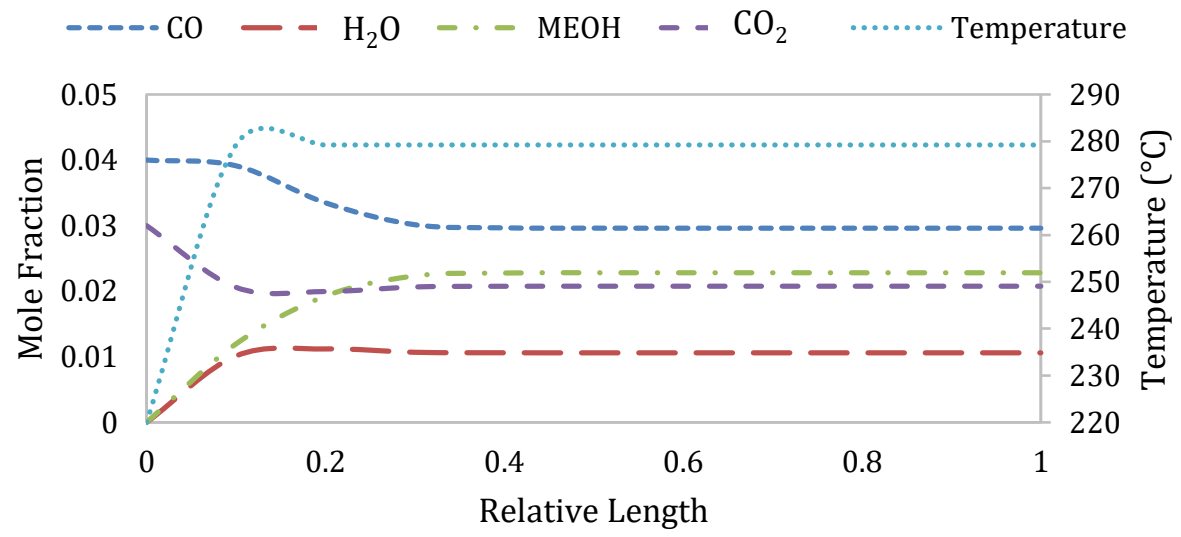

Figure 2.10: Concentration and Temperature Profile of the Methanol Synthesis Reactor

Two key factors for optimal methanol production are module (M) of the feed syngas, defined as $\left(\mathrm{H}_{2}-\mathrm{CO}_{2}\right) /\left(\mathrm{CO}+\mathrm{CO}_{2}\right)$, and the $\mathrm{CO} / \mathrm{CO}_{2}$ ratio. A module of 2 and a high $\mathrm{CO} / \mathrm{CO}_{2}$ ratio are 
recommended for higher reaction rates and high single-pass syngas conversion. The syngas produced by the ATR reactor has a module of 1.7 to 1.8 . This module can be adjusted to 2 by either adding hydrogen to the ATR reactor or removing $\mathrm{CO}_{2}$ from the syngas. In this study, $\mathrm{CO}_{2}$ is removed from the syngas by using the Rectisol technology as mentioned earlier. It should be noted that if the module is adjusted by using hydrogen, then there can be a higher energy penalty due to the hydrogen generation and purification units.

\subsubsection{Methanol Dehydration Unit}

The configuration of the methanol dehydration unit is shown in Fig. 2.11. Methanol from the methanol synthesis unit is heated to the desired temperature using a fired heater and fed to the methanol dehydration reactor. The reactor effluent is cooled to $60^{\circ} \mathrm{C}$ and fed to the DME purification column operating at about 10 bar. The desired DME purity is 99.8 mol\% which is obtained by manipulating the reflux ratio in the DME purification column. The bottom stream from the DME purification column is fed to the methanol-water separation column from which 98 mol\% pure methanol is recovered and mixed with the methanol from the methanol purification unit.

The methanol dehydration reactor is modeled as a PFR with LHHW kinetics, operating at $250^{\circ} \mathrm{C}$, 10 bar with a WHSV of $4.05 \mathrm{~h}^{-1}$ [87]. The reaction takes place on a $\gamma-\mathrm{Al}_{2} \mathrm{O}_{3}$ catalyst with a loading of $44,140 \mathrm{~kg}$ (particle density $=2141 \mathrm{~kg} / \mathrm{m}^{3}$; bed voidage $=0.4$ ) [88]. The DME purification column and methanol-water separation column are modeled as equilibrium-based models. NRTLRK EOS with regressed binary interaction parameters mentioned in the Section 2.7.2 is used as the thermodynamic model for this unit.

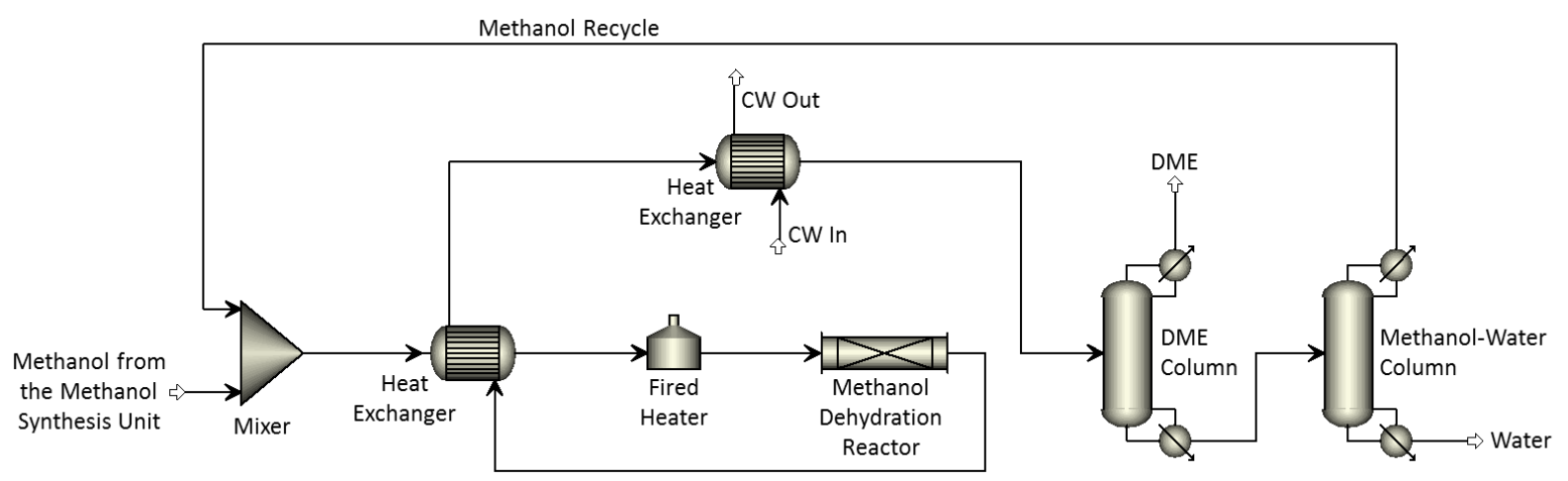

Figure 2.11: Configuration of DME Synthesis Unit 
The rate model of the methanol dehydration reaction is shown in Table 2.9 [89]. Kinetic parameters of the model are taken from Mollavali et al. [89]. The equilibrium constant for this reaction, given by Eq. 2.5, is obtained from the work of Diep and Wainwright [90].

$\ln K_{e q}=\frac{2835.2}{T}+1.675 \ln T-2.39 \times 10^{-4} T-13.360$

The reactor model is validated with the work of Bercic and Levec_[91], as shown in Appendix C. Due to the lack of experimental data in the open literature, a more comprehensive validation could not be performed. However, the results of the rate-based reactor model are also compared with a Gibbs free energy minimization reactor model, as shown in Appendix C.

Table 2.9: Rate Model of the Methanol Dehydration Reaction

No. Reaction Rate Model

$\Delta \mathrm{H}_{298}$

$(\mathrm{kJ} / \mathrm{kmol})$

$15 \quad 2 \mathrm{CH}_{3} \mathrm{OH} \leftrightarrow \mathrm{CH}_{3} \mathrm{OCH}_{3}+\mathrm{H}_{2} \mathrm{O} \quad r_{15}=\frac{k_{15} P_{\mathrm{CH}_{3} \mathrm{OH}}-\left(k_{15} / K_{15}\right)\left(P_{D M E} P_{\mathrm{H}_{2} \mathrm{O}} / P_{\mathrm{CH}_{3} \mathrm{OH}}\right)}{K_{\mathrm{CH}_{3} \mathrm{OH}} P_{\mathrm{CH}_{3} \mathrm{OH}}+\left(P_{\mathrm{H}_{2} \mathrm{O}} / K_{\mathrm{H}_{2} \mathrm{O}}\right)+1} \quad-23,000$

\subsection{Heat Recovery Steam Generation (HRSG) and Steam Cycle}

To satisfy the utility requirement in the process, the purge streams rich in fuel gases from the process, along with additional shale gas, is fed to the HRSG. The quantity of the additional shale gas required in the HRSG varies between 1-10\% of the shale gas fed to the pre-reforming reactor. The configuration of the single-pressure HRSG with reheat and SC is shown in Fig. 2.12, similar to the steam side of a typical combined cycle plant. The main heat sources are the hot flue gas (blue color) from the combustor and the hot syngas from the ATR reactor (Cyan color). This section is configured and modeled by suitably modifying our previous work in this area as a part of IGCC and coal-biomass to liquids processes [44,92]. Boiler feed water (BFW) is heated up to $130^{\circ} \mathrm{C}$ before splitting into the high pressure (HP - green color), intermediate pressure (IP - pink color) and low pressure (LP - red color) streams. The HP stream is pumped to $138 \mathrm{bar}$, preheated using the HP preheater and then heated up to near its saturation temperature using the HP Economizer 1 and HP Economizer 2. This stream is then sent to the HP Evaporators 1 and 2 for generating saturated steam. The saturated steam is sent through the superheaters before sending it to the HP steam turbine. The IP stream is heated up to near-saturation temperature using the IP 
economizer and then sent to the IP evaporator for generating saturated steam. Saturated LP steam is generated in the LP evaporator. Design spec is used to ensure that the temperature difference between the hot streams and cold streams is at least $10^{\circ} \mathrm{C}$ in the LP and IP evaporators. Design specs are also implemented to ensure that the steam requirements in the ATR reactor, IP steam to the header, and LP steam to the header are achieved by manipulating the split fraction of the corresponding splitters. The HP steam generated from the HRSG is used to drive the steam turbine. Various stages of the steam turbine are named as follows: HP ST, IPST 1 \& 2, LP ST 1 \& LP ST 2. The isentropic efficiency and the operating conditions of each section are based on the studies conducted for similar applications [44,93-95].

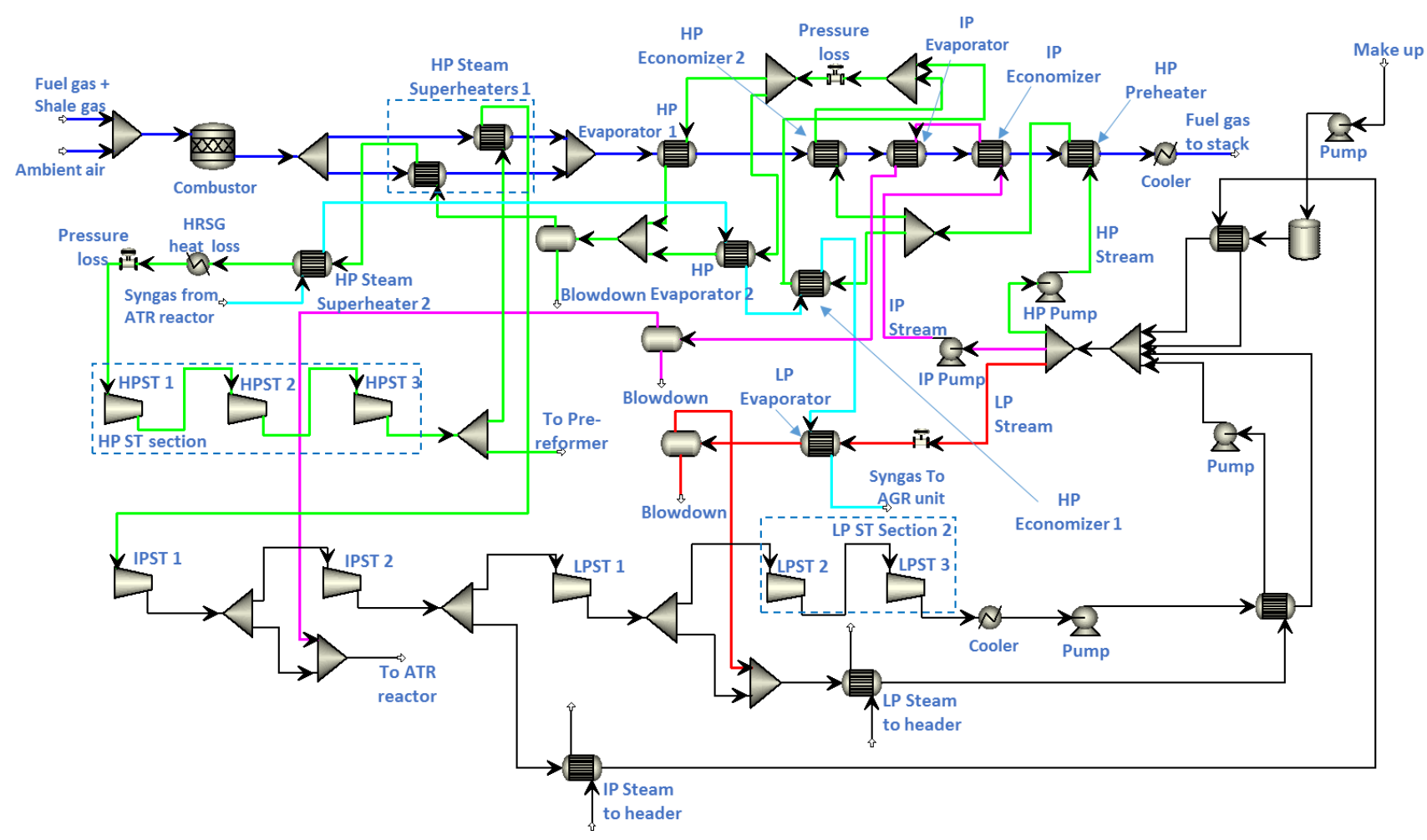

Figure 2.12: The configuration of HRSG and SC

More information on the steam turbine can be found in Table 2.10. The net overall efficiency $\left(\eta_{e}\right)$ of the HRSG and SC, defined by Eq. 2.6, is $24.85 \%$ for the direct DME synthesis process. In Eq. 2.6, $Q_{T}$ is the thermal energy; $Q_{F}$ is the calorific value of the fuel (LHV basis). In this study, steam is extracted from various stages to satisfy the utility requirement in the process, as shown in Fig. 2.12. If steam extraction to ATR and pre-reforming reactor, and the steam to the LP and IP header are not considered then the net overall efficiency is $42.4 \%$. 
$\eta_{e}=Q_{E} / Q_{F}$

The HRSG \& SC plant can satisfy all the steam requirement in the indirect DME process, direct $\operatorname{DME}\left(\mathrm{H}_{2} / \mathrm{CO}=2\right)$ process with both AGR technologies and direct DME $\left(\mathrm{H}_{2} / \mathrm{CO}=1\right)$ with Rectisol technologies. In the direct DME process, when the syngas $\mathrm{H}_{2} / \mathrm{CO}=1$ and MDEA/PZ is used for $\mathrm{CO}_{2}$ removal, an auxiliary boiler is used to satisfy the steam requirement for the MDEA/PZ unit. The amount of the shale gas used in this auxiliary boiler is about $7.9 \%$ of the amount of the shale gas fed to the pre-reforming reactor. The amount of electricity generated in the SC is enough to satisfy the requirement in the direct DME synthesis plants, while for the indirect DME plant additional electricity must be bought from the grid.

\section{Table 2.10: Operating conditions for the steam turbines}

\begin{tabular}{ll}
\hline ST section & $\begin{array}{c}\text { Operating condition } \\
\text { (pressure, isentropic efficiency) }\end{array}$ \\
\hline HP ST section & HPST1: 91.5 bar, 0.8 \\
& HPST2: $57.2 \mathrm{bar}, 0.875$ \\
& HPST3: $31.01 \mathrm{bar}, 0.89$ \\
IP ST section & IPST1: $21.3 \mathrm{bar}, 0.89$ \\
& IPST2: $11.01 \mathrm{bar}, 0.893$ \\
LP ST section & LPST1: $6.01 \mathrm{bar}, 0.91$ \\
& LPST2: $1.7 \mathrm{bar}, 0.92$ \\
& LPST3: $0.067 \mathrm{bar}, 0.92$
\end{tabular}

\subsection{Results and Discussion}

Table 2.11 provides the summary of the base case (i.e. $\mathrm{H}_{2} / \mathrm{CO}=1$ ) material balance for the direct synthesis route with the stream numbers marked in Fig. 2.1. Two key design variables investigated in this study for the direct synthesis process are the $\mathrm{CO}_{2}$ recycle and the $\mathrm{H}_{2} / \mathrm{CO}$ ratio in the DME production section inlet stream. Sensitivity analysis of the syngas synthesis and AGR units for varying $\mathrm{CO}_{2}$ feed and $\mathrm{H}_{2} / \mathrm{CO}$ ratio is presented in Section 2.10.1. In Section 2.10.2, the effect of feed composition in the DME reactor and sensitivity of methanol content on the reboiler duty in the direct syngas-to-DME production process are discussed. Various studies on the indirect syngas-to-DME production process are discussed in Section 2.10.3. 
Table 2.11: Summary of Material Balance for Base Case $\left(\mathrm{H}_{2} / \mathrm{CO}=1\right)$

\begin{tabular}{|c|c|c|c|c|c|}
\hline Stream \# & 1 & 2 & 3 & 4 & 5 \\
\hline Temperature $\left({ }^{\circ} \mathrm{C}\right)$ & 40.0 & 532 & 939 & 35.0 & 25.0 \\
\hline Pressure (bar) & 30.4 & 30.1 & 19.9 & 50.6 & 50.0 \\
\hline Total Flow (kg/hr) & 5,200 & 8,412 & 27,645 & 20,106 & 15,925 \\
\hline Total Flow (kmol/hr) & 98,047 & 141,821 & 561,990 & 424,302 & 243,021 \\
\hline \multicolumn{6}{|l|}{ Mole Fraction } \\
\hline $\mathrm{CH}_{3} \mathrm{OH}$ & & & trace & & \\
\hline $\mathrm{CO}_{2}$ & 0.009 & 0.048 & 0.154 & 0.209 & 0.010 \\
\hline $\mathrm{CO}$ & & trace & 0.286 & 0.392 & 0.490 \\
\hline $\mathrm{N}_{2}$ & 0.003 & trace & trace & trace & trace \\
\hline $\mathrm{H}_{2}$ & & 0.070 & 0.287 & 0.394 & 0.496 \\
\hline $\mathrm{CH}_{4}$ & 0.838 & 0.676 & trace & trace & trace \\
\hline $\mathrm{H}_{2} \mathrm{O}$ & & 0.200 & 0.270 & trace & \\
\hline $\mathrm{C}_{2} \mathrm{H}_{6}$ & 0.120 & & & & \\
\hline $\mathrm{C}_{3} \mathrm{H}_{8}$ & 0.030 & & & & \\
\hline Stream \# & 6 & 7 & 8 & 9 & 10 \\
\hline Temperature $\left({ }^{\circ} \mathrm{C}\right)$ & -1.21 & -1.21 & 48.1 & 60.0 & 61.5 \\
\hline Pressure (bar) & 45.0 & 45.0 & 45.0 & 20.9 & 15.0 \\
\hline Total Flow (kg/hr) & 4,235 & 4,207 & 8,885 & 10,267 & 2,396 \\
\hline Total Flow (kmol/hr) & 184,221 & 88,177 & 239,456 & 305,234 & 110,345 \\
\hline \multicolumn{6}{|l|}{ Mole Fraction } \\
\hline $\mathrm{CH}_{3} \mathrm{OH}$ & 0.021 & & 0.415 & 0.368 & \\
\hline $\mathrm{CO}_{2}$ & 0.392 & 0.206 & 0.086 & & \\
\hline $\mathrm{CO}$ & 0.036 & 0.301 & 0.027 & & \\
\hline $\mathrm{N}_{2}$ & trace & 0.017 & trace & & \\
\hline $\mathrm{H}_{2}$ & & 0.428 & & & \\
\hline $\mathrm{H}_{2} \mathrm{O}$ & 0.026 & & 0.448 & 0.398 & \\
\hline $\mathrm{C}_{2} \mathrm{H}_{6} \mathrm{O}$ & 0.521 & 0.045 & 0.021 & 0.233 & 0.999 \\
\hline
\end{tabular}




\subsubsection{Syngas Synthesis and AGR Unit}

\subsubsection{Effect of $\mathrm{CO}_{2}$ Recycle on Syngas Synthesis Unit}

Due to high hydrogen content in the shale gas, obtaining a low $\mathrm{H}_{2} / \mathrm{CO}$ ratio $(<1.6)$ is difficult. Recycling of $\mathrm{CO}_{2}$ from the downstream AGR unit and DME production unit to the ATR reactor is required to obtain a lower ratio, as shown in Fig. 2.13. Providing more $\mathrm{CO}_{2}$ to the ATR unit results in production of more $\mathrm{CO}$ thereby reducing the $\mathrm{H}_{2} / \mathrm{CO}$ ratio, as seen in Fig. 2.13.

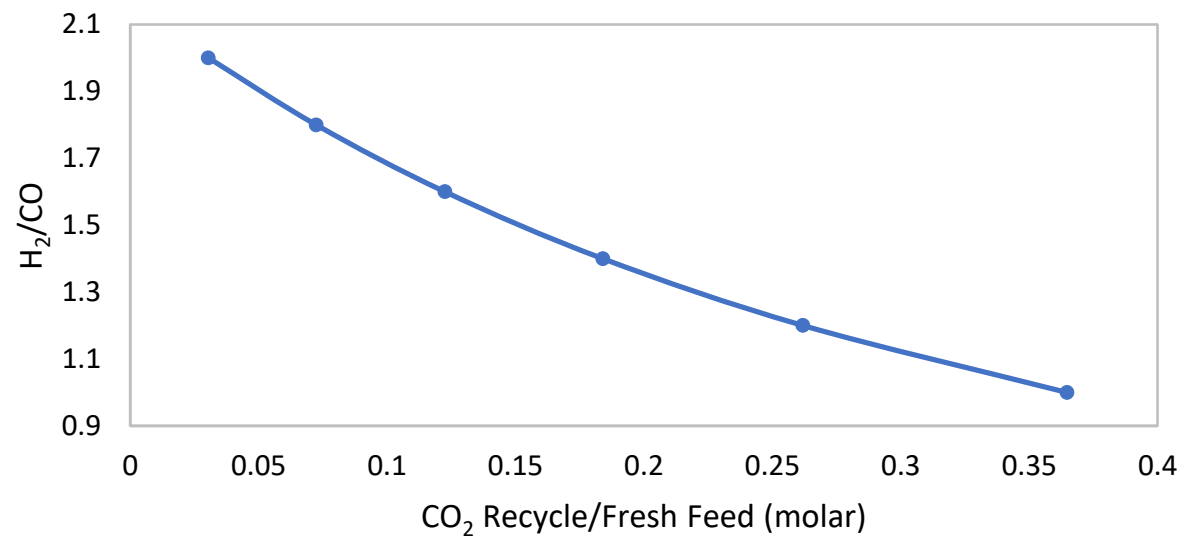

Figure 2.13: Sensitivity of $\mathrm{H}_{2} / \mathrm{CO}$ Ratio to the $\mathrm{CO}_{2}$ Recycle Ratio

Recycle of $\mathrm{CO}_{2}$ has advantages and disadvantages. For example, to obtain $\mathrm{H}_{2} / \mathrm{CO}$ ratio of $1,87 \%$ of the total $\mathrm{CO}_{2}$ produced is utilized in the ATR reactor. The main disadvantage of having a $\mathrm{CO}_{2}$ recycle is the increase in the utility usage due to the compression of $\mathrm{CO}_{2}$ before feeding it to the ATR reactor. It also results in more utility consumption in other sections of the process. Another effect of the higher recycle ratio is the increase in the equipment size, which is not captured in this work. The advantage of having a $\mathrm{CO}_{2}$ recycle is the higher carbon yield. As seen in Table 2.12, $\mathrm{CO}_{2}$ requirement reduces with the increase in the $\mathrm{H}_{2} / \mathrm{CO}$ ratio. Electricity and cooling water usage shown are for the compression of oxygen feed to the ATR reactor and $\mathrm{CO}_{2}$ for recycle. The increase in the utility requirement is mainly due to compression of $\mathrm{CO}_{2}$ recycle. It should be noted that the $\mathrm{O}_{2} / \mathrm{C}$ and steam/C ratio are independent variables for each case and hence are different. As mentioned earlier, these two variables are manipulated to control the temperature and composition at the ATR reactor outlet. 
Table 2.12: Effect of the $\mathrm{CO}_{2}$ Recycle on Syngas Synthesis Unit

\begin{tabular}{cccc}
\hline Case & $\mathbf{H}_{2} / \mathbf{C O}=\mathbf{1}$ & $\mathbf{H}_{2} / \mathbf{C O}=\mathbf{1 . 5}$ & $\mathbf{H}_{2} / \mathbf{C O}=\mathbf{2}$ \\
\hline $\mathrm{O}_{2} / \mathrm{C}$ (molar) & 0.7 & 0.64 & 0.65 \\
Steam/C (molar) & 0.6 & 0.58 & 0.65 \\
$\mathrm{CO}_{2}$ Recycle/Fresh Feed (molar) & 0.44 & 0.19 & 0 \\
Electricity Consumed (MW) & 5 & 3 & 2 \\
Cooling Water Required (MW) & 126 & 96 & 85 \\
\hline
\end{tabular}

\subsubsection{Effect of $\mathrm{H}_{2} / \mathrm{CO}$ Ratio on the AGR Unit}

As discussed in Section 2.10.1.1, higher $\mathrm{CO}_{2}$ recycle is required to obtain a lower $\mathrm{H}_{2} / \mathrm{CO}$ ratio. As a result of utilizing more $\mathrm{CO}_{2}$ in the ATR reactor, the partial pressure of $\mathrm{CO}_{2}$ increases in the ATR outlet. Table 2.13 compares the operating costs and utility consumptions in the AGR unit due to the change in the $\mathrm{H}_{2} / \mathrm{CO}$ ratio. For fair comparison, only $1 \mathrm{~mol} \%$ of $\mathrm{CO}_{2}$ in the clean syngas stream goes to the DME production section in all case studies. Energy consumptions in the refrigeration unit and syngas compressor are included in the results of the Rectisol process. Energy consumption in the syngas compressor downstream of the AGR unit is included in the results of the MDEA/PZ process. Costs of electricity, cooling water and low pressure steam (LPS) are assumed to be $\$$ 16.8/GJ, \$ 0.354/GJ and \$ 14.05/GJ, respectively [96]. For the Rectisol process, the major utility consumption is due to the syngas compressor before the AGR unit and the reboiler duty for solvent regeneration, while for the MDEA/PZ process, more than $40 \%$ of the utility consumption is due to solvent regeneration. As expected, for both processes the solvent circulation rate decreases with the increase in the $\mathrm{H}_{2} / \mathrm{CO}$ ratio because of the decrease in the amount of $\mathrm{CO}_{2}$ produced in the ATR unit. However, it should be noted that the cost per unit amount of $\mathrm{CO}_{2}$ captured increases as the $\mathrm{H}_{2} / \mathrm{CO}$ ratio increases as seen in Table 2.13. This is due to the decrease in the $\mathrm{CO}_{2}$ partial pressure, which has strong impact in the physical absorption process. 
Table 2.13: Effect of $\mathrm{H}_{2} / \mathrm{CO}$ Ratio on $\mathrm{CO}_{2}$ Removal Technologies

\begin{tabular}{ccccccc}
\hline & \multicolumn{2}{c}{$\mathbf{H}_{2} / \mathbf{C O}=\mathbf{1}$} & \multicolumn{2}{c}{$\mathbf{H}_{2} / \mathbf{C O}=\mathbf{1 . 5}$} & \multicolumn{2}{c}{$\mathbf{H}_{2} / \mathbf{C O}=\mathbf{2}$} \\
\hline AGR technology & Rectisol & MDEA/PZ & Rectisol & MDEA/PZ & Rectisol & MDEA/PZ \\
Total pressure (bar) & 50 & 10 & 50 & 10 & 50 & 10 \\
$\mathrm{CO}_{2}$ mole\% & 21.0 & 21.0 & 11.9 & 11.9 & 5.2 & 5.2 \\
$\mathrm{CO}_{2}$ feed $\left(10^{4} \mathrm{~kg} / \mathrm{hr}\right)$ & 18.5 & 18.5 & 9.62 & 9.62 & 3.88 & 3.89 \\
Solvent circulation rate $\left(10^{5} \mathrm{~kg} / \mathrm{hr}\right)$ & 11.4 & 5.46 & 8.81 & 2.96 & 6.21 & 1.21 \\
$\mathrm{CO}_{2}$ captured & $94 \%$ & $96 \%$ & $90 \%$ & $93 \%$ & $78 \%$ & $81 \%$ \\
Utility Requirements & & & & & & \\
Electricity $(\mathrm{GJ} / \mathrm{hr})$ & 196 & 113 & 168 & 119 & 147 & 117 \\
Cooling water $(\mathrm{GJ} / \mathrm{hr})$ & 357 & 401 & 303 & 246 & 246 & 133 \\
5 barg steam $(\mathrm{GJ} / \mathrm{hr})$ & 157 & 416 & 114 & 223 & 79 & 89 \\
Cost $\left(\$ / \mathrm{Mt}\right.$ of $\mathrm{CO}_{2}$ captured) & 32 & 44 & 53 & 58 & 121 & 103 \\
Cost $\left(\$ / \mathrm{Mt}\right.$ of $\mathrm{CO}_{2}$ captured) w/o & 19 & 32 & 24 & 36 & 53 & 41 \\
syngas compressor & & & & & & \\
\hline
\end{tabular}

For chemical absorption, the increase in cost per unit amount of $\mathrm{CO}_{2}$ captured is due to the increase in the solvent to $\mathrm{CO}_{2}$ flowrate ratio (molar) from 1.16 to 1.23 as the partial pressure of $\mathrm{CO}_{2}$ decreases from 2.1 bar to 0.52 bar, respectively. Considering the cost of $\mathrm{CO}_{2}$ capture, it is observed that the Rectisol process is a better option for lower $\mathrm{H}_{2} / \mathrm{CO}$ ratio cases (i.e. 1 and 1.5) in comparison to the MDEA/PZ process. For $\mathrm{H}_{2} / \mathrm{CO}$ ratio of 2 , MDEA/PZ process is preferred in comparison to the Rectisol process.

\subsubsection{Direct Syngas-to-DME Production Section}

The overall utility usage by the DME production section in the base case (i.e. $\mathrm{H}_{2} / \mathrm{CO}=1$ ) is studied by evaluating two different $\mathrm{CO}_{2}$ capture technologies for the AGR unit, as shown in Table 2.14. It shows how the choice of the AGR technology affects the utility usage in the DME production section. Costs of medium pressure steam (MPS) and natural gas are assumed to be $\$ 14.83 / \mathrm{GJ}$ and $\$ 2.64$ /GJ, respectively $[96,97]$. It should be noted that the overall refrigeration duty shown is only for the refrigeration required in the DME production section. The refrigeration duty required in the AGR unit is not considered because it is not considered to be part of the DME production section. 
Table 2.14: Utility Consumption by DME Production Section when $\mathrm{H}_{2} / \mathrm{CO}=1$

\begin{tabular}{ccc}
\hline $\begin{array}{c}\text { Syngas Production Section with AGR } \\
\text { technology }\end{array}$ & Rectisol & MDEA/PZ \\
\hline Refrigeration Unit & 47 & 51 \\
Electricity (GJ/hr) & 179 & 201 \\
Cooling Water (GJ/hr) & & \\
DME Synthesis Unit & 7 & 7 \\
Fired Heater (GJ/hr) & 99 & 168 \\
Cooling water (GJ/hr) & 1 & 1 \\
Electricity (GJ/hr) & & \\
DME Separation Unit & 1 & 1 \\
Electricity (GJ/hr) & 274 & 303 \\
Cooling Water (GJ/hr) & 191 & 218 \\
MPS (GJ/hr) & 223 & 234 \\
LPS (GJ/hr) & 6,998 & 7,676 \\
Total Utility Cost $(\$ / \mathrm{hr})$ & &
\end{tabular}

As mentioned earlier, the Rectisol process uses chilled methanol as a solvent at $-28^{\circ} \mathrm{C}$ for $\mathrm{CO}_{2}$ absorption. As a result, cold process streams are available in the AGR unit which can be utilized to cool the DME reactor effluent. The DME reactor effluent is chilled because $\mathrm{CO}_{2}$ solubility in DME increases at lower temperature and higher pressure. When MDEA/PZ is used in the AGR unit, there are no cold streams available. Therefore, chilling of the DME reactor effluent is accomplished only by the refrigeration unit. This increases utility consumption in the refrigeration unit resulting in the increase in the utility cost of the DME production unit when MDEA/PZ is used in the AGR unit. Similar results are obtained for higher $\mathrm{H}_{2} / \mathrm{CO}$ ratios as well.

\subsubsection{Effect of Feed Composition on DME Productivity}

Composition of the fresh feed to the DME reactor has a strong impact on DME productivity, as shown in Fig. 2.14. Maximum DME productivity of $16.7 \mathrm{~mol} / \mathrm{kg}$ catalyst $\mathrm{hr}$ is achieved when $\mathrm{H}_{2} / \mathrm{CO}$ is 1 . 


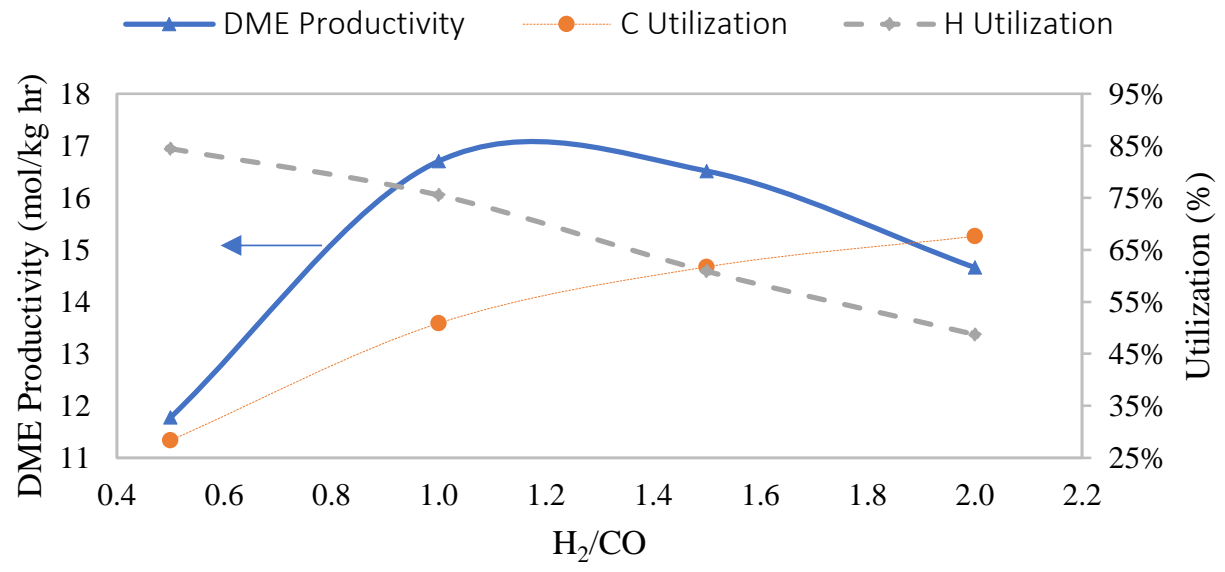

\section{Figure 2.14: Effect of the $\mathrm{H}_{2} / \mathrm{CO}$ ratio on DME Productivity at $260^{\circ} \mathrm{C}, 50$ bar, $1.35 \mathrm{~h}-1$ WHSV}

In comparison to the $\mathrm{H}_{2} / \mathrm{CO}$ ratio of 1 , the DME productivity decreases by $42 \%$ and $14 \%$ when the $\mathrm{H}_{2} / \mathrm{CO}$ ratio changes to 0.5 and 2 , respectively. As the $\mathrm{H}_{2} / \mathrm{CO}$ ratio increases, carbon utilization goes up, but hydrogen utilization goes down. The reduction in carbon utilization in the CO-rich region is due to the insufficient supply of hydrogen for CO hydrogenation reaction (Reaction 9). In the hydrogen-rich region, maximum carbon utilization is reached while ample amount of hydrogen is still available, which accumulates in the recycle loop. Due to this imbalance in the $\mathrm{H}_{2}$ and $\mathrm{CO}$ conversion, and the recycle of unconverted syngas to the DME reactor, the $\mathrm{H}_{2} / \mathrm{CO}$ ratio in the total feed (i.e. after the recycle is mixed) to the DME reactor increases to 1.02, 2.20 and 3.70, when the $\mathrm{H}_{2} / \mathrm{CO}$ ratio in the fresh feed is $1,1.5$ and 2, respectively. Maximum DME productivity of $17 \mathrm{~mol} / \mathrm{kg}$ catalyst $\mathrm{hr}$ is achieved when there is no $\mathrm{CO}_{2}$ in the fresh feed. The productivity decreases by $7 \%$ when the $\mathrm{CO}_{2}$ content is $3 \mathrm{~mol} \%$, as shown in Fig. 2.15. This shows that the DME productivity is highly sensitive to the $\mathrm{CO}_{2}$ content in the feed stream. 


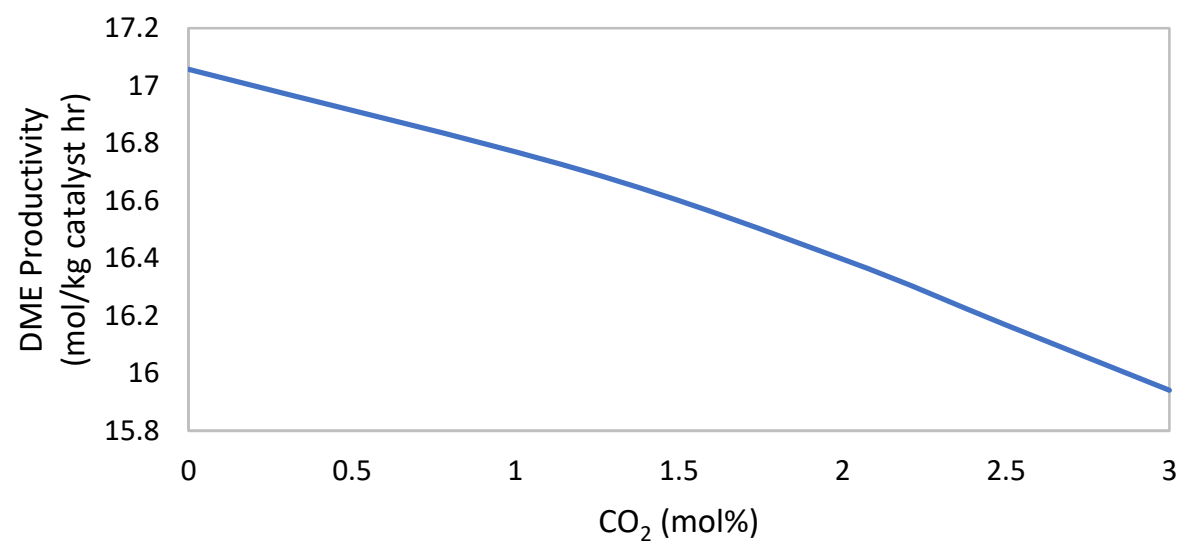

Figure 2.15: Effect of the $\mathrm{CO}_{2}$ Content on DME Productivity

\subsubsection{DME Separation Unit}

A summary of some important streams for the base case is shown in Table 2.15, with the stream numbers marked in Fig. 2.8. As mentioned in Section 2.7.2, DME is an excellent solvent for capturing $\mathrm{CO}_{2}$ at low temperature and high pressure. In this study, the DME reactor effluent stream is cooled to $0^{\circ} \mathrm{C}$ because the low operating temperature is beneficial for physical absorption. Unfortunately, the authors could not find the VLE data of $\mathrm{DME}^{-\mathrm{CO}_{2}}$ system below $0^{\circ} \mathrm{C}$. Cooling this stream to a lower temperature might be beneficial but is not investigated here since extrapolation of the thermodynamic model can lead to errors. 
Table 2.15: Material Balance for DME Separation Unit $\left(\mathrm{H}_{2} / \mathrm{CO}=1\right)$

\begin{tabular}{cccccc}
\hline Stream \# & $\mathbf{1}$ & $\mathbf{2}$ & $\mathbf{3}$ & $\mathbf{4}$ & $\mathbf{5}$ \\
\hline Temperature $\left({ }^{\circ} \mathrm{C}\right)$ & 0.000 & -1.207 & -1.207 & 15.4 & 41.9 \\
Pressure (bar) & 49.9 & 45.0 & 45.0 & 45.0 & 45.0 \\
Total Flow (kg/hr) & 8,442 & 4,207 & 4,235 & 7,686 & 13,120 \\
Total Flow (kmol/hr) & 272,397 & 88,177 & 184,221 & 190,448 & 423,677 \\
Mole Fraction & & & & & \\
$\mathrm{CH}_{3} \mathrm{OH}$ & 0.011 & & 0.021 & 0.482 & 0.288 \\
$\mathrm{CO}_{2}$ & 0.299 & 0.206 & 0.392 & & 0.184 \\
$\mathrm{CO}$ & 0.168 & 0.301 & 0.036 & & 0.030 \\
$\mathrm{~N}_{2}$ & 0.010 & 0.017 & trace & & trace \\
$\mathrm{H}_{2}$ & 0.214 & 0.428 & & & \\
$\mathrm{CH}_{4}$ & 0.002 & trace & trace & & trace \\
$\mathrm{H}_{2} \mathrm{O}$ & 0.013 & & 0.026 & 0.518 & 0.312 \\
$\mathrm{C}_{2} \mathrm{H}_{6} \mathrm{O}$ & 0.284 & 0.045 & 0.521 & & 0.183 \\
\hline
\end{tabular}

\begin{tabular}{ccccc}
\hline Stream \# & $\mathbf{6}$ & $\mathbf{7}$ & $\mathbf{8}$ & $\mathbf{9}$ \\
\hline Temperature $\left({ }^{\circ} \mathrm{C}\right)$ & -23.4 & 60.0 & 61.5 & 33.4 \\
Pressure (bar) & 21.0 & 20.9 & 15.0 & 45.0 \\
Total Flow (kg/hr) & 2,853 & 10,267 & 2,396 & 3,008 \\
Total Flow (kmol/hr) & 118,443 & 305,234 & 110,345 & 39,168 \\
Mole Fraction & & & & \\
$\mathrm{CH}_{3} \mathrm{OH}$ & & 0.368 & & trace \\
$\mathrm{CO}_{2}$ & 0.848 & & & 0.036 \\
$\mathrm{CO}$ & 0.139 & & & 0.339 \\
$\mathrm{~N}_{2}$ & trace & & & 0.021 \\
$\mathrm{H}_{2}$ & & 0.398 & & trace \\
$\mathrm{H}_{2} \mathrm{O}$ & & 0.233 & 0.999 & \\
$\mathrm{C}_{2} \mathrm{H}_{6} \mathrm{O}$ & & & & \\
\hline
\end{tabular}


Methanol-water mixture is used in the absorber to capture the DME from the vapor stream of the flash vessel. The design objective was specified to limit the DME loss to $\leq 1 \mathrm{~mol} \%$. To satisfy this specification, the methanol content in the solvent stream is adjusted. As shown in Fig. 2.16, DME capture increases with the increase in the methanol content, while $\mathrm{CO}_{2}$ capture changes negligibly.

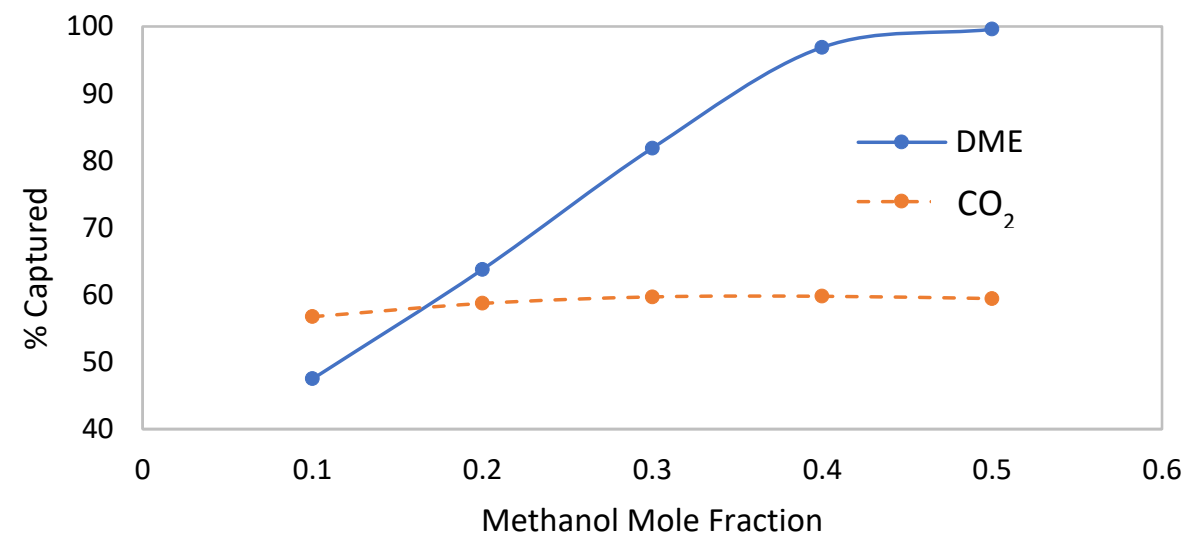

Figure 2.16: Effect of Methanol Content on $\mathrm{DME}$ and $\mathrm{CO}_{2}$ Captured in the Absorber

The change in the methanol content also impacts the overall duty of the $\mathrm{CO}_{2}$ and DME columns, as shown in Fig. 2.17. An increase in the methanol content in the solvent stream of the absorber decreases the reboiler duty of the $\mathrm{CO}_{2}$ column. The heat of vaporization of water and methanol is $40.7 \mathrm{~kJ} / \mathrm{mol}$ and $37.6 \mathrm{~kJ} / \mathrm{mol}$, respectively. So, as the water content decreases and methanol content increases, less energy is required in the reboiler. On the other hand, an increase in the methanol content in the DME column increases the reboiler duty. This is because of the high solubility of DME in methanol thereby requiring higher reflux ratio and reboiler duty to achieve this difficult separation. 


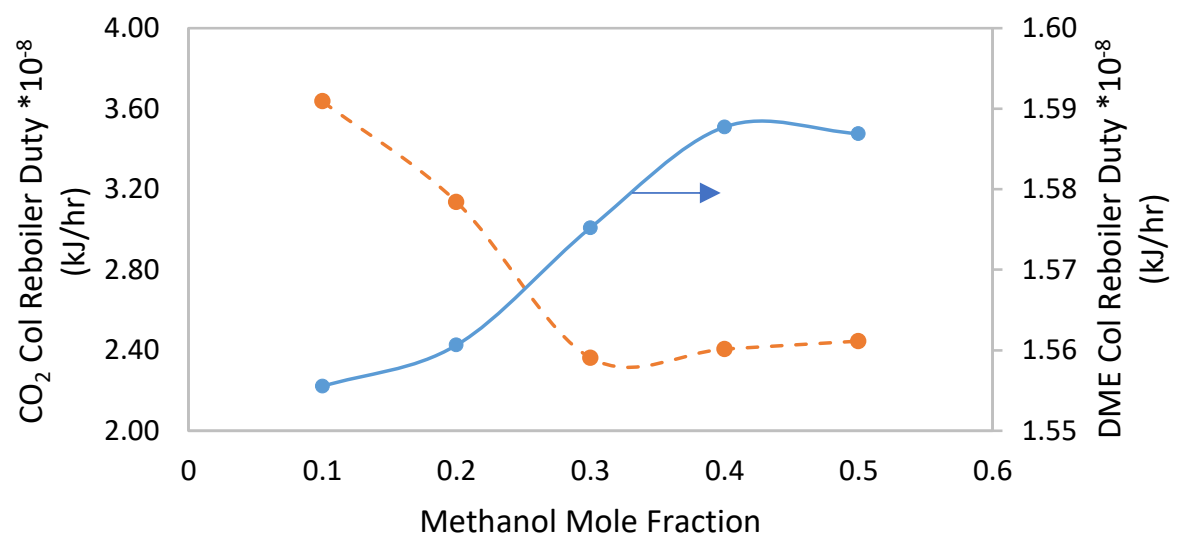

Figure 2.17: Effect of the Methanol Content on Reboiler Duty

\subsubsection{Indirect Syngas-to-DME Process}

\subsubsection{Methanol Synthesis Reactor}

The module of the fresh syngas, defined as $\left(\mathrm{H}_{2}-\mathrm{CO}_{2}\right) /\left(\mathrm{CO}+\mathrm{CO}_{2}\right)$, has a strong impact on the methanol production, as shown in Fig. 2.18.

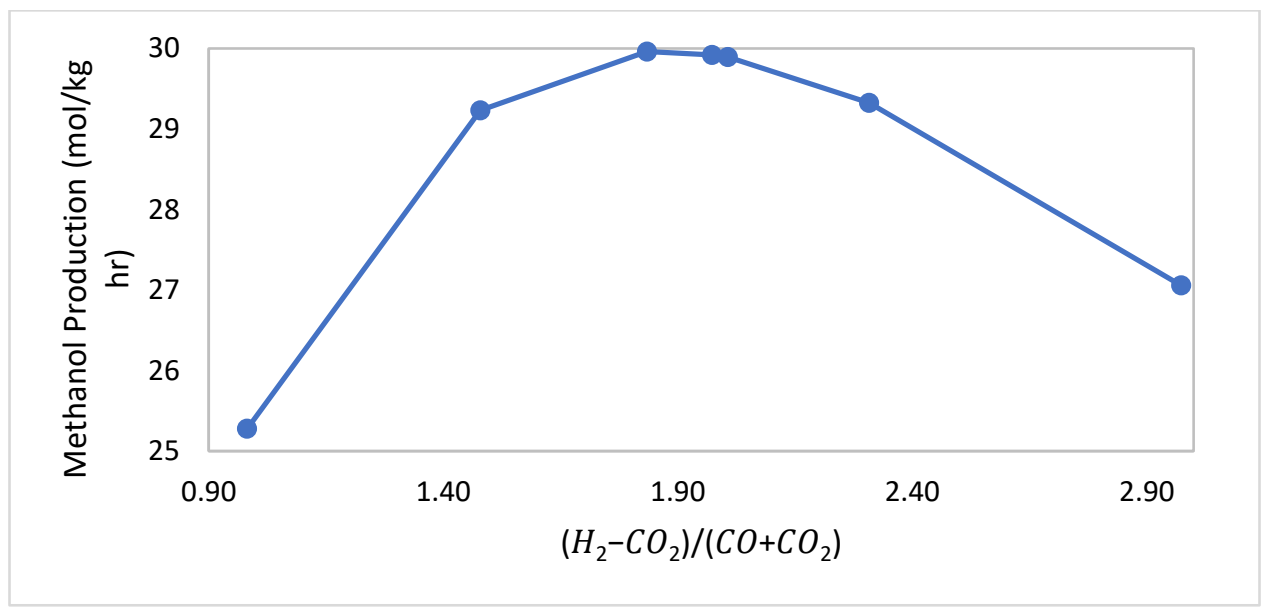

Figure 2.18: Effect of Syngas Module on Methanol Production at $250^{\circ} \mathrm{C}, 60$ bar and 3.24 h-1 WHSV

Maximum methanol production of $30 \mathrm{~mol} / \mathrm{kg} \mathrm{hr}$ is achieved when the module of fresh syngas, containing $1 \mathrm{~mol} \% \mathrm{CO}_{2}$, is 1.83 . When the module of the fresh syngas is 1 and 3 , methanol production drops by $16 \%$ and $10 \%$, respectively. The decrease in methanol production for module far away from 2 is due to the imbalance in $\mathrm{H}_{2}$ and $\mathrm{CO}$ components which limits the reaction and the methanol production. 


\subsubsection{Effect of $\mathrm{CO}_{2}$ Capture Rate on Energy Usage}

Effects of varying amount of $\mathrm{CO}_{2}$, in the fresh syngas stream to the DME production section on the overall process energy usage and DME produced are shown in Table 2.16.

Table 2.16: Effect of $\mathrm{CO}_{2}$ Capture on Indirect DME Production Process

\begin{tabular}{cccc}
\hline Case & $\mathbf{1}$ & $\mathbf{2}$ & $\mathbf{3}$ \\
\hline AGR Technology & Rectisol & Rectisol & - \\
Solvent Circulation Rate $(\mathrm{kg} / \mathrm{hr})$ & 620,738 & 413,344 & - \\
$\mathrm{CO}_{2}$ mol \% allowed in Syngas & 1 & 3 & 5.2 \\
DME Produced $(\mathrm{kg} / \mathrm{hr})$ & 105,430 & 104,005 & 101,869 \\
Electricity $(\mathrm{GJ} / \mathrm{hr})$ & 365 & 359 & 352 \\
Cooling Water $(\mathrm{GJ} / \mathrm{hr})$ & 1338 & 1310 & 1244 \\
Fired Heater $(\mathrm{GJ} / \mathrm{hr})$ & 148 & 154 & 0 \\
MPS (GJ/hr) & 242 & 239 & 235 \\
LPS (GJ/hr) & 120 & 95 & 44 \\
HPS (GJ/hr) & 97 & 97 & 96 \\
Utility Cost $(\$ / \mathrm{hr})$ & 13,774 & 13,292 & 11,949
\end{tabular}

Three cases were considered in which $1 \mathrm{~mol} \%, 3 \mathrm{~mol} \%$ and $5.2 \mathrm{~mol} \%$ (no $\mathrm{CO}_{2}$ capture) was allowed in the clean syngas stream to the DME production section. When more $\mathrm{CO}_{2}$ (case 2 and 3) was allowed in the clean syngas stream, the DME production decreased by $1.2 \%$ and $3.2 \%$, respectively. Moreover, an increase in $\mathrm{CO}_{2} \mathrm{~mol} \%$ in the clean syngas feed also reduced the overall energy usage. In case 3, since the AGR unit was not considered, hot streams from the syngas production unit are utilized to heat the feed streams of the methanol synthesis and methanol dehydration reactors eliminating the need for feed heaters.

\subsection{Conclusion}

Binary interaction parameters for DME- $\mathrm{CO}_{2}, \mathrm{DME}-\mathrm{H}_{2} \mathrm{O}$, and DME-CO are not available in Aspen Plus or open literature. So, experimental data has been used to regress them using experimental data to increase the validity of these parameters for a wide range of operating conditions. Comparison between the Rectisol process and the MDEA/PZ process shows that the Rectisol process has a lower $\mathrm{CO}_{2}$ capture penalty than the later mainly due to the higher $\mathrm{CO}_{2}$ partial 
pressure. Sensitivity studies on the DME reactor show that the maximum DME productivity can be obtained when $\mathrm{H}_{2} / \mathrm{CO}$ ratio is 1 , and at lower $\mathrm{CO}_{2}$ concentration in the feed. While it is difficult to achieve this ratio for shale-gas derived syngas, process configurations are developed by integrating $\mathrm{CO}_{2}$ recycle streams between DME and syngas production plant to make this possible. A novel DME separation process is also developed that uses the product DME as the solvent, and water-methanol mixture. Several options considered in this study such as the higher $\mathrm{CO}_{2}$ recycle would results in larger equipment sizes and therefore for thorough investigation of these options, capital cost must be considered. The results discussed in this chapter can also be used for technoeconomic optimization studies. With additional information like transportation and storage cost, global market demand and raw material availability, the results discussed in this chapter can be useful in making decision about the technology selection, plant size, and the location of plant in real life. 


\section{Chapter 3. Techno-Economic Optimization of Shale gas to DME Production Process via Direct and Indirect Synthesis Route}

The shale gas to dimethyl ether (DME) process via direct synthesis route with a syngas $\mathrm{H}_{2} / \mathrm{CO}=$ 1 has a higher DME yield than that via indirect synthesis route. However, the direct synthesis route involves various energy and capital-intensive processes, such as the complicated DME separation process, and the $\mathrm{CO}_{2}$ recycle and compression process. In this chapter, techno-economic analysis of shale gas to DME process via direct and indirect synthesis route is performed using Aspen Process Economic Analyzer (APEA ${ }^{\circledR}$ ) based on the rigorous process model developed in Aspen Plus ${ }^{\circledR}$. Effects of different $\mathrm{CO}_{2}$ removal technologies and DME synthesis technologies from syngas are evaluated. Both, direct and indirect plants are optimized in Aspen Plus Equation Oriented (EO) environment, using the rigorous process models. The effects of key design parameters (i.e. $\mathrm{H}_{2} / \mathrm{CO}$ in the syngas) as well as investment parameters (i.e. prices of raw materials, products, and utilities, plant scale) on the process economics have been evaluated. The direct DME synthesis route processing a syngas with $\mathrm{H}_{2} / \mathrm{CO}=1$ and using the Rectisol process for $\mathrm{CO}_{2}$ capture has $63.3 \%$ overall thermal efficiency on the lower heat value (LHV) basis, which is the highest of all combinations studied in this work. The breakeven DME price of an optimized 5,000 MTPD direct DME synthesis process at $20 \%$ internal rate of return (IRR) is 14.36 \$MMBTU (yielding an equivalent diesel price of $1.23 \$ / \mathrm{gal}$ ). The equivalent diesel price of the direct DME synthesis process is much lower than the current U.S. market diesel price of about $2.3 \$ /$ gal as of October 2020 , indicating the feasibility of the process. Similarly, the breakeven DME price is 13.03 \$/MMBTU for indirect DME synthesis process (yielding an equivalent diesel price of 1.11 \$/gal).

\subsection{Literature Review}

A few techno-economic studies are available on indirect and direct DME production processes where natural gas, coal, or biomass is used as the feedstock. Yoon and Han [98] presented a review of the DME production technologies and the DME market in the Asia-Pacific region. Fornell et al. 
[99] conducted a conceptual study on co-production of ethanol and DME via indirect synthesis route from Kraft pulp mill based bio-refinery. Trippe et al. [100] performed a techno-economic study on the production of DME from lignocellulose biomass via direct synthesis route. Clausen et al. [101,102] and Zhou et al. [103] performed techno-economic studies on producing DME from biomass, and from coal and natural gas mixture via the direct synthesis route. In most of those studies, the reactors were modeled as either equilibrium or stoichiometric reactors. Zhu et al. [104] performed a techno-economic study on the conversion of biomass to liquid fuels. They considered various liquid fuels including DME, and the synthesis of DME was carried out via indirect route. Larson [105] performed a detailed study on process design and economics of co-production of methanol and electricity, DME and electricity, as well as methanol and DME from coal via the direct synthesis route. Another study by Larson et al. [106] focused on the production of FischerTropsch liquids and DME via direct synthesis route through the gasification of biomass. Coproduction of DME as part of polygeneration integrated gasification combined cycle (IGCC) plants and indirect biomass to liquids plants has also been studied by several authors [107,108]. However, to the best of our knowledge, there is no plant-wide techno-economic study available in the open literature on direct DME production process where shale gas is used as the feedstock.

Most of the literature on the optimization of the direct DME synthesis process using shale gas have focused on optimization of the reactor operating conditions to improve DME productivity. Omata et al. [109] optimized the temperature gradient in the reactor to improve the DME yield in a direct DME synthesis process using syngas. $\mathrm{Hu}$ et al. [110] optimized the reactor dimensions and operating conditions of a pipe-shell reactor to maximize DME productivity. Yasari et al. [111] modeled a pseudo-homogenous tubular fixed bed reactor for direct DME synthesis from syngas. They maximized the reactor yield by optimizing the operating conditions such as feed rate, pressure, and shell temperature. A pseudo-homogenous industrial scale fixed bed reactor was investigated by Vakili et al. [112] for the direct synthesis of DME from syngas. They maximized the DME production by optimizing the operating conditions and internal configuration of the reactor. Papari et al. [36] developed a 1-dimensional heterogeneous industrial slurry reactor for direct synthesis of DME from syngas and $\mathrm{CO}_{2}$. They also performed optimization to maximize $\mathrm{CO}$ conversion and DME productivity by optimizing reactor operating conditions such as gas velocity, catalyst mass and concentration, syngas composition, temperature, and pressure. Optimization of operating conditions for the indirect DME synthesis process has been performed 
by several research groups [113-116]. Most of these works have used reduced models for technoeconomic optimization since it can be computationally challenging to use rigorous process models for large-scale processes. Farahani et al. [117] performed techno-economic optimization of a methanol to DME production process using Aspen Hysys interfaced with MATLAB. The process model included one reactor and two distillation columns with 4 decision variables. High et al. [118] also performed techno-economic optimization of methanol to DME production process using Aspen Hysys interfaced with MATLAB. Kiss et al. [119] developed a rigorous process model for the indirect DME synthesis process from methanol using reactive distillation (RD) in Aspen Plus. Techno-economic optimization was performed using Aspen Plus interfaced with MATLAB. Arpornwichanaop et al. [120] developed a model of a DME production process from crude glycerol in Aspen Plus RD process. The authors evaluated the impact of a few variables on the total annual cost (TAC). Review of the literature presented above points to several gaps that this research seeks to fill in. First, one typical approach in the literature on techno-economic optimization of direct and indirect synthesis routes is to use simple cost correlations. While this approach makes the optimization problem tractable, inaccuracies in the cost correlations can lead to a suboptimal solution. In this work, while cost correlations are still used for techno-economic optimization, corrections factors were estimated from APEA that has a rigorous database of the cost data that are updated typically twice a year. Second, due to the complexity of the DME synthesis processes and strong mass and energy integration among various equipment items, simple process models can lead to a sub-optimal solution to the techno-economic optimization problem. In this work, rigorous process models are used for optimization. Third, an appropriate discounted profitability criterion needs to be used as the optimization objective. Since the investment options are mutually exclusive in this case (i.e. one would either select the direct route or the indirect route, but not both), the option with the greatest positive net present value (NPV) should be selected [96]. Fourth, this work presents plant-wide optimization of the direct DME synthesis process using shale gas, which is currently lacking in the literature. Fifth, while there are several techno-economic optimization studies for the indirect DME synthesis route, there is a lack of studies when shale gas is used as the feed. Sixth, techno-economic optimizations of both the direct and indirect DME synthesis routes are presented in this study using same software platforms, similar modeling rigor and assumptions, and same cost correlations. 
The discussion in Chapter 2 shows that there are various tradeoffs between the indirect and direct processes. While the direct route leads to higher DME yield than the indirect route, there are additional equipment items and energy penalty associated with the direct route. Therefore, a detailed techno-economic analysis is necessary with due consideration of capital and operating costs. For a fair comparison, each route needs to be optimized while evaluating possible candidate technologies, where alternatives exist. Therefore, a detailed techno-economic optimization is presented in this work for DME synthesis by the indirect and direct synthesis routes using shale gas as the feed. Due to the significant mass and energy integration in the DME synthesis routes, it is challenging to solve the techno-economic optimization studies using the SM mode that solves the blocks sequentially. Therefore, in this study, the equation oriented (EO) mode in Aspen Plus is utilized, which solves all the model equations simultaneously leading to easier and faster convergence. A DMO solver is used to solve the optimization problem and it uses a successive quadratic programming (SQP) algorithm with line search and trust region methods for generating iterates. The optimization objective is the maximization of modified form of NPV that uses the annualized CAPEX and OPEX. Impact of key parameters such as the AGR technology, $\mathrm{H}_{2} / \mathrm{CO}$ syngas ratio, $\mathrm{CO}_{2}$ recycle, utility and raw material prices, plant scale, contingency, and internal rate of return (IRR) on process economics is studied. To summarize, the following contributions have been made:

- Rigorous techno-economic models have been developed for two distinct $\mathrm{CO}_{2}$ capture technologies and for varying syngas $\mathrm{H}_{2} / \mathrm{CO}$ ratio.

- Plant-wide techno-economic optimization has been performed for the direct DME and indirect synthesis process with shale gas as the feedstock using the rigorous process models developed in Aspen plus, rather than using the reduced-order models. Optimization for both the process routes have been performed on the same software platform to maintain consistency in model rigor and assumptions.

- Cost-correlations with corrections factors derived from the rigorous APEA database and using the appropriate profitability criteria, as the objective function, has been used in performing the techno-economic optimization.

- Several sensitivity studies have been conducted including the effect of H2/CO ratio, raw material and utility prices, plant scale, contingency, and internal rate of return (IRR) on the breakeven DME price, capital cost (CAPEX), and operating cost (OPEX). 


\subsection{Economic Analysis}

The economic analysis in this study was performed using APEA, with the 2015 pricing basis. The steady state process models developed in Aspen Plus, and the stream data consisting of mass and energy balances are exported to APEA to perform discounted cash flow analysis. The economic assumptions are shown in Table 3.1 [40,121]. These parameters are kept similar for both direct and indirect DME production processes and their respective cases. All processes are described as a licensed process, located in North America, with January 1, 2015, as the start date of engineering.

\section{Table 3.1: Parameters for investment analysis}

\begin{tabular}{llll}
\hline Investment parameter & Value & Investment parameter & Value \\
\hline Contingency & $26 \%$ & $\begin{array}{l}\text { Working capital } \\
\text { percentage }\end{array}$ & $12 \%$ per year \\
Tax rate & $40 \%$ per year & Plant overhead & $50 \%$ \\
$\begin{array}{l}\text { Desired internal rate of } \\
\text { return }\end{array}$ & $10 \%$ per year & G \& A expenses & $8 \%$ per year \\
Salvage value & $20 \%$ & O \& M escalation & $3 \%$ per year \\
Project capital escalation & $1 \%$ per year & $\begin{array}{l}\text { No. of periods for } \\
\text { analysis }\end{array}$ & 20 year \\
Products and raw material & $1 \%$ per year each & $\begin{array}{l}\text { Operating hours per } \\
\text { year }\end{array}$ & 8000 hour \\
escalation & & Length of start-up & 30 week \\
Utility escalation & $1 \%$ per year & period & \\
\hline
\end{tabular}

\subsection{Total Capital Cost Estimation}

As stated before, there is no economic study yet in the open literature on the DME production technology being considered here. Therefore, the estimated capital cost of the entire plant could not be compared or validated with any literature data. However, the plant is divided into three sections, namely syngas synthesis section, AGR section, and DME production section and the total 
direct cost or the equipment cost of each section is compared separately with the literature data by setting the scale of that particular plant section with the literature. The heat exchangers sizing is performed using the Aspen EDR as discussed in Section 2.4, while the columns are sized in Aspen Plus. Costs of process equipment items like distillation columns, heat exchangers, vessels, pumps, compressors, furnace, etc. are estimated using Aspen Icarus database. Costs of equipment items like reactors, ASU unit, and HRSG and SC are estimated using the cost correlations or deduced using the data available in the literature, by using Eq. 3.1 [96].

$C=C_{0}\left(\frac{S}{S_{0}}\right)^{f} n^{m}$

In Eq. 3.1, $C$ is the total direct cost; $C_{0}$ is the installed unit base cost; $S$ is the capacity of each unit per train; $S_{0}$ is the base capacity of the unit; $f$ is the scaling exponent; $n$ is the number of trains and $m$ is the scaling exponent when there are multiple trains (typical value is 0.9 [121]). Multiple trains come into play when the scaling parameter is higher than the maximum value $\left(S_{\max }\right)$.

The reference base capacity, scaling factors, installed unit base cost and scaling parameter for direct DME production process and the indirect DME production process is shown in Table 3.2. It should be noted that the final equipment cost has been escalated to the 2015 year using the appropriate CEPCI index. The direct cost of the boiler fired with the shale gas is calculated using Eq. (3.2) [122], where $Q$ is the heat input $\left(10^{6} \mathrm{~kJ} / \mathrm{h}\right)$. This boiler is assumed to be a field-erected, water-tube boiler.

$C[\$]=1,604,153+13,359 Q$

The cost of equipment items that are calculated using the correlation shown in Eq. 3.1-3.2 are specified in APEA as quoted equipment. The labor cost is considered $40 \%$ of the total installed cost for reactors and shale gas fired boiler, $11 \%$ for HRSG \& SC, and 10\% for ASU and PSA unit $[105,123]$. All the pumps in the process are mapped as single stage centrifugal pump and a spare is considered for each of them. Single- or multi-stage compressors in the process are mapped to horizontal centrifugal compressors in APEA. 
Table 3.2: Cost correlation parameters

\begin{tabular}{|c|c|c|c|c|c|c|c|}
\hline Process Model & $\begin{array}{c}C_{0} \\
(\mathrm{MM} \$)\end{array}$ & $S_{0}$ & $S_{\max }$ & $\begin{array}{c}\text { Scaling } \\
\text { basis }\end{array}$ & Units & $f$ & Ref. \\
\hline Pre-reforming reactor & 18.7 & 1800 & - & $\begin{array}{c}\text { Plant thermal } \\
\text { input }\end{array}$ & LHV, MW & 0.75 & [124] \\
\hline ATR reactor & 10.3 & 12.2 & 35 & $\begin{array}{l}\text { Natural gas } \\
\text { feed }\end{array}$ & $\mathrm{kg} / \mathrm{s}$ & 0.67 & [125] \\
\hline $\begin{array}{l}\text { Direct DME synthesis } \\
\text { reactor }\end{array}$ & 14.7 & 2.61 & - & Fresh feed & $\mathrm{kmol} / \mathrm{s}$ & 0.67 & [106] \\
\hline $\begin{array}{c}\text { Methanol synthesis } \\
\text { reactor }\end{array}$ & 10.0 & 106.7 & - & $\begin{array}{c}\text { Total gas } \\
\text { feed }\end{array}$ & $\mathrm{kg} / \mathrm{s}$ & 0.65 & [126] \\
\hline $\begin{array}{c}\text { Methanol dehydration } \\
\text { reactor }\end{array}$ & 15.8 & 2.91 & - & $\begin{array}{l}\text { Methanol } \\
\text { feed }\end{array}$ & $\mathrm{kmol} / \mathrm{s}$ & 0.65 & [106] \\
\hline ASU unit & 57.6 & 1839 & 2500 & Oxygen out & TPD & 0.5 & $\begin{array}{c}{[40,12} \\
1]\end{array}$ \\
\hline $\begin{array}{l}\text { HRSG + Steam } \\
\text { turbine }\end{array}$ & 94.7 & 200 & - & Net power & MWe & 0.67 & [105] \\
\hline PSA unit & 44.8 & 1 & - & $\begin{array}{c}\mathrm{H}_{2} \\
\text { production }\end{array}$ & HHV, GW & 0.55 & [127] \\
\hline Rectisol process & 28.8 & 200,000 & 700,000 & Syngas feed & $\mathrm{Nm}^{3} / \mathrm{h}$ & 0.63 & [128] \\
\hline
\end{tabular}

The material of construction (MOC) for any specific equipment item in the process is specified based on its operating conditions, steam compositions and common industrial practice [51,121,129]. The MOC for most of the equipment items is carbon steel (CS). The MOC for compressors and heat exchangers handling $\mathrm{NH}_{3}$ is stainless steel (SS) 316 or 304, with due consideration of corrosion. The MOC of equipment items that operate under high hydrogen partial pressure and temperature above $200^{\circ} \mathrm{C}$ is selected based on the Nelson curve [129]. The MOC for equipment with $\leq 0^{\circ} \mathrm{C}$ temperature and high pressure, mainly the absorber in the Rectisol process 
and some equipment items in the DME separation unit, is A515, 304S or SS304, to avoid equipment failure due to brittleness under low temperature operation. Due to the large throughput, the Rectisol process has two trains. Table 3.3 shows the direct cost, MOC and equipment type for the Rectisol process in the direct DME process with an $\mathrm{H}_{2} / \mathrm{CO}=1$.

Table 3.3: Summary of equipment costing and specification for Rectisol process (Direct DME production process; $\mathrm{H}_{2} / \mathrm{CO}=1 ; 2,647$ MTPD DME)

\begin{tabular}{|c|c|c|c|c|}
\hline Equipment name & Equipment type & $\begin{array}{l}\text { No. of } \\
\text { items/ spare }\end{array}$ & MOC & Direct cost \\
\hline $\mathrm{CO}_{2}$ absorber & TW PACKED & 2 & A515, 0.5CIS & $\$ 7,486,200$ \\
\hline Stripper tower & TW TRAYED & 2 & $\mathrm{CS}, \mathrm{A} 285 \mathrm{C}$ & $\$ 2,109,700$ \\
\hline Stripper condenser & HE FLOAT HEAD & 2 & $\mathrm{CS}, \mathrm{CS}$ & $\$ 413,600$ \\
\hline Stripper condenser drum & HT HORIZ DRUM & 2 & CS & $\$ 172,200$ \\
\hline Stripper reboiler & HE FLOAT HEAD & 2 & $\mathrm{CS}, \mathrm{CS}$ & $\$ 462,200$ \\
\hline Stripper reflux pump & CP CENTRIF & 4 & CS & $\$ 47,800$ \\
\hline Syngas feed compressor & GC CENTRIF & 1 & CS & $\$ 10,224,900$ \\
\hline Syngas recycle compressor & GC CENTRIF & 2 & CS & $\$ 5,682,200$ \\
\hline $\mathrm{NH}_{3}$ compressor & GC CENTRIF & 1 & SS304 & $\$ 13,358,900$ \\
\hline Methanol circulation pump & CP CENTRIF & 4 & CS & $\$ 2,090,200$ \\
\hline $\mathrm{NH}_{3}-\mathrm{CH}_{3} \mathrm{OH}$ heat exchanger & HE FLOAT HEAD & 1 & 304S, SS304 & $\$ 301,000$ \\
\hline Other heat exchangers & HE FLOAT HEAD & 4 & $\mathrm{CS}, \mathrm{CS}$ & $\$ 5,231,900$ \\
\hline $\begin{array}{l}\text { Flash vessel for water } \\
\text { decantation }\end{array}$ & HT CYLINDER & 1 & CS & $\$ 173,800$ \\
\hline High pressure $\mathrm{CO}_{2}$ K.O. drum & VT CYLINDER & 2 & $\mathrm{CS}$ & $\$ 1,334,600$ \\
\hline
\end{tabular}

Note: Equipment type and MOC code names are as per the Aspen Icarus reference [130] 


\subsection{Operating and Maintenance Cost}

The operating and maintenance costs considered in the economic analysis are raw material costs, utility costs, operating labor and supervision, maintenance labor, operating supplies, laboratory charges, and general \& administrative (G\&A). As mentioned before, steam and electricity requirement can be satisfied by the plant. For satisfying the cooling water requirement, a cooling water tower is costed by using the Aspen utility module. Initial costs of ammonia used in the refrigeration cycle and methanol and MDEA/PZ solvent for $\mathrm{CO}_{2}$ capture are inserted as quoted equipment in APEA.

Table 3.4: Prices of raw material, product, utility, catalyst, and labor

\begin{tabular}{llll}
\hline & $\$$ /unit & Unit & Reference \\
\hline Shale gas & 2.67 & GJ & U.S. EIA [131] \\
Methanol & 0.548 & $\mathrm{~kg}$ & Natural gas tech [132] \\
MDEA/PZ & 2.16 & $\mathrm{~kg}$ & Jiang \& Bhattacharyya [121] \\
Ammonia & 0.552 & $\mathrm{~kg}$ & \\
DME & 4.69 & $\mathrm{GJ}$ & Yoon \& Han [98] \\
Hydrogen & 1.42 & $\mathrm{~kg}$ & \\
Electricity & 29.11 & $\mathrm{GJ}$ & \\
Shale gas reforming catalyst & 18.4 & $\mathrm{~m}{ }^{3}$ & NETL [123] \\
Direct DME synthesis catalyst & 23.5 & $\mathrm{~kg}$ & Trippe et. al., [100] \\
Methanol synthesis catalyst & 20.1 & $\mathrm{~kg}$ & Jones \& Zhu [126] \\
Methanol dehydration catalyst & 24.0 & $\mathrm{~kg}$ & Jones \& Zhu [126] \\
Operator & 50 & hour & Jiang \& Bhattacharyya [121] \\
Supervisor & 80 & hour & Jiang \& Bhattacharyya [121] \\
\hline
\end{tabular}

The costs of catalysts used in syngas, methanol and DME section is included in the direct cost of the reactor. The catalyst life is assumed to be 5 years [121]. The replacement cost of chemicals 
and catalyst is annualized and included as a raw material in APEA. Separate catalyst cost for the pre-reforming and ATR reactor is not available in the open literature. So, the catalyst cost of these reactors is considered as the shale gas reforming catalyst cost. For both processes, 3 working shifts are assumed with a total of 25 operators and 2 supervisors. The prices of raw materials, utility, and catalyst are shown in Table 3.4.

\subsection{Optimization in Aspen Plus Equation Oriented Environment}

It was desired to perform a techno-economic optimization using Aspen Plus and APEA. However, currently, it is not possible to run an optimizer in the Aspen environment where both the Aspen Plus and APEA model are considered together. In addition, the traditional sequential modular (SM) approach could not reliably solve even the process optimization problems where process economics were completely ignored. The SM approach either failed to converge or converged after hours or days of iterations. The main reason for such failures is the significant mass and energy integration in the process, for which the equation oriented (EO) approach is more appropriate. To solve these issues, an approximate economic model is developed in EO environment and then this model along with the rigorous process model (i.e. original process model described earlier) is used in Aspen EO environment for techno-economic optimization. The objective function includes the fixed capital investment and operating cost over a 20 year period considering an internal rate of return of $10 \%$, as shown in Eq. (3.3) [96].

$\operatorname{Min} f(x): F C I_{T M}+O P E X \cdot P_{A, F}$

s.t.

$h(x)=0$

$g(x) \leq 0$

$x_{\min } \leq x \leq x_{\max }$

In Eq. 3.3, $F C I_{T M}$ is the fixed capital investment; $O P E X$ is the operating cost; $P_{A, F}$ is a multiplication factor taking into account the time value of money; $h(x)$ and $g(x)$ represents the equality and inequality constraints of the process model. The $O P E X$ term includes the cost of utilities, raw materials, and purge gas. The price of the purge gas calculated based on the lower heating value is considered as a credit. The $P_{A, F}$, and $F C I_{T M}$ are calculated using Eq. 3.4 and 3.5, respectively [96].

$P_{A, F}=(P / A, i, n) \cdot(P / F, i, n)=\frac{(1+i)^{n}-1}{i \cdot(i+1)^{n}} \cdot \frac{1}{(1+i)^{n}}$ 


$$
\begin{aligned}
F C I_{T M}=\sum_{i=1}^{n} C_{T M, i}=1.26 \cdot \sum_{i=1}^{n} C_{B M, i}=1.26 \cdot \sum_{i=1}^{n} C_{p, i}^{0} \cdot F_{B M, i} \\
=1.26 \cdot \sum_{i=1}^{n} C_{p, i}^{0} \cdot\left(B_{1, i}+B_{2, i} \cdot F_{M, i} \cdot F_{p, i}\right)
\end{aligned}
$$

where $(P / A, i, n)$ is the uniform series present worth factor; $(P / F, i, n)$ is the single payment present worth factor; $n$ is the number of compounding periods in the interval; $i$ is the interest rate per compounding period; $C_{T M, i}$ is the total module $\operatorname{cost} ; C_{p, i}^{0}$ is the purchase cost of the equipment at ambient temperature and pressure; $F_{M, i}$ is the material factor; $F_{P, i}$ is the pressure factor; $B_{1}$ and $B_{2}$ are constants; and $n$ represents the equipment items. The fixed capital investment is the sum of bare module cost of all equipment multiplied by a fee \& contingency of $26 \%$. The purchased equipment cost is calculated using Eq. 3.6 [96].

$\log _{10} C_{p, i}^{0}=K_{1, i}+K_{2, i} \cdot \log _{10} A_{i}+K_{3, i} \cdot\left[\log _{10} A_{i}\right]^{2}$

In this equation, $K_{1, i}, K_{2, i}, K_{3, i}$ are constants and $A$ is the sizing parameter. The values of all the above parameters and information on sizing parameters can be found in Turton et al. (2018) [96]. Purchase cost of all the equipment items except the reactors is calculated using Eq. 3.6. The cost of the reactors is calculated using Eq. 3.1. Even though a simplified cost model is used here, it was desired that this cost model be similar to the APEA model. Therefore, the key differences between this model and the APEA model are noted and corrective measures are taken to keep the differences low. First, it can be noted that the bare module cost is shown in Eq. 3.5 has indirect cost included in it, while in APEA indirect cost is estimated collectively for the entire plant and not separately for individual equipment item. So, a sensitivity study is performed for various direct and indirect DME plant configurations and operating conditions to estimate the percentage indirect cost that can be included for each equipment type in the approximate calculation so that the indirect costs between two approaches are similar. Secondly, there is a difference in the capital cost calculated by the two approaches. Correction factors are calculated by changing the sizes of standard equipment items for each equipment type by $\pm 20 \%$ using both cost estimation approaches and this correction factor is used to readjust the cost calculated by the model to the APEA cost. For optimization, we mainly focus on the ISBL unit, including reactors, separation columns, absorbers, compressors, pumps, flash vessels, and most of the heat exchangers. To avoid temperature cross in heat exchangers during optimization, the minimum approach temperature is specified to be $10^{\circ} \mathrm{C}$. The minimum approach temperature for condensers is specified to be $5^{\circ} \mathrm{C}$. Ammonia is used as the cold utility in the condenser of the $\mathrm{CO}_{2}$ separation column. These 
constraints are implemented in Aspen Plus using design specifications. To have a fair comparison between the base case and the optimized case, certain constraints are implemented on the optimization problem, as shown in Table 3.5. The lowest temperature of the condenser is restricted to $30-40^{\circ} \mathrm{C}$ for all the columns, except the $\mathrm{CO}_{2}$ separation column, because the utility and the price associated with the utility is expected to be discontinuous as it is assumed that the utility type needs to be changed below $30^{\circ} \mathrm{C}$. The lower bound of the condenser temperature for towers is varied to achieve a desired separation or to prevent the loss of the main component from that column. Before performing optimization, the process flowsheet is first converged in Aspen Plus using the SM approach and then synchronized with the Aspen Plus EO environment to create EO variables. The results from the Aspen Plus SM mode are then used as the starting point for the optimization problem.

Table 3.5: Constraints on variables for the optimization of direct and indirect DME plant

\begin{tabular}{|c|c|c|}
\hline \multicolumn{3}{|l|}{ Direct DME synthesis production process constraints } \\
\hline Variable & Lower bound & Upper bound \\
\hline DME production rate $(\mathrm{kmol} / \mathrm{h})$ & 2,394 & 2,396 \\
\hline DME purity (mol \%) & 99.9 & \\
\hline Clean syngas $\mathrm{CO}_{2}(\mathrm{~mol} \%)$ & 1 & 3 \\
\hline DME purification column - Condenser temperature $\left({ }^{\circ} \mathrm{C}\right)$ & 40 & \\
\hline Stripper - Condenser temperature $\left({ }^{\circ} \mathrm{C}\right)$ & 30 & \\
\hline $\mathrm{CO}_{2}$ separation column - Condenser temperature $\left({ }^{\circ} \mathrm{C}\right)$ & -28 & \\
\hline \multicolumn{3}{|l|}{ Indirect DME synthesis production process constraints } \\
\hline Variable & Lower bound & Upper bound \\
\hline DME production rate $(\mathrm{kmol} / \mathrm{h})$ & 2,292 & \\
\hline DME purity (mol \%) & 99.9 & \\
\hline Clean syngas $\mathrm{CO}_{2}(\mathrm{~mol} \%)$ & 1 & 3 \\
\hline Methanol purity (mol \%) & 99.8 & \\
\hline Stripper - Condenser temperature $\left({ }^{\circ} \mathrm{C}\right)$ & 35 & \\
\hline Methanol purification column - Condenser temperature $\left({ }^{\circ} \mathrm{C}\right)$ & 35 & \\
\hline
\end{tabular}

\subsection{Results and Discussion}

In this section, results from the economic analysis and optimization of DME production process via direct and indirect DME synthesis are discussed. Both processes are scaled up to 5,000 MTPD 
DME production rate for fair comparison and validation against a 5,000 MTPD scale direct DME production process analyzed by Yoon \& Han [98]. Optimization results for both direct and indirect DME production processes are discussed and compared with the base case. Economics of the direct DME plant $\left(\mathrm{H}_{2} / \mathrm{CO}=1\right.$ and 2$)$ is compared with that of the indirect DME plant. Furthermore, comparison of capital costs for different process sections is also presented. Impact of changes in shale gas price, electricity price, IRR, contingency percentage on the breakeven DME price is studied. Finally, the impact of the plant scale on the breakeven DME price and the project CAPEX and OPEX is also analyzed.

\subsubsection{Process Performance Analysis}

Performance results for direct and indirect shale gas to DME production process for the base case, where the shale gas feed is similar, are shown in Table 3.6. Electricity equivalent (LHV basis) is calculated for makeup methanol, shale gas, and steam using the efficiency factors mentioned later. The equivalent electrical efficiency on LHV basis is calculated, using Eq. 3.7, to evaluate the performance of the shale gas to DME processes for different synthesis routes, $\mathrm{H}_{2} / \mathrm{CO}$ ratio and AGR technologies. The auxiliary boiler and fired heater are assumed to have an efficiency of 0.905. An efficiency factor of 0.622 is used for calculating electricity equivalent of gas and liquid fuels [133]. An efficiency factor of 0.436 is used to calculate the electricity equivalent of steam generated in the reactors [134]. For the direct DME synthesis route, the direct syngas to DME reaction is highly exothermic, while for the indirect route the methanol synthesis reaction is exothermic. The steam generated in these two reactors in converted into electricity using a steam turbine. The cooling water requirement in the process is considered in the form of the amount of electricity required to circulate the water in the process.

Electricity Equi.Eff. $(L H V, \%)=\frac{E_{\text {product }}+E_{\text {byproduct }}+W_{\text {generation }}}{E_{\text {shale gas }}+E_{\text {otherfuels }}+W_{\text {consumption }}}$ 
Table 3.6: Performance results for direct and indirect shale gas to DME process

\begin{tabular}{|c|c|c|}
\hline \multicolumn{2}{|c|}{ Direct DME Synthesis } & $\begin{array}{c}\text { Indirect DME } \\
\text { Synthesis }\end{array}$ \\
\hline $\mathrm{H}_{2} / \mathrm{CO}=1$ & $\mathrm{H}_{2} / \mathrm{CO}=\mathbf{2}$ & $\frac{\mathrm{H}_{2}-\mathrm{CO}_{2}}{\mathrm{CO}+\mathrm{CO}_{2}}=2$ \\
\hline
\end{tabular}

\begin{tabular}{lccccc}
\hline Acid-gas removal (AGR) Technology & Rectisol & MDEA/PZ & Rectisol & MDEA/PZ & Rectisol \\
\hline Energy Consumption & & & & & \\
\hline Shale gas to pre-reforming reactor (kg/h) & 98,047 & 98,047 & 98,047 & 98,047 & 98,047 \\
Makeup methanol* (kg/h) & 2,756 & 0 & 556 & 0 & 612 \\
Electricity consumption (MW) & 134 & 122 & 109 & 100 & 102 \\
Shale gas to HRSG (kg/h) & 848 & 848 & 848 & 1,886 & 848 \\
Shale gas to auxiliary boiler (kg/h) & 0 & 7,903 & 0 & 0 & 0 \\
Fired Heater (MW) & 1.81 & 2.02 & 2.50 & 2.50 & 35.3 \\
\hline Energy Generation & & & & & \\
\hline DME (MTPD) & 2,647 & 2,640 & 2,133 & 2,112 & 2,531 \\
Hydrogen (MTPD) & 0 & 0 & 126 & 129 & 0 \\
Electricity generation (MW) & 60.4 & 53.8 & 51.1 & 45.0 & 42.5 \\
Reactor steam generation (MW) & 76.0 & 76.3 & 60.6 & 60.6 & 56.1 \\
\hline Overall performance & & & & & \\
\hline DME yield & $58.9 \%$ & $58.8 \%$ & $47.5 \%$ & $47.0 \%$ & $56.3 \%$ \\
Equivalent electrical efficiency w/o H 2 & $63.3 \%$ & $59.4 \%$ & $52.9 \%$ & $51.9 \%$ & $58.4 \%$ \\
Equivalent electrical efficiency with $\mathrm{H}_{2}$ & - & - & $65.6 \%$ & $65.0 \%$ & - \\
\hline
\end{tabular}

${ }^{*}$ Required in the Rectisol process

As shown in Table 3.6, the direct DME synthesis process with $\mathrm{H}_{2} / \mathrm{CO}=1$ and Rectisol technology has a higher DME yield and equivalent electrical efficiency than the other process when $\mathrm{H}_{2}$ is not considered as a byproduct. The electricity usage in this process is high mainly because of the air separation unit and the refrigeration cycles. However, it has the highest thermal efficiency compared to the other process cases. The direct DME synthesis process with $\mathrm{H}_{2} / \mathrm{CO}=2$ produces $\mathrm{H}_{2}$ along with DME as a byproduct. This is because when the $\mathrm{H}_{2} / \mathrm{CO}$ ratio is high, carbon utilization increases and hydrogen utilization decreases and as a result, $\mathrm{H}_{2}$ is accumulated in the 
recycle loop [6]. However, the thermal efficiency of this process is low because of the high shale gas requirement, low DME production and relatively high electricity requirement compared to the amount of DME produced. The indirect DME process route has a lower thermal efficiency than the direct DME synthesis route when $\mathrm{H}_{2} / \mathrm{CO}=1$ because of the lower DME production in the indirect process compared to the direct process. The efficiency obtained in this study is similar to the efficiencies reported in the open literature for production of DME from coal or biomass as the feedstock [104-107].

\subsubsection{Economic Model Validation}

The validation of the economic model for shale gas to DME production processes via direct and indirect synthesis route is performed by comparing with the limited information available in the open literature. The investment parameters and the prices of raw material, product, solvents etc. as reported in Tables 3.1 and 3.4 are used for validation. As noted earlier, currently there is no open literature that has looked into the economics of the process with exactly the same configurations as in this study. Therefore, we divided the process into three main sections - syngas production section, AGR section, and DME production section and compared them separately. In the syngas production section, the cost of the pre-reforming reactor, ATR reactor, and ASU unit is calculated using cost correlation, as mentioned earlier, and therefore, economics of these units are not further validated. For the AGR section, the direct cost of the Rectisol process calculated using Aspen Icarus database is validated by comparing with the direct cost calculated using the cost correlation from open literature, as shown in Table 3.7. The total installed cost of the MDEA/PZ process is compared using the data available in the U.S. DOE's report [135] on design and economics of Fischer-Tropsch technology using the amine-based $\mathrm{CO}_{2}$ absorption process. In that study, the $\mathrm{CO}_{2}$ capture process was divided into two sections- $\mathrm{CO}_{2}$ absorption section and solvent regeneration section. The cost of the $\mathrm{CO}_{2}$ absorption section is a function of the inlet syngas flow rate, and the cost of the solvent regeneration section is a function of the $\mathrm{CO}_{2}$ rejection rate [135]. In our study, the flash vessel, stripper feed pump and the stripper are included in the solvent regeneration section while the rest of the equipment items are included in the $\mathrm{CO}_{2}$ absorption section. Using the appropriate scaling factors, the total installed cost calculated using APEA for our model is compared with the U.S. DOE report [135], as shown in Table 3.7. Larson and Tingjin [105] performed a techno-economic study on the production of synthetic fuel using indirect coal liquefaction, in which DME is produced by the direct synthesis route. Using the cost correlation 
for recycle LP DME synthesis and purification, the overnight installed cost was calculated and compared with the APEA estimated cost, as shown in Table 3.7. The total installed cost includes the field materials used for installation, general and administrative ( $G$ \& A) overheads, contract fee, freight, insurance and taxes (8\% of direct cost [136]), and total design, engineering and procurement cost. The discrepancy between the APEA cost and the cost estimated using cost correlation is mainly due to the differences in the indirect expenses, and G \&A overheads. An overall plant-wide comparison could not be performed for the indirect shale gas to DME production process due to the lack of information in the open literature. However, the total equipment purchase cost (TEPC) for the DME production section has been reported by Zhu et al., [104] for a biomass to DME plant with an indirectly-heated gasifier, as shown in Table 3.7. For validation of the indirect DME production section, the TEPC estimated in APEA was scaled down to that of Zhu et al. [104], and a good agreement was obtained.

Table 3.7: Comparison of AGR and DME production section cost with literature

\begin{tabular}{cccc}
\hline Section & $\begin{array}{c}\text { APEA Cost } \\
\text { (MM\$) }\end{array}$ & $\begin{array}{c}\text { Cost Correlation } \\
\text { (MM\$) }\end{array}$ & Reference \\
\hline Acid-gas removal-Rectisol & 50.7 & 50.6 & Kreutz et al. [128] \\
Acid-gas removal -MDEA/PZ & 40.2 & 44.6 & U.S. DOE [135] \\
DME production & 86.5 & 79.2 & Larson and Tingjin \\
Syngas-to-DME via indirect & 11.8 & & Zhu et al. [104] \\
synthesis & & 10.3 &
\end{tabular}

Note: $M D E A / P Z-M e t h y l$ diethanolamine/piperazine

The total project capital cost (TPCC) and the production cost for natural gas to DME process via direct synthesis estimated by JFE, Haldor Topsøe \& Toyo has been reported by Yoon and Han [98]. In Table 3.8, we show the comparison between the TPCC and DME production cost estimated in this work with that of Yoon and Han [98]. The shale gas price used for validation is 0.579 \$/MMBTU, electricity price is 29.1 \$GJ, and DME price is 4.45 \$/MMBTU. 
Table 3.8: Comparison of shale to DME production process via direct synthesis $\left(\mathrm{H}_{2} / \mathrm{CO}=\right.$ 1; 5,000 MTPD DME)

\begin{tabular}{lccc}
\hline \multicolumn{1}{c}{ 2015 Basis } & Yoon and Han & \multicolumn{2}{c}{ APEA model } \\
& {$[98]$} & $\begin{array}{c}\text { w/ Rectisol } \\
\text { process }\end{array}$ & $\begin{array}{c}\text { w/ MDEA/PZ } \\
\text { process }\end{array}$ \\
\hline Total project capital cost (TPCC) & $684.4-976.1$ & 1,132 & 1,417 \\
(MM\$, 2015 US dollar) & & & 4.26 \\
DME production cost (\$MMBTU) & $4.30-5.83$ & 4.85 & \\
\hline
\end{tabular}

Note: $M D E A / P Z$ - Methyl diethanolamine/piperazine

The DME production cost was calculated using Eq. 3.8.

DME production cost

$$
=\frac{\text { Fixed cost }+ \text { Manufacturing costs }+ \text { Plant overhead }+G \& A}{\text { DME production }}
$$

The estimated TPCC in this work is higher than Yoon and Han [98] for both the AGR technologies. The reason for this difference could not be determined since a number of investment parameters, as mentioned in Table 3.1, has not been reported by Yoon and Han [98]. However, the DME production cost for both AGR technologies is comparable. The DME production cost for the case with Rectisol as the AGR technology is slightly higher than the case with MDEA/PZ as the AGR technology because of the higher raw material and utility costs and operating costs.

\subsubsection{Direct Vs Indirect Synthesis Route}

In this section, the effect of $\mathrm{H}_{2} / \mathrm{CO}$ ratio on the economics of direct DME production process is discussed, and compared with the indirect DME production process, as shown in Table 3.9. The numbers inside the bracket are for direct DME synthesis with MDEA/PZ as the AGR technology. It should be noted that for all the cases except the indirect synthesis process, there is some excess electricity available, for which credit is taken while evaluating process economics. Moreover, for the direct synthesis process, with $\mathrm{H}_{2} / \mathrm{CO}=2$, hydrogen is sold as the byproduct as discussed earlier. 
Table 3.9: Effect of $\mathrm{H}_{2} / \mathrm{CO}$ ratio on direct DME synthesis process and comparison with indirect DME synthesis route (10\% IRR; 5,000 MTPD DME)

\begin{tabular}{|c|c|c|c|}
\hline & \multicolumn{2}{|c|}{ Direct DME synthesis } & \multirow{2}{*}{$\begin{array}{c}\text { Indirect DME } \\
\text { synthesis }\end{array}$} \\
\hline & $\mathrm{H}_{2} / \mathrm{CO}=1$ & $\mathrm{H}_{2} / \mathrm{CO}=2$ & \\
\hline Acid-gas removal (AGR) Technology & $\begin{array}{c}\text { w/ Rectisol } \\
(\text { w/ MDEA/PZ) }\end{array}$ & $\begin{array}{c}\text { w/ Rectisol } \\
\text { (w/ MDEA/PZ) }\end{array}$ & w/ Rectisol \\
\hline Total project capital investment (MM\$) & $\begin{array}{c}1,132 \\
(1,231)\end{array}$ & $\begin{array}{c}1,403 \\
(1,267)\end{array}$ & 998 \\
\hline Total operating cost $(\mathrm{MM} \$)$ & $\begin{array}{c}441 \\
(375)\end{array}$ & $\begin{array}{c}492 \\
(406)\end{array}$ & 421 \\
\hline Raw material and Utility cost (MM\$) & $\begin{array}{l}234 \\
(209)\end{array}$ & $\begin{array}{c}266 \\
(264)\end{array}$ & 231 \\
\hline Total product sales (MM\$) & $\begin{array}{c}223 \\
(232)\end{array}$ & $\begin{array}{c}378 \\
(390)\end{array}$ & 218 \\
\hline $\begin{array}{l}\text { Breakeven DME price w/o hydrogen as a } \\
\text { byproduct (\$/MMBTU) }\end{array}$ & $\begin{array}{c}10.1 \\
(9.94)\end{array}$ & $\begin{array}{c}12.1 \\
(11.2)\end{array}$ & 9.76 \\
\hline $\begin{array}{l}\text { Breakeven DME price with hydrogen as } \\
\text { a byproduct ( } \$ \text { MMBTU) }\end{array}$ & - & $\begin{array}{c}8.91 \\
(7.98)\end{array}$ & - \\
\hline
\end{tabular}

Note: $M D E A / P Z$ - Methyl diethanolamine/piperazine

As seen in Table 3.9, when $\mathrm{H}_{2} / \mathrm{CO}=1$, the direct synthesis route with the MDEA/PZ technology has a slightly lower breakeven DME price than the direct route, with the Rectisol technology, mainly due to the lower operating cost and higher revenue earned in the former. For the direct DME synthesis process with $\mathrm{H}_{2} / \mathrm{CO}=2$, the difference in the breakeven DME price between the two processes is much more pronounced. The direct process with the Rectisol technology has a much higher breakeven price than the MDEA/PZ case because of the higher solvent circulation rate as a result of the lower $\mathrm{CO}_{2}$ partial pressure when the $\mathrm{H}_{2} / \mathrm{CO}$ ratio is high. The higher solvent circulation rate, in turn, leads to the higher operating cost and equipment cost as shown in Table 3.9. The breakeven DME price for the direct synthesis route with $\mathrm{H}_{2} / \mathrm{CO}=2$ is much lower than the direct synthesis route with $\mathrm{H}_{2} / \mathrm{CO}=1$ and indirect synthesis process when $\mathrm{H}_{2}$ is also considered as a byproduct for sale. If $\mathrm{H}_{2}$ is not considered as a byproduct, then the indirect DME synthesis process has the lowest breakeven DME price because of the low TPCC. To understand the 
difference between the direct and indirect DME production process and also to analyze the impact of $\mathrm{H}_{2} / \mathrm{CO}$ ratio on the process, the total direct cost of each section - syngas synthesis section, AGR section and DME production section- is plotted separately in Fig. 3.1. It should be noted that Fig. 3.1 includes the refrigeration unit, but not the ASU, HRSG \& SC, and PSA unit.

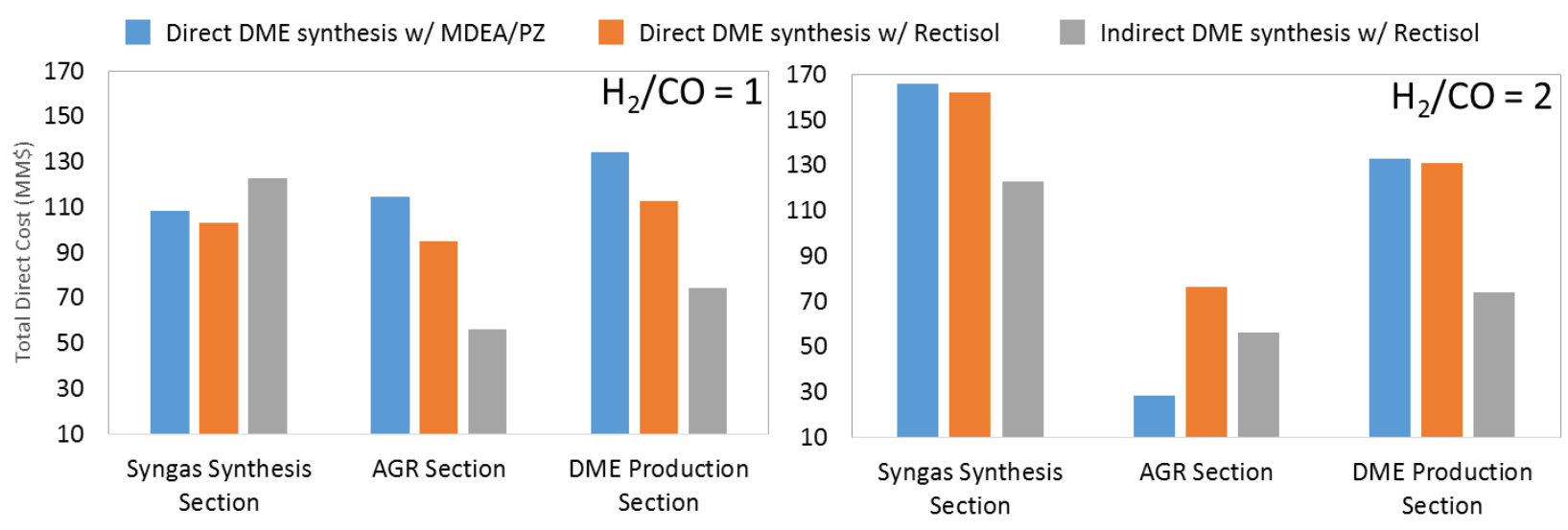

Figure 3.1: Breakdown of plant total direct cost by section (10\% IRR, 5,000 MTPD DME)

When $\mathrm{H}_{2} / \mathrm{CO}=1$ in the direct DME route, the direct cost of the syngas production section is the lowest (slightly lower than MDEA/PZ case) for the Rectisol technology because its DME yield is higher than the other cases. So, for producing the same amount of DME, the amount of shale gas required is low and this, in turn, reduces the direct cost of the equipment items because of smaller equipment size. For the AGR section, the indirect DME synthesis process has the lowest capital cost because the $\mathrm{CO}_{2}$ content in the inlet stream to the AGR section is less and as a result, the circulation rate of the solvent is lower. The DME production section in the direct synthesis route, with MDEA/PZ technology, has the highest direct cost because of the refrigeration cycle that is used for cooling the DME synthesis reactor outlet stream to subzero temperature and also for $\mathrm{CO}_{2}$ recycling. In the direct synthesis route with Rectisol technology, the DME synthesis reactor outlet stream is cooled using the process streams available in the AGR section. No cooling of that stream is required in the indirect synthesis route.

When $\mathrm{H}_{2} / \mathrm{CO}=2$, the direct cost of the syngas production section is the lowest for the indirect DME synthesis process because of its higher DME conversion and yield compared to the direct synthesis plant. As a result, for the same DME production much lesser shale gas feed is required, which directly impacts size and cost of the equipment items. When $\mathrm{H}_{2} / \mathrm{CO}=2$, the direct cost of the AGR section is the lowest for the direct DME synthesis route with the MDEA/PZ technology. This is because the MDEA/PZ technology that is based on chemical absorption leads to lower 
solvent circulation rate than the physical absorption-based Rectisol technology for low $\mathrm{CO}_{2}$ partial pressure [6]. The lower solvent circulation rate leads to smaller equipment sizes. The direct cost of the DME production section is the lowest for the indirect DME synthesis route because the syngas flowrate is lower in that case and it does not require a refrigeration unit.

\subsubsection{Economics of Optimized Process}

Techno-economic optimization was performed on the base case direct and indirect DME route in Aspen Plus EO environment to determine the optimal operating condition, as mentioned in Section 3.5. It should be noted that for the direct route, optimization is not performed on all the process cases. As reported in Section 3.6.1, the direct route with $\mathrm{H}_{2} / \mathrm{CO}=1$ and Rectisol technology has a higher overall equivalent electrical efficiency among all direct synthesis cases. Therefore, direct, and indirect DME routes with Rectisol technology are optimized. A total of 13 decision variables are selected for both the processes. Values of the objective function calculated using the modified cost correlations were compared with that using APEA for different values of the decision variables. Maximum differences between the two values were found to be less than 1\%. Table 3.10 shows the value of the decision variables for the base case and optimized case. Different initial values were evaluated, and it was observed that all decision variables reached the same optimum value. Total module cost of 26 equipment items for the direct synthesis process and 29 equipment items for the indirect one is considered in the objective function. These equipment items are selected based on their impact on the objective function. The equipment items that are considered in the optimization objective are those that contribute to almost $90 \%$ of the capital cost. 
Table 3.10: Decision variable values before and after optimization

\begin{tabular}{lcc}
\hline Direct DME synthesis production process decision variables & $\begin{array}{c}\text { Initial } \\
\text { Value }\end{array}$ & $\begin{array}{c}\text { Optimized } \\
\text { Value }\end{array}$ \\
\hline Direct DME syn. reactor temperature $\left({ }^{\circ} \mathrm{C}\right)$ & 260 & 261 \\
Flash vessel pressure- DME production section (bar) & 45.0 & 46.5 \\
DME purification column- molar reflux ratio & 1.51 & 1.00 \\
DME purification column- molar distillate to feed ratio & 0.233 & 0.230 \\
DME purification column- pressure (bar) & 15.0 & 8.94 \\
$\mathrm{CO}_{2}$ separation column- molar reflux ratio & 2.00 & 1.57 \\
$\mathrm{CO}_{2}$ separation column- molar bottoms to feed ratio & 0.7825 & 0.784 \\
Direct DME syn. Reactor pressure (bar) & 50.0 & 48.0 \\
Flash vessel pressure- Rectisol process (bar) & 15.0 & 23.0 \\
CO 2 absorber pressure- Rectisol process (bar) & 50.0 & 46.0 \\
Stripper- molar bottoms to feed ratio & 0.897 & 0.893 \\
Methanol solvent flowrate (kmol/h) & 35,598 & 35,970 \\
Shale gas feed flowrate $(\mathrm{kmol} / \mathrm{h})$ & 5,200 & 5,216 \\
\hline Indirect DME synthesis production process decision variables & Initial & Optimized \\
& Value & Value \\
\hline Methanol synthesis reactor temperature $\left({ }^{\circ} \mathrm{C}\right)$ & 250 & 221 \\
DME separation column- molar reflux ratio & 5.00 & 3.21 \\
DME separation column- molar distillate to feed ratio & 0.409 & 0.410 \\
Methanol dehydration reactor temperature $\left({ }^{\circ} \mathrm{C}\right)$ & 250 & 248 \\
Flash vessel pressure- Rectisol process $($ bar) & 12.0 & 13.4 \\
Methanol-water column- molar reflux ratio & 2.64 & 2.43 \\
Methanol purification column- molar reflux ratio & 0.400 & 0.350 \\
Methanol purification column- molar bottoms to feed ratio & 0.981 & 0.960 \\
Stripper- molar reflux ratio & 0.503 & 0.100 \\
Striper- molar bottoms to feed ratio & 0.963 & 0.956 \\
Flash vessel pressure-methanol syn. section (bar) & 45.0 & 57.5 \\
Methanol solvent flowrate (kmol/h) & 19,372 & 15,697 \\
Shale gas feed flowrate (kmol/h) & 5,200 & 4,963 \\
\hline
\end{tabular}

The comparison between the optimized and base case process is shown in Table 3.11. The economics reported in Table 3.11 were calculated in APEA using base case and optimized process models and the investment parameters, raw material, and utility prices from Table 3.1 and 3.4, respectively. 
Table 3.11: Comparison of the economics between the base case and optimized case for $10 \%$ IRR

\begin{tabular}{lccc}
\hline Direct DME Synthesis Process & $\begin{array}{c}\text { Base } \\
\text { case }\end{array}$ & $\begin{array}{c}\text { Optimized } \\
\text { case }\end{array}$ & $\begin{array}{c}\text { \% } \\
\text { change }\end{array}$ \\
\hline Total project capital cost (TPCC) (MM\$) & 684 & 663 & $-3.07 \%$ \\
Total raw material \& utility cost (MM\$/year) & 113 & 114 & $-0.88 \%$ \\
DME production rate (MTPD) & 2,647 & 2,647 & \\
Breakeven DME price (\$/MMBT) & 11.98 & 10.84 & $-9.52 \%$ \\
\hline Indirect DME Synthesis Process & Base & Optimized & \% \\
case & 577 & 576 & $-0.17 \%$ \\
Total project capital cost (MM\$) & 108 & 99 & $-8.33 \%$ \\
Dotal raw material \& utility cost (MM $\$ /$ year) & 2,531 & 2,533 & \\
DME price (\$/MMBTU) & 10.43 & 10.38 & $-0.48 \%$ \\
\hline
\end{tabular}

As shown in Table 3.11, the TPCC of the direct DME synthesis process decreased by $3.07 \%$ after optimization. As mentioned earlier, there is excess electricity produced in the direct DME synthesis process, credit for which is taken while evaluating the process economics. As seen in Table 3.10, the pressure of the direct DME synthesis reactor and the $\mathrm{CO}_{2}$ absorber for the optimized case is lower than the base case. Lower pressure reduces the compression duty. Moreover, the flash vessel in the DME production section, vapor from which is sent through an absorber and then recycled to the direct DME synthesis reactor, operates at a higher pressure reducing the recycle compressor duty. Due to the low electricity usage in the optimized case compared to the base case, slightly more revenue is earned due to the electricity sale. The raw material and utility costs are slightly higher for the optimized direct synthesis route in comparison to the base case due to the increase in the shale gas flowrate. Overall, these changes lead to a $9.52 \%$ decrease in the breakeven DME price of the direct synthesis process in comparison to the base case. For the indirect DME production process, the decrease in the TPCC is $0.17 \%$, which is not as considerable as the direct synthesis routes. However, the raw material and utility costs decreased by $8.33 \%$ for the optimized indirect route as excess electricity is produced which could be sold for credit as opposed to the base case where no excess electricity is available. Overall, the breakeven DME price of the optimized indirect process is $0.48 \%$ lower than that of the base case.

\subsubsection{Sensitivity Analysis}

The direct DME synthesis process is not commercialized yet. Several investment parameters that are independent of the process technology and process operating conditions can affect the 
economic feasibility of this technology. In this section, effects of the project scale, variations in the shale gas and electricity prices, IRR, and contingency on the breakeven DME price are evaluated. The impact of project scale, shale gas and electricity price, and the contingency are evaluated assuming 20\% IRR. Moreover, most of the large-scale industrial methanol plants have a production capacity of approximately 5,000 MTPD so the sensitivity studies are carried out at this plant scale [137].

\subsubsection{Sensitivity to Internal Rate of Return, Shale Gas, and Electricity Price}

IRR is one of the most important measures for the commercialization potential of a chemical plant. Fig. 3.2 and 3.3 show the change in the breakeven DME price (also equivalent diesel price) due to change in the shale gas price at various IRR for the direct and indirect synthesis processes, respectively. To make a fair comparison, the credit for electricity is kept constant for a given IRR. Typically, a 20\% IRR is considered to be a reasonable return for a gas to liquid (GTL) plant [123]. A 15\% IRR can be considered to be a lower bound for commercialization potential of a GTL project considering the risks associated with the market price of raw materials. A target of $25 \%$ IRR is high but is often considered in many GTL projects due to the risk associated with plant overheads, capital cost escalation, decrease in the product price, and increase in feedstock prices. For reference, the equivalent diesel price is also shown in Fig. 3.2 and 3.3. The equivalent diesel price for the direct DME plant ranges from $0.675 \$ /$ gal to $1.663 \$ /$ gal and for indirect DME synthesis plant, it ranges from $0.589 \$ / \mathrm{gal}$ to $1.530 \$ /$ gal. Compared to these prices the current average U.S. diesel price, as of April 2018, is $2.75 \$$ /gal [138] indicating the economic feasibility of the process. 


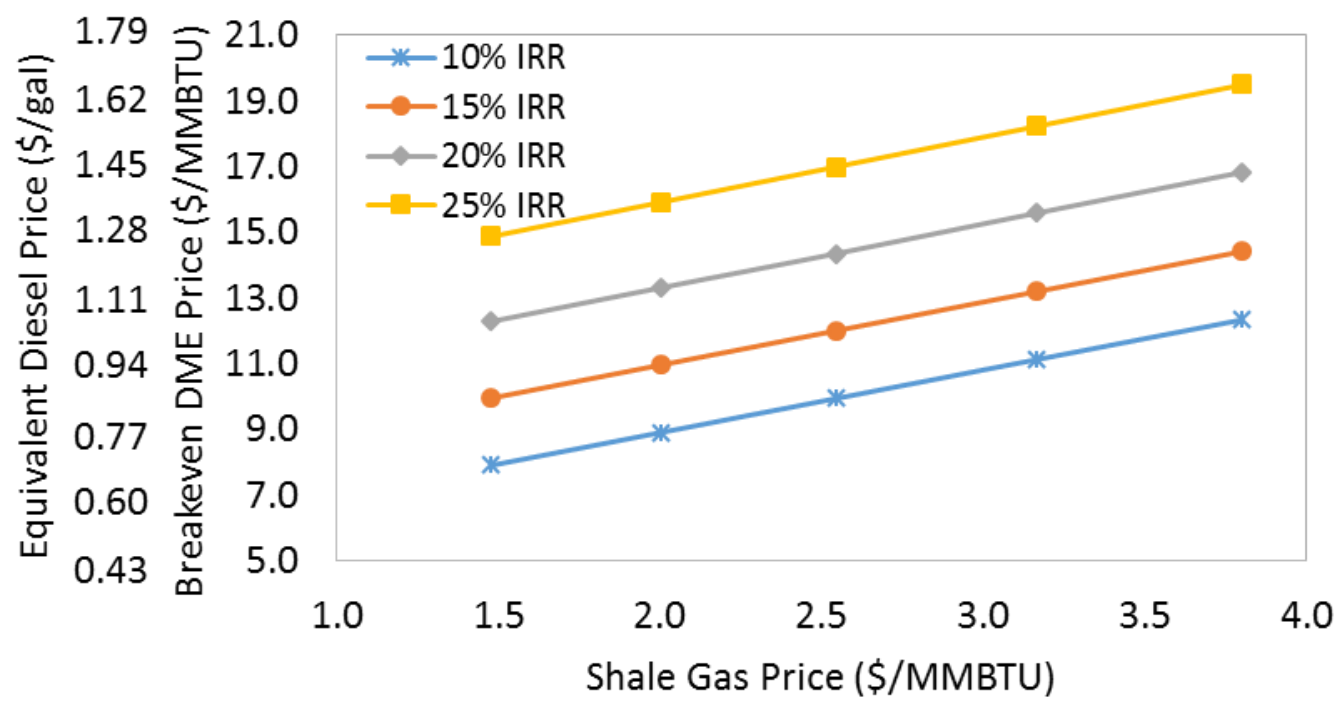

Figure 3.2: Feasibility envelop for direct DME synthesis process (Rectisol Technology; 5,000 MTPD DME)

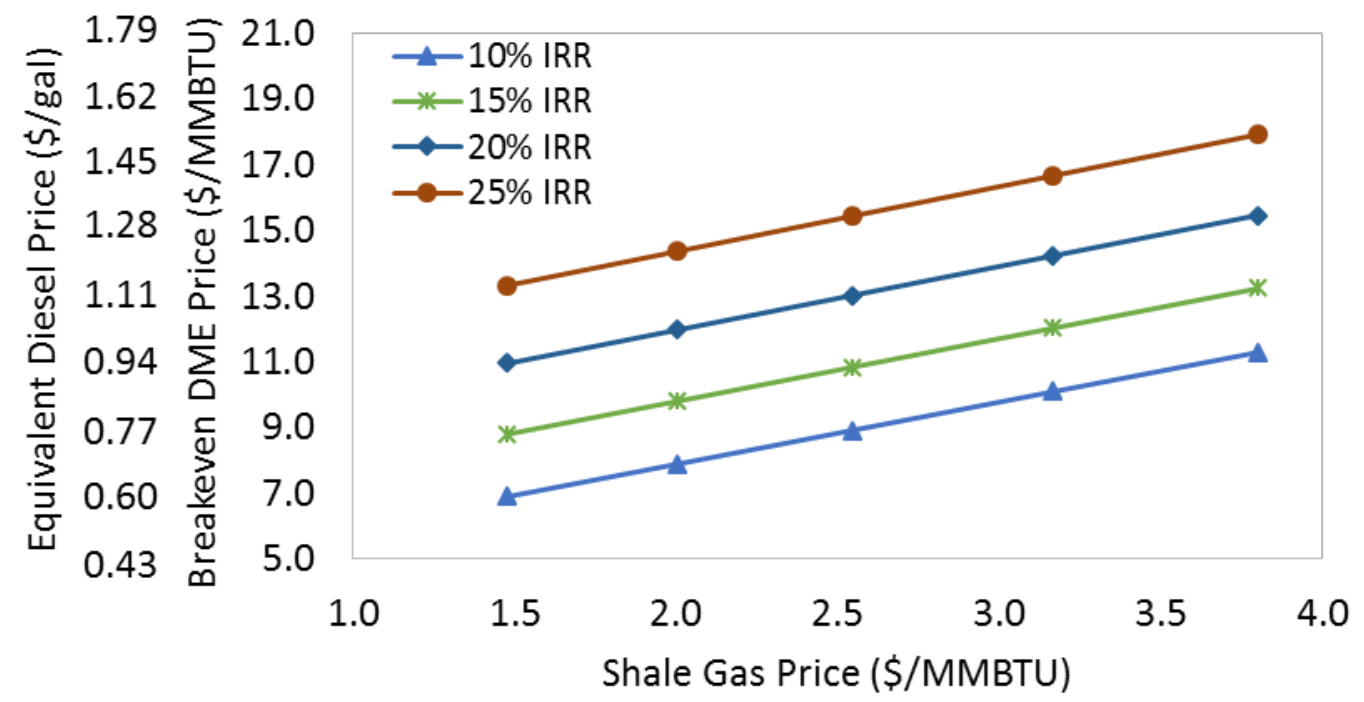

Figure 3.3: Feasibility envelop for indirect DME synthesis process (Rectisol Technology; 5,000 MTPD DME)

Since, electricity is co-produced in both DME plants, the effect of $\pm 20 \%$ variation in the electricity selling price on the breakeven DME price is shown in Fig. 3.4. It is observed that the electricity price has a negligible effect on the breakeven DME price mainly because of the low quantity of the co-produced electricity. 


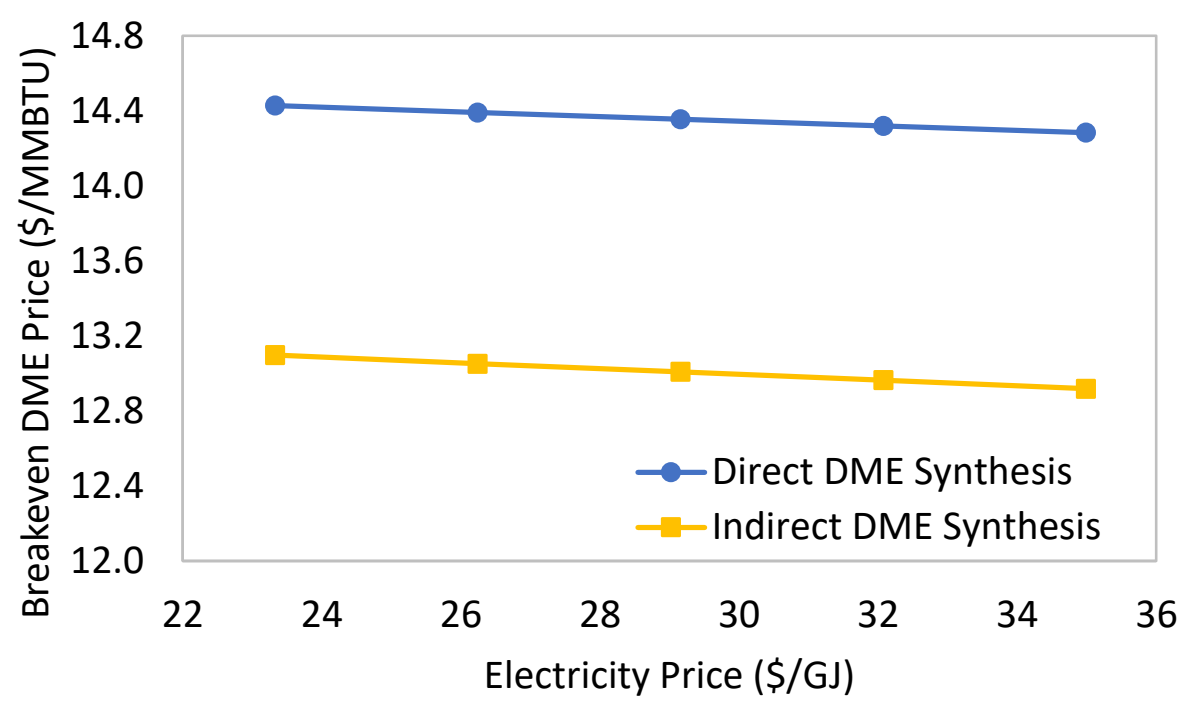

Figure 3.4: Effect of electricity price on breakeven DME price (Rectisol Technology, 20\% IRR; 5,000 MTPD DME)

\subsubsection{Project Scale and Contingency}

The sensitivity of the increase in project scale to breakeven DME price, capital cost (CAPEX), and operating cost (OPEX) is shown in Fig. 3.5 for both the direct and indirect DME synthesis processes. For a fair comparison, the electricity credit is kept constant for a given plant scale. As expected, the breakeven DME price decreases with the increase in project scale. After 7,500 MTPD project scale, there is a steeper decrease in the breakeven DME price because the increase in the CAPEX when going from 7,500 to 10,000 MTPD is $19.8 \%$ and $8.24 \%$ for direct and indirect DME synthesis, respectively. Similarly, the increase in the OPEX for direct and indirect synthesis process is $31.3 \%$ and $31.6 \%$, respectively. 

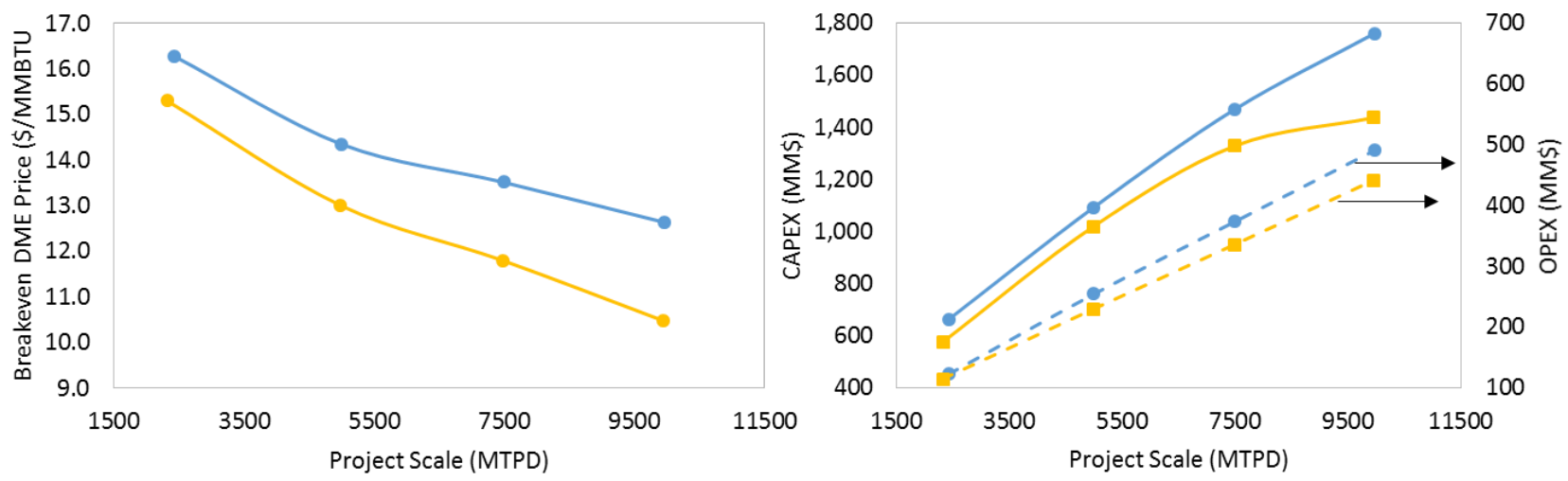

Figure 3.5: Effect of project scale on breakeven DME price, CAPEX, and OPEX (Rectisol Technology, 20\% IRR). Direct synthesis process (circle w/ blue line); indirect synthesis process (square w/ yellow line)

Since the direct DME synthesis process from shale gas is not yet commercialized, there is a high uncertainty associated with the TPCC. The TPCC is found to vary widely in the open literature [98]. Fig. 3.6 shows the effect of the variation in contingency on the breakeven DME price with respect to variation in the shale gas price. The electricity credit is kept constant for a given plant contingency.

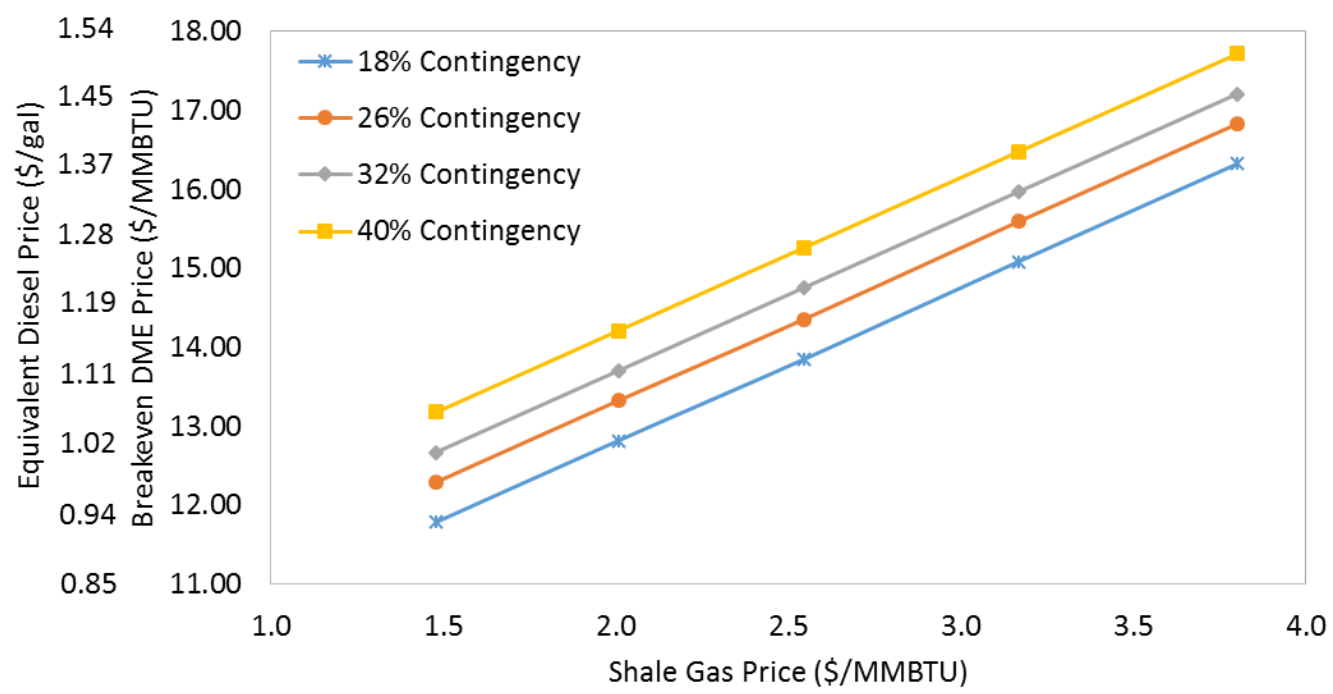

Figure 3.6: The sensitivity of breakeven DME price to plant contingency for direct DME synthesis process (Rectisol Technology; 20\% IRR; 5,000 MTPD DME)

As seen in Fig. 3.6, the breakeven DME price varies between 11.79 \$/MMBTU-17.71 \$/MMBTU, corresponding to the equivalent diesel price of 1.01 \$/gal-1.51 \$/gal. The analysis shows that even with $40 \%$ contingency, the direct DME production process can still be economically feasible. 


\subsection{Conclusion}

In this chapter, techno-economic optimization of DME production process via direct and indirect synthesis routes has been conducted based on rigorous process models developed in Aspen Plus. The economic model has been compared with the open literature when possible. The direct DME production process with $\mathrm{H}_{2} / \mathrm{CO}=1$ and Rectisol technology has the highest DME yield of 58.9\% and has the highest overall equivalent electrical efficiency of $63.3 \%$ when hydrogen is not considered as a byproduct. The direct DME production process with $\mathrm{H}_{2} / \mathrm{CO}=2$ and Rectisol technology has the highest overall equivalent electrical efficiency of $65.6 \%$ when credit is taken for hydrogen. Direct and indirect DME synthesis plants are optimized in Aspen Plus EO environment. After optimization, the breakeven DME price of the direct and indirect synthesis processes decreased by $9.52 \%$ and $0.48 \%$, respectively. When the project scale is increased from 2,500 MTPD to 10,000 MTPD, the breakeven DME price decreases by $22.4 \%$ for the direct DME process and $31.3 \%$ for the indirect DME process. For 10,000 MTPD project scale, the breakeven DME price is $12.64 \$$ MMBTU (equivalent diesel price - $1.08 \$ /$ gal) and 10.48 \$MMBTU (equivalent diesel price $-0.89 \$ / g a l$ ) for direct and indirect synthesis processes, respectively. For a 5,000 MTPD project scale, the breakeven DME price is $19.49 \$ / M M B T U$ for $25 \%$ IRR considering the price of shale gas to be $3.8 \$$ MMBTU. The process is still economically feasible at this breakeven DME price because the equivalent diesel price is $1.66 \$ / g a l$, which is considerably lower than the current market diesel price. At $40 \%$ project contingency, the breakeven DME price for 5,000 MTPD plant is 17.71 \$ /MMBTU, corresponding to equivalent diesel price of $1.51 \$ / g a l$. The breakeven DME price is not sensitive to electricity price, but this can change if a higher amount of electricity is produced. Shale gas composition as well as economic and investment parameters do vary widely based on the country/region. The approach presented in this study is generic and can be readily extended to the techno-economic optimization of commercial DME plants in any country/region thus maximizing not only the profitability but also reducing the scale-up risk. 


\section{Chapter 4. Dynamic Data Reconciliation, Parameter Estimation, and Multi- Scale Reactor Modeling of the Direct Non-Oxidative Methane Dehydroaromatization Process}

This chapter presents dynamic data reconciliation, parameter estimation, and multi-scale fixedbed reactor model for the direct non-oxidative methane dehydroaromatization (DHA) process. Due to rapid coke formation, catalysts in the non-oxidative methane DHA reactors get deactivated. A model for deactivation is required for designing the cycle conditions and number of reactors for a fixed-bed DHA process. Therefore, a model for the catalyst deactivation is developed along with rate models for other DHA reactions. Due to the very fast coke formation rate on the fresh catalyst, there is coke formation during the induction period. Extent of catalyst deactivation at the end of the induction period is desired for estimation of reaction rate parameters, but that cannot be measured. Therefore, an algorithm is developed for estimation of the initial state of the reactor and the kinetic parameters by coupling an iterative direct substitution approach with an optimization approach. Experimental data from an in-house reactor are used for developing the kinetic model. Using the rate model, a dynamic, heterogeneous, multi-scale reactor model, with embedded heating is developed. The model couples the catalyst pellet level model with a reactor level model. Impacts of temperature, $\mathrm{L} / \mathrm{D}$ ratio, and scheduling of reactors on variability in conversion and yield with time are studied.

\subsection{Literature Review}

Majority of the studies in the area of non-oxidative methane DHA process has been focused on catalyst development, studying reactor operating conditions, and analyzing different methods for catalyst regeneration. Guo et al. [139] have performed a non-oxidative methane DHA study in presence of $\mathrm{FeSiO}_{2}$ catalyst at $950^{\circ}-1090^{\circ} \mathrm{C}$ and atmospheric pressure. Many researchers have studied the catalyst performance of HZSM-5 used for non-oxidative methane DHA reaction with various transition metals such as Mo, W, Re, Co, Ga, Mn etc. [28,140-144]. Other research groups 
have performed experimental studies to analyze the effect of operating conditions such as pressure, weight hourly space velocity (WHSV), inlet stream composition, and reactor temperature on methane conversion, product selectivity, and coking [145-148]. As catalyst deactivation due to coking is one of the main issues, several strategies have been studied in the open literature to either reduce coking or regenerate the catalyst by periodic feeding of oxygen, co-feeding of carbonmonoxide, or cycling $\mathrm{CH}_{4}-\mathrm{H}_{2}$ switching [148-151]. Very few authors have performed studies on constructing rate models for non-oxidative methane DHA reactions. Li et al. [152] have optimized catalytic membrane reactors for non-oxidative methane conversion process. Their proposed rate model does not include the effect of catalyst deactivation and was developed using the data for one specific temperature. Gao et al. [153] have conducted experimental studies and developed models for methane DHA reactions in a hydrogen-selective membrane reactor by using a Mo/MCM-22 catalyst. They have estimated the kinetic parameters of three global reactions using the experimental data when the reactions were in pseudo-steady state region. The authors also did not consider the impact of catalyst deactivation on the reaction kinetics. Iliuta et al. [154] have performed experimental studies on methane DHA reactions on a Ru-Mo-HZSM-5 catalyst in a fixed bed reactor over a temperature range of $600^{\circ}-700^{\circ} \mathrm{C}$ at atmospheric pressure. The kinetic parameters in their Langmuir-Hinshelwood-Hougen-Watson (LHHW) rate model have been estimated and validated under the assumption of steady state in absence of catalyst deactivation. Wong et al. [155] have developed an elementary step-based steady state reaction kinetics model over HMZM-22 and Mo/HZSM-5 catalyst. Their model has been validated using the experimental steady-state data collected in $600^{\circ}-700^{\circ} \mathrm{C}$ temperature range while varying reactor space times and inlet methane mole fractions. Fayzullaev et al. [156] have studied the kinetics and mechanism of methane DHA reactions over $\left(\mathrm{MoO}_{3}\right)_{\mathrm{x}}\left(\mathrm{ZrO}_{2}\right)_{\mathrm{y}}\left(\mathrm{ZnO}_{2}\right)_{\mathrm{z}} /$ bentonite catalyst over a temperature range of $600^{\circ}-750^{\circ} \mathrm{C}$. They have proposed four main reactions and have estimated the kinetic parameters for those reactions using the experimental data from the system when methane conversion was maximum assuming steady state operation. Yao et al. [157] have studied the intrinsic kinetic of non-oxidative methane DHA on a Mo/HZSM-5 catalyst at different space velocities in the temperature range of $640^{\circ}-750^{\circ} \mathrm{C}$ under atmospheric pressure. They have proposed a LHHW rate model for direct formation of benzene from methane and decomposition of methane and benzene to carbon. Their rate model does not consider the coke formation rate. The parameters in the rate model were estimated using the data under steady-state assumption. A kinetic study for methane 
DHA reactions at the temperature range of $700^{\circ}-800^{\circ} \mathrm{C}$ under atmospheric pressure was performed by Jeong et al. [158]. In their experiment, the catalyst was not pre-carburized, so during the methane DHA reaction $\mathrm{CO}$ and $\mathrm{CO}_{2}$ were present in the reactor for carburization of catalyst. They have proposed LLHW rate models considering 6 reactions while treating catalyst activity as a timevarying parameter. A pseudo-homogenous 1-D steady-state reactor model was developed and used for parameter estimation in MATLAB using 'Isqcurvefit'. Considerable discrepancy between the model results and experimental data can be observed for methane conversion and yield of practically all products including benzene, toluene, ethane, ethylene, and naphthalene. Karayaka et al. [159] have developed a detailed reaction mechanism, involving 46 elementary reaction steps, for the methane DHA reactions based on mean-field approximation. They have also developed a 1-dimensional axial flow packed bed reactor and validated their model results for methane conversion and aromatics yield with data from literature at different space velocities and temperature. Seeking to improve the validity of the same three reactions as Li et al. [152] for a temperature range of $677^{\circ}-750^{\circ} \mathrm{C}$, Zhu et al. [160] have used the detailed mechanisms proposed by Karayaka et al. [159] for first estimating the species concentration and molar rate data. Later, they have estimated the kinetic parameters of the three global reactions using the concentration and molar rate data, without the consideration of catalyst activity loss, by using Chemkin-Pro and MATLAB. In terms of reactor modeling, majority of studies have focused on development and optimization of isothermal membrane reactors for methane DHA process [152,161-165], considering the reaction rate model without the effect of catalyst deactivation. Models of heterogenous multi-scale dynamic fixed-bed reactors with integrated heating and consideration of catalyst deactivation effect are still lacking in open literature. Such a model can be useful in developing and optimizing cyclic reactor process and can also be used in developing a plant-wide model to analyze the economic feasibility of methane DHA process. To summarize, the following contributions have been made:

- A dynamic data reconciliation methodology is developed to ensure that mass balance at each time instance is satisfied. Data reconciliation is required for this system as the coke formation rate at each time instance is unknown/unmeasured, and the measurements available from GC at each time instant does not necessarily satisfy carbon and hydrogen balance. This methodology can be applied to any other reaction system. 
- A reaction mechanism for methane DHA that includes a model for the catalyst deactivation rate is developed and the kinetic parameters are estimated using in-house experimental data. It can be noted that the catalyst deactivation model for the methane DHA is generally ignored in the current literature.

- In this work, we seek to address an important issue that the initial amount of coke formed, before the outlet gas phase measurements are available, is likely to be unknown. However due to introduction of feed to the fresh catalyst, there can be rapid coke formation. If this amount of coke formed during the induction period is not considered while estimating the reaction rate parameters, it can lead to over-prediction of catalyst deactivation rate. To this end, an algorithm is developed by coupling an iterative direct substitution approach with an optimization algorithm for optimal estimation of the initial state of the reactor and the kinetic parameters using the in-house experimental data.

- The overall reaction system is endothermic, so external energy should be supplied for high single pass conversion. Multi-tubular fixed bed reactors with embedded heating are simple yet promising solutions for such systems. However, due to coking reactions, the fixed bed reactors need to be cycled. Since the reactor outlet goes to other section of the plant for separation and further processing of the products to make them satisfy the desired quality requirements, it is desired that the variability of flow and yield from the fixed bed reactors remains within acceptable limit for the downstream systems. To satisfy this requirement, a sensitivity study is presented to show the effect of reactor operational time consideration on variability of conversion and product yield. This is followed by a case study on consideration of parallel reactor operation on variability in conversion and yield.

\subsection{Experimental Procedure}

In this section, information on the catalyst preparation method and approach to perform the methane DHA experiments is presented.

\subsubsection{Catalyst Preparation}

The molybdenum-loaded ZSM-5 (Mo/ZSM-5) catalysts were prepared by incipient wetness technique. The H-ZSM5 zeolite support $(\mathrm{Si} / \mathrm{Al}=23)$ was made by calcinating the $\mathrm{NH}_{4}-\mathrm{ZSM} 5$ (Zeolyst International, Inc.) at $550^{\circ} \mathrm{C}$. The molybdenum loading was $4 \mathrm{wt} \%$ and the preparation method is described in one of the previous publications by some of the co-authors [166]. 


\subsubsection{Reactor Configuration and Operating Conditions}

The freshly prepared catalyst was first pressed and sieved to have a particle size of 80 mesh, and the catalyst was carburized by methane-hydrogen mixture gas $\left(\mathrm{CH}_{4}: \mathrm{H}_{2}=1: 4\right)$ in a traditional fixedbed reactor at $600^{\circ} \mathrm{C}$ for 4 hours with a total flow rate of $50 \mathrm{~mL} / \mathrm{min}$. It has been reported that the active $\mathrm{MoC}_{\mathrm{x}}$ species is formed by carburization of the molybdenum-zeolite catalyst, which can effectively enhance the catalyst performance $[167,168]$. Methane DHA reactions were carried out in $8 \mathrm{~mm}$ inner diameter (ID) quartz tube reactor with a bed length of about 1.02 inch. A thermocouple was positioned at the catalyst bed center to measure the temperature. The feedstock contained 50 vol\% of methane, balanced by nitrogen, and the total flow rate was $100 \mathrm{~mL} / \mathrm{min} .0 .5$ gram of catalyst was loaded in each experiment. The experimental setup is shown in Fig. 4.1.

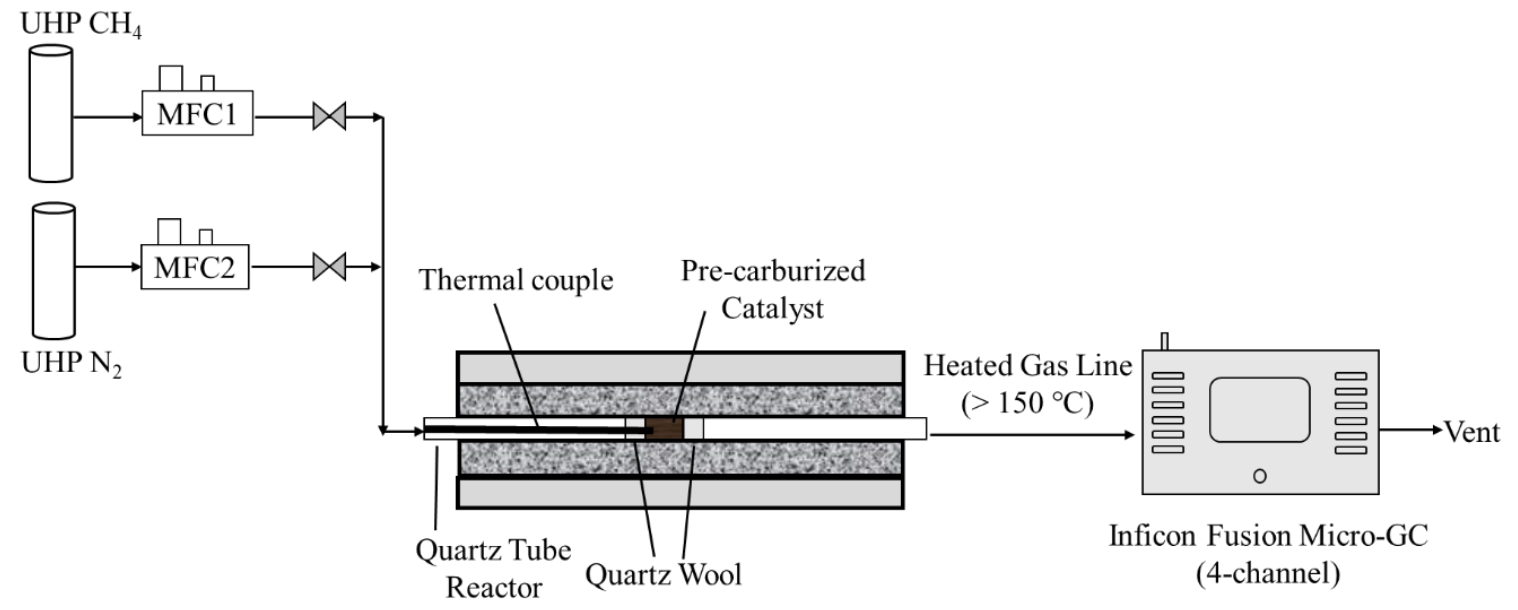

Figure 4.1: Experimental setup for conducting methane DHA reactions

The experiments were carried out at temperatures $725^{\circ} \mathrm{C}, 750^{\circ} \mathrm{C}, 775^{\circ} \mathrm{C}$, and $800^{\circ} \mathrm{C}$. The outlet of the reactors was maintained at a temperature higher than $150^{\circ} \mathrm{C}$ to prevent the benzene and toluene from condensation. Product composition was analyzed by an Inficon Fusion Micro Gas Chromatography (4-channel). Only hydrogen, ethane, ethylene, benzene, and toluene are considered as products. All experiments were conducted under atmospheric pressure.

\subsubsection{Thermogravimetric Analysis (TGA)}

TGA experiments were performed to quantify the coke and analyze coke composition at the end of experimental runs. Experiments were carried out in a Discovery SDT 650 unit manufactured by TA Instruments. The temperature profile of the TGA is shown in Appendix F. The spent catalyst sample was first stabilized at $50^{\circ} \mathrm{C}$ for 2 hours (step 1; $100 \mathrm{~mL} / \mathrm{min} \mathrm{He}$ ). Then, the temperature 
was raised to $200^{\circ} \mathrm{C}$ at a rate of $10^{\circ} \mathrm{C} / \mathrm{min}$ (step 2), kept for 1 hour (step 3) to remove the moisture, and brought down to $50^{\circ} \mathrm{C}$ (step 4). The moisture removal steps were under the inert environment $(100 \mathrm{~mL} / \mathrm{min} \mathrm{He})$. The feed gas was switched to $5 \mathrm{vol} \% \mathrm{O}_{2}$ and stabilized for 1 hour (step 5, 100 $\mathrm{mL} / \mathrm{min} 5 \mathrm{vol} \% \mathrm{O}_{2}$ balanced $\mathrm{He}$ ). Subsequently, the sample was raised to $1200^{\circ} \mathrm{C}$ at a rate of 5 ${ }^{\circ} \mathrm{C} / \mathrm{min}$ (step 6), isothermal for 1 hour to oxide the coke fully (step 7), then cooled down to the room temperature (step 8, $100 \mathrm{~mL} / \mathrm{min} \mathrm{He}$ ). All gases used in TGA were UHP grade. The TGA results for the spent catalysts samples is shown in Fig. 4.2.
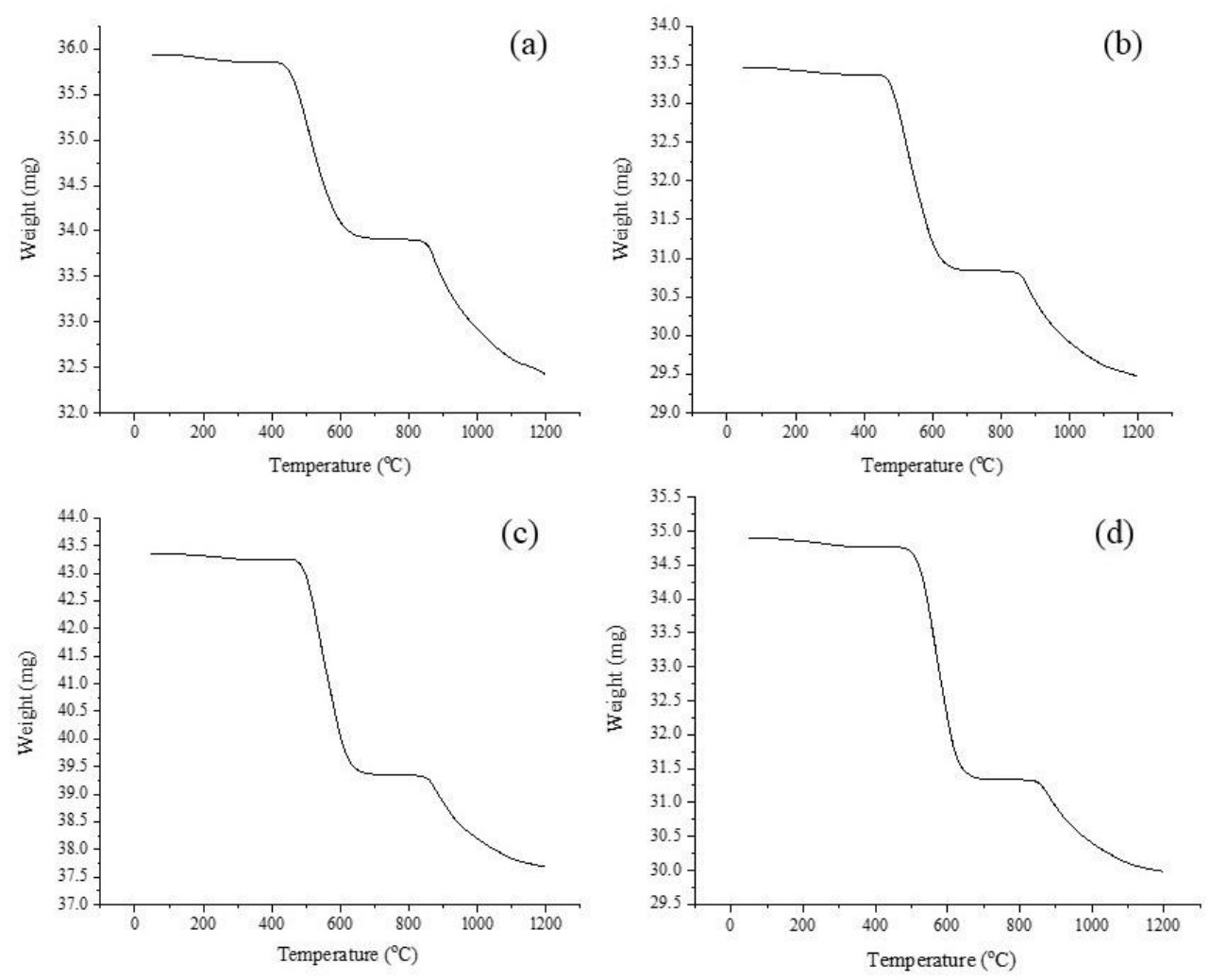

Figure 4.2: TGA result of the spent catalyst samples: (a): $725^{\circ} \mathrm{C}$; (b): $750^{\circ} \mathrm{C} ;(\mathrm{c}): 7^{\circ} 5^{\circ} \mathrm{C}$; (d): $800^{\circ} \mathrm{C}$ (only the step 6 in the Figure F.1. is shown here; the weight at the end of step 7 and the detailed reading can be found in Appendix $F$

The distribution of coke type for the spent samples for one of the experimental runs is shown in Table 4.1. Here, peak 1, 2 and 3 represents heavy aromatics, graphite like coke on external surface, and polyaromatic coke in the ZSM-5 channel, respectively. Weight loss percentage is out of the total weight loss. Weight loss of peak 3 is calculated by the weight at the end of peak 2 minus the weight at the end of step 7, as shown in the Appendix F. 
Table 4.1: Numerical summary of the TGA result of the spent samples from different reaction temperatures $\left(\mathrm{a}: 7^{\circ} \mathrm{C} ; \mathrm{b}: 7^{\circ} 0^{\circ} \mathrm{C} ; \mathrm{c}: 7^{\circ} 5^{\circ} \mathrm{C} ; \mathrm{d}: 800^{\circ} \mathrm{C}\right)$

\begin{tabular}{cccccccc}
\hline Samples & Peak 1 & Peak 2 & Peak 3 & Peak 1 & Peak 2 & Peak 3 & Coke wt \% \\
\hline \multicolumn{7}{c}{ Temperature $\left({ }^{\circ} \mathbf{C}\right)$} & \multicolumn{7}{c}{ Weight Loss (\%) } \\
b & 220 & 523 & 895 & 2.27 & 51.94 & 45.79 & $11.34 \%$ \\
c & 220 & 540 & 896 & 2.08 & 61.43 & 36.49 & $13.80 \%$ \\
d & 220 & 550 & 898 & 1.65 & 67.05 & 31.30 & $14.82 \%$ \\
\hline \multirow{2}{*}{ Coke wt $\%$} & 230 & 572 & 901 & 2.68 & 67.93 & 29.39 & $16.42 \%$ \\
\hline
\end{tabular}

\subsection{Dynamic Parameter Estimation}

The reactions considered in these studies, their corresponding rate models, consideration of the empirical equation for catalyst activity, experimental data reconciliation, and the approach for the dynamic parameter estimation will be discussed. MATLAB, Microsoft Excel, and Aspen Custom Modeler (ACM) V9.0 is used in this study.

\subsubsection{Methane DHA Reaction Rate Model}

There is lack of consensus on reaction pathways for non-oxidative methane DHA reactions $[148,155,159,169]$. The most common pathway that has been agreed upon starts with a short induction period in which $\mathrm{MoO}_{3}$ is converted into $\mathrm{Mo}_{2} \mathrm{C}$, making the catalyst active for methane DHA reaction. The $\mathrm{C}-\mathrm{H}$ bond in methane molecules gets activated by $\mathrm{Mo}_{2} \mathrm{C}$, producing $\mathrm{CH}_{\mathrm{x}} *$ and $\mathrm{H}^{*}$ species. The $\mathrm{CH}_{\mathrm{x}}{ }^{*}$ species can further dehydrogenate $\mathrm{CH}^{*}, \mathrm{C}^{*}$, and react with each other to form $\mathrm{C}_{2}$ species such as ethane, ethylene, acetylene. The $\mathrm{C}_{2} \mathrm{~S}$ can further undergo oligomerization reaction on the HZSM-5 sites to form aromatics. Each of these steps have the potential for coke formation, and usually two types of coke can form i.e. graphite-like $\mathrm{C}$ and aromatic-type coke [148]. In this study, the reaction scheme is developed based on the analysis of the experimental data. Ethylene was consistently produced at all temperatures during the experiments. Acetylene production was not detected till $750^{\circ} \mathrm{C}$. Ethane production was not continuous in all experimental runs. R1, the ethylene dimerization reaction, is considered. Ethylene is then converted to benzene 
in R2. R3 represents the decomposition reaction of methane to carbon and hydrogen capturing catalyst deactivation over time.

$2 \mathrm{CH}_{4} \leftrightarrow \mathrm{C}_{2} \mathrm{H}_{4}+2 \mathrm{H}_{2}$

$3 \mathrm{C}_{2} \mathrm{H}_{4} \leftrightarrow \mathrm{C}_{6} \mathrm{H}_{6}+3 \mathrm{H}_{2}$

$\mathrm{CH}_{4} \leftrightarrow \mathrm{C}+2 \mathrm{H}_{2}$

The proposed rate model R1-R3 are given by Eq. 4.1-4.3, respectively. The rate equation includes a separable catalyst activity term to consider the effect of catalyst deactivation over time. The model for catalyst deactivation given by Eq. 4.3 is similar to that of Dumez and Froment [170], and Acharya and Hughes [171] where the authors investigated catalyst deactivation for dehydrogenation of butene- 1 .

$$
\begin{aligned}
& r_{1}=\exp \left(-\alpha \cdot C_{c}\right) \cdot A_{1} \cdot \exp ^{\left(-\frac{E_{1}}{R \cdot T}\right)}\left(f_{C H_{4}}^{2}-\frac{f_{C_{2} H_{4}} \cdot f_{H_{2}}^{2}}{K_{p 1}}\right) \\
& r_{2}=\exp \left(-\alpha \cdot C_{c}\right) \cdot A_{2} \cdot \exp ^{\left(-\frac{E_{2}}{R \cdot T}\right)}\left(f_{C_{2} H_{4}}^{3}-\frac{f_{C_{6} H_{6}} \cdot f_{H_{2}}^{3}}{K_{p 2}}\right) \\
& r_{3}=\frac{r_{c}}{\varphi_{C M} M_{C H 4}}=\frac{1}{\varphi_{C M} M_{C H 4}} \exp \left(-\alpha \cdot C_{c}\right) \cdot A_{3} \cdot \exp ^{\left(-\frac{E_{3}}{R \cdot T}\right)}\left(f_{C H_{4}}-\frac{f_{H_{2}}^{2}}{K_{p 3}}\right)
\end{aligned}
$$

In Eq. 4.1-4.3, $C_{c}$ denotes catalyst coke content $\left(\mathrm{kg}_{\text {coke }} / \mathrm{m}_{\text {cat-vol }}^{3}\right) ; \alpha$ is the catalyst activity parameter $\left(m_{\text {cat-vol }}^{3} / \mathrm{kg}_{\text {coke }}\right) ; A_{i}$ is the pre-exponential factor for reaction $i$ $\left(\frac{\mathrm{kmol}}{\mathrm{m}_{\text {cat-vol }}^{3} \mathrm{~s} \mathrm{bar}^{2}}\right.$ for $i=1, \frac{\mathrm{kmol}}{\mathrm{m}_{\text {cat-vol }}^{3} \mathrm{sbar}^{3}}$ for $i=2, \frac{\mathrm{kg}_{\text {coke }}}{\mathrm{m}_{\text {cat-vol }}^{3} \mathrm{sbar}}$ for $\left.i=3\right) ; E_{i}$ is the activation energy of reaction $i(\mathrm{~J} / \mathrm{mol}) ; R$ is the gas constant $(\mathrm{J} / \mathrm{mol} / \mathrm{K}) ; T$ is the reactor temperature $(K)$; $K_{p i}$ is the equilibrium constant (bar); $M_{C H 4}$ is the molecular weight of methane $\left((\mathrm{kg} / \mathrm{kmol}) ; \varphi_{C M}\right.$ is the coke yield from methane $\left(\mathrm{kg}_{\text {coke }} / \mathrm{kg}_{\mathrm{CH} 4}\right) ; r_{i}$ is the reaction rate $\left(\mathrm{kmol} / \mathrm{m}_{\text {cat-vol }}^{3} / \mathrm{s}\right) ; r_{c}$ is the coke formation rate $\left(\mathrm{kg}_{\text {coke }} / \mathrm{m}_{\text {cat-vol }}^{3} / \mathrm{s}\right) ; f_{i}$ is the fugacity of component $i$ (bar).

The equilibrium constant in Eq. 4.1-4.3 is calculated using van't Hoff's equation [172], given by Eq. 4.4 as follows:

$R T \ln K=-\Delta G$

$K=K_{f} \cdot K_{p}$ 
where $\Delta G$ is the Gibbs free energy of the reaction $(J / m o l)$. In Eq. $4.5, K_{f}$ and $K_{p}$ are the equilibrium constants calculated using fugacity coefficient and partial pressure of the components. The reaction system considered here operates around atmospheric pressure. Under the given operating pressure and temperature, the deviation from ideality is negligible, thus: $K_{f} \approx 1$. Therefore, $K=K_{p}$.

\subsubsection{Data Reconciliation}

Both systematic and random measurement errors do occur in the experimental data thus mass balances may not be satisfied. In addition, for this system, the coke that gets formed remains within the reactor, and real time measurement of coke cannot be performed. Moreover, the GC measurements does not necessarily satisfy carbon and hydrogen balances at every time instant. To satisfy material balances including carbon and hydrogen atomic balances at every time instant, data reconciliation is performed by solving the following optimization problem:

$\min \sum_{i} \sum_{j} \sum_{m} W_{i j} \cdot\left(F_{\text {model }, \text { out }, i, j, m}-F_{\text {exp }, i, j, m}\right)^{2}$

s.t. $F_{i, j, m} \geq 0$

$M\left(F_{i, j, m}, \eta_{i, j, m, k}\right)=0$

Here index $i$ represents each data set where time series data were collected by maintaining the reactor at a specific temperature, index $j$ represents the gaseous species, index $m$ represents each discrete time instant at which measurement are available. $F_{\text {model }}$ and $F_{\text {exp }}$ denote the reconciled and experimental component molar flowrate, respectively, at the reactor outlet and $W$ denotes the weights. $M\left(F_{i, j, m}, \eta_{i, j, m, k}\right)$ denotes the equality constraints where $\eta_{i, j, m, k}$ denotes the reaction rate of the $k^{\text {th }}$ reaction, that are considered as decision variables. Gas phase dynamics for the lab scale small reactor is very fast and can be neglected. Therefore, equality constraints that includes the following mass/atom balance equations can be written as:

$$
\begin{aligned}
& F_{\text {model, }, i n, i, j, m}-F_{\text {model }, \text { out }, i, j, m}+/-\sum \vartheta_{j, k} \eta_{i, j, m, k}=0 \\
& \sum F_{\text {model }, i n, i, j, m} N_{c, j}-\sum F_{\text {model }, \text { out }, i, j, m} N_{c, j}-\eta_{i, j, m, 3} N_{c, \text { coke }}=0 \\
& \sum F_{\text {model }, i n, i, j, m} N_{H, j}-\sum F_{\text {model }, \text { out }, i, j, m} N_{H, j}=0
\end{aligned}
$$


Here, $\vartheta_{k}$ is the stoichiometric coefficient; $N_{c}$ and $N_{H}$ denote the carbon and hydrogen atom number for the species $j$. Different initial guesses are evaluated, and the results are similar for all the cases that converged. The experimental and the reconciled data for $775^{\circ} \mathrm{C}$ is shown in Fig. 4.3. Data reconciliation for two additional temperatures is shown in Appendix G. The reconciled data is then used for estimating the kinetic parameters. This optimization problem is solved using the "fmincon" subroutine in MATLAB using a sequential quadratic programming algorithm.
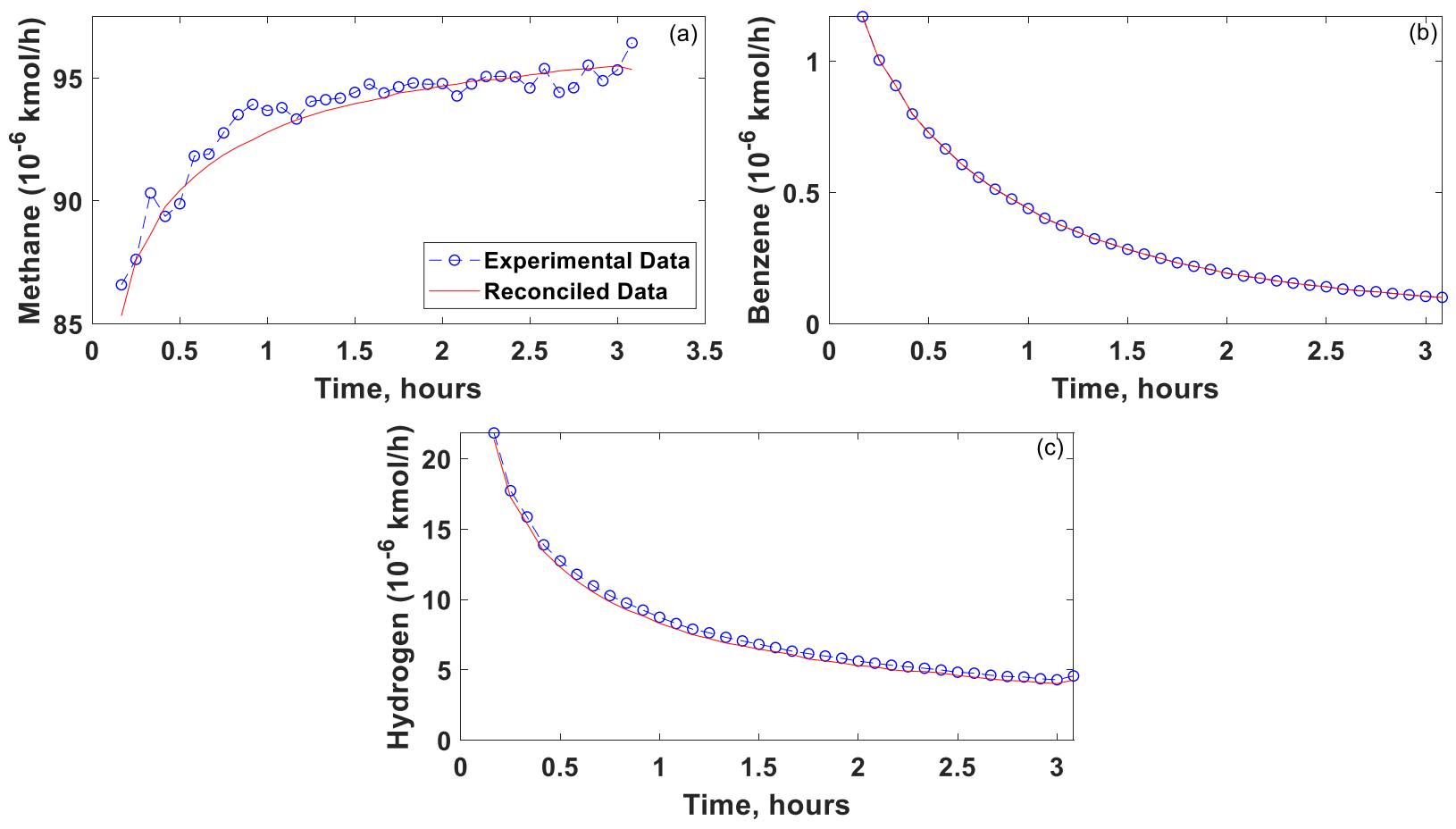

Figure 4.3: Comparison of experimental and reconciled data for $775^{\circ} \mathrm{C}$. (a) methane; (b) benzene; (c) hydrogen

\subsubsection{Model Development for the Laboratory Reactor and Parameter Estimation}

For parameter estimation, a one-dimensional homogenous fixed bed reactor model of the laboratory-scale reactor is developed in ACM. The time dependent PDEs are solved using method of lines by discretizing in space but keeping the time continuous. Backward finite difference is used for discretizing in space while implicit Euler method with variable step length is used for integration. The physical properties of the gas phase are calculated using property calls in ACM, based on the state variables and composition. Soave-Redlich-Kwong (SRK) equation of state (EOS) in Aspen Properties is used as the thermodynamic model. The following assumptions are made for model development. 
- Pressure drop is negligible because the length of the reactor is very small.

- Uniform velocity is assumed because the reactor diameter is small and the reactor-to-particle ratio is more than 10 [173].

- Mass transfer resistances is negligible because the catalyst is in powdered form.

- Reactor is maintained at isothermal conditions.

- Radial variation is not considered because the reactor diameter is small.

The conservation equation for gaseous species is given by Eq. 4.10:

$u_{s} \frac{\partial\left(C_{g a s, i}\right)}{\partial z}-\left(1-\varepsilon_{l a b}\right) \cdot \sum r_{j}=0$

with the following boundary condition: $C_{g a s, i}(z=0)=C_{g a s, i, i n l e t}$.

In addition, Eq. 4.11 is considered:

$\sum y_{g a s, i}=1$

Catalyst deactivation rate is given by Eq. 4.12:

$\frac{d C_{c}}{d t}=r_{c}$

In Eq. 4.10-4.12, $C_{g a s, i}$ is the concentration of gas species $i\left(\mathrm{kmol} / \mathrm{m}^{3}\right) ; y_{g a s, i}$ is the mole fraction of species $i ; u_{s}$ is the gas superficial velocity $(\mathrm{m} / \mathrm{s}) ; \varepsilon_{\text {lab }}=0.4$ is the lab reactor bed voidage. In addition to dynamic parameter estimation, the unknown initial state of the reactor must also be estimated. Due to the very fast coke formation rate on the fresh catalyst, there is coke formation immediately upon introduction of the feed before measurement data can be collected. The amount is unknown and needs to be estimated for capturing the initial state of the reactor. An iterative direct substitution algorithm is developed as shown in Fig. 4.4 to estimate the coke concentration at the end of the induction period, i.e. the initial condition $\left(t=t_{\text {ini }}\right)$ for Eq. 4.12. The algorithm starts with a guess for the coke concentration at the initial condition (i.e. $t=t_{\text {ini }}$ ). For the first iteration, i.e. at $i=1, C_{c}=0$ at $t=t_{\text {ini }}$ for all four temperatures. After parameters are estimated, the estimated parameters and the partial pressure of methane and hydrogen from the experimental data during induction period, i.e., $t<t_{\text {ini }}$ are used in Eq. 4.3 to calculate the coke concentration at the end of the induction period. If the absolute difference between the guess for the coke concentration and the calculated coke concentration is above the tolerance, then the calculated 
concentration is considered as the new guess for the initial coke concentration at the next iteration. It should be noted that the initial estimate of the coke concentration is critical to avoid resulting bias in the estimate of the catalyst deactivation parameter.

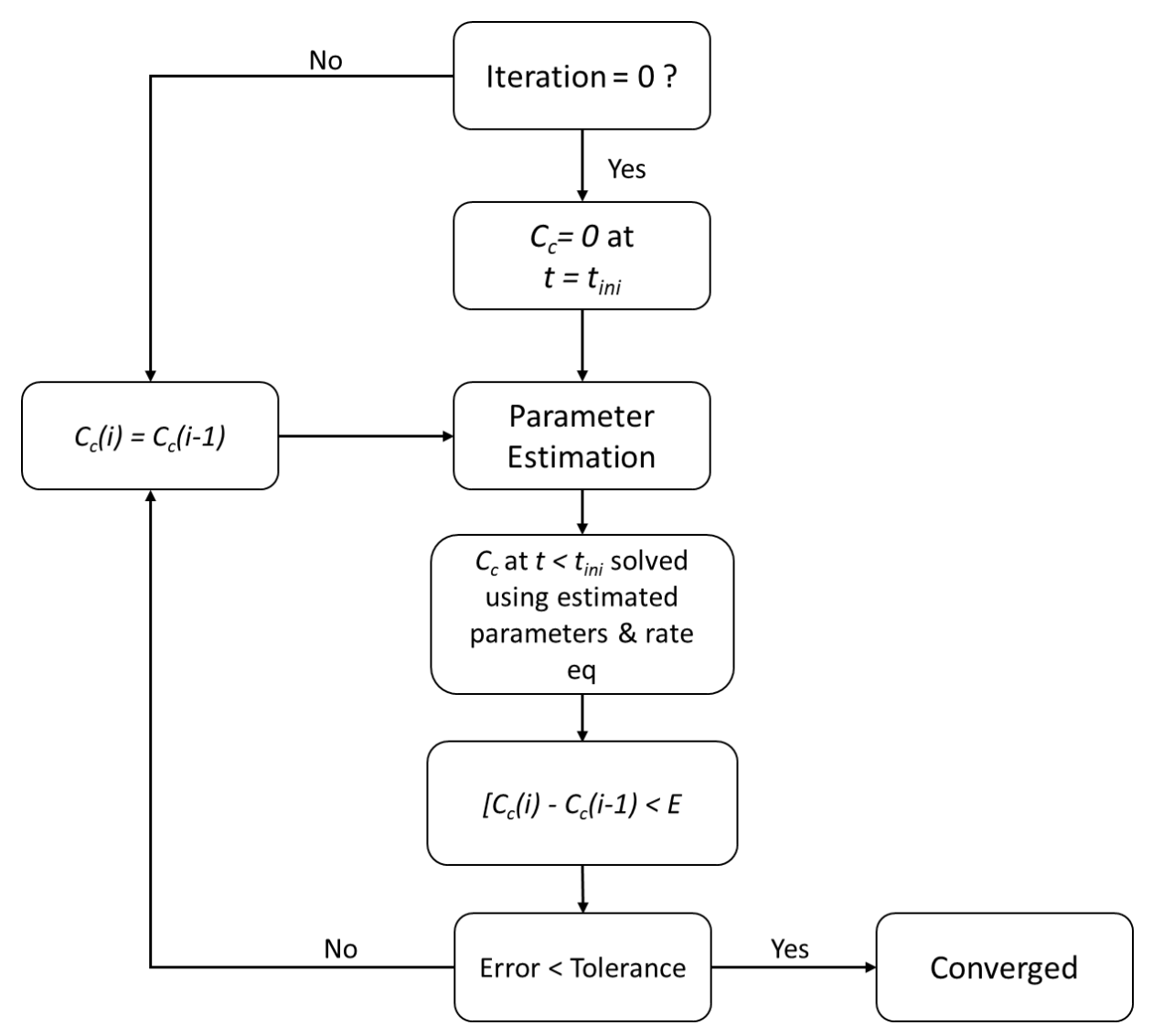

Figure 4.4: Algorithm to predict initial coke concentration for dynamic parameter estimation

The reconciled data for all temperatures is normalized and used in parameter estimation. Maximum log likelihood objective function is used for dynamic parameter estimation, given as follows:

$$
\begin{array}{r}
\max _{\theta, \gamma}\left\{-\frac{1}{2} \sum_{i=1}^{N M e a s}\left(n_{i}(\log 2 \pi+1)+n_{i} \log \left[\frac{1}{n_{i}} \sum_{j=1}^{N D y n} \sum_{k=1}^{M i j} w_{j}^{2} \frac{\left(\hat{z}\left(t_{i j k}\right)-z\left(t_{i j k}\right)\right)^{2}}{z_{i j k}^{\gamma i}}\right]+\right.\right. \\
\left.\left.\gamma_{i} \sum_{j=1}^{N D y n} \sum_{k=1}^{M i j} \log w_{j} z\left(t_{i j k}\right)\right)\right\}
\end{array}
$$

s.t. $f\left(x_{i}\right)=0$

$\theta^{L} \leq \theta \leq \theta^{U}$ 
where $\gamma_{i}$ is the heteroscedasticity parameter for measured variable $z(j) ; w_{j}$ is the weight for experiment $j ; n_{i}$ is the total number of measurements for variable $i$ over all the experiments; $\theta$ denote parameters to be estimated; NDyn is the total number of dynamic experiments; $\hat{z}\left(t_{i j k}\right)$ is the $k^{t h}$ measurement of variable $z(j)$ in experiment $i$ at time $t_{i j k} ; M_{i j}$ is the number of measurements of variable $j$ in experiment $i$; NMeas is the number of unique variables $z(j)$ measured over all experiments; $f\left(x_{i}\right)$ are the mass balance equality constraints (Eqs. 4.10-4.12).

A total of 7 kinetic parameters i.e. the pre-exponential factor $\left(A_{i}\right)$ and activation energy $\left(E_{i}\right)$ for the 3 reactions, and the catalyst activity parameter $(\alpha)$ is estimated. A direct search based Nelder-Mead solver is used to perform the estimation in ACM. This solver is based on the simplex algorithm with a penalty function implementation to ensure that the solutions lies within the bounds. Comparison of the model results with the experimental data, for $725^{\circ} \mathrm{C}, 750^{\circ} \mathrm{C}, 775^{\circ} \mathrm{C}$ temperature, is shown in Fig. 4.5. The comparison for $800^{\circ} \mathrm{C}$ is shown in Appendix H. In this study, two experiments were conducted for each temperature. The standard deviation calculated using the two sets of experimental data is also denoted in Fig. 4.5.
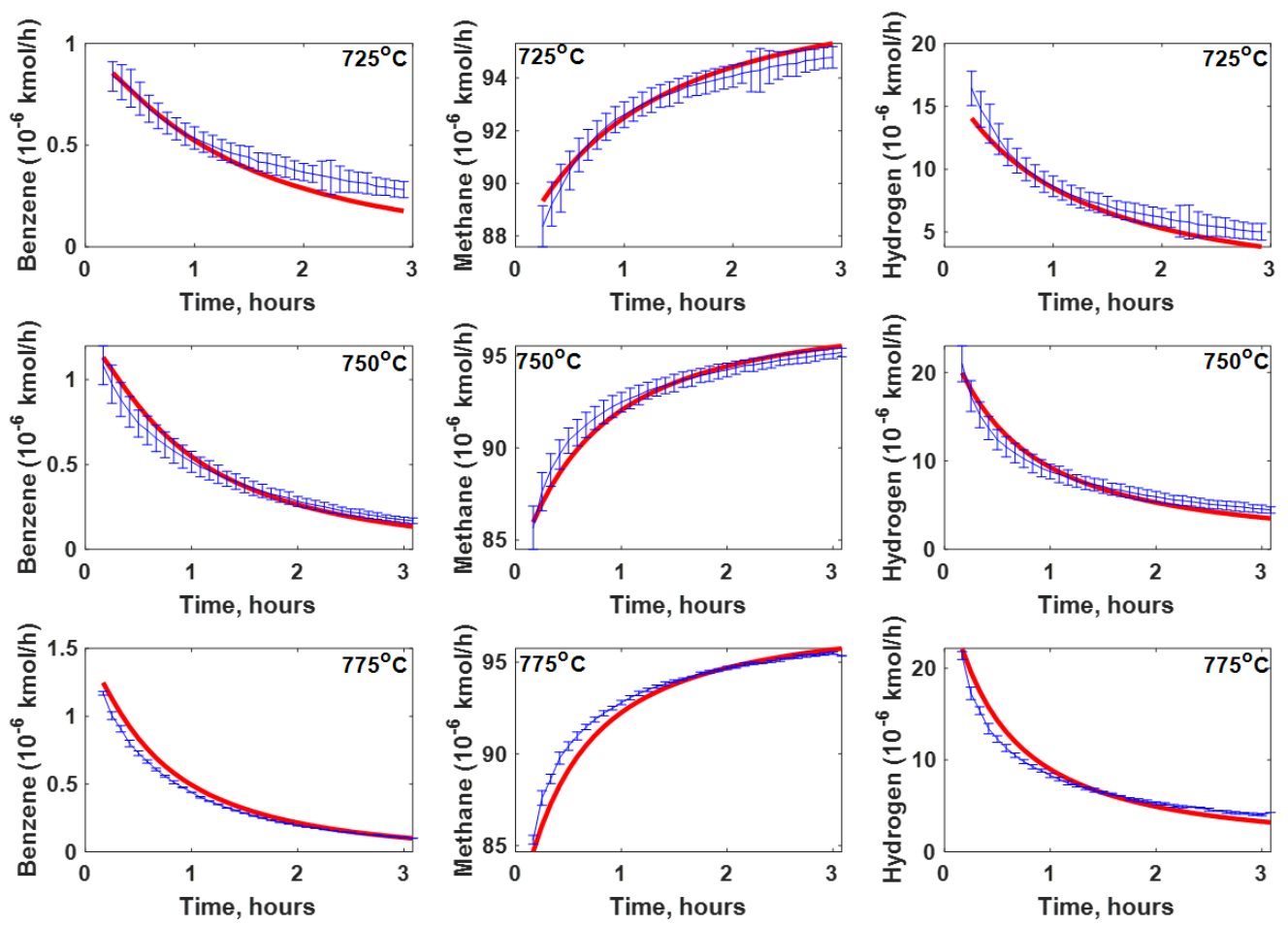

Figure 4.5: Comparison of model prediction with experimental data for three temperatures at 1 atmosphere. Model Prediction: Red line; Experimental Data: Blue line also includes standard deviation in the data 
The estimated values of the parameters are shown in Table 4.2. The activation energies estimated here are in the range to those reported by other researcher for similar reactions $[156,158,160]$.

Table 4.2: Estimated values of the kinetic rate parameters and catalyst activity

\begin{tabular}{ccc}
\hline Parameter & Value & Units \\
\hline$A_{1}$ & 9.95 & $\mathrm{kmol} / \mathrm{m}_{\text {cat-vol }}^{3} \mathrm{~s} \mathrm{bar}^{2}$ \\
$A_{2}$ & $3.79 \cdot 10^{6}$ & $\mathrm{kmol} / \mathrm{m}_{\text {cat }- \text { vol }}^{3} \mathrm{~s} \mathrm{bar}{ }^{3}$ \\
$A_{3}$ & $2.23 \cdot 10^{4}$ & $\mathrm{~kg}_{\text {coke }} / \mathrm{m}_{\text {cat } \text { vol }}^{3} \mathrm{~s} \mathrm{bar}$ \\
$E_{1}$ & 51.1 & $\mathrm{~kJ} / \mathrm{mol}$ \\
$E_{2}$ & 30.04 & $\mathrm{~kJ} / \mathrm{mol}$ \\
$E_{3}$ & 104.1 & $\mathrm{~kJ} / \mathrm{mol}$ \\
$\alpha$ & $3.001 \cdot 10^{-2}$ & $\mathrm{~m}_{\text {cat }-\mathrm{vol} / \mathrm{kg} g_{\text {coke }}}$
\end{tabular}

To compare the coke deposited on the catalyst with the experimental TGA results, cumulative amount of coke is calculated using the dynamic model with estimated kinetic parameters. Table 4.3 shows that the model results agree well with the experimental data.

Table 4.3: Comparison of model coke prediction with experiment

\section{Coke weight $\%$}

\begin{tabular}{ccc} 
Temperature $\left({ }^{\circ} \mathbf{C}\right)$ & Experiment & Model \\
\hline 725 & $11.34 \% \pm 0.389 \%$ & $13.69 \%$ \\
750 & $13.80 \% \pm 0.410 \%$ & $15.16 \%$ \\
775 & $14.82 \% \pm 0.622 \%$ & $16.58 \%$ \\
800 & $16.42 \% \pm 0.460 \%$ & $17.95 \%$
\end{tabular}




\subsection{Fixed Bed Reactor Model Development}

In this section, the development of heterogeneous fixed bed reactor model is presented. The overall reaction system is highly endothermic, so it is desired to provide external heat to the reactor to achieve higher single pass conversion. A multi-tubular fixed bed reactor with triangular pitch arrangement is considered where the hot utility flows in the tubes while the shell side is packed with catalyst through which the gas flows. The model is multi-scale coupling both the catalyst pellet level and bulk reactor level model. Radial variation of transport variables is considered within the catalyst pellet, while variation in axial direction only is considered at the reactor scale. Similar to before, the PDEs are solved by method of lines. Backward finite difference is used for all $1^{\text {st }}$ order differential equations, and central finite difference method is used for $2^{\text {nd }}$ order differential equation, for discretizing in space.

\subsubsection{Gas Phase Species Balance}

The dynamic bulk gas phase species balance is given by Eq. 4.14:

$\varepsilon_{b} \cdot \frac{\partial C_{g a s, i}}{\partial t}=-\varepsilon_{b} \frac{\partial\left(C_{g a s, i} \cdot u_{g a s}\right)}{\partial z}+k_{g a s, i} \cdot \frac{6\left(1-\varepsilon_{b}\right)}{d_{p}}\left(C_{c a t, s u r, i}-C_{g a s, i}\right)$

where $i$ denotes the gas species $\mathrm{CH}_{4}, \mathrm{C}_{2} \mathrm{H}_{4}, \mathrm{C}_{6} \mathrm{H}_{6}, \mathrm{H}_{2}, \mathrm{~N}_{2}$.

The equation for coke produced over time is as follows:

$\frac{d C_{c}}{d t}=r_{c}$

The overall species conservation equation is also written (Eq. 4.16).

$\varepsilon_{b} \cdot \frac{\partial \rho_{g a s}}{\partial t}=-\varepsilon_{b} \frac{\partial\left(\rho_{\text {gas }} \cdot u_{\text {gas }}\right)}{\partial z}+\frac{6\left(1-\varepsilon_{b}\right)}{d_{p}} \sum k_{g a s, i} \cdot\left(C_{c a t, s u r, i}-C_{g a s, i}\right)$

Where $\rho_{\text {gas }}$ is the bulk gas density $\left(\mathrm{kmol} / \mathrm{m}^{3}\right) ; C_{c a t, s u r, i}$ is the gas concentration on the catalyst surface $\left(\mathrm{kmol} / \mathrm{m}^{3}\right) ; d_{p}$ is diameter of the catalyst pellet $(\mathrm{m}) ; \varepsilon_{b}$ is the bed voidage; $k_{g a s, i}$ is the gas mass transfer coefficient $(\mathrm{m} / \mathrm{s})$. The boundary condition at the reactor inlet $($ at $\mathrm{z}=0)$ is given as $C_{g a s, i}(z=0)=C_{g a s, i, i n l e t}, u_{g a s, i}(z=0)=u_{g a s, i, i n l e t}, \rho_{\text {gas }, i}(z=0)=\rho_{\text {gas }, i, i n l e t}$.

The summation equation given by Eq. 4.11 is also included. The inlet gas interstitial velocity is calculated using Eq. 4.17 as follows: 
$u_{\text {gas,inlet }}=\frac{F_{\text {gas,inlet }}}{\rho_{\text {gas,inlet }} \cdot A_{\text {bed }} \cdot \varepsilon_{b}}$

where $F_{\text {gas,inlet }}$ is the inlet gas molar flowrate $\left(\frac{\mathrm{kmol}}{\mathrm{s}}\right)$ and $A_{\text {bed }}$ is the catalyst bed area $\left(\mathrm{m}^{2}\right)$.

\subsubsection{Pressure Drop}

The Ergun equation is used to calculate the pressure drop inside the reactor [174].

$\frac{d P}{d z}=-\frac{150 \cdot \mu_{g a s}}{d_{p}} \cdot \frac{\left(1-\varepsilon_{b}\right)^{2}}{\varepsilon_{b}{ }^{3}} \cdot\left(\varepsilon_{b} \cdot u_{g a s}\right)+\frac{1.75 \cdot \rho_{\text {gas }}}{d_{p}} \cdot \frac{\left(1-\varepsilon_{b}\right)}{\varepsilon_{b}{ }^{3}} \cdot\left(\varepsilon_{b} \cdot u_{g a s}\right)^{2} \cdot M_{g a s}$

where $M_{g a s}$ is the molecular weight of the gas $(\mathrm{kg} / \mathrm{kmol}) ; P$ is the reactor pressure (bar). The boundary condition is as follows: $P(z=0)=P_{\text {inlet }}$.

\subsubsection{Gas Phase and Tube Wall Energy Balance}

The bulk gas phase energy balance is written as [175],

$$
\begin{array}{r}
\varepsilon_{b} \cdot \rho_{\text {gas }} \cdot \frac{\partial H_{\text {gas }}}{\partial t}=-\varepsilon_{b} \cdot \frac{\partial\left(H_{\text {gas }} \cdot \rho_{\text {gas }} \cdot u_{\text {gas }}\right)}{\partial z}+h_{g c} \cdot \frac{6\left(1-\varepsilon_{b}\right)}{d_{p}} \cdot\left(T_{\text {cat }, \text { surf }}-T_{\text {gas }}\right) \\
+\frac{6\left(1-\varepsilon_{b}\right)}{d_{p}} \sum H_{\text {gas }} \cdot k_{\text {gas }, i} \cdot\left(C_{\text {cat }, i}-C_{\text {gas }, i}\right)+\frac{4}{d_{\text {tube }}} \cdot h_{\text {wall }} \cdot\left(T_{\text {wall }}-T_{\text {gas }}\right)
\end{array}
$$

The tube wall energy balance is written as follows,

$$
\begin{array}{r}
\rho_{\text {tube }} \cdot C_{p, t u b e} \cdot \frac{\partial T_{\text {wall }}}{\partial t}=\lambda_{\text {tube }} \cdot \frac{\partial^{2} T_{\text {wall }}}{\partial z^{2}}-\frac{4}{d_{t, \text { out }}} \cdot h_{\text {wall }} \cdot\left(T_{\text {wall }}-T_{\text {gas }}\right)+. . \\
. .+\frac{4}{d_{t, \text { in }}} \cdot h_{h t f} \cdot\left(T_{h t f}-T_{\text {wall }}\right)
\end{array}
$$

and the corresponding boundary conditions are as follows:

$T_{\text {wall,inlet }}=T_{\text {gas,inlet }}$

$\frac{\partial T_{w a l l}(z=L)}{\partial \mathrm{z}}=0$

where $H_{g a s}$ is the gas enthalpy $(J / m o l) ; h_{g c}$ is the gas heat transfer coefficient $\left(W / m^{2} / K\right) ; h_{\text {wall }}$ is the tube wall heat transfer coefficient $\left(W / \mathrm{m}^{2} / K\right) ; h_{h t f}$ is the heat transfer coefficient of the heat transfer fluid $\left(\mathrm{W} / \mathrm{m}^{2} / \mathrm{K}\right)[176] ; T_{\text {wall }}$ is the tube wall temperature; $T_{\text {gas }}$ is the bulk gas 
temperature; $T_{h t f}$ is the temperature of heat transfer fluid; $d_{t, i n}$ and $d_{t, o u t}$ is inner and outer tube diameter $(m)$. The boundary condition at reactor inlet is $H_{\text {gas }}(z=0)=H_{\text {gas,inlet }}$. The heat transfer fluid considered here is a molten salt with a constant temperature.

\subsubsection{Catalyst Phase - Gas Species Balance}

Variation of gas concentration in the radial direction inside the porous catalyst particle is considered. Inside the catalyst particle, the dominating mass transport mechanism is diffusion, while the convection term is assumed to be negligible due to small pore radius and negligible pressure difference. The dynamic gas species mass balance inside the spherical catalyst particle is given by:

$\emptyset \cdot \frac{\partial C_{c a t, i}}{\partial t}=\frac{\emptyset}{r^{2}} \cdot \frac{\partial}{\partial r}\left(D_{e f f, i} \cdot r^{2} \cdot \frac{\partial C_{c a t, i}}{\partial r}\right)+\sum r_{j}$

At the catalyst surface,

$-D_{e f f, i} \cdot \frac{\partial C_{c a t, i}\left(z, r=r_{p}\right)}{\partial r}=k_{g a s, i} \cdot\left(C_{c a t, i}\left(z, r=r_{p}\right)-C_{g a s, i}(z)\right)$

At the catalyst center,

$\frac{\partial C_{c a t, i}(z, r=0)}{\partial r}=0$

Here, $D_{e f f, i}$ is the effective diffusivity of gas in the catalyst $\left(\mathrm{m}^{2} / \mathrm{s}\right)$. It considers both molecular and Knudsen diffusivity; $\emptyset$ is the catalyst porosity.

\subsubsection{Catalyst Phase Energy Balance}

The temperature variation within the catalyst in radial direction in spherical coordinates is given as follows [175]:

$$
\begin{array}{r}
\left((1-\emptyset) \cdot \rho_{c a t} \cdot C_{p, c a t}+\emptyset \cdot \sum C_{p, c a t, g a s, i} \cdot C_{c a t, i}\right) \cdot \frac{\partial T_{c a t}}{\partial t}=\frac{\lambda_{c a t}}{r^{2}} \cdot \frac{\partial}{\partial r}\left(r^{2} \cdot \frac{\partial T_{c a t}}{\partial r}\right)+. . \\
. .+\emptyset \cdot\left(D_{e f f, i} \cdot \frac{\partial C_{c a t, i}}{\partial r} \cdot C_{p, c a t, g a s, i} \cdot \frac{\partial T_{c a t}}{\partial r}\right)+(1-\emptyset) \cdot \sum \Delta H_{r e a c, j} \cdot r_{j}
\end{array}
$$

Boundary condition:

$\frac{\partial T_{c a t}}{\partial r}(z, r=0)=0$ 


$$
\begin{aligned}
-\lambda_{c a t} \cdot \frac{\partial T_{c a t}\left(z, r=r_{p}\right)}{\partial r}-\sum H_{i} \cdot D_{e f f, i} \cdot \frac{\partial C_{c a t, i}\left(z, r=r_{p}\right)}{\partial r} \\
\quad=h_{g c} \cdot\left(T_{c a t}\left(z, r=r_{p}\right)-T_{g}\right)+\sum H_{g a s} \cdot k_{g a s, i} \cdot\left(C_{c a t, i}-C_{g a s, i}\right)
\end{aligned}
$$

where $\lambda_{\text {cat }}$ is the thermal conductivity of the catalyst; $\Delta H_{r e a c, j}$ is the heat of reaction of reaction $j ; \rho_{c a t}$ is particle density $\left(\mathrm{kg} / \mathrm{m}^{3}\right) ; C_{p, c a t}$ is the heat capacity of the solid catalyst $(\mathrm{J} / \mathrm{mol} / \mathrm{K})$; $C_{p, c a t, g a s, i}$ is the heat capacity of species $i$ in catalyst phase $(J / m o l / K)$. Initially, it is assumed that the temperature of the catalyst is same as the gas temperature.

\subsubsection{Mass \& Heat Transfer Coefficient, and Effective Diffusivity}

The mass transfer coefficient $\left(k_{g a s, i}\right)$ and the bulk gas heat transfer coefficient $\left(h_{g c}\right)$ are calculated using the correlations given by Mobed et al. [174], Barton and Adams II [175]. Like before, the physical properties of the gas used in these equations is calculated using SRK EOS in ACM. The effective diffusivity $\left(D_{e f f, i}\right)$ of gas in catalyst phase is calculated using the following equation:

$\frac{1}{D_{e f f, i}}=\frac{1}{D_{k n u d, e f f, i}}+\frac{1}{D_{m i x, e f f, i}}$

The effective Knudsen diffusivity $\left(D_{k n u d, e f f, i}\right)$ is calculated using the correlation given by Satterfield [177] as follows: The gas constant $(R)$ is added to this equation to make the units consistent.

$D_{i, k n u d, e f f}=19,400 \cdot \frac{\emptyset^{2}}{\tau \cdot S_{g} \cdot \rho_{p}} \sqrt{\frac{T_{c a t} \cdot R}{M_{g a s, i}}}$

The effective molecular diffusivity $\left(D_{m i x, e f f, i}\right)$ is calculated using the following equation:

$D_{m i x, e f f, i}=\frac{D_{m i x, i} \cdot \emptyset}{\tau}$

where $S_{g}$ is the specific area of the catalyst pellet $\left(\mathrm{m}^{2} / g\right) ; \tau$ is the tortuosity of the catalyst; $\rho_{p}$ is the particle density; $M_{i}$ is the molecular weight of the gas species $i(\mathrm{~kg} / \mathrm{kmol})$.

\subsubsection{Tube Wall Heat Transfer Coefficient}

The heat transfer coefficient of the tube wall is calculated based on the theory of small cylinders immersed in fluids, given by Penny et al. [178]. 
$h_{\text {wall }}=\frac{\lambda_{\text {eff }}}{d_{\text {tube }}} \cdot\left(0.333+0.26 \cdot \operatorname{Re}^{0.533}\right) \cdot \operatorname{Pr}^{0.333} \cdot\left(\frac{d_{\text {tube }}}{d_{p}}\right)^{0.1}$

where $R e$ and $P r$ are Reynolds and Prandtl number, respectively.

$R e=\frac{d_{p} \cdot \varepsilon_{b} \cdot u_{g a s} \cdot \rho_{g a s}}{\mu_{g a s}}$

$\operatorname{Pr}=\frac{C_{p, g a s} \cdot \mu_{g a s}}{\lambda_{g a s}}$

where $\mu_{\text {gas }}$ is the dynamic viscosity of the gas $(c P) ; \lambda_{g a s}$ is the thermal conductivity of the gas. The effective thermal conductivity $\lambda_{\text {eff }}$ of the fluid-solid phase is calculated using the equation given by Penny et al. [178], as follows:

$\lambda_{e f f}=\lambda_{g a s}\left\{1-\sqrt{\left(1-\varepsilon_{b}\right)}+\frac{2 \cdot \sqrt{\left(1-\varepsilon_{b}\right)}}{1-\omega B} \cdot\left[\frac{(1-\omega) B}{(1-\omega B)^{2}} \cdot \ln \left(\frac{1}{\omega B}\right)-\frac{B+1}{2}-\frac{B-1}{1-\omega B}\right]\right\}$

$B=1.25 \cdot\left[\frac{1-\varepsilon_{b}}{\varepsilon_{b}}\right]^{10 / 9}$

$\omega=\frac{\lambda_{\text {gas }}}{\lambda_{\text {cat }}}$

\subsubsection{Bed Voidage and Number of Tubes}

Bed voidage is calculated using the correlation given by Mobed et al. [174], Barton and Adams [175], as follows:

$\varepsilon_{b}=0.38+0.073 \cdot\left(1-\frac{\left(\frac{d_{r e c}}{d_{p}}-2\right)^{2}}{\left(\frac{d_{r e c}}{d_{p}}\right)^{2}}\right)$

A triangular pitch layout is assumed for tubes inside the reactor, and the following equation is used to calculate the number of tubes:

$N t=\frac{\pi}{4} \cdot \frac{C T P}{C L} \cdot \frac{d_{r e c}^{2}}{P t^{2}}$ 
$P t=P r \cdot d_{\text {tube }}$

The bed area is calculated using the following equation:

$A_{\text {bed }}=A_{\text {rec }}-\left(\frac{\pi}{4} \cdot d_{\text {tube }}^{2} \cdot N t\right)$

Here, $d_{\text {rec }}$ is the reactor diameter $(m)$; $C T P$ is the tube count constant; $C L$ is the tube layout constant; $P t$ is the tube pitch; $P r$ is the tube pitch ratio; $A_{b e d}$ is the area of the catalyst bed; $A_{\text {rec }}$ is the reactor area. All the properties of the gas mixture and individual gas component is calculated using Aspen Plus property package, unless specified. The thermal conductivity of the catalyst is assumed to be that of the HZSM-5 support taken from literature [179], and the thermal conductivity of gas is assumed to be negligible compared to the catalyst. The values of the key parameters are shown in Table 4.4.

Table 4.4: Values of some key parameters used for simulation

\begin{tabular}{cc}
\hline Parameter & Value \\
\hline Specific area of the catalyst pellet, $S_{g}$ & $209.93 \mathrm{~m}^{2} / \mathrm{g}$ \\
Catalyst porosity, $\varnothing$ & 0.35 \\
Tortuosity, $\tau$ & 0.5 \\
Tube count constant, CTP & 0.93 \\
Tube layout constant, CL & 0.866 \\
Tube pitch ratio, Pr & 1.25 \\
Outer tube diameter, $d_{t, o u t}$ & $0.0254 \mathrm{~m}$ \\
Inner tube diameter, $d_{t, \text { in }}$ & $0.02 \mathrm{~m}$ \\
Catalyst pellet diameter, $d_{p}$ & $4.8 \mathrm{~mm}$ \\
Catalyst bulk density & $800 \mathrm{~kg} / \mathrm{m}^{3}$ \\
\hline
\end{tabular}

\subsection{Results and Discussions}

Sensitivity studies, for the heterogenous fixed bed reactor model, with respect to key process variables is performed to study their impact on catalyst deactivation rate, reactant conversion, and product yield. Before performing dynamic simulation studies, a snapshot is created by setting $C_{c}=$ 0 which is used to initialize the reactor. It should be noted that since this analysis is based off the model from which results can be generated at all desired time instants including the induction 
period, no initial coke formation needs to be considered. After initialization, dynamic simulations are carried out considering all the equations mentioned earlier, including catalyst deactivation. For this system, the residence time is in seconds compared to the reactor operating time, so the initial condition of the reactor before the feed gas is introduced is expected to have little to no effect on the results. The reactor length and diameter are $2.5 \mathrm{~m}$ and $1.74 \mathrm{~m}$, respectively. Yield is calculated as follows:

$Y=\frac{N \cdot F_{p, o u t, i}}{F_{r, \text { in }}}$

Here, $F_{p, o u t, i}$ and $F_{r}$ is the molar flowrate of product and reactant; $N$ is the carbon number.

\subsubsection{Impact of Temperature}

The effect of temperature on conversion, product yield, and catalyst activity is studied as shown in Fig. 4.6. The reactor is subjected to $325 \mathrm{kmol} / \mathrm{h}$ of total feed $\left(y_{\mathrm{CH}_{4}}=0.9 ; y_{\mathrm{N}_{2}}=0.1\right)$ at three temperatures $\left(700^{\circ} \mathrm{C}, 750^{\circ} \mathrm{C}, 800^{\circ} \mathrm{C}\right)$ and 2.1 bar inlet pressure. The temperature of the heat transfer fluid is set to be the respective inlet gas temperature. The reactor temperature remains almost constant at the desired temperature. Here, catalyst activity is calculated using the exponential part in Eq. (4.1-4.3) i.e. $e^{-\alpha \cdot \bar{C}_{c}}$.As seen in Fig. 4.6a, methane conversion increases with the increase in temperature due to the endothermicity of the reaction but decreases with time due to coke formation. This is seen in Fig. 4.6d, which shows the decrease in catalyst activity with time. Benzene yield increases initially with the increase in temperature. However, higher temperature causes faster deactivation and faster decrease in the benzene yield as a result. On the other hand, ethylene yield increases with temperature. This study can help in calculating the number of reactors and their scheduling as a function of the temperature with due consideration of the cyclic operation. While the rate of catalyst deactivation and regeneration time can affect the total number of reactors undergoing reaction in parallel and those undergoing regeneration (with some, if any, idling), the operating temperature also affects the conversion and selectivity and thus the amount of products being formed at any time instant. Obviously, to capture these effects, an economic study would be required to obtain the optimal number of reactors and their operating conditions. 

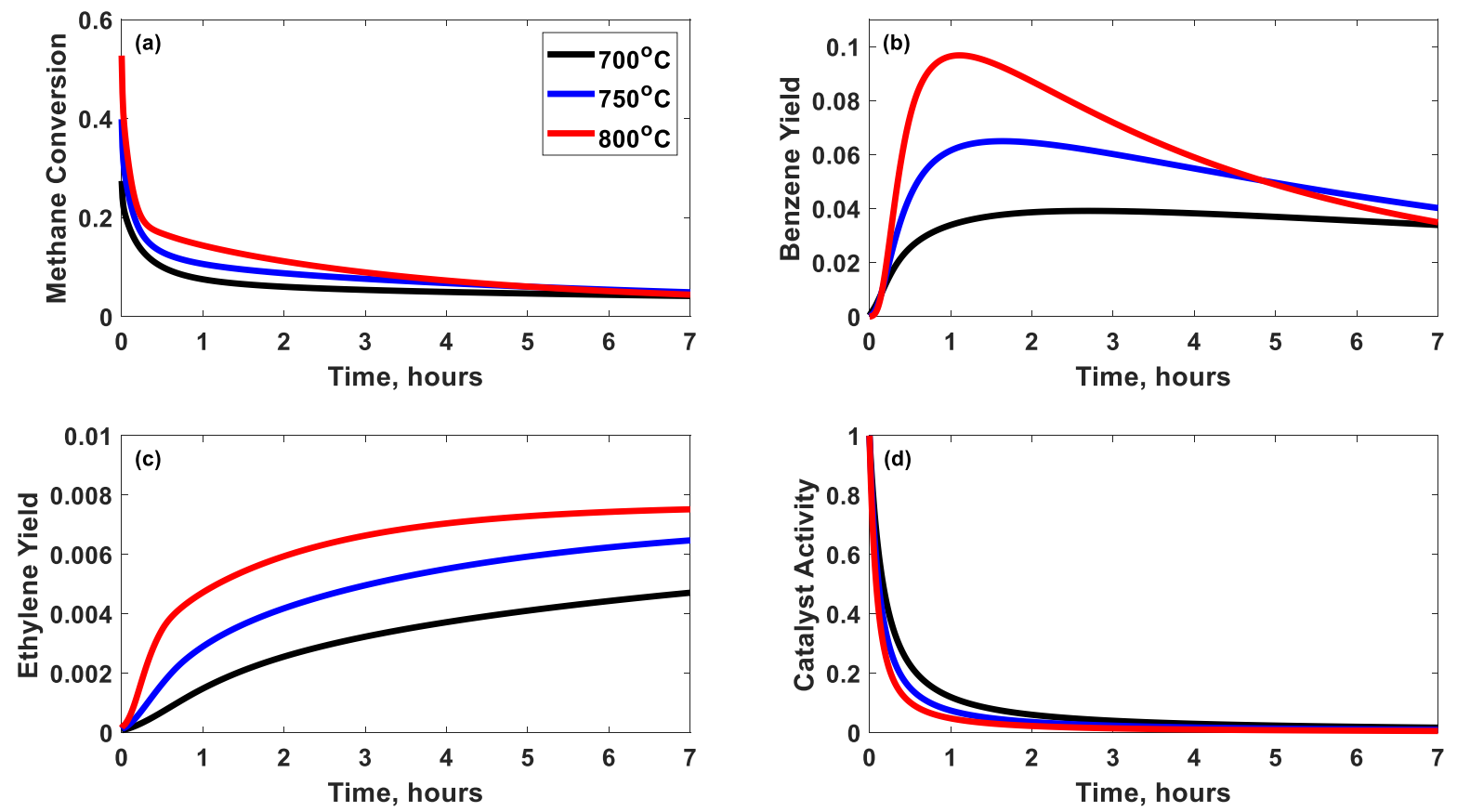

Figure 4.6: Effect of temperature on reactor performance parameters. (a) Methane conversion; (b) Benzene yield; (c) Ethylene yield; (d) Catalyst Activity

Dynamic variability of the key variables with respect to space is shown in Fig. 4.7 when the temperature of the heat transfer fluid is constant at $700^{\circ} \mathrm{C}$. It is observed that there is a decrease in the temperature in the initial section of the reactor due to initiation of the methane dimerization reaction (Reaction R1). As a result, the ethylene yield is maximum in that section of the reactor. However, the ethylene yield keeps decreasing due to the conversion of ethylene to benzene as seen by the increase in benzene yield in the later section of the reactor. Initially, the rate of catalyst deactivation is very fast. With the increase in time, the rate of catalyst deactivation decreases due to hydrogen formation and selectivity to Reactions R1 and R2 increases. Therefore, there is an increase in benzene and ethylene yield with the increase in time. 

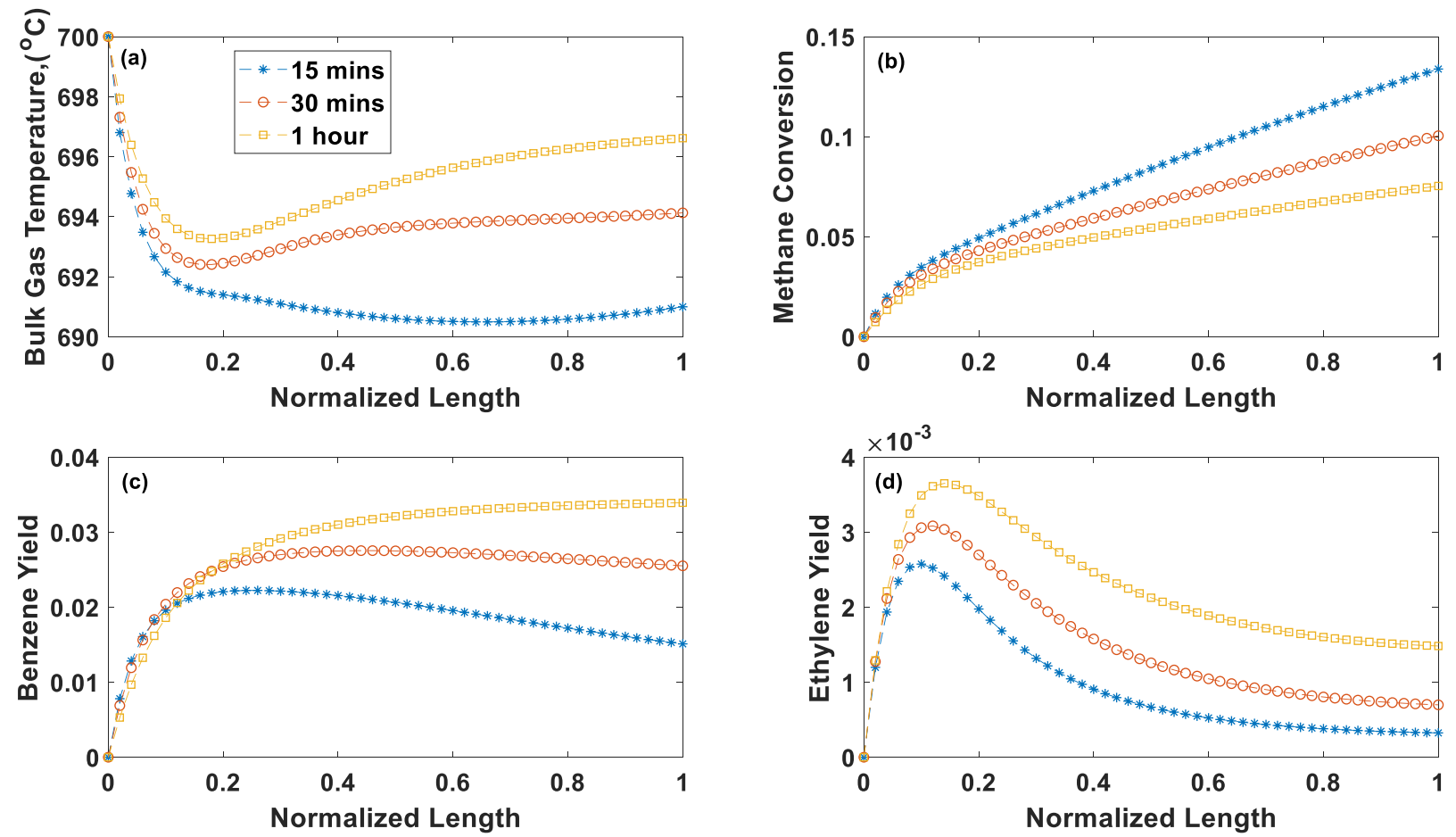

Figure 4.7: Profile of performance parameters over reactor length at different time instant for reactor operating at $700^{\circ} \mathrm{C}$ and 2.1 bar inlet pressure. (a) Bulk gas temperature; (b) Methane conversion; (c) Benzene yield; (d) Ethylene yield

\subsubsection{Impact of $L / D$ and Inlet Flowrate}

The effect of L/D ratio and inlet flowrate, for constant reactor volume, on reactor pressure drop and methane conversion is shown in Fig. 4.8. The reactor is assumed to operate isothermally at steady state at $700^{\circ} \mathrm{C}$ and 2.1 bar inlet pressure, and $C_{c}=0$. These operating conditions are selected for this specific study for simplicity to avoid the complex effect of coke formation and resulting dynamics on the methane conversion and pressure drop so that the pressure drop, and methane conversion is mainly affected by the $\mathrm{L} / \mathrm{D}$ ratio and inlet flowrate as intended. Thus, the results can be treated as the best-case scenario under isothermal operation. Methane DHA has light gases at the reactor outlet which needs to be separated downstream and that requires compression of the stream. So, it is desired that the pressure drop is kept low in the reactor to decrease the compression power. As shown in Fig. 4.8b., pressure drop increases considerably as the L/D ratio increases especially at higher inlet flowrate. For example, when $\mathrm{L} / \mathrm{D}=1.9$ and $300 \mathrm{kmol} / \mathrm{h}$, pressure drop is $>1 \mathrm{bar}$ along the reactor length, while for $230 \mathrm{kmol} / \mathrm{h}$ the pressure drop is about $0.65 \mathrm{bar}$. Similarly, for the $\mathrm{L} / \mathrm{D}=1.9$, methane conversion is lower for $300 \mathrm{kmol} / \mathrm{h}$ compared to 230 
$\mathrm{kmol} / \mathrm{h}$ due to higher pressure drop and lower residence time. So, for a given inlet flowrate, sizing the reactor appropriately is of key importance for methane DHA system.

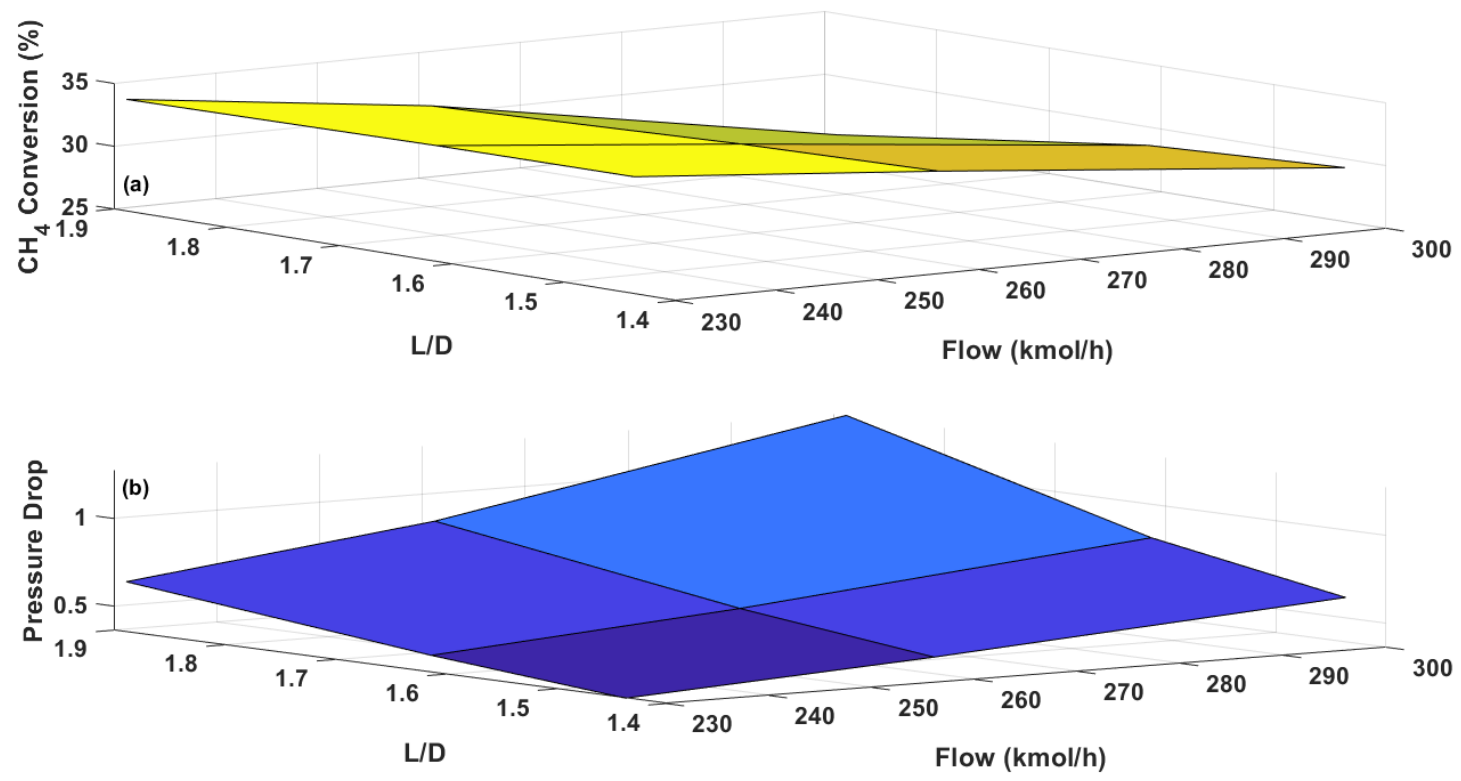

Figure 4.8: Pressure drop and methane conversion for different $L / D$ ratio and inlet flowrate. (a) Methane conversion; (b) Pressure drop

\subsubsection{Variability in Methane Conversion and Product Yield}

Fixed bed reactors are simple to construct and operate, but since the rate of catalyst deactivation is fast for methane DHA reactions, the variation in reactant conversion and product yield over time can be high if the reactor and their operational cycle is not appropriately designed. Since the products and unconverted reactants are sent to the separation sections, variabilities in reactant conversion and product yield with time can have adverse impact on the operational efficiency of separation units such as the distillation columns and can lead to difficulties in achieving desired product specifications. So, it will be desired that the variabilities with time are maintained within certain range. Fig. 4.9a shows the effect of deactivation (i.e. as the online time of the reactor increases) on the time-average methane conversion and variability in methane conversion. Here, effect of catalysts deactivation is included as given by Eq. (4.1) -(4.3) and the variability is represented by standard deviation. Results presented in Figs. 4.9a and 4.9b are cumulative. For example, time-average methane conversion for catalyst activity of $70 \%$ indicates the average conversion calculated by considering the conversion over the entire time the catalyst activity 
decreased from $100 \%$ to $70 \%$. Fig. $4.9 \mathrm{~b}$ shows the effect of deactivation on the time-average benzene yield and variability in benzene yield.
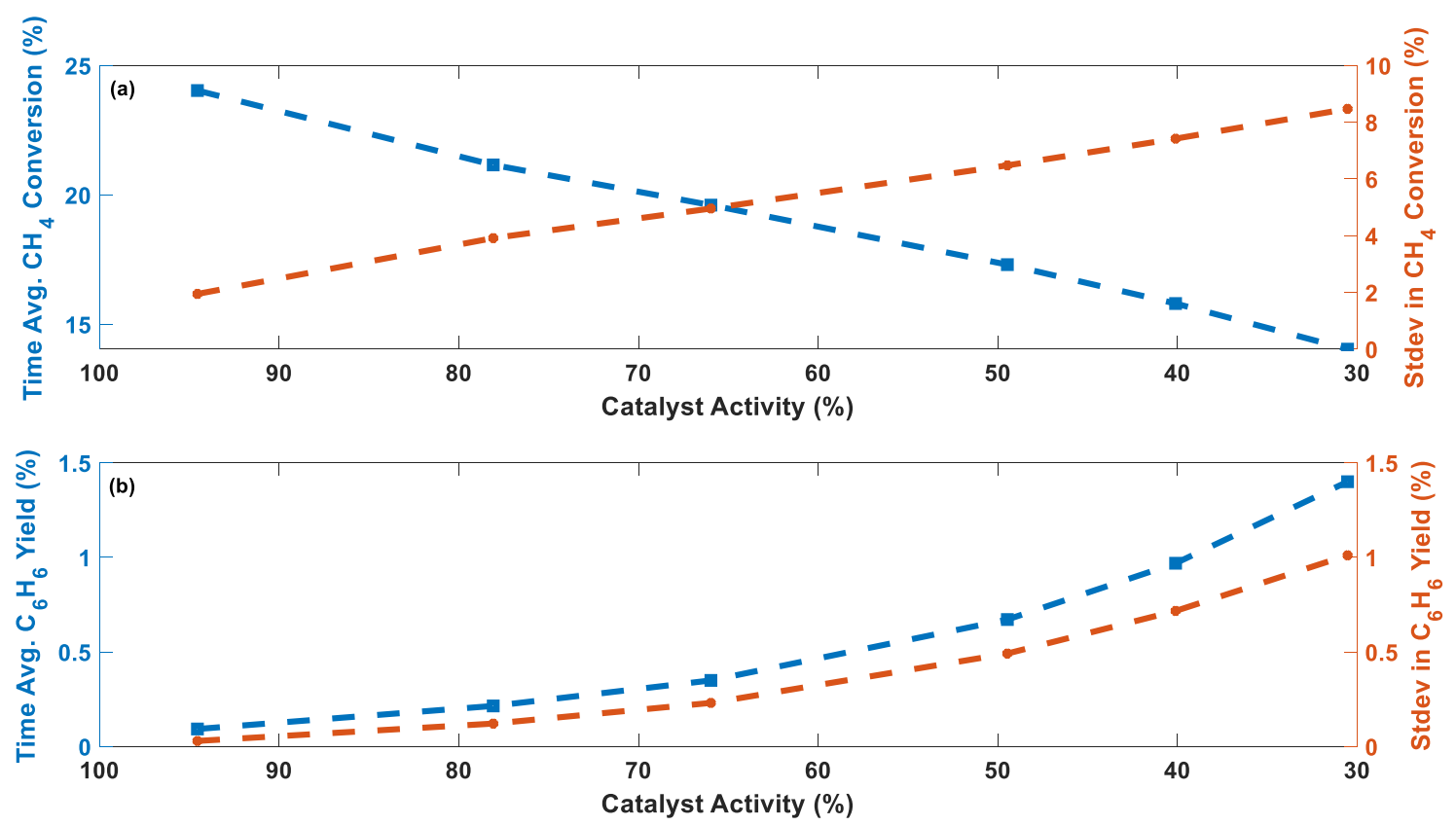

Figure 4.9: Effect of change in catalyst activity on time average values of and standard deviation in (a) Methane Conversion; (b) Benzene Yield (700' C, $2.1 \mathrm{bar}, 325 \mathrm{kmol} / \mathrm{h}(\mathrm{CH} 4$ $-0.9, \mathrm{~N} 2-0.1 \mathrm{~mol} \%$ )

As seen in Fig. 4.9a, the standard deviation of methane conversion increases from $\sim 3.9 \%$ to $6.5 \%$ when the catalyst activity drops from $\sim 78 \%$ to $50 \%$. The standard deviation of benzene yield is small however there is still an increase from $0.12 \%$ to $\sim 0.5 \%$. Acceptable variability in methane conversion and benzene yield is expected to be different depending on the downstream separation technologies, process control, and acceptable variability in product qualities. One way to reduce this variability during the operational cycle is to have parallel reactors configuration. As one aims for higher benzene yield i.e. keeping the reactor online for a longer time, a higher number of parallel reactors are required to keep the standard deviation in conversion and yield within a certain limit. Moreover, a higher number of parallel reactors where each reactor operates at different state of deactivation at any time is also likely to allow operation at considerable higher deactivation and therefore overall higher cycle time without much variability in the overall conversion. A study is performed to show the impact of parallel reactor operation on the standard deviation of methane conversion. For this purpose, a reactor operating at $700^{\circ} \mathrm{C}$ with 2.1 bar operating pressure, and feed is $325 \mathrm{kmol} / \mathrm{h}\left(y_{\mathrm{CH}_{4}}=0.9 ; y_{N_{2}}=0.1\right)$ is considered. The feed is equally divided into the 
number of parallel reactors. The dimensions of each reactor are kept similar. The regeneration time is calculated using Eq. 4.37, similar to Dumez and Froment [170]:

$t_{r}=t_{\text {purge }}+t_{\text {evac }}+R_{o x} \cdot \bar{C}_{c}$

Where $t_{r}$ is the regeneration time; $t_{\text {purge }}$ is the time taken to purge the system; $t_{\text {evac }}$ is evacuation time; $R_{o x}$ is the rate of oxidation of coke $(0.05$ hours per coke wt $\%) ; \bar{C}_{c}$ denotes the cumulative coke content $(\mathrm{wt} \%)$ in the catalyst before regeneration is initiated. The reactors are taken offline and assumed to undergo regeneration when the catalyst activity drops to $35 \%$. At this catalyst activity, the average coke content on the catalyst amounts to $4.3 \mathrm{wt} \%$. While developing the schedule for parallel reactor configuration, one must ensure that at any instant of time same number of parallel reactors remain online. Although, this condition can be satisfied by many possible schedules with the same cycle time, but those schedules can greatly vary in terms of the state of catalyst deactivation at any instant of time. To analyze the impact of schedule, here several such feasible schedules are prepared by specifying the offset time between each reactor that enters the reaction stage. Thus an offset time of $t_{\text {offset }}$ would indicate that if a fully active reactor enters the reaction stage at $t_{\text {reac }}$, then the $2^{\text {nd }}$ fully active reactor would enter the reaction stage at $t_{\text {reac }}+$ $t_{\text {offset }}$. Obviously depending on the number of parallel reactors available and the cycle time (that includes reaction and regeneration time as defined above), there is a maximum offset time beyond which the cycle is no more feasible, i.e. same number of parallel reactors will not be available at each instant of time. Fig. 4.10 shows the impact of the offset time for the 2 parallel reactor operation. 


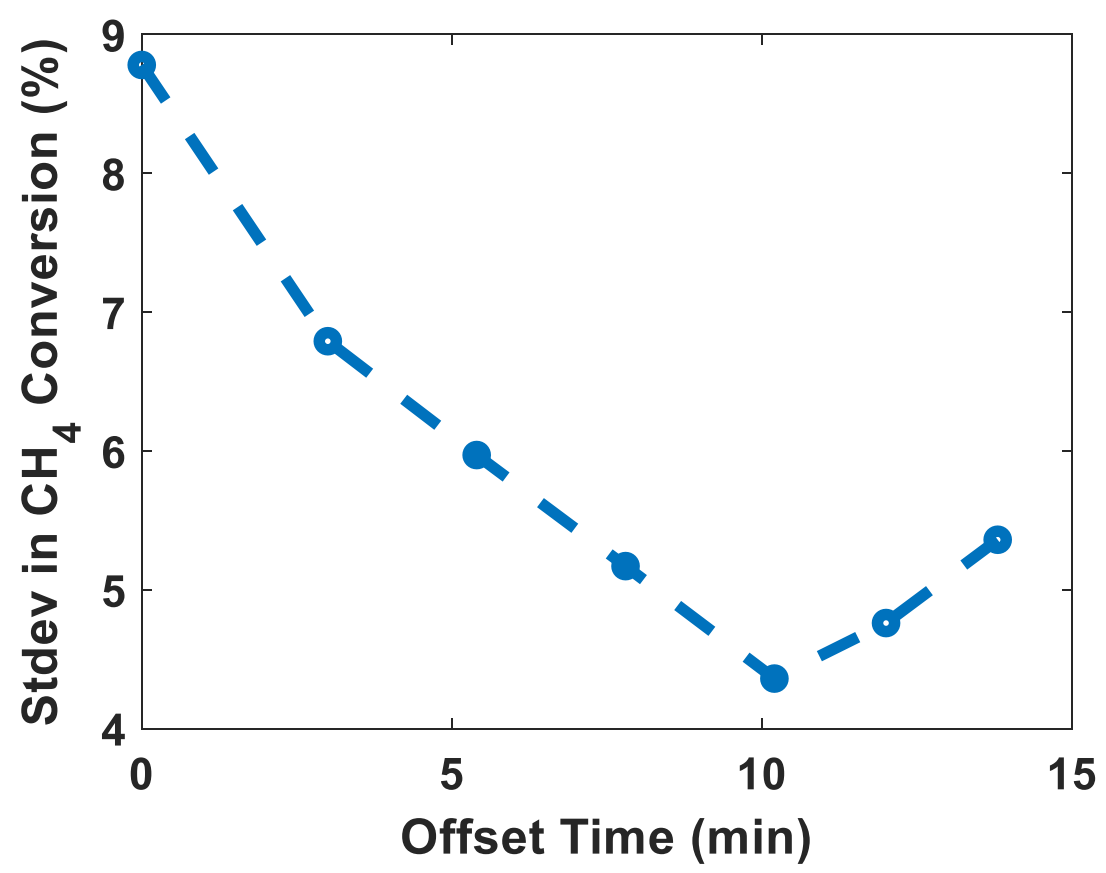

Figure 4.10: Sensitivity of methane standard deviation w.r.t off-set time between reactor \#1 and \#2 in a 2 reactor parallel cyclic operation

As shown in Fig. 4.10, when the offset time between reactor \#1 and \#2 is zero i.e. both reactors has the same activity at each instant of time, the standard deviation in the methane conversion is the highest. As the offset time increases, the standard deviation in methane conversion decreases. However, as the offset time is increased further, there are time instants when catalyst activity of both reactors become low therefore increasing the standard deviation with further increase in offset time. The Gantt chart corresponding to the offset time that leads to the minimum deviation in methane conversion for the 2 parallel reactor operation is shown in supporting information, Appendix I. Studies are also conducted for the 3 parallel reactor operation similar to above. Table 4.5 compares results for the 2 and 3 parallel reactor schedules when they reach the minimum standard deviation in methane conversion.

Table 4.5: Sensitivity study results for parallel reactor operation

\begin{tabular}{cccc}
\hline $\begin{array}{c}\text { Parallel } \\
\text { reactors }\end{array}$ & $\begin{array}{c}\text { Time for activity } \\
\text { to reach 35\% }\end{array}$ & $\begin{array}{c}\text { Time average } \\
\text { CH4 conversion }\end{array}$ & $\begin{array}{c}\text { St. dev in } \mathbf{C H}_{4} \\
\text { conversion }\end{array}$ \\
\hline 2 & $20.4 \mathrm{~min}$ & $27.9 \%$ & $4.36 \%$ \\
3 & $25.8 \mathrm{~min}$ & $33.7 \%$ & $2.43 \%$ \\
\hline
\end{tabular}


As the number of parallel reactors increases, the residence time in each of the reactors increases thus increasing the time average $\mathrm{CH}_{4}$ conversion as observed in Table 4.5. As the number of parallel reactors increase, the standard deviation in methane conversion decreases and the time taken for the activity to drop to $35 \%$ increases. Even though higher residence time leads to higher coke formation in comparison to aromatics formation, the cumulative amount of coke formed is more for lower number of parallel reactors due to higher cumulative $\mathrm{CH}_{4}$ feed flow (for the entire cycle) to the catalyst ratio. Similar observations are reported by Xu et al. [180], where they studied the effect of superficial velocity on lifetime aromatics productivity and coke formation in a fixedbed reactor for different bed heights.

\subsection{Conclusion}

Kinetic reaction rate model for methane DHA reactions, with coke formation rate, is able to predict the coke deposited on the catalyst within $11 \%$ average error when compared to the experimental TGA data. A dynamic model of the laboratory scale reactor is developed and used for estimation of the kinetic model parameters by using the laboratory data. A data reconciliation approach is developed for closing the mass balance of the laboratory data. As the initial state of the catalyst's activity is not known, an algorithm is developed for estimating the initial state of catalyst activity while performing data reconciliation and parameter estimation. Model results compare well with the experimental data at different temperatures. A model of a commercial scale multi-tubular fixed bed reactor is developed coupling the catalyst pellet and reactor level model, and considering internal and external mass transfer resistances, heat transfer resistances, and the reaction limitation. It is observed that higher temperature can increase methane conversion and benzene yield. However, the rate of catalyst deactivation is much faster which can lead to a large variability in the methane conversion. A lower L/D ratio is found to be beneficial to keep the pressure drop low and methane conversion high. Due to fast deactivation, methane DHA reactors would require a cyclic operation if fixed bed reactors are used. As the catalysts become deactivated, variability in benzene yield and methane conversion increases thus limiting the amount of time a reactor can undergo reaction. When parallel reactors are considered to reduce variability in conversion and yield, it is observed that there is an optimal cycle schedule when the variability in methane conversion and benzene yield is minimum. When the number of parallel reactors increases, timeaverage methane conversion increases, standard deviation in methane conversion decreases, and time-average benzene yield decreases. 


\section{Chapter 5. Dynamic Data Reconciliation, Parameter Estimation, and Multi- Scale Modeling of the Microwave-Assisted Methane Dehydroaromatization Process}

In this chapter, dynamic data reconciliation and parameter estimation has been performed for methane DHA reaction system using the experimental data generated from a MW reactor. A custom reaction rate model has been used in which the catalyst deactivation effect on the reaction rate has been considered. The amount of heat generated at a specific catalyst site has been modeled using Maxwell's equation. For integrating the Maxwell's equation with process model, a reduced order model is developed. The reduce order model is a function of temperature, dielectric properties, and input power. A 2-D multi-scale heterogenous industrial scale MW reactor model has been developed coupling catalyst pellet level and reactor level model. The reduced order MW propagation model has been coupled with heat and mass transfer equations to study the effect the MW on heat, mass, and reaction limitation. Temperature difference between the metal particles sites and catalyst support sites have also been investigated.

\subsection{Literature Review}

Microwave (MW) heating has been industrially utilized for a long time with applications in wood drying, drugs, and food industry. In the food industry, MW has been used for various purposes including cooking, drying, pasteurization and thawing. In recent years, it has been progressively utilized to improve the reaction kinetics for both the homogenous and heterogeneous catalysis frameworks [181]. Quick volumetric heating, minimal loss of energy, higher reaction rate than the traditional thermal heating, and improvement of selectivity of desired products in MW-assisted reactors have led to considerable research on MW-enhanced reaction engineering.

Several experimental works on MW-assisted DHA have been reported. Julian et al. [29] studied the non-oxidative methane DHA reaction under MW and conventional heating on Mo/HZSM-5 
catalyst. They reported higher $\mathrm{C}_{2}$ hydrocarbons, and benzene formation under $\mathrm{MW}$ heating compared to conventional heating. Moreover, they also reported double the amount of coke formation under conventional heating as compared to MW heating. Conde et al. [182-184] studied the effect of different parameters such as catalyst type (nickel, iron, and activated carbon), MW operating frequency, and power on the product distribution of methane DHA reaction. They reported that activated carbon catalyst had the highest methane conversion and benzene selectivity at 4.6 GHz frequency and $500 \mathrm{~W}$ power. Marun et al. [185] studied the performance of methane DHA reaction at $2.45 \mathrm{GHz}$ frequency subjected to different catalyst types, input power, and helium diluent gas. They reported that the applied power had to be optimized based on the catalyst type to make the catalyst active. Moreover, they also showed the effect of diluent gas on the product distribution. Lu et al. [186] studied MW-assisted non-oxidative methane conversion to butene under different inlet hydrogen partial pressures in a two-stage fixed-bed reactor. Their study found that decreasing the $\mathrm{CH}_{4}: \mathrm{H}_{2}$ ratio from 1:5 to 1:3, resulted in decrease in methane conversion from $73.2 \%$ to $67.2 \%$, while the butene selectivity remained unchanged.

As opposed to the experimental works on MW-assisted methane DHA, the current literature is rather scarce on mathematical modeling. There are several gaps in the literature that this work seeks to address. The first issue that this study seeks to address is the lack of a reaction rate model including catalysts deactivation. Methane DHA reactions including MW-assisted methane DHA lead to coke formation. As the coke keeps building in the catalyst, its activity keeps dropping. The coke formation rate not only affects the selectivity of products and carbon utilization but leads to a dynamic process due to the temporal decrease of the catalyst activity. Consideration of this dynamics is an important aspect for reactor design and operation. Few authors have proposed reaction rate model for non-oxidative methane DHA reaction under conventional heating system using steady-state data and without incorporating the effect of catalyst deactivation [152-157,160]. Currently there is no reaction rate model in the open literature on the coke formation rate and catalyst deactivation rate as a result of coke formation. One of the difficulties in developing such a rate model is that the temporal evolution of coke formed in the catalyst cannot be currently measured. Furthermore, the dynamic data available from the gas chromatography (GC) does not necessarily satisfy carbon and hydrogen balances thus the dynamic data need to be reconciled for satisfying atom/species balances. As the parameters of the coke formation rate model and catalyst 
deactivation rate model are time-invariant, a dynamic data reconciliation and parameter estimation problem is solved for the proposed rate law. Another gap in the open literature that this work seeks to address is a process model for a fixed bed reactor that includes coupled mass transfer, heat transfer, reaction kinetics, and absorption of MW power by the catalyst particles. As the metal sites in the catalyst are likely to absorb MW power than support sites, there can be local inhomogeneity in temperature distribution within the catalyst particles and between metal and support sites. Gerasev [187] developed a dynamic two-phase packed bed reactor model under MW heating considering a hypothetical endothermic reaction. MW propagation was modeled using Lambert's law. Similarly, Cherbanski [188] developed a transient two-dimensional packed bed reactor model to study heat transfer between the solid-gas phase when subjected to conventional and MW heating. No reaction was considered, and Lambert's law was used to model the MW propagation inside the bed. Haneishi et al. [189] studied the impact of MW irradiation on a 2proponal dehydrogenation system. COMSOL Multiphysics software was used where the electromagnetic field distribution was coupled with heat transfer. It is not clear how heat transfer was modeled. Haneishi et al. [190] conducted another study to understand the effect of nonuniform temperature distribution on rate enhancement of dehydrogenation of ethylbenzene. Bhattacharya et al. [191,192] conducted a comprehensive theoretical analysis on the effect of MW heating for a gas phase first order endothermic reaction. They developed a 1-D homogenous packed bed reactor model considering heat and mass transfer and coupled them with the Helmholtz equation for MW propagation. Muley et al. [193] developed a two phase packed bed reactor model in COMSOL, coupling the heat transfer equations with the RF electromagnetics module to study the effect of shape, size, and position of the HZSM-5 catalyst bed within the MW reactor on the temperature distribution within the bed. Overall, it can be observed that the existing literature lacks consideration of inter and intra-particle mass transfer, reaction kinetics including coke formation and catalyst deactivation, and comprehensive heat transfer model considering heat transfer between the metal sites, support sites and the gas within the catalyst particles and between the bulk and catalyst particles where the MW absorption by both metal and support sites area taken into consideration. Furthermore, there is hardly any reactor model for the MW- assisted methane DHA (lacks multi-scale model that includes both the bulk scale and the catalysts scale and includes all the mechanism noted above for methane DHA). In this work, a multi-scale model is developed including all the mechanisms noted above where MW propagation is modeled by Maxwell's 
equation. However as solving Maxwell's equation coupled with other equations is computationally intensive for numerical discretization approaches and is infeasible in Aspen Custom Modeler that is used here, an approach using a reduced order model is developed. In summary, following contributions are made in this study:

- A reaction rate model including coke formation rate and the catalyst deactivation rate has been proposed. Dynamic data reconciliation and parameter estimation has been performed for this rate model using the experimental data for DHA reactions from an in-house MW-assisted reactor.

- For calculating spatial variation of absorption of MW power, Maxwell's equation is used. For numerical tractability and implementation in the process simulation software environment, a reduced order model is then developed where the MW power absorbed is expressed as a function of reactor radius, MW frequency, temperature, and dielectric properties. This reduced order model can be easily implemented on most software platforms and solved with other reactor modeling equations without the need to solve the coupled Maxwell's equations.

- A dynamic commercial scale heterogenous multi-scale fixed bed MW reactor model is developed where the catalyst pellet level model is coupled with reactor level model considering the electromagnetic effects, inter-particle and intra-particle heat and mass transfer, and reaction rate model that includes coke formation model and catalysts deactivation model. For the catalyst level model, separate energy balances are considered for the metal particles and the catalyst support.

\subsection{Experimental Procedure}

In this section, procedure to prepare the catalyst and the approach to perform the methane DHA MW catalysis reaction is discussed.

\subsubsection{Catalyst Preparation}

The molybdenum-loaded ZSM-5 (4 wt\% Mo/ZSM-5) catalysts was prepared by incipient wetness technique. The H-ZSM5 zeolite support $(\mathrm{Si}: \mathrm{Al}=23)$ was made by calcinating the $\mathrm{NH}_{4}-\mathrm{ZSM} 5$ purchased from Zeolyst International, Inc. The detailed catalyst composition, preparation method, and calcination temperature is described in our previous publication [166]. 


\subsubsection{Microwave (MW) Reactor Configuration and Design of Experiment}

DHA reactions were carried out in $8 \mathrm{~mm}$ inner-diameter (ID) quartz tube reactors. The feedstock contained 50 vol\% methane, balanced by nitrogen. The MW reactor unit is Lambda MC1330 with an adjustable frequency range from 5850 to $6650 \mathrm{MHz}$, and the maximum power is $180 \mathrm{~W}$. The microwave reaction set-up is described in the previous publications by some of the authors $[194,195]$ and the reactor configuration is shown in Fig. 5.1. 0.5 grams of catalyst was loaded in each experiment. The catalyst was pre-carburized by methane-hydrogen mixture gas $\left(\mathrm{CH}_{4}: \mathrm{H}_{2}=\right.$ $1: 4$, in volume) in a traditional fixed-bed reactor at $600^{\circ} \mathrm{C}$ for 4 hours with a total flow rate of 50 $\mathrm{mL} / \mathrm{min}$. In this study, the MW frequency was set as $5850 \mathrm{MHz}$ and weight hourly space velocity was $12000 \mathrm{~mL} / \mathrm{g} \mathrm{cat} . / \mathrm{hr}$ was used. Before initiating feed gas in every experiment, the catalyst was heated in inert environment (nitrogen). The MW irradiation was applied throughout the entire reaction period. E-H tuners (not shown in the figure) were adjusted to maintain the reflectance at nearly zero, so the reflected power can be neglected. The temperature is controlled by a proportional-integral-derivative (PID) controller. The outlet gas products were monitored by a 4channel Inficon Fusion micro gas chromatography (MicroGC). A BriskHeat heating tape was applied to maintain the temperature of outlet gas line from the reactor higher than $140{ }^{\circ} \mathrm{C}$ to prevent condensation of benzene and toluene products in the gas line.

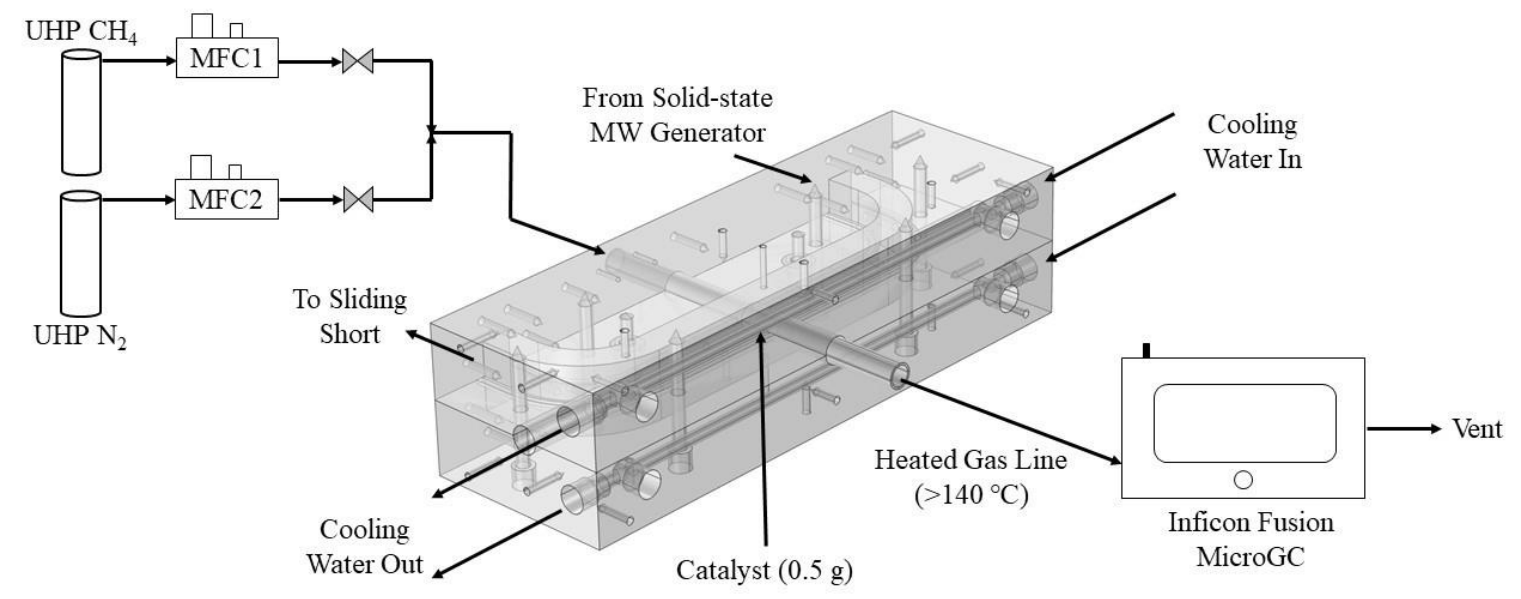

Figure 5.1: Experimental setup for variable-frequency MW reactor

\subsubsection{Thermogravimetric Analysis (TGA)}

The TGA experiments were carried out in a Discovery SDT 650 unit (TA Instruments) to analyze the type and amount of the coke residual on the spent catalyst. The sample was first stabilized at 
$50{ }^{\circ} \mathrm{C}$ for 2 hours (step $1 ; 100 \mathrm{~mL} / \mathrm{min}_{2}$ ) so that the house gas in the test chamber can be purged. Then, the temperature was ramped to $200{ }^{\circ} \mathrm{C}$ at a rate of $10{ }^{\circ} \mathrm{C} / \mathrm{min}$ and isothermal for 1 hour to remove the moisture, and then cooled down to $50{ }^{\circ} \mathrm{C}$. Next, the feed gas was switched to $5 \mathrm{vol} \%$ $\mathrm{O}_{2}$ (in balanced $\mathrm{N}_{2}$ ) and purged for 1 hour. Subsequently, the sample was raised to $900{ }^{\circ} \mathrm{C}$ at a rate of $5{ }^{\circ} \mathrm{C} / \mathrm{min}$, then cooled down to the room temperature. The temperature profile for the entire process is shown in Fig. 5.2. All gases used in TGA were UHP grade.

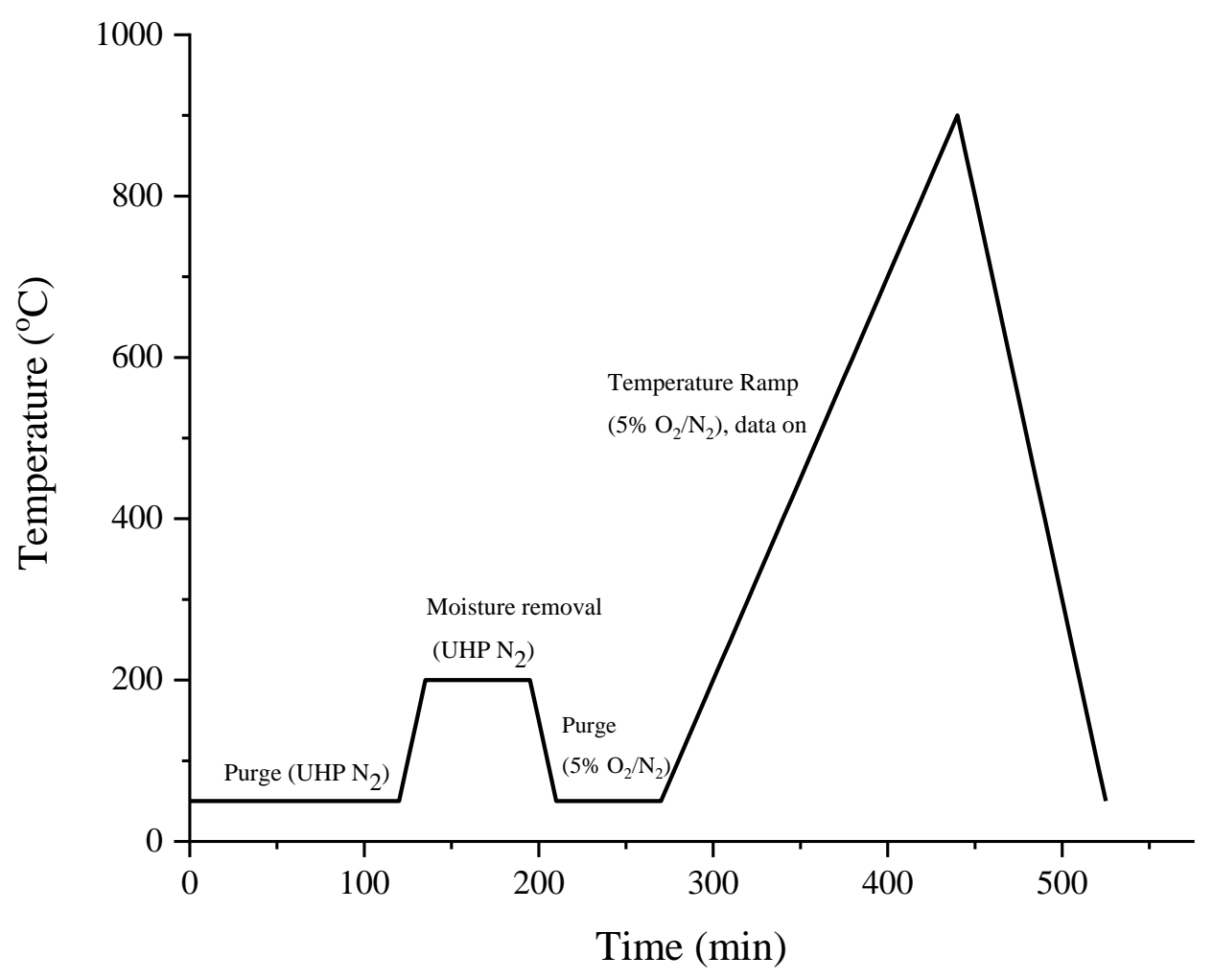

Figure 5.2: TGA temperature profile for MW-assisted non-oxidative methane DHA reaction

\subsection{Reaction Model, Dynamic Data Reconciliation, and Parameter Estimation}

In this section, first the reaction rate model including a model for the coking rate and catalysts deactivation rate are developed for the methane DHA reactions. Kinetic model parameters are estimated through dynamic data reconciliation and parameter estimation by leveraging the inhouse experimental data.

\subsubsection{Reaction Rate Model}

The exact reaction pathway for non-oxidative methane DHA reaction system is still debatable $[148,155,159,169]$. However, the most common pathway that has been agreed upon starts with the 
formation of $\mathrm{C}_{2} \mathrm{~S}$ such as ethane, ethylene, and acetylene. The $\mathrm{C}_{2} \mathrm{~S}$ can further react on the HZSM5 support to form aromatics. Each of these steps have the potential to form coke namely graphitetype $\mathrm{C}$ and aromatics-type coke [148]. Based on the products obtained in the experimental data, reactions considered in this study are shown in Table 5.1 .

Table 5.1: Non-oxidative methane DHA reactions

\begin{tabular}{cccc}
\hline No. & Name & Reaction & $\Delta \mathbf{H} @ \mathbf{2 5}^{\circ} \mathbf{C}(\mathbf{k J} / \mathbf{m o l})$ \\
\hline 1 & Methane Dimerization & $2 \mathrm{CH}_{4} \leftrightarrow \mathrm{C}_{2} \mathrm{H}_{4}+2 \mathrm{H}_{2}$ & 201.9 \\
2 & Benzene Formation & $3 \mathrm{C}_{2} \mathrm{H}_{4} \leftrightarrow \mathrm{C}_{6} H_{6}+3 H_{2}$ & -156.8 \\
3 & Methane Decomposition & $\mathrm{CH}_{4} \leftrightarrow \mathrm{C}+2 \mathrm{H}_{2}$ & 74.81 \\
\hline
\end{tabular}

The custom rate model considered for the reactions in Table 5.1 is given by Eq. 5.1-5.3. Effect of catalyst deactivation on the reaction rate due to coking is taken into account by including a separable exponential term which is a function of catalyst coke content $\left(\mathrm{C}_{\mathrm{c}}\right)$ and activity parameter $(\alpha)$. The catalyst deactivation model is similar to the studies on dehydrogenation of butene-1 $[170,171]$.

$r_{1}=\exp \left(-\alpha \cdot C_{c}\right) \cdot A_{1} \cdot \exp ^{\left(-\frac{E_{1}}{R \cdot T}\right)}\left(f_{C H_{4}}^{2}-\frac{f_{C_{2} H_{4}} \cdot f_{H_{2}}^{2}}{K_{p 1}}\right)$

$r_{2}=\exp \left(-\alpha \cdot C_{c}\right) \cdot A_{2} \cdot \exp ^{\left(-\frac{E_{2}}{R \cdot T}\right)}\left(f_{C_{2} H_{4}}^{3}-\frac{f_{C_{6} H_{6}} \cdot f_{H_{2}}^{3}}{K_{p 2}}\right)$

$r_{3}=\frac{r_{c}}{\varphi_{C M} M_{C H 4}}=\frac{1}{\varphi_{C M} M_{C H 4}} \exp \left(-\alpha \cdot C_{c}\right) \cdot A_{3} \cdot \exp ^{\left(-\frac{E_{3}}{R \cdot T}\right)}\left(f_{C_{H}}-\frac{f_{H_{2}}^{2}}{K_{p 3}}\right)$

In Eq. 5.1-5.3, $A_{i}$ is the pre-exponential factor; $E_{i}$ is the activation energy; $\varphi_{C M}$ is the coke yield from methane; $R$ is the gas constant; $f_{i}$ is the fugacity; $T$ is the temperature. Fugacity coefficient were calculated for a range of operating conditions for this reaction system, and the coefficient was very close to 1 . So, partial pressure is used in terms of fugacity in Eq. 5.1-5.3. The equilibrium constants $\left(K_{p i}\right)$ are calculated using the Van't Hoff equation.

\subsubsection{Dynamic Data Reconciliation}

Experimental data does not necessarily satisfy carbon and hydrogen balance. Another drawback is that the real time measurement of coke formation rate is not currently possible. Use of the experimental data that do not satisfy mass balances can lead to bias in parameter estimation. So, 
before parameter estimation can be conducted, following dynamic data reconciliation problem is solved:

$$
\min \sum_{i} \sum_{j} \sum_{m} W_{i j} \cdot\left(F_{\text {model }, o u t, i, j, m}-F_{\text {exp }, i, j, m}\right)^{2}
$$

s.t. $F_{\text {modelout }, i, j, m} \geq 0$

$F_{\text {model }, i n, i, j, m}-F_{\text {model }, o u t, i, j, m}+/-\sum \vartheta_{j, k} \eta_{i, j, m, k}=0$

$\sum F_{\text {model }, i n, i, j, m} N_{c, j}-\sum F_{\text {model }, o u t, i, j, m} N_{c, j}-\eta_{i, j, m, 3} N_{c, c o k e}=0$

$\sum F_{\text {model }, i n, i, j, m} N_{H, j}-\sum F_{\text {model }, o u t, i, j, m} N_{H, j}=0$

Here index $i$ represents experimental data set for each temperature, index $j$ represents the gaseous species, index $m$ represents each discrete time instant at which measurements are available. $F_{\text {model }}$ and $F_{\text {exp }}$ denote the reconciled and experimental component molar flowrate, respectively, at the reactor outlet and $W$ denotes the weights. $\eta_{i, j, m, k}$ denotes the reaction rate of the $k^{\text {th }}$ reaction. The inequality constraints denoted by Eq. 5.5 ensure that the molar flowrates are positive. Eq. 5.6 represents the mass balance in terms of extent of reaction. Eq. 5.7 and 5.8 represents carbon and hydrogen atom balance. The optimization problem is solved using 'fmincon' in MATLAB with a sequential quadratic programming algorithm. The experimental and the reconciled data are shown in Fig. 5.3. 

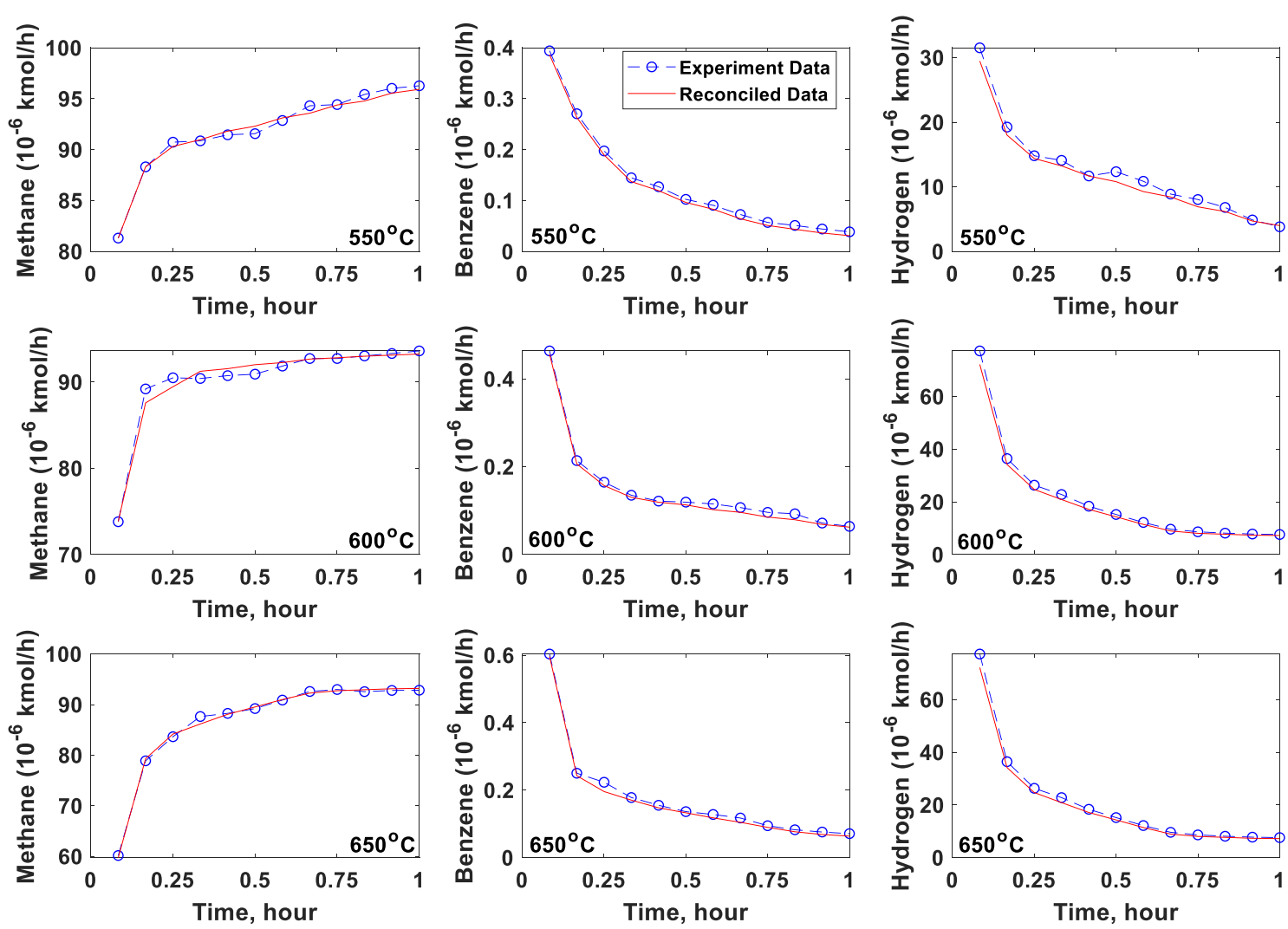

\section{Figure 5.3: Experimental and reconciled data at three experimental temperatures for methane, benzene, and hydrogen}

\subsubsection{Dynamic Parameter Estimation}

A dynamic 1-D homogeneous reactor model is developed in Aspen Custom Modeler (ACM) V9® to perform dynamic parameter estimation. Soave-Redlich-Kwong (SRK) equation of state (EOS) is used as the thermodynamic package in ACM. Resulting PDAEs are solved using method of lines where the spatial direction is discretized while time is considered as a continuous variable. Backward finite difference (BFD) method is used for spatial discretization. The implicit Euler method with variable step length is used for numerical integration. Dimensions of the reactor are $26 \mathrm{~mm} \times 8 \mathrm{~mm}$. Due to the small length of the reactor, pressure drop is neglected and uniform velocity is assumed because the reactor-to-particle diameter ratio is more than 10 [173]. The catalyst is in powder form, so mass transfer limitations are also neglected. Radial variation is not considered due to the small reactor diameter, and the reactor is assumed to be operating under isothermal conditions at the temperature maintained by the PID controller as described in Section 5.2 . 
The gaseous species conservation equation is given by Eq. 5.9:

$u_{s} \frac{\partial\left(C_{g a s, i}\right)}{\partial z}-\left(1-\varepsilon_{l a b}\right) \cdot \sum r_{j}=0$

with the following boundary condition: $C_{g a s, i}(z=0)=C_{g a s, i, i n l e t}$.

In addition, Eq. 5.10 is considered:

$\sum y_{g a s, i}=1$

Catalyst deactivation rate is given by Eq. 5.11:

$\frac{d C_{c}}{d t}=r_{c}$

For this reaction system, coke formation starts as soon as the methane feed is introduced to the reactor so there can be some amount of coke before the first measurements are available. This initial amount of coke needs to be taken into consideration during parameter estimation to avoid over estimation of coke formation rate. An iterative direct substitution algorithm is developed as shown in Fig. 5.4, and it is integrated with dynamic parameter estimation to simultaneously predict the initial coke concentration at the end of induction period $\left(t=t_{\text {ini }}\right)$ and estimate the kinetic parameters. Parameter estimation is started with zero coke concentration at the initial condition (i.e. at $i=1, C_{c}=0$ at $t=t_{i n i}$ for all temperatures), and kinetic parameters are estimated. The estimated parameters are then used to calculate the true coke content using Eq. 5.3 and 5.11 using the experimental data during induction period, i.e., $t<t_{\text {ini }}$. The algorithm converges when the absolute difference between the guess for the coke concentration and the calculated coke concentration is below the tolerance. 


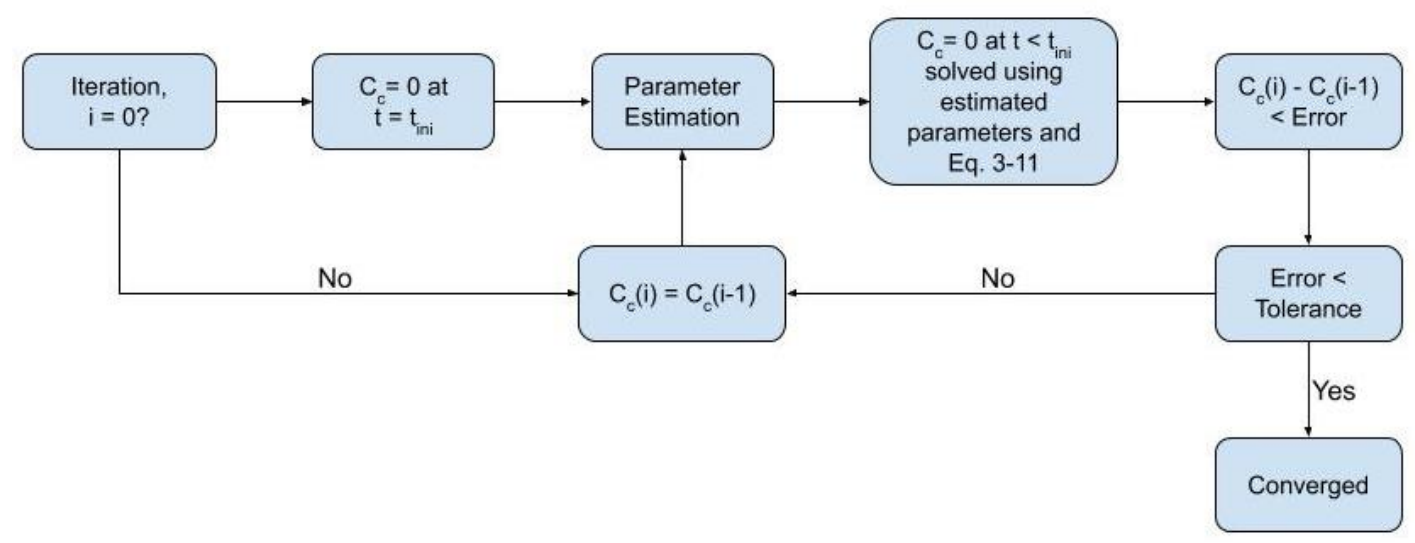

\section{Figure 5.4: Algorithm to simultaneously predict the initial coke concentration and perform dynamic parameter estimation}

There are temperature measurement challenges associated with MW reactors [196]. The standard thermocouple cannot be inserted in the catalyst bed and used for measuring the temperature because of the interaction of electromagnetic waves with the thermocouple. In addition, insertion of a thermocouple in the catalyst bed would result in the inhomogeneity of catalyst bed which can lead to inaccurate results. Infrared (IR) temperature sensors have been used by many research groups for temperature measurement in a MW reactor [196]. However, it has been reported to grossly under-measure the actual temperature of system because the IR sensor measures the temperature of the outermost material in the reactor system, which can be the reactor wall or the catalyst particle near the wall. However, MW reactors heat from the inside out which makes things more complicated [196]. For a solid-gas heterogenous reaction system, it has been reported by several researchers that a particular reaction resulting in the same amount of reactant conversion under $\mathrm{MW}$ at $>200^{\circ} \mathrm{C}$ less than the conventional heating system, due to the formation of the hotspots. However, the current technology is not capable of measuring temperature of the hotspot due to reasons mentioned in a detailed review paper by Priecel et al. [196]. Recent temperature measurement at West Virginia University using an IR imaging camera in a fluidized bed MW reactor, showed that the center of the reactor was at $150^{\circ}-200^{\circ} \mathrm{C}$ higher than the reactor walls. Therefore it was decided to also estimate the deviation of the true temperature in the catalyst from the measurement temperature denoted by $\Delta T$, i.e. $T_{\text {true }}=T_{\text {exp }}+\Delta T$, where $\Delta T$ is bounded between $0-240^{\circ} \mathrm{C}$ in the optimization problem. The parameters that are estimated are the activation energies and pre-exponential factors of the three reactions, catalyst activity parameter, and the true 
$\Delta \mathrm{T}$ of the reactor system. A log likelihood objective function given as follows is used for dynamic parameter estimation:

$$
\begin{array}{r}
\max _{\theta, \gamma}\left\{-\frac{1}{2} \sum_{i=1}^{N M e a s}\left(n_{i}(\log 2 \pi+1)+n_{i} \log \left[\frac{1}{n_{i}} \sum_{j=1}^{N D y n} \sum_{k=1}^{M i j} w_{j}^{2} \frac{\left(\hat{z}\left(t_{i j k}\right)-z\left(t_{i j k}\right)\right)^{2}}{z_{i j k}^{\gamma i}}\right]+\right.\right. \\
\left.\left.\gamma_{i} \sum_{j=1}^{N D y n} \sum_{k=1}^{M i j} \log w_{j} z\left(t_{i j k}\right)\right)\right\}
\end{array}
$$

s.t. $f\left(x_{i}\right)=0$

$\theta^{L} \leq \theta \leq \theta^{U}$

where $\gamma_{i}$ is the heteroscedasticity parameter for measured variable $z(j) ; w_{j}$ is the weight for experiment $j ; n_{i}$ is the total number of measurements for variable $i$ over all the experiments; $\theta$ denote parameters to be estimated; NDyn is the total number of dynamic experiments; $\hat{z}\left(t_{i j k}\right)$ is the $k^{\text {th }}$ measurement of variable $z(j)$ in experiment $i$ at time $t_{i j k} ; M_{i j}$ is the number of measurements of variable $j$ in experiment $i$; NMeas is the number of unique variables $z(j)$ measured over all experiments; $f\left(x_{i}\right)$ are the mass balance equality constraints (Eq. 5.9-5.11). Comparison of the model results with the reconciled experimental data is shown in Fig. 5.5. 

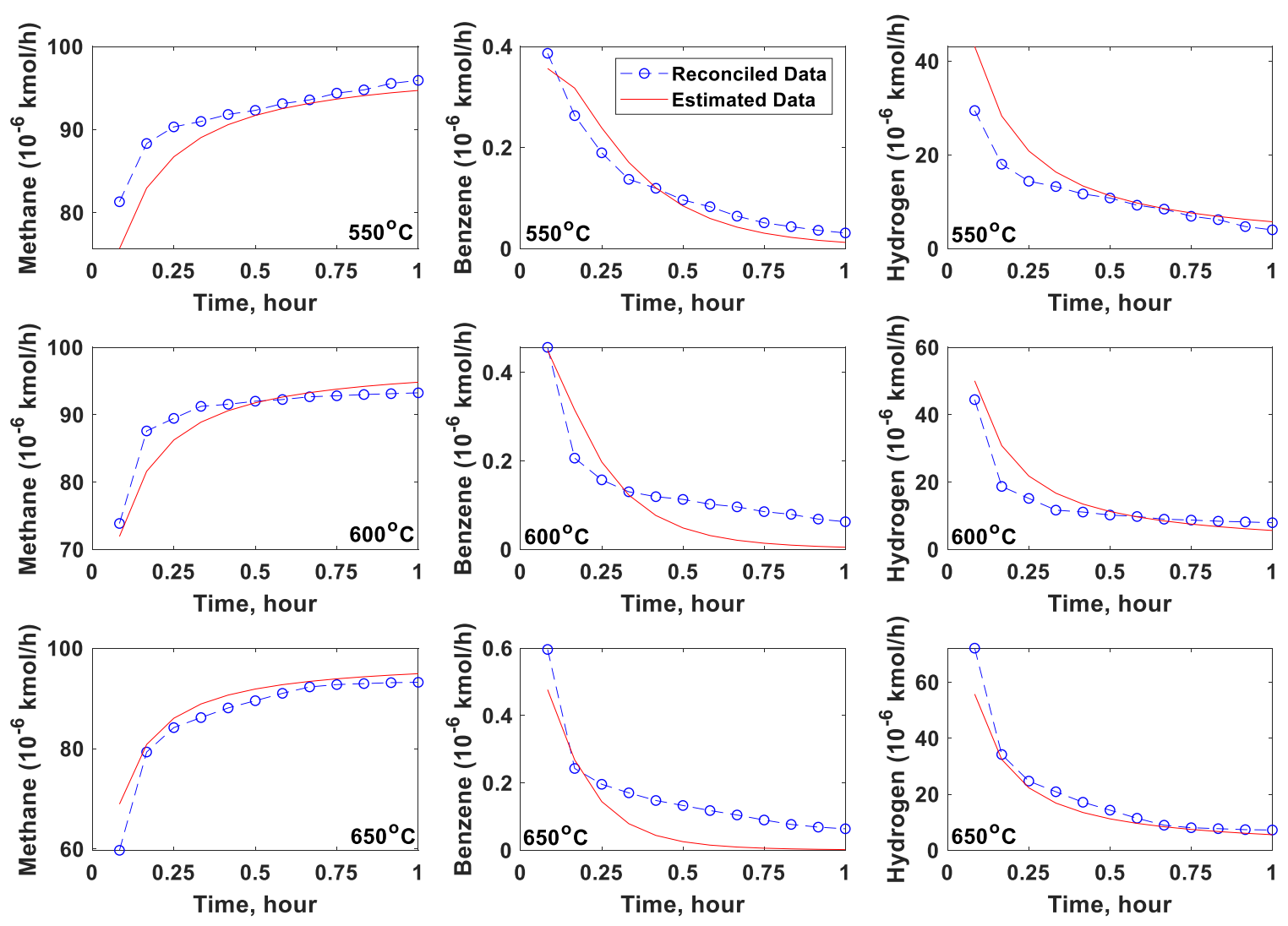

\section{Figure 5.5: Comparison of estimated and reconciled data after performing parameter estimation}

The initial guess for the decision variables is the values estimated for the methane DHA reaction via conventional heating. While the activation energy for a reaction is expected to be similar for a given catalyst irrespective of the sources of heat, but the pre-exponential factors can differ. The estimated decision variables for the MW case are shown in Table 5.2. For comparison purpose, the decision variables for non-MW case is also shown. 
Table 5.2: Comparison of estimated kinetic parameters between MW and non-MW experimental study

\begin{tabular}{|c|c|c|c|}
\hline Parameter & Value (MW) & Value (non-MW) & Units \\
\hline$E_{1}$ & 51.1 & 51.1 & $\mathrm{~kJ} / \mathrm{mol}$ \\
\hline$E_{2}$ & 30.02 & 30.04 & $\mathrm{~kJ} / \mathrm{mol}$ \\
\hline$E_{3}$ & 98.3 & 104.1 & $\mathrm{~kJ} / \mathrm{mol}$ \\
\hline$A_{1}$ & 10.0 & 9.95 & $\mathrm{kmol} / \mathrm{m}_{\text {cat-vol }}^{3} \mathrm{~s} \mathrm{bar}^{2}$ \\
\hline$A_{2}$ & $2.77 \cdot 10^{6}$ & $3.79 \cdot 10^{6}$ & $\mathrm{kmol} / \mathrm{m}_{\text {cat-vol }}^{3} \mathrm{~s} \mathrm{bar}^{3}$ \\
\hline$A_{3}$ & $7.37 \cdot 10^{4}$ & $2.23 \cdot 10^{4}$ & $k g_{\text {coke }} / \mathrm{m}_{\text {cat-vol }}^{3} s$ bar \\
\hline$\alpha$ & $2.69 \cdot 10^{-2}$ & $3.001 \cdot 10^{-2}$ & $m_{\text {cat-vol }}^{3} / k_{\text {coke }}$ \\
\hline$\Delta T$ & 238 & - & ${ }^{\circ} \mathrm{C}$ \\
\hline
\end{tabular}

Cumulative amount of coke deposited on the catalyst is calculated using the dynamic model with the estimated kinetic parameters. The model predicted coke deposition is compared with the experimental TGA data for two temperatures as shown in Table 5.3. There is fair agreement between the model coke prediction and experiment.

Table 5.3: Comparison of model coke prediction with experiment

\begin{tabular}{ccc}
\hline & \multicolumn{2}{c}{ Coke weight\% } \\
Temperature $\left({ }^{\circ} \mathrm{C}\right)$ & Experiment & Model \\
\hline 550 & $16.54 \%$ & $22.27 \%$ \\
600 & $23.11 \%$ & $24.97 \%$ \\
\hline
\end{tabular}

\subsection{Microwave Power Absorption and Reduced Order Model Development}

Microwave is an electromagnetic radiation wave with a frequency ranging from $300 \mathrm{MHz}$ to 300 $\mathrm{GHz}[197,198]$. Microwave heating of a material depends on the dielectric property of that material. The dielectric response of the material is quantified by the dielectric complex permittivity, given by Eq. 5.13 [199]. 
$\varepsilon=\varepsilon^{\prime}+i \varepsilon$

In Eq. 5.13, the real part is called the dielectric constant and it represents the ability of the material to absorb the MW energy. The imaginary part denotes the dielectric loss factor and it represents the ability of the material to convert the absorbed MW energy into heat. The ratio of the dielectric loss factor to the dielectric constant is called the loss tangent. It is a good indicator of the ability of the material to absorb the MW energy and generate heat, with higher loss tangent representing a material that can be heated efficiently by MW and vice versa. The temperature distribution within a reactor depends on the distribution of electromagnetic field that results in MW power absorption. MW power absorption can be typically modeled by using two methods [197,200,201]: 1) Lambert's law approximation. 2) Maxwell's Equation. Lambert's law is a simplified approach in which it is assumed that the MW power decreases exponentially as a function of penetration depth in the reactor. It is based on the transmission of wave and does not take into consideration the reflection of waves. A more rigorous approach for modeling MW power absorption is to use Maxwell's equation which considers both transmission and reflection. Microwaves are assumed to be incident on the cylindrical reactor as shown in Fig. 5.6. The power absorbed is assumed to be varying only in the radial direction.

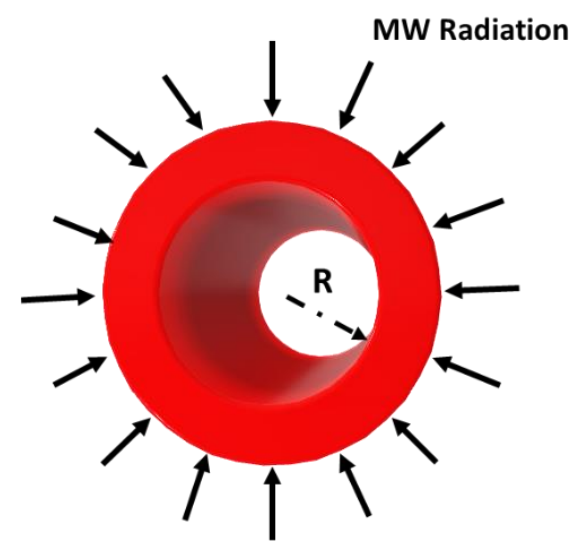

Figure 5.6: Schematic of cylindrical MW reactor and incident MW

The electromagnetic field distribution in space and time is given by Maxwell's equation as follows [202].

$\nabla \times E=-\frac{\partial B}{\partial t}$ 
$\nabla \times H=J+\frac{\partial D}{\partial t}$

$J=\sigma(\omega) E(t)$

$D=\varepsilon(\omega) E(t)$

$B=\mu(\omega) H(t)$

Here, $\mathrm{E}$ and $\mathrm{H}$ are the electric and magnetic field; $\mathrm{J}$ is the current flux; $\mathrm{D}$ is the electric displacement; and $\mathrm{B}$ is the magnetic induction; $\sigma$ is the electric conductivity; $\omega$ is the angular frequency; $\mu$ is the permeability. The phasor representation of electric and magnetic field is given by $E=\bar{E} e^{-i \omega t}$ and $H=\bar{H} e^{-i \omega t}$. Substituting this equations in Eq. 5.14-5.15, along with Eq. 5.16-5.18, results in,

$\nabla \times \bar{E}=i \omega \mu(\omega) \bar{H}$

$\nabla \times \bar{H}=-i \omega \varepsilon(\omega) \bar{E}$

The reactor is filled with Mo/HZSM-5 which is a dielectric material, and the electric field component is responsible for dielectric heating. So, the magnetic field component is neglected in this analysis, the magnetic permeability is approximated by its value in free space $\left(\mu_{0}\right)[202,203]$. The time derivative with respect to the electricity conductivity and dielectric constant can be neglected because the time scale of MW propagation is much smaller than thermal diffusion. Moreover, assuming the condition of electroneutrality within the system [202], Eq. 5.19 and 5.20 can be combined to give a uniform plane wave propagation in radial direction, given by Eq. 5.21 (for simplicity, the overbar has been dropped).

$\frac{d^{2} E_{z}}{d r^{2}}+\frac{1}{r} \frac{d E_{z}}{d r}+k_{1}^{2} E_{z}=0$

where $k_{1}^{2}=\omega^{2} \mu_{0} \varepsilon_{0}\left(\varepsilon_{r}^{\prime}+i \varepsilon_{r}^{\prime \prime}\right) ; \mu_{o}$ is the free space permeability; $\varepsilon_{o}$ is the free space permittivity; $\varepsilon_{r}^{\prime}$ and $\varepsilon_{r}^{\prime \prime}$ are relative dielectric constant and dielectric loss factor. Using dimensionless variables $r^{*}=\frac{r}{R}$ and $u=\frac{E_{Z}}{E_{0}}$, where $E_{o}$ is the intensity of incident electric field from the waveguide on the reactor wall, and noting that $u=E_{R}+i E_{I}$, Eq. 5.21 reduces to real and imaginary component of electric field as follows: 
$\frac{d^{2} E_{R}}{d r^{* 2}}+\frac{1}{r^{*}} \frac{d E_{R}}{d r^{*}}+\Psi E_{R}-\Omega E_{I}=0$

$\frac{d^{2} E_{I}}{d r^{* 2}}+\frac{1}{r^{*}} \frac{d E_{I}}{d r^{*}}+\Psi E_{I}+\Omega E_{R}=0$

where, $\Psi=R^{2} \omega^{2} \mu_{o} \varepsilon_{o} \varepsilon_{r}^{\prime}$ and $\Omega=R^{2} \omega^{2} \mu_{o} \varepsilon_{o} \varepsilon_{r}^{\prime \prime}$. The boundary conditions at center of the reactor is given as follows:

$A t r^{*}=0, \quad \frac{d E_{R}}{d r^{*}}=\frac{d E_{I}}{d r^{*}}=0$

When a plane wave is incident on a cylindrical surface, part of it is scattered and part of it is absorbed. Radiation boundary condition is used to account for this phenomena on the surface of the cylindrical reactor [204,205], given as follows. The derivation of the radiation boundary condition is shown in Appendix $\mathrm{J}$.

$\frac{d E_{R}}{d r^{*}}+c_{1} E_{R}+c_{2} E_{I}=c_{3}$

$\frac{d E_{I}}{d r^{*}}+c_{1} E_{I}-c_{2} E_{R}=c_{3}$

, where,

$c_{1}=R \alpha_{o}\left[\frac{J_{1}\left(\alpha_{o} R\right) J_{o}\left(\alpha_{o} R\right)+Y_{1}\left(\alpha_{o} R\right) Y_{o}\left(\alpha_{o} R\right)}{J_{o}^{2}\left(\alpha_{o} R\right)+Y_{o}^{2}\left(\alpha_{o} R\right)}\right]$

$c_{2}=\frac{2}{\pi}\left[\frac{1}{J_{o}^{2}\left(\alpha_{o} R\right)+Y_{o}^{2}\left(\alpha_{o} R\right)}\right]$

$c_{3}=-\frac{4}{\pi}\left[\frac{Y_{o}\left(\alpha_{o} R\right)}{J_{o}^{2}\left(\alpha_{o} R\right)+Y_{o}^{2}\left(\alpha_{o} R\right)}\right]$

$c_{4}=-\frac{4}{\pi}\left[\frac{J_{o}\left(\alpha_{o} R\right)}{J_{o}^{2}\left(\alpha_{o} R\right)+Y_{o}^{2}\left(\alpha_{o} R\right)}\right]$ 
The microwave power absorbed is given by Eq. 5.31 as follow:

$Q_{a b s}=\frac{1}{2} \omega \varepsilon_{o} \varepsilon_{r}^{\prime \prime} E_{o}^{2}\left(E_{R}^{2}+E_{I}^{2}\right)$

$E_{o}=\sqrt{\frac{P_{o} \cdot \pi \cdot \alpha_{o} \cdot R}{c \cdot \varepsilon_{o}}}$

Here $Q_{a b s}$ is microwave power absorbed per unit volume; $R$ is the reactor radius; $\alpha_{o}$ is the free space wavenumber; $P_{o}$ is the incident MW power flux. Since, ACM does not have the capability to handle complex values and Bessel functions, the system of differential equations 5.22-5.30 are solved in MATLAB using 'bvp4c' subroutine. However, the reactor model is implemented in ACM, a reduced order model (ROM) is developed for the MW power absorbed by using the results generated in MATLAB. In the proposed ROM, the MW power absorbed is a function of reactor radius, temperature, MW frequency, and dielectric property. It can be observed in Fig. 5.7 that the absorbed MW power has a steep near-linear drop from the center of the reactor to radius $\left(r_{o}\right)$, followed by a damped sine wave type characteristic for the remaining portion. To capture these characteristics, two sets of equations are used, where Eq. 5.34 captures the change in the MW power absorbed from center to $r_{o}$ and Eq. 5.35 represents the behavior for radius $\geq r_{o}$.

$$
\begin{aligned}
& P o w=\pi f \varepsilon_{o} E_{o}^{2}\left(\frac{\varepsilon_{r}^{\prime \prime}}{\varepsilon_{r}^{\prime}}\right) \\
& Q_{f i t, 1}=P o w \cdot\left(a_{1}+T \cdot a_{2}\right) \cdot\left[\cos ^{2}\left(\frac{r}{r_{0}} \cdot \frac{\pi}{2}\right)\right], 0 \leq r \leq r_{0} \\
& Q_{f i t, 2}=P o w \cdot\left(b_{1}+T \cdot b_{2}\right) \cdot e^{-b_{3} \cdot\left(r-r_{0}\right)} \cdot a b s\left[\sin \left(2 \pi\left(\frac{f}{c}\right) \cdot\left(r-r_{0}\right) \cdot b_{4}\right)\right], r_{0} \leq r \leq 1
\end{aligned}
$$

It is desired that the ROM satisfies the boundary conditions given by Eq. 5.36 and 5.37. At the center of the reactor, the MW power absorbed is finite and maximum and at $r=r_{o}$ MW power absorbed is zero.

$$
\text { At } r=0, \quad \frac{d Q_{f i t, i}}{d r}=0
$$


At $r=r_{o}, \quad Q_{f i t, i}=0$

here $a_{i}$ and $b_{i}$ are the parameters; $c$ is the velocity of light; $f$ is the MW frequency; $T$ is the temperature; $r$ is normalized variable reactor radius. Parameters of the ROM are estimated at two distinct frequencies $2.45 \mathrm{GHz}$ and $915 \mathrm{MHz}$ because $\mathrm{MW}$ reactors are constructed based on the frequency of operation. It can be noted that commercial fixed frequency MW generators are available at these two distinct frequencies. A bigger waveguide is required for $915 \mathrm{MHz}$ and the same waveguide cannot be used to operate the reactor at $2.45 \mathrm{GHz}$ [196]. Temperature range of $550^{\circ}-800^{\circ} \mathrm{C}$ with dielectric properties of $4 \mathrm{wt} \% \mathrm{Mo} / \mathrm{HZSM}-5(\mathrm{Si}: \mathrm{Al}=23)$ at those temperatures are used for estimating the parameters. Dielectric properties of the catalyst is obtained based on the data from Julian et al. [206]. The characteristics of MW power absorbed with respect to radius is extremely non-linear depending on the specific frequency and therefore two sets of parameters are estimated by least squares minimization using 'Lsqcurvefit' subroutine in MATLAB. The estimated parameters are given in Appendix K. Fig. 5.7 shows the comparison of the MW power absorbed with respect to radius using the Maxwell's equation $\left(Q_{\text {Maxwell }}\right)$ versus the $\operatorname{ROM}\left(Q_{R O M}\right)$ for these four cases- $550^{\circ} \mathrm{C}$ and $2.45 \mathrm{GHz}, 550^{\circ} \mathrm{C}$ and $915 \mathrm{MHz}, 800^{\circ} \mathrm{C}$ and $2.45 \mathrm{GHz}$, and $800^{\circ} \mathrm{C}$ and $915 \mathrm{MHz}$. For all these cases an excellent match was obtained. Comparison for $600^{\circ} \mathrm{C}, 700^{\circ} \mathrm{C}$, and $750^{\circ} \mathrm{C}$ are shown in Appendix K. The ROM facilitates fast and easy computation of the MW power absorbed with negligible loss of accuracy and thus can be computationally advantageous for other software platforms as well as without requiring solving the coupled complex Maxwell's equations. 

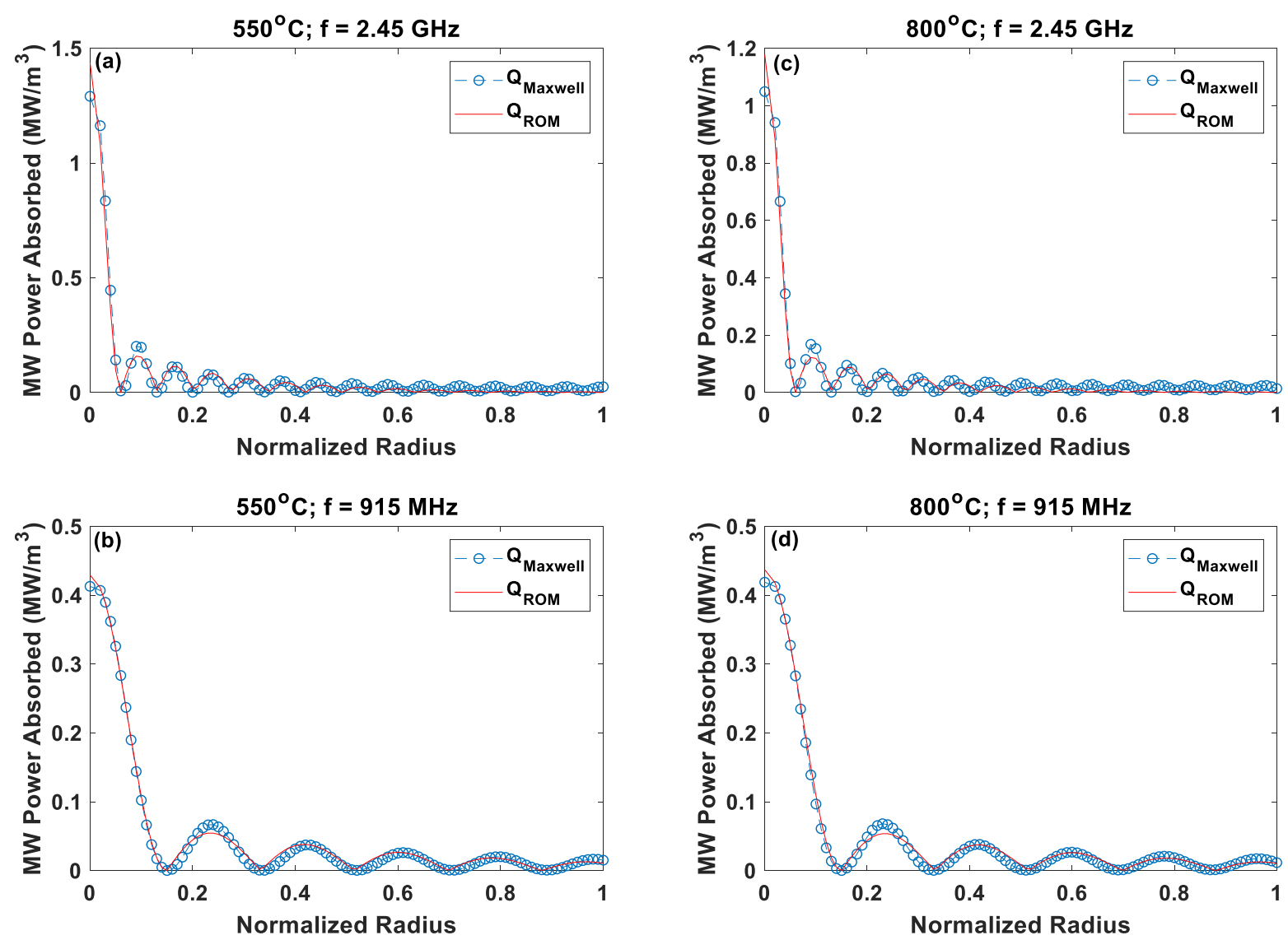

Figure 5.7: MW power absorbed modeled using Maxwell's equation and reduced order model. 550 ${ }^{\circ} \mathrm{C}$ - (a) $2.45 \mathrm{GHz}$ (b) $915 \mathrm{MHz} ; 800^{\circ} \mathrm{C}$ - (c) $2.45 \mathrm{GHz}$ (d) $915 \mathrm{MHz}$

\subsection{Microwave Reactor Model Development}

MW reactor is assumed to be made of quartz glass and it is a single tube reactor. It is also assumed that no heat transfer fluid circulates through the reactor, to avoid absorption of MW by the heat transfer fluid. 2-D multi-scale dynamic heterogenous fixed-bed MW reactor is developed in Aspen Custom Modeler V9®. Particle and reactor level models are developed and coupled leading to a multi-scale model.

Following assumptions are made for the model development.

- Metal particles are assumed to be uniformly distributed inside the HZSM-5 catalyst support. The temperature of the metal particles in each control volume (CV) is assumed to be same, but different from one $\mathrm{CV}$ to the other. 
- Temperature is considered to vary in the radial direction in the catalyst support, but the temperature inside the metal particle is assumed to be the same everywhere due to the nanometer size of the dispersed metal particles.

- Heat transfer between the metal particles-support, bulk gas-catalyst support, bulk gas-reactor wall is modeled in addition modeling heat loss through reactor wall.

- Conductive heat transport between the catalyst particles is modeled.

\subsubsection{Gas Phase Species Balance}

The transient bulk gas phase species balance is given by Eq. 5.38:

$\varepsilon_{b} \cdot \frac{\partial C_{g a s, i}}{\partial t}=-\varepsilon_{b} \frac{\partial\left(C_{g a s, i} \cdot u_{g a s}\right)}{\partial z}+k_{g a s, i} \cdot \frac{6\left(1-\varepsilon_{b}\right)}{d_{c p}}\left(C_{c a t, s u r, i}-C_{g a s, i}\right)$

where $i$ denotes the gas species $\mathrm{CH}_{4}, \mathrm{C}_{2} \mathrm{H}_{4}, \mathrm{C}_{6} \mathrm{H}_{6}, \mathrm{H}_{2}, \mathrm{~N}_{2}$. The evolution of coking profile over time is modeled using Eq. 5.39

$\frac{d C_{c}}{d t}=r_{c}$

The overall species conservation equation is also written (Eq. 5.40).

$\varepsilon_{b} \cdot \frac{\partial \rho_{g a s}}{\partial t}=-\varepsilon_{b} \frac{\partial\left(\rho_{g a s} \cdot u_{g a s}\right)}{\partial z}+\frac{6\left(1-\varepsilon_{b}\right)}{d_{c p}} \sum k_{g a s, i} \cdot\left(C_{c a t, s u r, i}-C_{g a s, i}\right)$

where $\rho_{g a s}$ is the bulk gas density; $C_{c a t, \text { sur, } i}$ is the gas concentration on the catalyst surface; $d_{c p}$ is diameter of the catalyst pellet; $\varepsilon_{b}$ is the bed voidage calculated using the equation given by Adams and Barton [175]; $k_{g a s, i}$ is the gas mass transfer coefficient. The boundary condition at the reactor inlet (at $\mathrm{z}=0)$ is given as $C_{g a s, i}(z=0)=C_{g a s, i, \text { inlet }}, u_{g a s, i}(z=0)=u_{\text {gas }, i, \text { inlet }}, \rho_{\text {gas }, i}(z=0)=$ $\rho_{\text {gas,i,inlet }}$. The summation equation given by Eq. 5.11 is also included. The inlet gas interstitial velocity is calculated using Eq. 5.41 as follows:

$u_{\text {gas }, \text { inlet }}=\frac{F_{\text {gas,inlet }}}{\rho_{\text {gas,inlet }} \cdot A_{\text {bed }} \cdot \varepsilon_{b}}$

where $F_{\text {gas,inlet }}$ is the inlet gas molar flowrate and $A_{\text {bed }}$ is the catalyst bed area. SRK is used as the thermodynamic model in ACM for the gas phase. 


\subsubsection{Bulk Gas Phase and Reactor Wall Energy Balance}

The bulk gas phase energy balance is written as,

$$
\begin{gathered}
\varepsilon_{b} \cdot \rho_{g a s} \cdot \frac{\partial H_{g a s}}{\partial t}=-\varepsilon_{b} \cdot \frac{\partial\left(H_{g a s} \cdot \rho_{g a s} \cdot u_{g a s}\right)}{\partial z}+h_{g c} \cdot \frac{6\left(1-\varepsilon_{b}\right)}{d_{c p}} \cdot\left(T_{c s, s u r f}-T_{g a s}\right)+. . \\
. .+\frac{6\left(1-\varepsilon_{b}\right)}{d_{c p}} \sum H_{g a s} \cdot k_{g a s, i} \cdot\left(C_{c a t, i}-C_{g a s, i}\right)+a_{w, i n} \cdot h_{w a l l} \cdot\left(T_{w a l l}-T_{g a s}\right)
\end{gathered}
$$

The boundary condition at reactor inlet is $H_{g a s}(z=0)=H_{g a s, \text { inlet }}$. The tube wall energy balance is given by Eq. 5.43,

$$
\begin{aligned}
\rho_{\text {tube }} \cdot C_{p, t u b e} & \cdot \frac{\partial T_{\text {wall }}}{\partial t} \\
& =\lambda_{\text {tube }} \cdot \frac{\partial^{2} T_{\text {wall }}}{\partial z^{2}}+a_{w, \text { in }} \cdot h_{\text {wall }} \cdot\left(T_{\text {wall }}-T_{\text {gas }}\right)-a_{w, o u t} \cdot h_{o} \cdot\left(T_{\text {wall }}-T_{\text {amb }}\right)
\end{aligned}
$$

and the boundary conditions for the tube wall are as follows:

at $z=0, \quad T_{\text {wall,inlet }}=T_{\text {gas,inlet }}$

at $z=L, \quad \frac{\partial T_{\text {wall }}(z)}{\partial z}=0$

where $H_{g a s}$ is the gas enthalpy; $h_{g c}$ is the gas heat transfer coefficient; $h_{w a l l}$ is the reactor wall heat transfer coefficient; $h_{o}$ is the external convective heat transfer coefficient [207]; $T_{\text {wall }}$ is the reactor wall temperature; $T_{g a s}$ is the bulk gas temperature; $T_{a m b}$ is the temperature of the surrounding; $T_{c s}$ is the catalyst support; $a_{w, \text { in }}$ and $a_{w, \text { out }}$ is the ratio of internal and external surface area to volume of the reactor wall.

\subsubsection{Catalyst Phase- Gas Mass Balance}

Variation of gas concentration in the radial direction inside the porous catalyst particle is also modeled. Inside the catalyst particle, the dominating mass transport mechanism is diffusion, while the convection term is assumed to be negligible due to small pore radius and negligible pressure difference. The transient gas species mass balance inside the spherical catalyst particle is given by: 
$\emptyset \cdot \frac{\partial C_{c a t, i}}{\partial t}=\frac{\emptyset}{r^{2}} \cdot \frac{\partial}{\partial r}\left(D_{e f f, i} \cdot r^{2} \cdot \frac{\partial C_{c a t, i}}{\partial r}\right)+\sum r_{j}$

The boundary conditions are as follows:

At $r=0, \quad \frac{\partial C_{c a t, i}(z, r)}{\partial r}=0$

At $r=r_{p}, \quad-D_{e f f, i} \cdot \frac{\partial C_{c a t, i}(z, r)}{\partial r}=k_{g a s, i} \cdot\left(C_{c a t, i}(z, r)-C_{g a s, i}(z)\right)$

Here, $D_{e f f, i}$ is the effective diffusivity of gas in the catalyst. It considers both molecular and Knudsen diffusivity; $\emptyset$ is the catalyst porosity.

\subsubsection{Catalyst Support and Metal Particle - Energy Balance}

The radial temperature variation within the catalyst support in spherical coordinates is given as follows:

$$
\begin{aligned}
\rho_{c s} \cdot C_{p, c s} \cdot \frac{\partial T_{c s}}{\partial t}=(1-\emptyset) \cdot \frac{\lambda_{c s}}{r^{2}} \cdot \frac{\partial}{\partial r}\left(r^{2} \cdot \frac{\partial T_{c s}}{\partial r}\right) & +\frac{3 h_{m p}}{r_{m p}} \cdot \frac{V_{f, m p}}{\left(1-V_{f, m p}\right)} \cdot\left(T_{m p}-T_{c s}\right) \\
& -\frac{\Delta H_{r, 2} \cdot r_{2}}{\left(1-V_{f, m p}\right)(1-\emptyset)}+Q_{c s, a b s}
\end{aligned}
$$

The boundary conditions for the catalyst support is as follows:

$$
\begin{aligned}
& \text { At } r=0, \quad \begin{array}{r}
\frac{\partial T_{c s}}{\partial r}(z, r)=0 \\
\text { At } r=r_{p}, \quad-\lambda_{c s} \cdot \frac{\partial T_{c s}(z, r)}{\partial r}=h_{g c} \cdot\left(T_{c s}(z, r)-T_{\text {gas }}\right)+\sum H_{\text {gas }} \cdot k_{\text {gas }, i} \cdot\left(C_{c a t, i}-C_{\text {gas }, i}\right) \\
+\lambda_{c s} \cdot \frac{\partial T_{c s}}{\partial r_{\text {reactor }}} \cdot \frac{d_{c p}}{6} \cdot A_{e q}
\end{array}
\end{aligned}
$$

where $\lambda_{c s}$ is the thermal conductivity of the catalyst support; $\Delta H_{r, 2}$ is the heat of reaction of reaction $2 ; \rho_{c s}$ is the catalyst support density; $C_{p, c s}$ is the heat capacity of the solid catalyst support; $A_{e q}$ is the ratio of equivalent reactor area to volume; $V_{f, m p}$ is the volume fraction of the metal particle; $r_{m p}$ is the radius of the metal particle; $h_{m p}$ is the heat transfer coefficient of the metal particle and catalyst support. Heat transfer coefficient, $h_{m p}$, is taken from a study by Collier et al. [208] on heat transfer between a particle and bed of much larger particles. The last term in catalyst 
surface boundary condition accounts for conduction of heat through the catalyst pellet matrix. Initially, it is assumed that the temperature of the catalyst is same as the gas temperature. The energy balance for the metal particle is given by Eq. 5.46.

$\rho_{m p} \cdot C_{p, m p} \cdot \frac{\partial T_{m p}}{\partial t}=Q_{m p, a b s}-\frac{3 h_{m p}}{r_{m p}} \cdot\left(T_{m p}-T_{c S}\right)-\frac{\sum_{j=1,3} \Delta H_{r, j} \cdot r_{j}}{V_{f, m p}(1-\emptyset)}$

\subsubsection{Pressure Drop}

The Ergun equation is used to calculate the pressure drop inside the reactor [174].

$\frac{d P}{d z}=-\frac{150 \cdot \mu_{g a s}}{d_{c p}} \cdot \frac{\left(1-\varepsilon_{b}\right)^{2}}{\varepsilon_{b}{ }^{3}} \cdot\left(\varepsilon_{b} \cdot u_{g a s}\right)+\frac{1.75 \cdot \rho_{g a s}}{d_{c p}} \cdot \frac{\left(1-\varepsilon_{b}\right)}{\varepsilon_{b}{ }^{3}} \cdot\left(\varepsilon_{b} \cdot u_{g a s}\right)^{2} \cdot M_{g a s}$

where $M_{\text {gas }}$ is the molecular weight of the gas; $P$ is the reactor pressure. The boundary condition is as follows: $P(z=0)=P_{\text {inlet }}$.

\subsubsection{Mass \& Heat Transfer Coefficient, and Effective Diffusivity}

The mass transfer coefficient $\left(k_{g a s, i}\right)$ and the bulk gas heat transfer coefficient $\left(h_{g c}\right)$ are calculated using the correlations given by Mobed et al. [174], Barton and Adams II [175]. The effective diffusivity $\left(D_{e f f, i}\right)$ of gas in catalyst phase is calculated using the following equation:

$\frac{1}{D_{e f f, i}}=\frac{1}{D_{k n u d, e f f, i}}+\frac{1}{D_{\text {mix }, e f f, i}}$

The effective Knudsen diffusivity $\left(D_{k n u d, e f f, i}\right)$ is calculated using the correlation given by Satterfield [177] as follows: The gas constant $(R)$ is added to this equation to make the units consistent.

$D_{i, k n u d, e f f}=19,400 \cdot \frac{\emptyset^{2}}{\tau \cdot S_{g} \cdot \rho_{c p}} \sqrt{\frac{T_{c a t} \cdot R}{M_{g a s, i}}}$

The effective molecular diffusivity $\left(D_{m i x, e f f, i}\right)$ is calculated using the following equation:

$D_{\text {mix }, e f f, i}=\frac{D_{m i x, i} \cdot \emptyset}{\tau}$

where $S_{g}$ is the specific area of the catalyst pellet; $\tau$ is the tortuosity of the catalyst; $\rho_{p}$ is the particle density; $M_{i}$ is the molecular weight of the gas species $i$. 


\subsubsection{Wall Heat Transfer Coefficients}

The internal and external wall heat transfer coefficient given by Ostace et al. [207], is shown in Eq. 5.51 and 5.52, respectively.

$$
\begin{aligned}
& h_{\text {wall }}=(12.5+0.0048 \cdot R e) \frac{\lambda_{\text {gas }}}{d_{\text {reactor }}} \\
& h_{o}=\left(\begin{array}{c}
\left.0.825+\frac{0.387 R a^{1 / 6}}{\left[1+\left(\frac{0.492}{P r}\right)^{9 / 16}\right]^{8 / 27}}\right)
\end{array}\right.
\end{aligned}
$$

where $R a, R e$, and $P r$ are Rayleigh, Reynolds and Prandtl number, respectively.

$R a=\frac{g \cdot \rho_{\text {gas }} \cdot \beta \cdot\left(T_{\text {gas }}-T_{\text {amb }}\right) \cdot L_{\text {reactor }}^{3}}{\mu_{\text {gas }} \cdot \alpha_{\text {air }}}$

$R e=\frac{d_{c p} \cdot \varepsilon_{b} \cdot u_{g a s} \cdot \rho_{g a s}}{\mu_{g a s}}$

$\operatorname{Pr}=\frac{C_{p, g a s} \cdot \mu_{g a s}}{\lambda_{g a s}}$

Where $g$ is the gravitational acceleration; $\beta$ is the thermal expansion coefficient; $L_{\text {reactor }}$ is the reactor length; $\alpha_{\text {air }}$ is the air thermal diffusivity. Like before, the PDEs are solved by method of lines. Backward finite difference is used for discretizing all $1^{\text {st }}$ order differential equations, while the central finite difference method is used for discretizing all $2^{\text {nd }}$ order differential equations in space. The reactor is discretized in radial and axial direction on reactor level, and radial direction on the particle level.

\subsection{Results and Discussion}

In this section, sensitivity analysis with respect to some of the key reactor variables is performed to understand their impact on reactor performance parameters. The value of some of the key variables used for these studies is shown in Table 5.4. The reactor is loaded with 4 wt $\%$ Mo/HZSM-5 catalyst. For all simulations, it is assumed that initially there is no coke on the catalyst. The volume fraction of the metal particles is calculated using the weight percentage of Mo and the reactor catalyst loading. 
Table 5.4: Values of some key parameters used for simulation

\begin{tabular}{cc}
\hline Parameter & Value \\
\hline Specific area of the catalyst pellet, $S_{g}$ & $209.93 \mathrm{~m}^{2} / \mathrm{g}$ \\
Catalyst porosity, $\emptyset$ & 0.35 \\
Tortuosity, $\tau$ & 0.5 \\
Reactor length, $L_{\text {reactor }}$ & $2 \mathrm{~m}$ \\
Reactor inner diameter, $D_{\text {reactor }}$ & $1.27 \mathrm{~m}$ \\
Reactor wall thickness, $W_{t h}$ & $9.53 \mathrm{~mm}$ \\
Catalyst pellet diameter, $d_{c p}$ & $4.8 \mathrm{~mm}$ \\
Metal particle radius, $r_{m p}$ & $80 \mathrm{~nm}$ \\
Catalyst bulk density & $800 \mathrm{~kg} / \mathrm{m}^{3}$ \\
$h_{m p}$ & $145 \mathrm{~W} / \mathrm{m}^{2} \mathrm{~K}$ \\
\hline
\end{tabular}

\subsubsection{Effect of MW Input Power and Frequency}

For this analysis, the reactor is fed with $340 \mathrm{kmol} / \mathrm{h}\left(\mathrm{CH}_{4}-90\right.$ mol\%, balance $\left.\mathrm{N}_{2}\right)$ at 2.1 bar and $800^{\circ} \mathrm{C}$. Initially, the reactor is maintained at $800^{\circ} \mathrm{C}$. The dielectric properties of the catalyst at this temperature are $\varepsilon^{\prime}=1.976$ and $\varepsilon^{\prime \prime}=0.06377$ [206]. Using these dielectric properties, reactor dimensions, and operating conditions, the volumetric average absorbed MW power varying in reactor radial direction is calculated using the ROM. The effect of MW frequency and input power on the volume average values of the following key performance variables are studied- reactor bulk gas temperature, methane conversion, product yield, and catalyst activity are studied. Results for 2.45 GHz frequency at different input powers are shown in Fig. 5.8. It should be noted that the input MW power remains the same through the reactor operating time. 

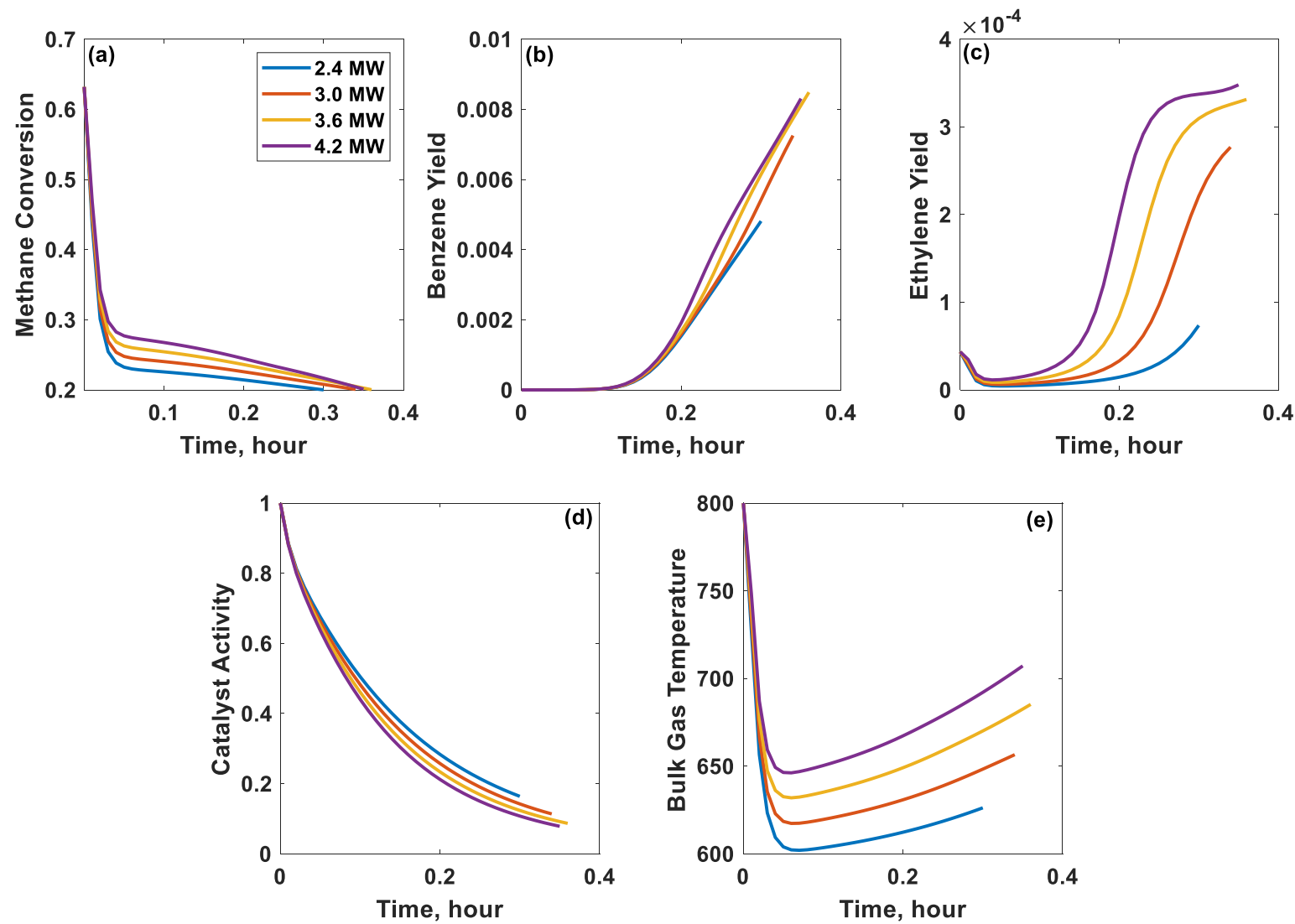

Figure 5.8: Impact of input $M W$ power on reactor performance parameter for $2.45 \mathrm{GHz}$ operating frequency: a) methane conversion, b) benzene yield, c) ethylene yield, d) catalyst activity, e) bulk gas temperature

In Fig. 5.8, the results for the operating time it takes for the methane conversion to drop $20 \%$ is shown. As seen, during the initial operating time of the reactor there is a considerable decrease in the bulk gas temperature that is mainly due to the dominating endothermic reaction (Reaction \#3, i.e. coking reaction). Due to the low temperature, reaction \#1 is barely initiated as seen by low yield of benzene and ethylene during this time as seen in Fig. 5.8b-5.8c. The reactor temperature starts to increase after some time as reaction \#3 slows down compared to other reactions. As expected, the catalyst activity decreases slowly for the lowest input power due to less methane conversion as seen in Fig. 5.8d. With the increase in input power, the bulk gas temperature starts to rise and as a result methane conversion increases, which reduces catalyst activity faster. Similar, phenomena are observed for $915 \mathrm{MHz}$ frequency as shown in Appendix L. As shown in Fig. 5.7, most of the MW energy is absorbed near the center. Considerably less power is being absorbed near the wall, thus the volume averaged power can be lower for larger diameter reactors leading to slower rise in temperature as seen in Fig. 5.8e. This aspect needs to be considered in the MW 
generator and reactor design as the reactor diameter is increased. Secondly, the MW input power needs to be modulated with time to have better product yield. Using the profiles in Fig. 5.8 and Appendix L, the integral MW power absorbed per $\mathrm{kg}$ of total product produced till the methane conversion drops to $20 \%$ is calculated at different power input. The results for $2.45 \mathrm{GHz}$ and 915 MHz frequency are shown in Fig. 5.9.

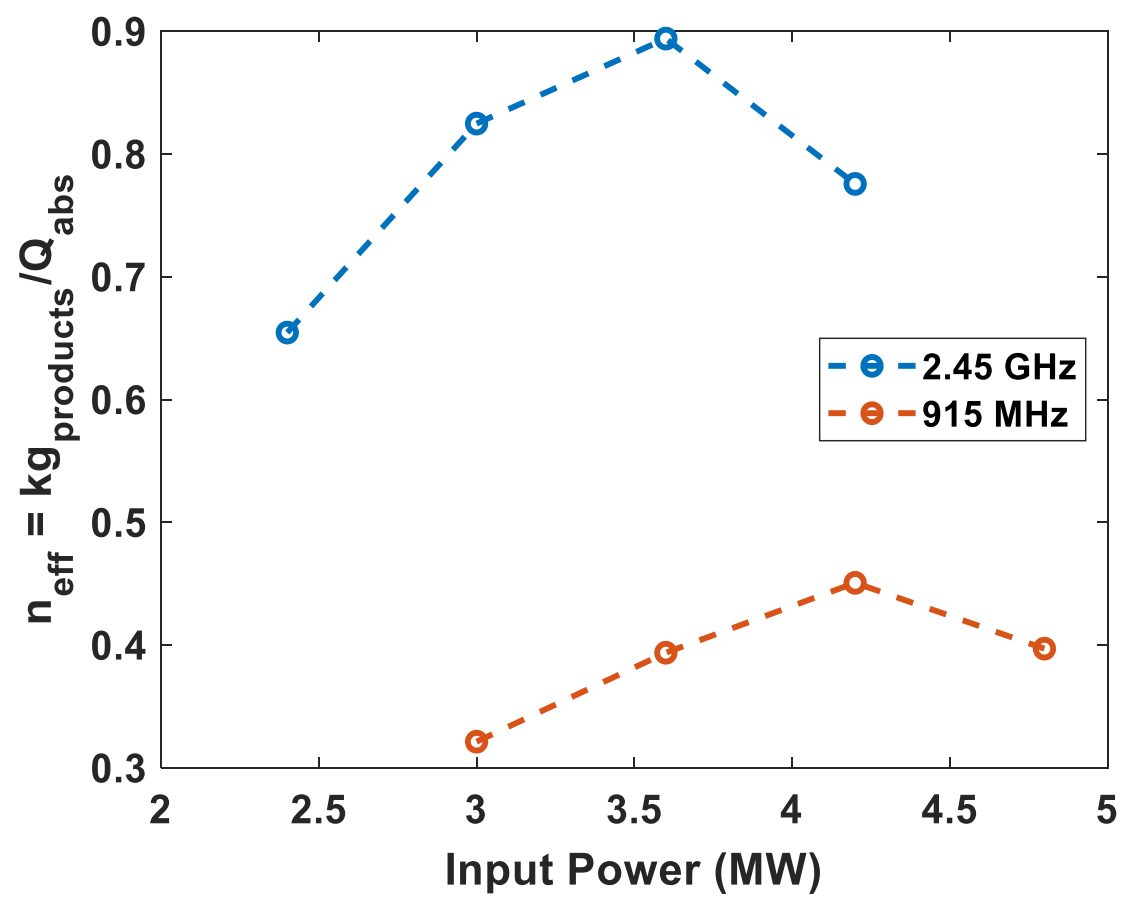

Figure 5.9: Sensitivity of input MW power on reactor performance

In Fig. 5.9, the product considers total amount of benzene and ethylene produced. As seen, $n_{\text {eff }}$ is higher for $2.45 \mathrm{GHz}$ compared to $915 \mathrm{MHz}$ frequency i.e. the power used to produce a $\mathrm{kg}$ of product is less for $2.45 \mathrm{GHz}$ compared to $915 \mathrm{MHz}$ frequency. This is mainly due to the efficiency of power absorption by the catalyst at a given frequency. For $2.45 \mathrm{GHz}$ and $915 \mathrm{MHz}$ frequency, cases when $n_{\text {eff }}$ is maximum, integral MW power input and the integral power absorbed is calculated for the operating time it takes for methane conversion to drop to 20\%. MW absorption efficiency i.e. the ratio of integral MW power absorbed to the integral input MW power is calculated, and it is found that the MW power absorption efficiency for $2.45 \mathrm{GHz}$ is $91 \%$, as compared to $73 \%$ for $915 \mathrm{MHz}$ frequency. Due to the lower absorption efficiency for $915 \mathrm{MHz}$, the reactor temperature is lower and as result less products are produced. So, more input power is required to produce the same amount of product. Based on the analysis, MW reactor operating at 
a frequency of $2.45 \mathrm{GHz}$ and an input power of 3.6 mega-watts, has the best performance i.e. highest efficiency. Reactor spatial variation of area average reactor performance parameters at 2.45 GHz for 3.6 mega-watts input MW power, is shown in Fig. 5.10.
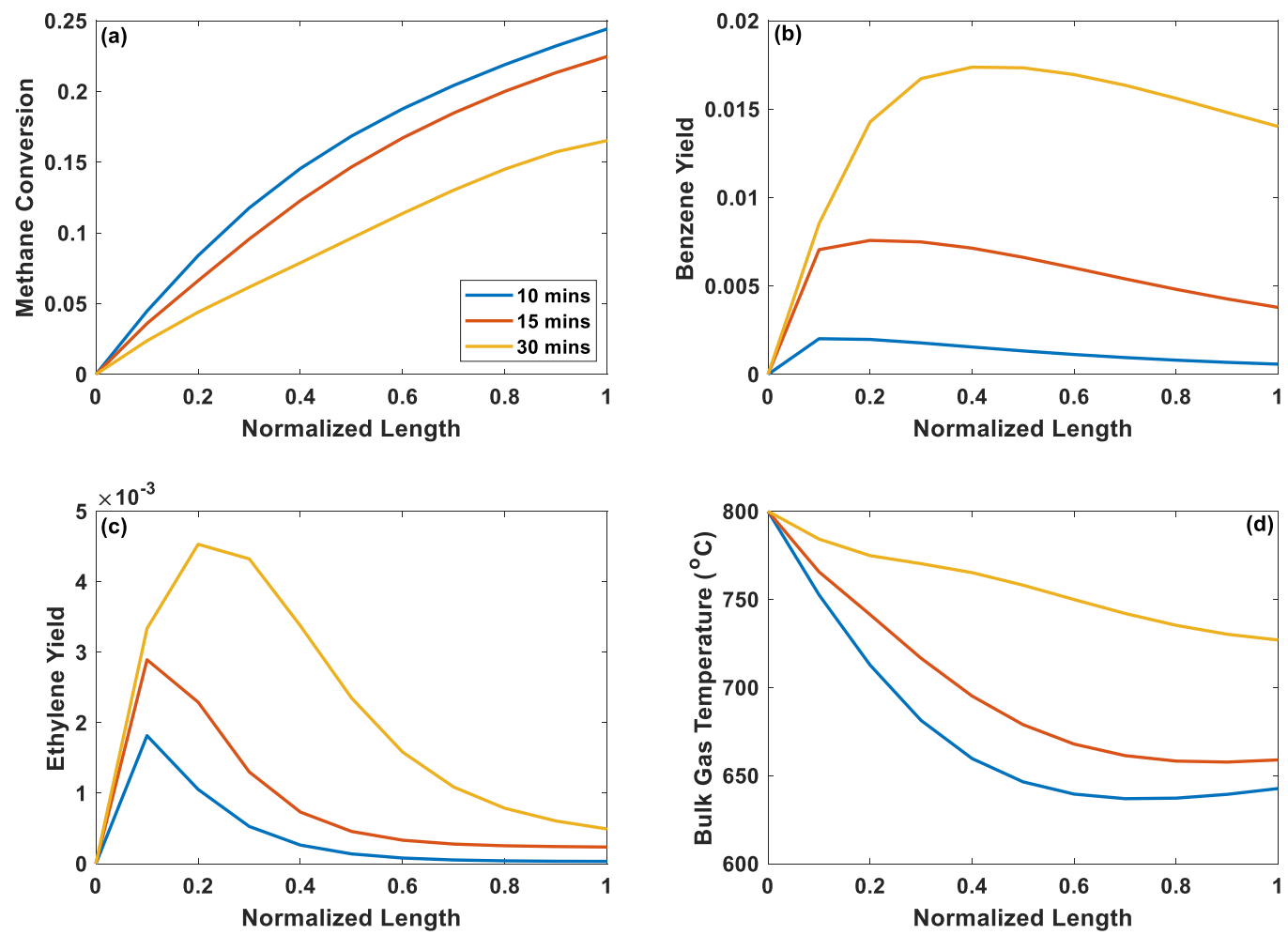

Figure 5.10: Spatial variation of area average (a) methane conversion, (b) benzene yield, (c) ethylene yield and (d) bulk gas temperature. $f=2.45 \mathrm{GHz}$; $P_{\text {in }}=3.6$ mega-watts

As seen in Fig. 5.10d, as the reactor operating time increases, the bulk gas temperature increases. With the increase in the reactor temperature, product yields increase as shown in Fig. 5.10b and 5.10c, but methane conversion decreases as shown in Fig. 5.10a due to decrease in catalyst activity. The reduction in the rate of reaction \#3 is maximum due to the decrease in catalyst activity, leading to higher methane partial pressure. Reaction \#1 and \#2 are benefited the most due to the higher methane partial pressure and higher temperature, and this results in higher benzene yield.

\subsubsection{Temperature Profile of Metal Particles and Catalyst Support}

For all the studies in this section, the reactor feed is $340 \mathrm{kmol} / \mathrm{h}\left(\mathrm{CH}_{4}-90\right.$ mol\%, balance $\left.\mathrm{N}_{2}\right)$ at 2.1 bar and $800^{\circ} \mathrm{C}$, with the input MW power $\left(P_{\text {in }}\right)$ is set at $2.4 \mathrm{MW}$. It is generally thought in the field of MW catalysis that the metal particles absorb more MW energy than the catalyst support, and as a result they are at a higher temperature than the support. For this to occur, the loss 
tangent of the $4 \mathrm{wt} \% \mathrm{Mo} / \mathrm{HZSM}-5$ catalyst must be higher than the HZSM-5 catalyst. However, the experimental data from Julian et al. [206] on dielectric measurements of this catalyst shows no significant change in the dielectric properties of $4 \mathrm{wt} \% \mathrm{Mo} / \mathrm{HZSM}-5$ catalyst with the addition of Mo to HZSM-5, as compared to HZSM-5 alone. Therefore, when the data from those studies are used, there is negligible temperature difference between the metal and support particles. However, depending on the catalysts type, metal particle can absorb more MW power than the catalyst support. Therefore, a hypothetical scenario is considered where the volumetric MW absorption by the metal particle is 200 times higher than that of the support material. The spatial variation of temperature in metal and support particles at an early time instant of $\mathrm{t}=1 \mathrm{sec}$ and at a later time instant of $t=1 \mathrm{~min}$ is shown in Fig. 5.11. The temperature profile shown is at the catalyst particle surface located near the reactor center, along the length of the reactor. Catalyst support and metal particle temperatures inside the catalyst particle at different reactor radial and axial locations were analyzed and no temperature difference was seen between the two. It is observed that even with increasing the MW absorption of metal particles by 200 times, there is hardly any temperature difference between the metal particles and the catalyst support. 

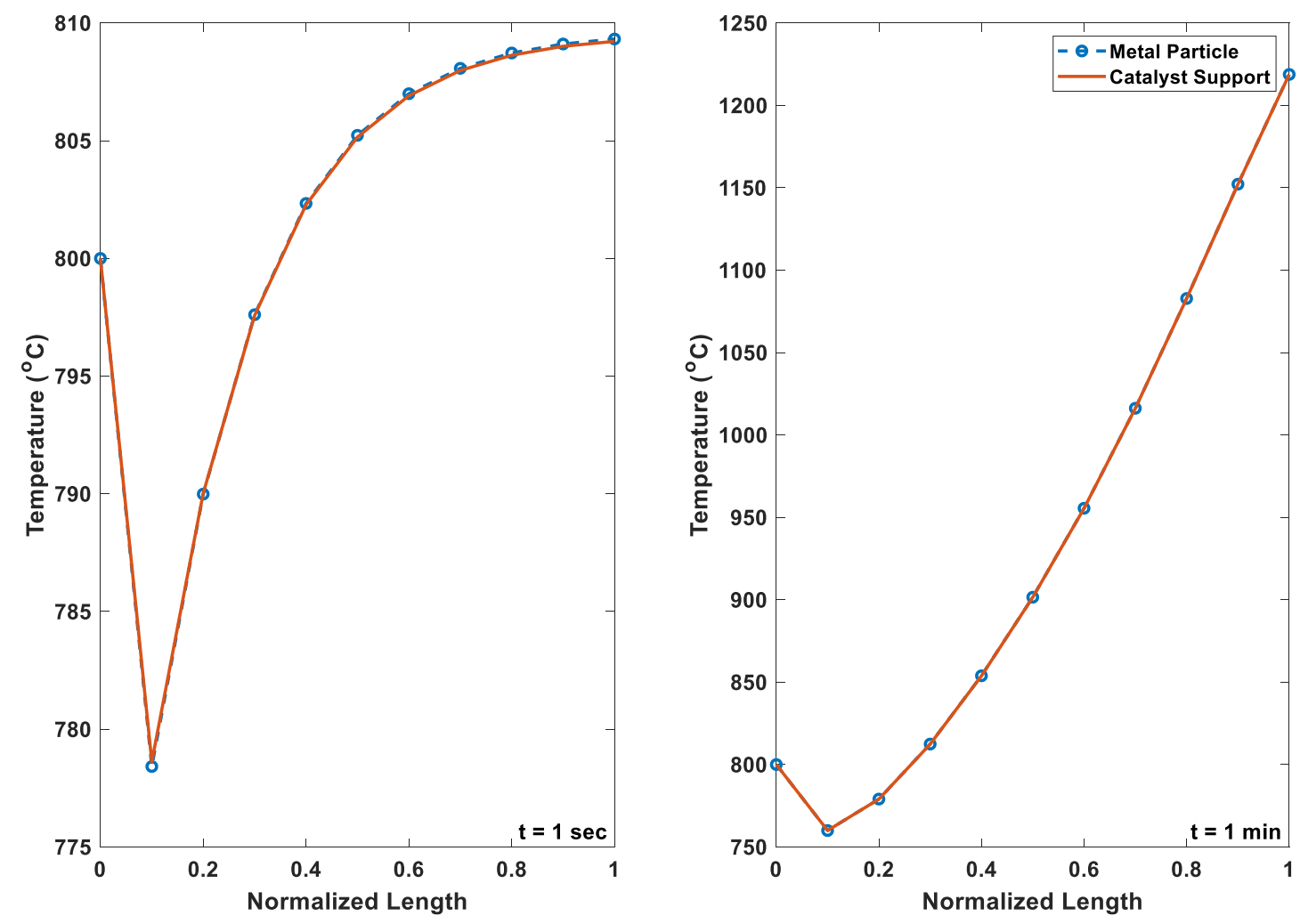

Figure 5.11: Spatial variation of metal particle and catalyst support temperature at $t=1 \mathrm{sec}$ and $t=1 \mathrm{~min}$, at the catalyst particle surface near the reactor center. $M W$ absorption capacity of metal particle is increased by 200 times

Another scenario is considered where the contact area between metal particles and support is reduced by $95 \%$ (Fig. 5.12a-5.12b) and 100\% (Fig. 5.12c), while the volumetric MW absorption by the metal particle is still specified to be 200 times higher than the support material. The reduction of contact area by $100 \%$ (i.e. minimal contact between metal and support particles) is not realistic but is investigated as the worst case scenario. The spatial temperature profile is shown in Fig. 5.12. For 95\% reduction in contact area, at $\mathrm{t}=1 \mathrm{sec}$, catalyst support temperature is approximately $5^{\circ} \mathrm{C}$ higher than the metal particles on the catalyst particle surface located near the reactor center at the reactor inlet. This is the reactor location at which highest temperature difference between the metal particle and catalyst support is seen. The maximum temperature difference between the metal particle and support is about $2^{\circ} \mathrm{C}$ near the reactor outlet. In general, the total power absorbed by metal particles and catalyst support is calculated and their ratio is about 2.45 i.e. the metal particles absorb 2.45 more MW energy than the catalyst support. It should be noted that the volume of catalyst support is about 80 times bigger than metal particles. Reaction 
\#1 and \#3 take place on metal particle, and reaction \#1 is about three times more endothermic than reaction \#3. In the initial part of the reactor, due to higher methane partial pressure both of these reactions are dominating and as a result the heat of reaction is higher than MW energy input on the metal particles. In contrast, rection \#2 takes place on the catalyst support and it is exothermic. So, the temperature of metal particle is lower than the support in the initial part of the reactor. Near the reactor exit, the relative rates of reaction \#1 and \#3 decrease, resulting in endothermic reaction heat being lower than the MW energy input. So, the temperature of metal particles is higher than the support. The temperature difference between the two disappears at $t=1 \mathrm{~min}$. Reducing the contact area between the metal particles and support by $100 \%$ shows a temperature difference of about $9^{\circ} \mathrm{C}$ between the two, as seen in Fig. 5.12c. This difference disappears at $\mathrm{t}=1 \mathrm{~min}$.
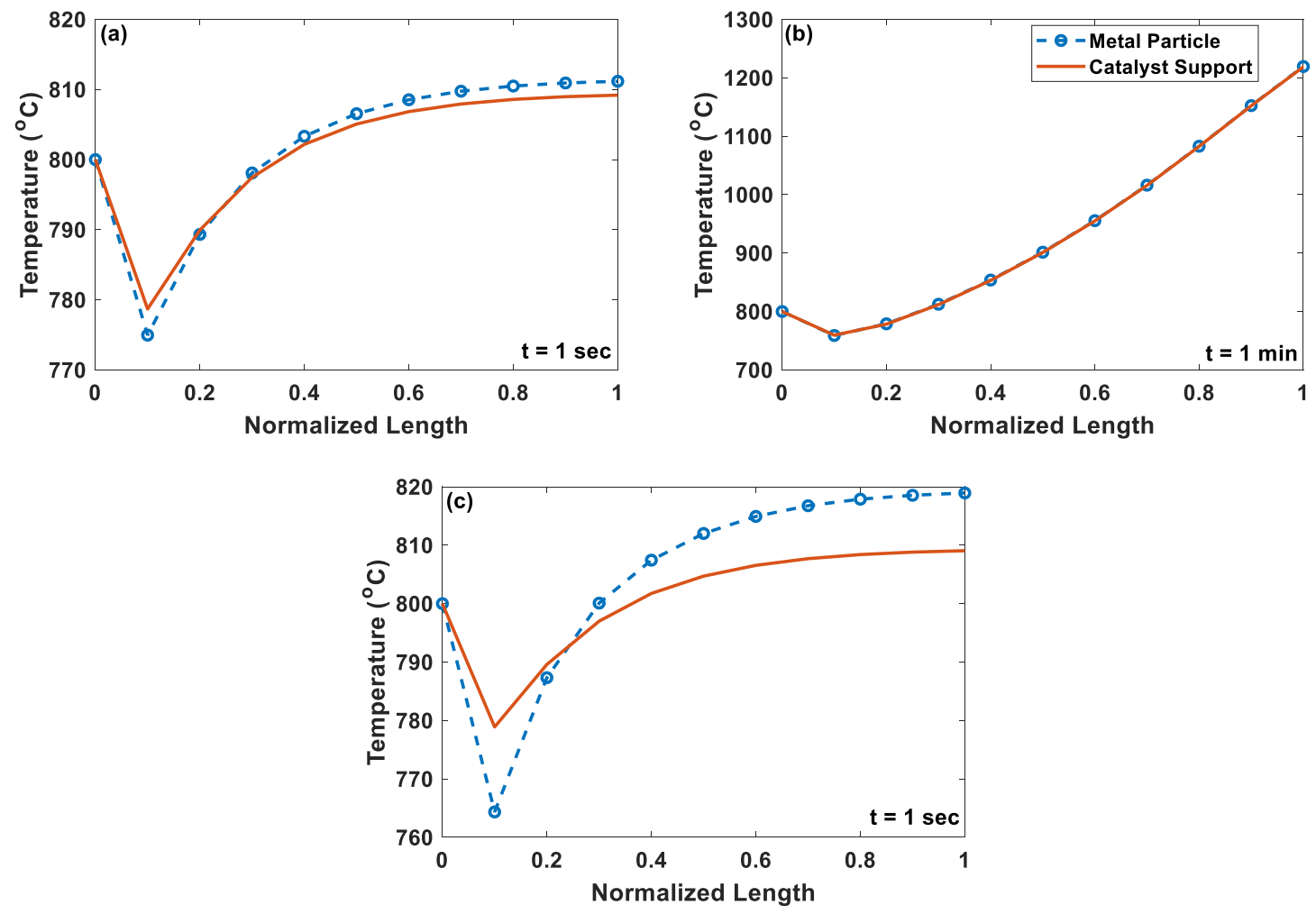

Figure 5.12: Spatial variation of metal particle and catalyst support temperature at $t=1$ sec and $t=1 \mathrm{~min}$, at the catalyst particle surface near the reactor center. (a)-(b) $\boldsymbol{h}_{m p} \cdot \boldsymbol{A}_{\text {contact }}$ reduced by $95 \%$; (c) $h_{m p} \cdot A_{\text {contact }}$ reduced by $100 \%$. MW power absorption by metal particles is 200 times higher than catalyst support

It is generally thought that reaction \#1 and \#3 only take place on the metal particle, while reaction \#2 takes place on the support [159,209]. While there is generally consensus that reaction \#1 and 
\#2 take place on the metal particle and support, respectively, the methane decomposition reaction (coke formation reaction) can take place on both metal particles and catalyst support [210,211]. All the studies presented until now considered reaction \#1 and \#3 occurring on the metal particle and reaction \#2 taking place on the support. Since reaction \#3 is highly endothermic, it is desired to study if the metal particle temperature becomes higher than the support material if reaction \#3 occurs on the support. Fig. 5.13 shows the spatial temperature profile for metal particles and support when only reaction \#1 is considered on the metal particle and reaction \#2 and \#3 are taking place on the support. The temperature profile showed is for the catalyst particle surface located near the reactor center, along the length of the reactor. One interesting thing to note here is that, unlike Fig. 5.12, there is no temperature difference between metal particles and support in the initial part of the reactor in both cases when the contact area is reduced by 95\% (Fig. 5.13a) and $100 \%$ (Fig. 5.13c). This is because the highly endothermic reaction \#1 and exothermic reaction \#2 is taking place on the catalyst support. The net reaction on the catalyst support is still endothermic, but its net endothermicity is less than reaction \#3. In contrast, near the exit of the reactor, the temperature difference between the particles and support is about $0.5^{\circ} \mathrm{C}$ and $2^{\circ} \mathrm{C}$ higher than Fig. 5.12 at $\mathrm{t}=1 \mathrm{sec}$, when contact area is reduced by $95 \%$ and $100 \%$, respectively. At $\mathrm{t}=1 \mathrm{~min}$ (Fig. $5.13 \mathrm{~b}$ ), there is no temperature difference between the metal particles and support. However, when the contact area is reduced by $100 \%$, metal particles are $11^{\circ} \mathrm{C}$ higher than the support at $\mathrm{t}=1 \mathrm{~min}$ (not shown here). 

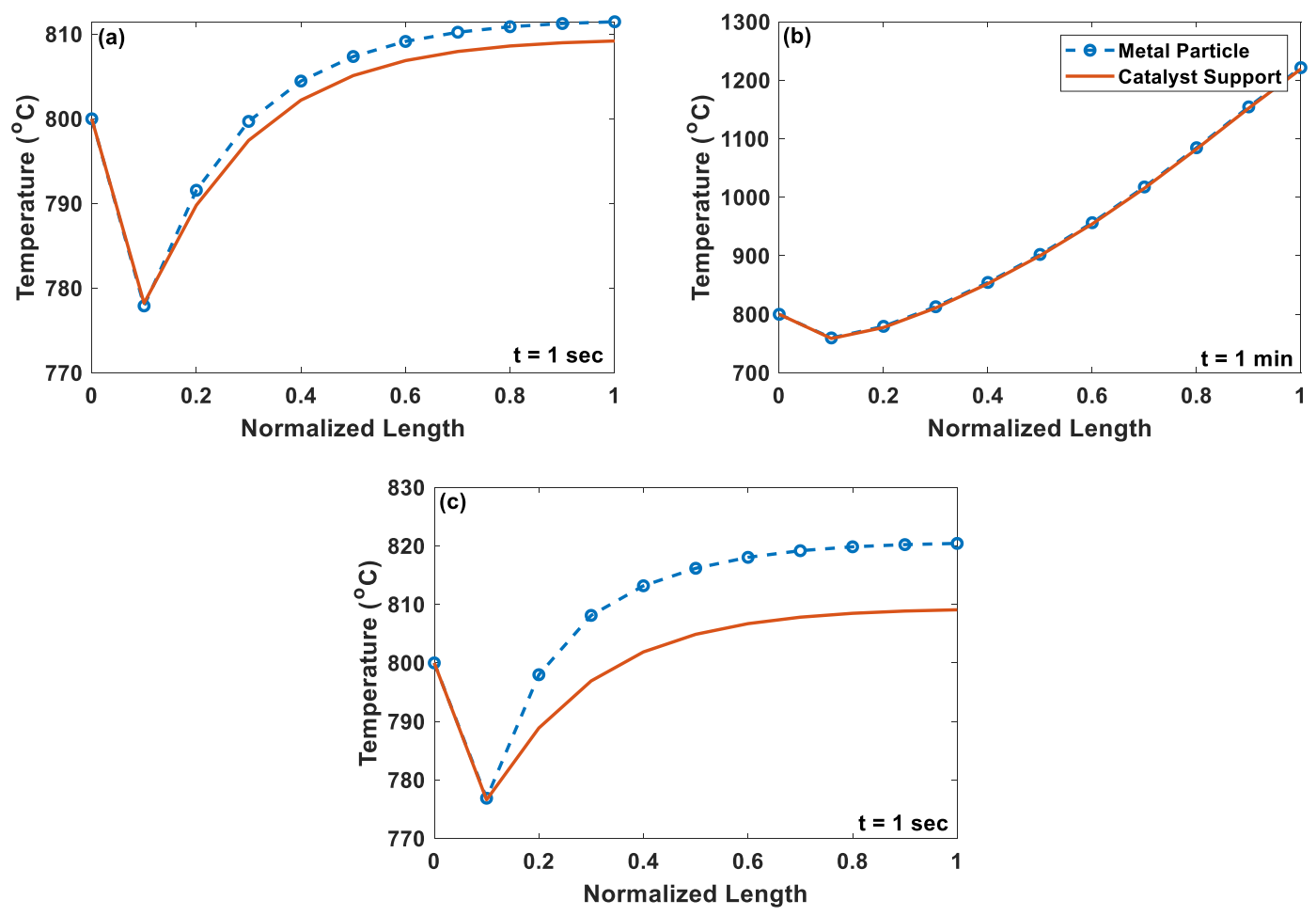

Figure 5.13: Spatial variation of volumetric average metal particle and catalyst support temperature at $\mathbf{t}=1 \mathrm{sec}$ and $\mathbf{t}=1 \mathrm{~min}$, at the catalyst particle surface near the reactor center. (a)-(b) $h_{m p} \cdot A_{\text {contact }}$ reduced by $95 \%$; (c) $h_{m p} \cdot A_{\text {contact }}$ reduced by $100 \% . \mathrm{MW}$ power absorption by metal particles is 200 times higher than catalyst support. Only reaction \#1 occurring on metal particle

\subsection{Conclusion}

A reaction rate law including coking reactions and impact of coke formation on deactivation rate is developed for the MW- assisted methane DHA. Dynamic data reconciliation is performed to satisfy the carbon and hydrogen balances in the in-house experimental data. For estimating the initial amount of coke and kinetic parameters, a model of the lab reactor is developed, and recursive successive substitution-based approach coupled with a nonlinear programming approach is solved. It is observed that the MW system shows faster coking than the conventional process. Maxwell's equations are used to model the propagation of the absorbed MW power in the radial direction of reactor. A ROM for the Maxwell's equations is developed where the MW power absorbed is expressed as a function of MW frequency, temperature, input power, and dielectric properties. The ROM is found to be very accurate and computationally advantageous compared to the Maxwell's equation. A multi-scale model of a commercial-scale, fixed-bed, heterogenous MW reactor is developed in which the a bulk-scale model that includes MW propagation is coupled with a catalyst 
particle-level model that includes inter-particle and intra-particle heat and mass transfer, and chemical reaction kinetics. The MW reactor operating at a frequency of $2.45 \mathrm{GHz}$ seems to perform better for the methane DHA for the given catalysts compared to $915 \mathrm{MHz}$ as evident by higher MW absorption and product formation efficiency. Analysis on temperature difference between metal particles and support shows a maximum temperature difference of $11^{\circ} \mathrm{C}$ between the two under a number of scenarios evaluated including when the metal particles absorbs 200 times more MW power than the catalysts support, contact area between metal and support particles are reduced by $95 \%-100 \%$ and considering the endothermic coke formation reaction to take place on the catalyst support. It should be noted that many of the observations here is for the specific catalysts and for methane DHA. There can be considerable differences for other MW-assisted reactive systems. The MW reactor system is very complex with considerable opportunities for better understanding of the micro-scale behavior of solid-gas catalysis. Combination of thermal and non-thermal effects may occur at the micro-scale. Further investigations in this area is desired for improved understanding. 


\section{Chapter 6. Plant-Wide Modeling and Techno-Economic Analysis of Direct Non-Oxidative Methane DHA Via Conventional and MW Catalysis}

\subsection{Introduction}

In the recent years, development of new drilling technologies has resulted in increased extraction of small quantity of natural gas from shale formation in remote locations. However, due to the remote location, cost of transporting the gas over long distances outweighs the revenue generated by selling it [212]. Pertaining to the difficulties and the high costs associated with transporting gases from remote location, an alternative is to convert the shale gas into liquids that are easier to transport and less taxing on the process economics. Small-scale gas-to-liquids (GTL) production plants, to produce premium liquid products, in remote locations where small quantities of shale gas is available is a viable option. However, one of the key concerns associated with the economic sustainability of small-sclae plants is the plant-scale. The fixed costs associated with these plants is higher than the mega-scale plant on normalized basis, and this can impact the economic feasibility of the process. There have been three studies in the open literature on the plant-wide modeling and techno-economic analysis of direct non-oxidative methane DHA process via conventional heating. Corredor et al. [213] performed plant-wide modeling and techno-economic analysis on non-oxidative methane DHA process, in which a membrane reactor was used. They performed heat integration and studied the impact of raw material and product price on process performance parameter. Similar study was performed by Perez-Uresti et al. [214] on production of benzene from shale-gas using a stoichiometric reactor. A more detail study was performed by Huang et al. [215] where they developed surrogate unit models and database to calculate component flows, assuming that the separation units consistently gave the desired separation and purification with change in outlet reactor stream product distribution. Using these models, they studied the economic feasibility of the methane DHA process by varying different process and economic parameters. In this chapter, plant-wide modeling, and techno-economic analysis of a small scale direct non-oxidative methane DHA process via conventional and MW-assisted heating 
will be discussed. A large-scale multi-step, shale gas conversion to aromatics via methanol synthesis, process is also developed for comparison basis. Aspen Plus V9® package is used to perform plant-wide modeling. Heat exchanger network is designed using Aspen Process Energy Analyzer, and the heat exchangers in the network are modeled using Heat Exchanger Design and Rating V9® (EDR) software. To perform techno-economic analysis, the complete flowsheet is imported to Aspen Process Economic Analyzer V9® (APEA). Impact of key process variables on the economic performance of the direct non-oxidative methane DHA process cases is also studied.

\subsection{Direct Non-oxidative Methane DHA Plant-Wide Model}

The dynamic reactor model developed in ACM could not be integrated with Aspen Plus due to software issues, so a reduced order methane DHA reactor model was coded in the Fortran calculator block. In this reaction system, since methane conversion is less, the unconverted methane needs to be recycled back to the reactor. The recycle streams contains impurities like hydrogen, ethylene, and benzene which can influence the reactant conversion and product yield. Initial analysis of the process showed that the mole percentage of hydrogen, ethylene, and benzene in recycle stream was $<1.5 \%,<0.04 \%$, and $<0.002 \%$, respectively. Using this information, timevarying profiles were generated using the $\mathrm{ACM}$ reactor model, with different feed concentrations at $700^{\circ} \mathrm{C}, 750^{\circ} \mathrm{C}$, and $800^{\circ} \mathrm{C}$ and 1.2 bar pressure for conventional heating process. The time varying profiles are shown in Appendix M. As discussed in Chapter 4, Section 4.5.3, scheduling is performed to calculate the time-average conversions and yield and calculate total number of required reactors. The operational schedule with the lowest standard deviation in conversion and yield is selected. As mentioned earlier, parallel reactors operation is desired to reduce the standard deviation in conversion and yield during an operational cycle. The total feed is equally divided into the number of parallel reactors. In this study, the maximum acceptable standard deviation in methane conversion was set to $4.5 \%$, and product yield was set to less than $1 \%$ because flash separation technology is used downstream. Using this baseline, initially a 2-reactor parallel operation was considered, however it resulted in higher standard deviation for methane conversion at $800^{\circ} \mathrm{C}$ than the setpoint. So, a 3-reactor parallel operation was considered which kept the standard deviation below the desired value. The reactors are taken offline when the catalyst activity drops to $30 \%$, and the cumulative average coke, $\bar{C}_{c}$, deposited at this time on the catalyst is 4.94 $\mathrm{wt} \%$. The time-average product distribution when pure methane is fed to the methane DHA conventional heating process operating at $700^{\circ} \mathrm{C}, 750^{\circ} \mathrm{C}$, and $800^{\circ} \mathrm{C}$ operation is shown in Table 
6.1. It should be noted that the product distribution in Table 6.1 will change depending on the inlet feed condition. The approximate number of total reactors required for cyclic operation are 6,6 , and 9 for $700^{\circ} \mathrm{C}, 750^{\circ} \mathrm{C}$, and $800^{\circ} \mathrm{C}$ operating temperature, respectively.

Table 6.1: Production distribution and total no. of reactors for methane DHA process with conventional heating

\begin{tabular}{cccc}
\hline \multicolumn{4}{c}{ Product Distribution (mass) } \\
\hline Components & $\mathbf{7 0 0}^{\circ} \mathrm{C}$ & $\mathbf{7 5 0}^{\circ} \mathrm{C}$ & $\mathbf{8 0 0}^{\circ} \mathrm{C}$ \\
\hline $\mathrm{CH}_{4}$ & $85.08 \%$ & $77.91 \%$ & $69.87 \%$ \\
$\mathrm{C}_{6} \mathrm{H}_{6}$ & $2.42 \%$ & $2.66 \%$ & $2.03 \%$ \\
$\mathrm{C}_{2} \mathrm{H}_{4}$ & $0.05 \%$ & $0.06 \%$ & $0.08 \%$ \\
$\mathrm{H}_{2}$ & $3.56 \%$ & $5.34 \%$ & $7.40 \%$ \\
$\mathrm{C}$ & $8.90 \%$ & $14.03 \%$ & $20.61 \%$ \\
\hline
\end{tabular}

The regeneration time for all three temperatures is same because the amount of coke deposited on the catalyst at $30 \%$ catalyst activity is similar. However, the time taken for the catalyst activity to drop to $30 \%$ increases as the reactor operating temperature goes up because reaction R3 is endothermic. So, the time-period for the reactor online would be longer for lower temperature as compared to higher temperature. As a result, to keep the process continuous more reactors will be required for the process with reactor operating at higher temperature. In this case, the time taken for catalyst activity to drop to $30 \%$ for $700^{\circ} \mathrm{C}$ and $750^{\circ} \mathrm{C}$ is not that different, as a result same number of total reactors can satisfy the cyclic operation. Correlations between the time-average methane conversion, product yield, and feed conditions were developed and used in Fortran calculator block. A RYield reactor block was then used in which the conversion and yield calculated based on feed condition were exported from the Fortran calculator block. It was ensured that the RYield reactor block operated within the conditions for which the reduced order model was developed. Similar procedure was followed for MW-assisted process and based on analysis, reactor operating at $800^{\circ} \mathrm{C}$ temperature was used for comparison because it had highest benzene yield. The product distribution for methane DHA via MW-assisted heating is shown in Table 6.2. The total number of reactors required for cyclic operation are 15. 
Table 6.2: Production distribution and total no. of reactors for methane DHA process with MW-assisted heating

\begin{tabular}{cc}
\hline Components & Product Distribution (mass) \\
\hline $\mathrm{CH}_{4}$ & $63.18 \%$ \\
$\mathrm{C}_{6} \mathrm{H}_{6}$ & $0.913 \%$ \\
$\mathrm{C}_{2} \mathrm{H}_{4}$ & $0.079 \%$ \\
$\mathrm{H}_{2}$ & $9.285 \%$ \\
$\mathrm{C}$ & $26.55 \%$ \\
\hline
\end{tabular}

The block flow diagram of direct non-oxidative methane DHA process for both conventional heating and MW-assisted heating is shown in Fig. 6.1. Conventional and MW-assisted methane DHA process has the same products, but differs in terms of conversion, yield, and heating requirement. So, the same set of equipment items with different operating conditions can work out, and as a result the process configuration for both the processes is similar. In this process, fresh methane (Stream S1), along with unconverted recycled methane (Stream S13) is fed to the methane DHA reactor operating at $\left(700^{\circ}-800^{\circ} \mathrm{C}\right)$ temperature and 1.2 bar pressure. Process heat exchangers (B1 and B4) and fired heaters (B2 and B3) are used to heat the feed stream to the desired temperature. 


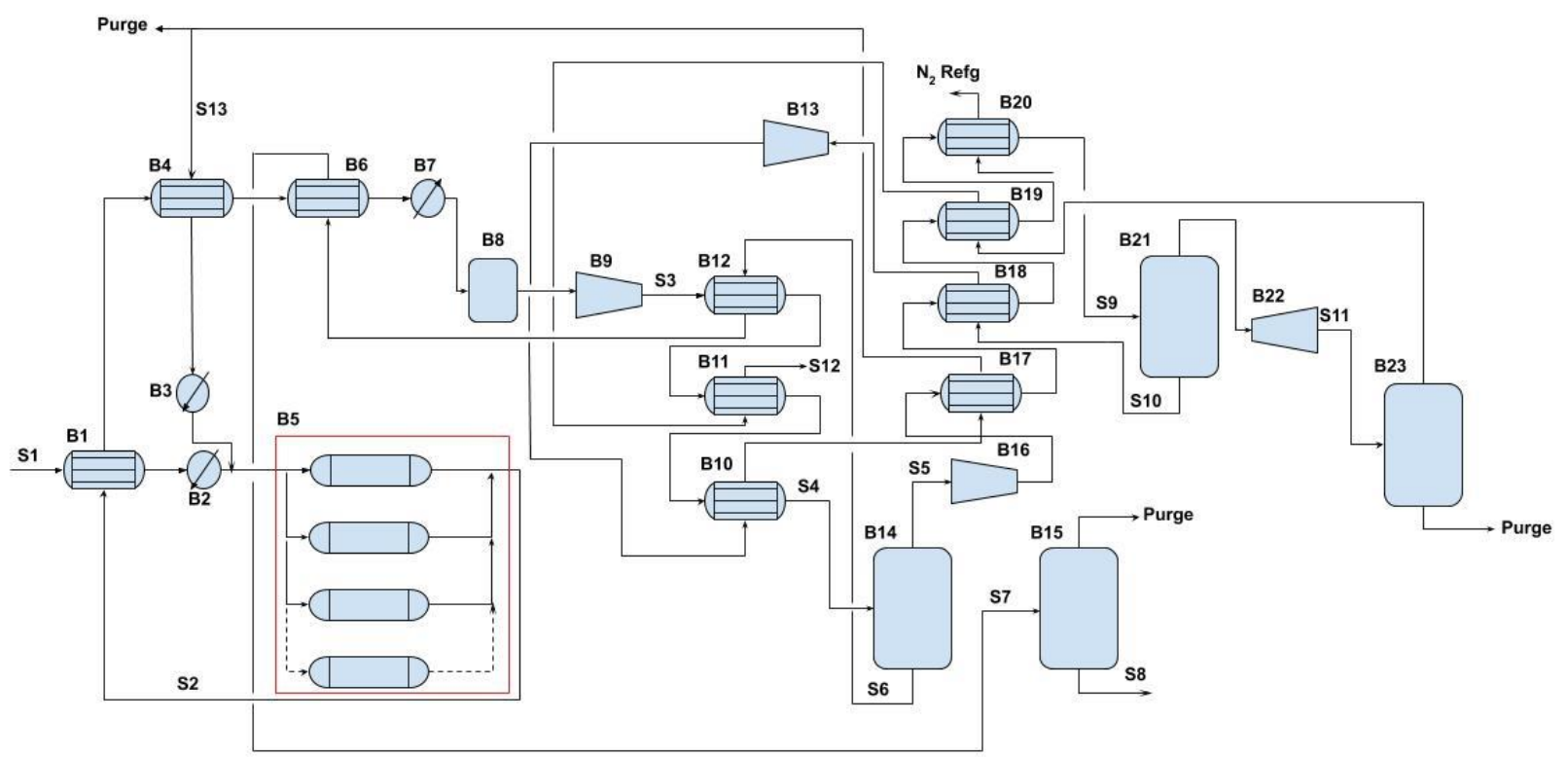

\section{Figure 6.1: Block flow diagram of direct non-oxidative methane DHA process via conventional and MW-assisted heating}

In both conventional and MW-assisted cases, a 3-reactor parallel operation is considered with each of the 3-reactors operating at different catalyst deactivation state. As mentioned before, the reactor is maintained at the desired temperature of operation with high enough thermal fluid flow or high MW energy input. So, the reactor outlet stream S2 is coming out at the reactor operating temperature, which is used to heat stream S1, S13 and S6, using process exchangers (B1, B4, and B6). Stream S2 is further cooled down to $35^{\circ} \mathrm{C}$ using a cooler (B7), and then compressed to 6 bar using a multistage compressor (B9). The outlet stream S3 from the compressor (B8) is cooled down to around $-75^{\circ} \mathrm{C}$ using process heat exchangers (B10-B12) and fed to a flash separator (B14). More than 99\% benzene and trace amount of light gases is condensed down in the liquid stream (S6) which is then passed through process exchangers (B12 and B6), to utilize the cooling duty in other process streams. After heat exchange, stream S7 which is rich in benzene is processed through a flash vessel (B15) to increase the purity of benzene to 99.8 mass\%. The vapor stream (S5) from the flash separator (B14) is compressed to 30 bar using a multi-stage compressor (B16). The outlet stream from the compressor is cooled down to $-170^{\circ} \mathrm{C}$ using process heat exchangers (B17-B19) and utility exchanger (B20). The ultra-cold stream S9 is then processed through a flash separator (B21) to separate hydrogen from unconverted methane and ethylene. Hydrogen is obtained in the vapor stream with a purity of $\sim 97 \mathrm{~mol} \%$. So, to further increase the hydrogen purity, the stream is passed through a turbo expander (B22) to drop the temperature and separate the 
impurities from the hydrogen through flash separator (B23). Hydrogen with a purity of 99.9 mol\% is obtained. The liquid stream (S10) from the flash separator (B21), containing mainly unconverted methane, is passed through process heat exchanger (B18) and then fed to a turbo expander (B13) to utilize the high pressure in generating electricity and reducing the temperature of the stream. The outlet stream from the turbo-expander is passed through process exchangers (B10 and B17) and recycled back to the reactor. $80 \%$ isentropic efficiency is used in the compressors and the turbo expanders. Design specifications are implemented to ensure that temperature crossing between the heat exchangers is avoided. A minimum approach temperature of $10^{\circ} \mathrm{C}$ is used to size heat exchangers that are at higher temperature. A minimum approach temperature of $5^{\circ} \mathrm{C}$ is used to size heat exchangers with sub-zero temperature. A 4-stage cascade refrigeration cycle is modeled to satisfy the cooling duty in the process. A summary of key streams for conventional heating process operating at $750^{\circ} \mathrm{C}$ and $\mathrm{MW}$-assisted process is shown in Table 6.3 and Table 6.4, respectively.

Table 6.3: Summary of key streams for methane DHA conventional heating process operating at $750^{\circ} \mathrm{C}$

\begin{tabular}{cccccccccc}
\hline & S1 & S2 & S4 & S5 & S8 & S9 & S10 & S12 & S13 \\
\hline Temp $\left({ }^{\circ} \mathrm{C}\right)$ & 35.0 & 750 & -76 & -76 & 50 & -170 & -170 & 29 & 30 \\
Pressure & 1.2 & 1.13 & 5.70 & 5.70 & 4.6 & 29.6 & 29.6 & 1.83 & 2.080 \\
Flow (kg/h) & 6594 & 21696 & 18621 & 18137 & 482 & 18137 & 16781 & 1141 & 15103 \\
Mass Frac & & & & & & & & & \\
$\mathrm{C}_{6} \mathrm{H}_{6}$ & & 0.0223 & 0.0260 & $1.3 \mathrm{E}-04$ & 0.998 & $1.3 \mathrm{E}-04$ & $1.4 \mathrm{E}-04$ & & $1.4 \mathrm{E}-04$ \\
$\mathrm{C}_{2} \mathrm{H}_{4}$ & & $5.8 \mathrm{E}-04$ & $6.7 \mathrm{E}-04$ & $6.9 \mathrm{E}-04$ & $4.1 \mathrm{E}-05$ & $6.9 \mathrm{E}-04$ & $7.4 \mathrm{E}-04$ & trace & $7.4 \mathrm{E}-04$ \\
$\mathrm{H}_{2}$ & & 0.0548 & 0.0638 & 0.0655 & trace & 0.0655 & $2.9 \mathrm{E}-03$ & 0.999 & $2.9 \mathrm{E}-03$ \\
$\mathrm{CH}_{4}$ & 1 & 0.781 & 0.910 & 0.934 & $2.0 \mathrm{E}-03$ & 0.934 & 0.996 & $1.20 \mathrm{E}-03$ & 0.996 \\
$\mathrm{C}$ & & 0.142 & & & & & & & \\
\hline
\end{tabular}


Table 6.4: Summary of key streams for MW-assisted methane DHA process

\begin{tabular}{cccccccccc}
\hline & S1 & S2 & S4 & S5 & S8 & S9 & S10 & S12 & S13 \\
\hline Temp $\left({ }^{\circ} \mathrm{C}\right)$ & 35 & 800 & -77 & -77 & 50 & -170 & -170 & 29 & 30 \\
Pressure & 1.2 & 1.13 & 5.7 & 5.7 & 4.6 & 29.6 & 29.6 & 1.8265 & 2.08 \\
Flow (kg/h) & 11230 & 25260 & 18554 & 18325 & 228 & 18325 & 15589 & 2302 & 14030 \\
Mass Frac & & & & & & & & & \\
$\mathrm{C}_{6} \mathrm{H}_{6}$ & & $9.1 \mathrm{E}-03$ & 0.0124 & $1.3 \mathrm{E}-04$ & 0.998 & $1.3 \mathrm{E}-04$ & $1.5 \mathrm{E}-04$ & & $1.5 \mathrm{E}-04$ \\
$\mathrm{C}_{2} \mathrm{H}_{4}$ & & $7.9 \mathrm{E}-04$ & $1.1 \mathrm{E}-03$ & $1.1 \mathrm{E}-03$ & $6.1 \mathrm{E}-05$ & $1.1 \mathrm{E}-03$ & $1.3 \mathrm{E}-03$ & trace & $1.3 \mathrm{E}-03$ \\
$\mathrm{H}_{2}$ & & 0.0928 & 0.126 & 0.128 & trace & 0.128 & $2.9 \mathrm{E}-03$ & 0.999 & $2.9 \mathrm{E}-03$ \\
$\mathrm{CH}_{4}$ & 1 & 0.632 & 0.860 & 0.871 & $1.9 \mathrm{E}-03$ & 0.871 & 0.996 & $1.2 \mathrm{E}-03$ & 0.9956 \\
$\mathrm{C}$ & & 0.265 & & & & & & & \\
\hline
\end{tabular}

\subsection{Shale Gas Conversion to Aromatics Via Methanol Synthesis Plant-Wide Model}

To compare the economics of the modular methane DHA process cases, it is necessary to analyze how it performs in comparison to a large-scale conventional aromatics production process. So, a shale gas conversion to aromatics via methanol synthesis process is also modeled in Aspen Plus as shown in Fig. 6.2. The upstream portion of the process till the methanol purification section is same as Fig. 2.2. Once methanol is purified, it is fed to the methanol to aromatics (MTA) reactor operating at $330^{\circ} \mathrm{C}$ and 14.7 bar pressure. The product distribution for the reactor is shown in Table 6.5 [14]. This product distribution has been slightly modified for simplicity, however the yield of all the key products have been kept the same. In this process a lot of other products i.e. propones, butanes, $\mathrm{C}_{9}$ aromatics etc. are formed in addition to the BTX, hydrogen, ethane/ethylene etc. The butanes i.e. butane/isobutylene is lumped and sent to the LPG pool. C9 aromatics is also separated and then sent to the gasoline pool. Similarly, further separation of propylene/propane is not considered. Further separation is not considered for this products for simplicity. 


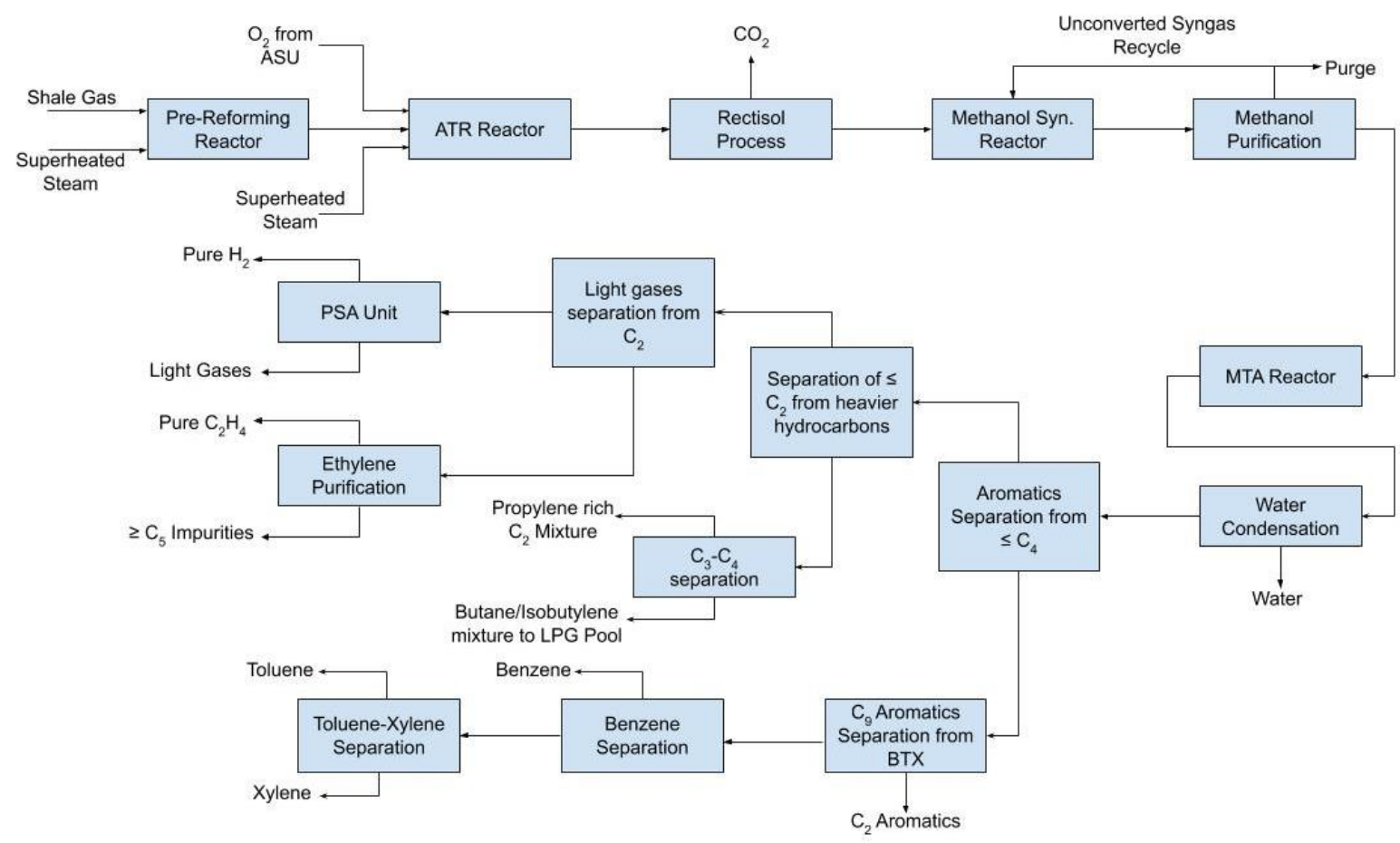

Figure 6.2: Conventional shale gas conversion to aromatics via methanol synthesis

The outlet of the MTA reactor is cooled down using process and utility heat exchangers and processed through a flash separator to remove excess water from rest of the products. The vapor stream from the flash separator is sent to a distillation column operating at 11 bar to separate the aromatics from hydrocarbons $\leq \mathrm{C}_{4}$. The liquid stream contains aromatics, small quantity of water, and trace amount of $\mathrm{C}_{4}(\mathrm{~s})$. This stream is cool down and fed to a distillation column operating at 2.2 bar to separate $\mathrm{C}_{9}$ from other aromatics. The purity of $\mathrm{C}_{9}$ obtain is $>99$ mass $\%$. The vapor stream from the column is fed to the benzene separation column to separate benzene from toluene and xylene. More than $99 \%$ of benzene is recovered with a purity of $>95$ mass $\%$. The liquid stream is then processed through a distillation column to separate toluene from xylene. The purity of toluene and xylene achieved is $>99.5$ mass \% and > 99 mass\%, respectively. The vapor stream from the $\mathrm{C}_{4}$ separation column is compressed to 35 bar using a multi-stage compressor and sent to deethanizer column to separate ethane(s) from propane(s) and heavier hydrocarbons. The liquid stream from the deethanizer column is processed through depropanizer column to separate the propane(s) from butane(s). 


\section{Table 6.5: Product distribution of MTA reactor [14]}

\begin{tabular}{cc}
\hline Components & Product Distribution (Mass) \\
\hline$H_{2} O$ & 56.3 \\
$H_{2}$ & 1.30 \\
$\mathrm{CH}_{4}$ & 0.759 \\
$\mathrm{C}_{2} \mathrm{H}_{6}$ & 0.239 \\
$\mathrm{C}_{3} \mathrm{H}_{8}$ & 1.97 \\
$\mathrm{C}_{4} \mathrm{H}_{10}$ & 2.23 \\
$\mathrm{C}_{2} \mathrm{H}_{4}$ & 4.25 \\
$\mathrm{C}_{3} \mathrm{H}_{6}$ & 3.36 \\
$\mathrm{C}_{4} \mathrm{H}_{9}$ & 1.45 \\
$\mathrm{C}_{6} \mathrm{H}_{6}$ & 0.986 \\
$\mathrm{C}_{7} \mathrm{H}_{8}$ & 4.17 \\
$\mathrm{C}_{8} \mathrm{H}_{10}$ & 11.5 \\
$\mathrm{C}_{9} \mathrm{H}_{12}$ & 11.4 \\
\hline
\end{tabular}

The vapor stream from the deethanizer column is processed through a light gas separation column to separate hydrogen and light gases from $\mathrm{C}_{2}$ and higher hydrocarbons impurities. The hydrogen rich stream is sent to the PSA unit to recovery $85 \%$ hydrogen with a purity of $99.99 \mathrm{~mol} \%$. The liquid stream from the light gas separation column is sent to ethylene purification column, to obtain ethylene with > 99.5 mass \% purity. For separation of $\mathrm{C}_{2}$ 's and light gases, very low temperatures are required in the distillation column. This cooling requirement is satisfied by using a single stage, and a 4-stage refrigeration cycle. For sub-cooling anywhere else in the process, the refrigeration duty available in cold process streams are first utilized and then the additional cooling duty is provided by the refrigeration cycle. As mentioned earlier, aspen energy analyzer is used to design 
the heat exchanger network. Design specifications are used to avoid temperature cross and to achieve desired product purity.

\subsection{Economic Analysis}

Economic analysis is performed using APEA, based on 2020 pricing data. The steady-state process models developed in Aspen Plus, along with all the stream data consisting of mass and energy balances is exported to APEA to perform the economic analysis. The investment parameters used for the economic studies is shown in Table 6.6. These parameters are kept similar for all the process cases, unless specified explicitly in this chapter. All processes are desired as licensed process, located in North America, with January 1, 2020, as the start date of engineering.

Table 6.6: Parameters for investment analysis

\begin{tabular}{|c|c|c|c|}
\hline Investment parameter & Value & Investment parameter & Value \\
\hline Contingency & $24 \%$ & $\begin{array}{l}\text { Working capital } \\
\text { percentage }\end{array}$ & $12 \%$ per year \\
\hline Tax rate & $40 \%$ per year & Plant overhead & $50 \%$ \\
\hline $\begin{array}{l}\text { Desired internal rate of } \\
\text { return }\end{array}$ & $20 \%$ per year & G \& A expenses & $8 \%$ per year \\
\hline Salvage value & $20 \%$ & $\mathrm{O} \& \mathrm{M}$ escalation & $3 \%$ per year \\
\hline Project capital escalation & $1 \%$ per year & $\begin{array}{l}\text { No. of periods for } \\
\text { analysis }\end{array}$ & 10 year \\
\hline $\begin{array}{l}\text { Products and raw material } \\
\text { escalation }\end{array}$ & $1 \%$ per year each & $\begin{array}{l}\text { Operating hours per } \\
\text { year }\end{array}$ & 8000 hour \\
\hline Utility escalation & $1 \%$ per year & $\begin{array}{l}\text { Length of start-up } \\
\text { period }\end{array}$ & 20 weeks \\
\hline
\end{tabular}

Note: Contingency is $18 \%$ for shale gas conversion to aromatics via methanol synthesis

\subsection{Capital Cost Estimation}

As mentioned before, APEA is used for performing discounted cash flow analysis. All the columns, flash vessels, compressors, pump, turbines, furnaces etc. are sized using APEA. Heat 
exchangers are sized using Aspen EDR and then imported to APEA. The cost of methane DHA conventional heating reactor is estimated as a shell and heat tube exchangers in APEA. Microwave reactor cost is not available in open literature, so its cost is estimated using the $6 / 10$ rule based on inside information. The cost of the MTA reactor was estimated using the cost-correlation available in literature [14]. The cost correlation parameters for microwave and MTA reactor is shown in Table 6.7. Cost of ATR reactor, pre-reforming reactor, methanol synthesis reactor, ASU unit, and PSA unit were estimated using the cost-correlation shown in Table 3.2.

Table 6.7: Cost correlation for microwave and MTA reactor

\begin{tabular}{cccccc}
\hline Description & $\boldsymbol{C}_{\boldsymbol{0}}(\mathbf{M M} \mathbf{\text { \$ } )}$ & $\boldsymbol{S}_{\boldsymbol{0}}$ & Units & Scale basis & $\boldsymbol{f}$ \\
\hline $\begin{array}{c}\text { Microwave } \\
\text { Reactor }\end{array}$ & 0.91 & 7.13 & $\mathrm{~kg} / \mathrm{s}$ & feed & 0.6 \\
MTA Reactor & 3.70 & 10.6 & $\mathrm{~kg} / \mathrm{s}$ & $\begin{array}{c}\text { Methanol } \\
\text { feed }\end{array}$ & 0.75 \\
\end{tabular}

The methane DHA plant-wide model developed in this study is different than what is available in the literature. So, the economic model could not be validated with the open literature. In case of the multi-step aromatics production via methanol synthesis process, the upstream portion until the methanol purification has been previously validated as shown in Chapter 3, section 3.6.4. The aromatics purification section is a simplified version of actual process due to the bundling up of some of the products. However, the equipment cost estimated using APEA was compared with the cost calculated using the cost-correlation in Niziolek et al.[14] for some of the key distillation columns: $\mathrm{C}_{2}$ separation, benzene distillation, toluene distillation, $\mathrm{C}_{9}$-aromatics separation, aromatics separation from $\mathrm{C}_{4}$, and light gases separation column. The error between APEA estimation and the cost-correlation was about $16 \%$. Single- or multi-stage compressors in the process are mapped to horizontal centrifugal compressors in APEA. Heat exchangers are mapped to floating head shell-and-tube heat exchangers. The material of construction (MOC) for any specific equipment item in the process is specified based on its operating conditions, stream compositions and common industrial practice [51,121,129]. Methane DHA uses cryogenic separation downstream and the temperatures are ultra-low, so the material of selection was based on the temperature and the composition of major species being processed by the equipment, as outline in reference [216]. 


\subsection{Operating \& Maintenance Cost Estimation}

The operating and maintenance costs considered in the economic analysis are raw material costs, utility costs, operating labor and supervision, maintenance labor, operating supplies, laboratory charges, and general \& administrative (G\&A). For the aromatics production process via methanol synthesis, the cost of catalyst, and consideration of catalyst lifetime is same as Chapter 3, Section 3.4. Since, the rate of catalyst deactivation is extremely fast in the methane DHA system, the same assumptions cannot be made. An initial cost of the catalyst is considered to start the process, and then a catalyst consumption rate of $0.01 \%$ per hour is assumed. For methane DHA process, 3 working shifts are assumed with a total of 4 operators and 1 supervisor, and for multi-step process 11 operators and 1 supervisor is assumed. The hourly wage of operators and supervisors is set to be $20 \$ / \mathrm{h}$ and $35 \$ / \mathrm{h}$, respectively. The cost of raw materials, utilities, and products is shown in Table 6.8 [14,96,217]. The cost of methane DHA catalyst is taken from Huang et al. [215]. Cost of electricity is based on the current market in the South Atlantic region. Methane price is calculated by taking the ratio of LHV values of methane to natural gas and multiplying it by the natural gas price.

Table 6.8: Price of raw materials, utilities, and products considered for economic analysis

\begin{tabular}{lccc}
\hline Item & Price & Item & Price \\
\hline Methane DHA catalyst & $275 \$ / \mathrm{kg}$ & Benzene & $0.83 \$ / \mathrm{kg}$ \\
Methane & $2.022 \$ / \mathrm{GJ}$ & Hydrogen & $3.046 \$ / \mathrm{kg}$ \\
Electricity & $17.47 \$ / \mathrm{GJ}$ & Toluene & $0.896 \$ / \mathrm{kg}$ \\
Cooling Water & $0.354 \$ / \mathrm{GJ}$ & M-Xylene & $0.836 \$ / \mathrm{kg}$ \\
Propane Refrigerant & $0.416 \$ / \mathrm{kg}$ & $\mathrm{C}_{3}$ mixture & $0.981 \$ / \mathrm{kg}$ \\
Ethylene Refrigerant & $0.810 \$ / \mathrm{kg}$ & LPG & $0.235 \$ / \mathrm{kg}$ \\
Nitrogen Refrigerant & $0.372 \$ / \mathrm{kg}$ & $\mathrm{C}_{9}$ Aromatics & $0.688 \$ / \mathrm{kg}$ \\
\hline
\end{tabular}




\subsection{Results and Discussion}

In this section, the comparison of economic performance between methane DHA conventional and MW-assisted heating will be discussed. Methane DHA processes will then be compared with the multi-step shale gas to aromatics via methanol synthesis process at two different scales. Sensitivity studies with respect to methane price, electricity price, catalyst variable cost, process scale, MW reactor cost on the internal rate of return (IRR) and net present value (NPV) will be studied.

\subsubsection{Process Performance Comparison}

Comparison of performance results for small scale methane DHA process via conventional and MW-assisted heating at different temperatures is shown in Table 6.9. For comparison, energy penalty is calculated defined by Eq. 6.1.

$E_{\text {penalty }}=\frac{\operatorname{ATPCC}\left(\frac{\$}{y e a r}\right)+R M\left(\frac{\$}{y e a r}\right)+U C\left(\frac{\$}{y e a r}\right)-\text { Credits }\left(\frac{\$}{y e a r}\right)}{E B F\left(\frac{k g}{y e a r}\right)}$

Here, $A T P C C$ is the annualized total project capital cost; $R M$ is the raw material cost; $U C$ is the utility cost; $E B F$ is the equivalent benzene flowrate. The credits here include the energy recovered by burning the purge gas and burning coke to generate electricity (Efficiency -0.37 ). The heat requirement to maintain the reactor temperature is the heat of reaction for conventional heating reactors. A heating efficiency of 0.85 is assumed. For MW reactor, electricity is used, which is calculated by dividing the heat of reaction by efficiency factor 0.35 to generate electricity, and then divided by efficiency factor of 0.8 to convert the electricity in microwaves. To calculate the benzene equivalent flow, the ratio of price of benzene and hydrogen with respect to benzene is taken. This ratio is then multiplied by their respective flowrate and summed up to give the equivalent benzene flow. For fair comparison, all the process cases were adjusted to the same plant scale based on the inlet fresh methane flowrate, using APEA. 
Table 6.9: Comparison of process performance between conventional and MW-assisted methane DHA Process $\left(\mathrm{CH}_{4}\right.$ fresh feed $\left.\sim 6594 \mathrm{~kg} / \mathrm{h}\right)$

\begin{tabular}{lcccc}
\hline & \multicolumn{3}{c}{ Conventional Heating } & MW-assisted \\
& $\mathbf{7 0 0}^{\circ} \mathbf{C}$ & $\mathbf{7 5 0}^{\circ} \mathbf{C}$ & $\mathbf{8 0 0}^{\circ} \mathbf{C}$ & $\mathbf{8 0 0}^{\circ} \mathbf{C}$ \\
\hline Annualized TPCC (MM\$/year) & 15.28 & 13.75 & 13.78 & 12.90 \\
RM Cost (MM\$/year) & 10.28 & 9.22 & 11.09 & 9.18 \\
UC (MM\$/year) & 5.04 & 4.91 & 4.67 & 7.03 \\
Credit (MM\$/year) & 6.26 & 6.67 & 7.11 & 7.49 \\
Benzene Production (kg/h) & 505 & 481 & 301 & 132 \\
Hydrogen Production (kg/h) & 959 & 1139 & 1259 & 1334 \\
Benzene Equivalent (10 6 kg/year) & 32.2 & 37.30 & 39.36 & 40.21 \\
$E_{\text {penalty }}$ \$/ $\left./ \mathrm{kg}\right)$ & 0.756 & 0.569 & 0.539 & 0.538 \\
\hline
\end{tabular}

With the increase in temperature, methane conversion is increasing and selectivity to coke is also increasing. So, when the fresh methane feed is kept similar in all three cases, the total methane feed to the reactor (fresh feed + recycle) is higher for the $700^{\circ} \mathrm{C}$ temperature compared to $750^{\circ} \mathrm{C}$. As a result, the benzene production is higher for $700^{\circ} \mathrm{C}$ compared to $750^{\circ} \mathrm{C}$ due higher total feed flowrate, even though the yield is highest was $750^{\circ} \mathrm{C}$ temperature. For MW-assisted process, the methane conversion is more at similar temperature to conventional heating and the selectivity to coke is also more compared to benzene. As a result, it has the lowest benzene production out of all the cases. Comparison of ATPCC shows that the $700^{\circ} \mathrm{C}$ conventional heating case is highest among the three due to the bigger equipment sizes required as the total flowrate in the system is more. The ATPCC of $800^{\circ} \mathrm{C}$ conventional heating is almost like the $750^{\circ} \mathrm{C}$ due to the requirement of a greater number of total reactors. In addition, the amount of hydrogen to be separated is more, so the size of the equipment in the refrigeration cycle increases as the flowrate of the refrigerant would increase to satisfy the cooling requirement. Similarly, MW case has the lowest ATPCC due to the lower total flowrate and cheaper cost of the MW reactors. The utility cost is highest for MW process, due to MW reactor electricity requirement and the refrigeration cycle. Since, multiple products are produced, energy penalty is calculated as mentioned before and it shows that MWassisted heating and conventional heating process at $800^{\circ}$ are very similar. The conventional 
heating case operating at $750^{\circ} \mathrm{C}$ is not that far away from the former two, while the process operating at $700^{\circ} \mathrm{C}$ is clearly not a candidate.

Small scale methane DHA process is compared with the large-scale multi-step shale gas to aromatics via methanol synthesis process to analyze the economic performance, as shown in Table 6.10. The investment parameters and prices shown in Table 6.6 and 6.8 are used to generate these results. The product distribution for the multi-step process is shown in Appendix N. Electricity equivalent efficiency is calculated on LHV basis, using Eq. 3.7. An efficiency factor of 0.436 is used to calculate electricity equivalent of steam [134]. Electricity equivalent of cooling water is calculated by estimating the electricity required in a pump to circulate the cooling water through the process. An efficiency factor of 0.622 is sued to calculate electricity equivalent of gas and liquid fuels [133].

Table 6.10: Comparison of methane DHA process with large-scale shale gas to aromatics via methanol synthesis production process

\begin{tabular}{|c|c|c|c|c|}
\hline \multirow[b]{2}{*}{ Item } & \multicolumn{3}{|c|}{ Methane DHA } & \multirow[b]{2}{*}{$\begin{array}{c}\text { Multi-step Shale gas } \\
\text { to Aromatics Via } \\
\text { MEOH synthesis }\end{array}$} \\
\hline & $\begin{array}{c}\text { Conventional } \\
\text { Heating } \\
\left(750^{\circ} \mathrm{C}\right)\end{array}$ & $\begin{array}{c}\text { Conventional } \\
\text { Heating } \\
\left(800^{\circ} \mathrm{C}\right)\end{array}$ & $\begin{array}{c}\text { MW- } \\
\text { Assisted }\end{array}$ & \\
\hline Methane Feed $(\mathrm{kg} / \mathrm{h})$ & 6594 & 6594 & 6594 & 98047 \\
\hline ATPCC (MM\$/year) & 13.75 & 13.78 & 12.90 & 93.13 \\
\hline $\mathrm{RM}+\mathrm{UC}(\$ /$ year $)$ & 14.13 & 14.52 & 16.22 & 322 \\
\hline Credits (\$/year) & 6.67 & 7.11 & 7.49 & 159 \\
\hline Benzene Eq. Flow (10 $10^{6} \mathrm{~kg} /$ year $)$ & 37.30 & 39.36 & 40.21 & 437 \\
\hline Energy Input (GJ/h) & 280 & 280 & 381 & 4039 \\
\hline Energy Output (GJ/h) & 194 & 189 & 186 & 2573 \\
\hline Electricity Equiv. Efficiency & $69.2 \%$ & $67.3 \%$ & $48.9 \%$ & $63.7 \%$ \\
\hline$E_{\text {penalty }}(\$ / \mathrm{kg})$ & 0.569 & 0.539 & 0.538 & 0.586 \\
\hline Internal Rate of Return (IRR) & $9.4 \%$ & $10.7 \%$ & $11.2 \%$ & $10 \%$ \\
\hline Net Present Value (NPV) (MM\$) & -28 & -25 & -22 & -187 \\
\hline
\end{tabular}

As seen, the energy penalty for the small scale methane DHA conventional and MW-assisted heating process is lower than the large-scale multi-step production process. The electricity 
equivalent efficiency of conventional heating methane DHA processes is superior to the large scale multi-step production process. The MW-assisted process has a lower efficiency mainly due to the electricity requirement in the MW reactor and the refrigeration cycle for cryogenic separation. The IRR of the MW-assisted process is more than all other methane DHA cases and the multi-step process. NPV for a 10 year period which is the summation of discounted cash flow and investment for each period at $20 \%$ IRR is negative for all cases. To understand how the plant scale would affect the process economics, the methane DHA process was scaled up, and similarly the multistep process was scaled down to the similar plant scale as the methane DHA process. The results are shown in Table 6.11. As expected, increasing the plant scale has a positive impact on the methane DHA processes. The energy penalty of all 3 methane DHA process cases are almost half than the multi-step aromatics production process. Indicating that a multi-step process would not be economically feasible at a smaller scale, also indicated by the IRR and NPV. Among the methane DHA processes, the MW-assisted process has the largest IRR with $18.8 \%$, but the NPV is still negative.

Table 6.11: Impact of plant scale on the performance of methane DHA process as compared to multi-step process

\begin{tabular}{|c|c|c|c|c|}
\hline \multirow[b]{2}{*}{ Item } & \multicolumn{3}{|c|}{ Methane DHA } & \multirow[b]{2}{*}{$\begin{array}{c}\text { Multi-Step Shale gas to } \\
\text { Aromatics Via MEOH } \\
\text { synthesis }\end{array}$} \\
\hline & $\begin{array}{c}\text { Conventional } \\
\text { Heating } \\
\left(7_{50}^{\circ} \mathrm{C}\right)\end{array}$ & $\begin{array}{c}\text { Conventional } \\
\text { Heating } \\
\left(800^{\circ} \mathrm{C}\right)\end{array}$ & $\begin{array}{c}\text { MW- } \\
\text { Assisted }\end{array}$ & \\
\hline Methane Fresh Feed (kg/h) & 19782 & 19782 & 19782 & 19782 \\
\hline ATPCC (MM\$/year) & 31.60 & 30.84 & 28.26 & 37.58 \\
\hline $\mathrm{RM}+\mathrm{UC}(\$ /$ year $)$ & 42.40 & 43.94 & 49.21 & 64.50 \\
\hline Credits (\$/year) & 20.02 & 21.51 & 22.71 & 31.90 \\
\hline Benzene Eq. Flow (106 kg/year) & 112 & 119 & 122 & 87.50 \\
\hline$E_{\text {penalty }}(\$ / k g)$ & 0.482 & 0.447 & 0.450 & 0.802 \\
\hline Internal Rate of Return (IRR) & $15.2 \%$ & $17.5 \%$ & $18.8 \%$ & $0 \%$ \\
\hline Net Present Value (NPV) (MM\$) & -31 & -16 & -7.3 & -130 \\
\hline
\end{tabular}




\subsubsection{Sensitivity Studies}

Based on the results in Table 6.11, the IRR between the different process cases are in close proximity to each other. Since, hydrogen price is one of the key drivers in deciding the economic performance of the process, in this section the effect of hydrogen price on the process IRR will be studied. Secondly, the price of electricity and methane changes depending on the market conditions and location of the plant. So, sensitivity studies are performed to study their impact on process economics. Lastly, the effect of catalyst cost and MW reactor cost on the economic performance of the process is also evaluated. The benzene selling price selected in this study is based on the average over a 2-year period. Its impact on the process economics is not trivial, so further investigation is not done on that end.

\subsubsection{Sensitivity to Hydrogen Price}

Hydrogen is produced in large quantities in this process. Its selling price has a huge impact on the economic performance of the process. The hydrogen selling price can change based on the methane market price. So, for the medium scale methane DHA process cases a feasibility envelope is created by changing the hydrogen and methane price that could lead to a given IRR and NPV for the process, as shown in Fig. 6.3. This plot is generated by varying only the price of methane and hydrogen, while keeping all the other parameters similar as before. For a GTL process, an IRR of $20 \%$ is considered reasonable and often time $25 \%$ IRR is targeted due to the risks associated with plant overheads, uncertainty in product selling price, market variability etc. [123,215,218]. Anything less than $15 \%$ is prohibitive economics. When the hydrogen price is lowest around $\$$ $1.98 / \mathrm{kg}$, the MW-assisted process has a lower IRR compared to the conventional heating $800^{\circ} \mathrm{C}$ case, and the absolute difference in the IRR between the two processes start to increase slowly with the increase in methane price. Hydrogen production in the MW-assisted process is only $6 \%$ higher than the conventional heating $800^{\circ} \mathrm{C}$ process. On the other hand, benzene production is about 2.3 times higher in conventional heating process operating at $800^{\circ} \mathrm{C}$ compared to the $\mathrm{MW}$ assisted process. So, as the hydrogen selling price decreases, the relative difference in the products sale between the two processes start to decrease, but the operating cost is still higher for the MWassisted process. For MW-assisted process, to achieve an IRR of 15\%, the hydrogen selling price has to be $\$ 2.73 / \mathrm{kg}$ and $\sim 3 / \mathrm{kg}$, when the methane price is $\$ 2.02 / \mathrm{GJ}$ and $\$ 3.01 / \mathrm{GJ}$, respectively. While for conventional heating process operating at $800^{\circ} \mathrm{C}$, the hydrogen selling price needs to be around $\$ 2.81 / \mathrm{GJ}$ and $\sim \$ 3.1 / \mathrm{GJ}$, when the methane price is lowest and highest, respectively. The 
MW-assisted process can achieve the required IRR of $20 \%$ when the hydrogen selling price is $\$$ $3.16 / \mathrm{kg}$, for base electricity and methane price. Similarly, conventional heating processes operating at $750^{\circ} \mathrm{C}$ and $800^{\circ} \mathrm{C}$ can achieve $20 \%$ IRR when the hydrogen selling price is $\$ 3.6 / \mathrm{kg}$ and $\$ 3.3 / \mathrm{kg}$, respectively.
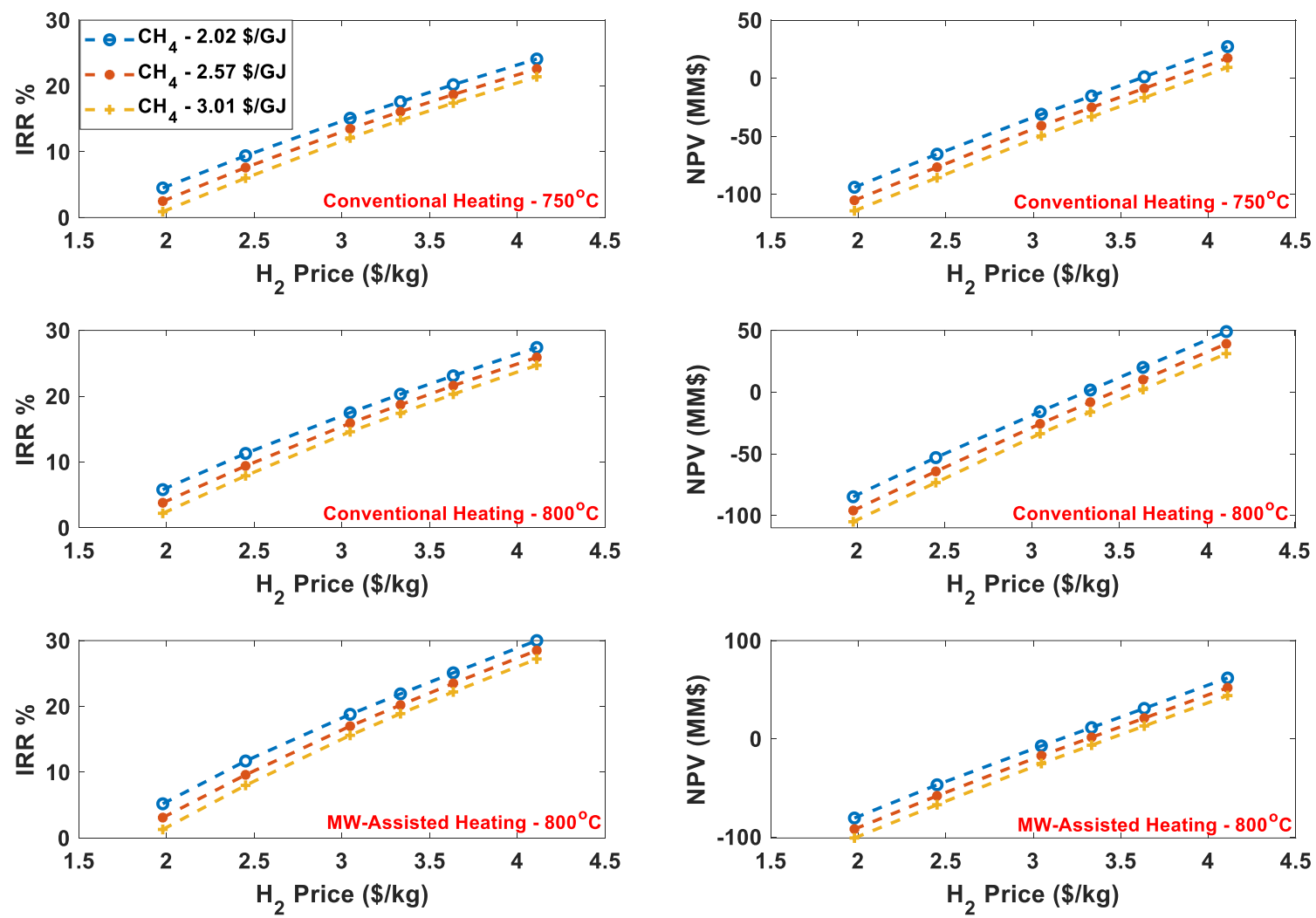

\section{Figure 6.3: Effect of methane and hydrogen price on IRR and NPV for methane DHA processes $(19782 \mathrm{~kg} / \mathrm{h} \mathrm{CH}$ feed)}

\subsubsection{Sensitivity to Electricity Price}

The impact of electricity price on the economic performance of methane DHA processes is analyzed, as shown in Fig. 6.4. The electricity price is based on the industrial sector price for New England and Mid-Atlantic region. For a given electricity price, sensitivity with respect to hydrogen selling price is also analyzed as shown in Fig. 6.4. The sensitivity of all three process cases to electricity price is relatively less than the methane price. For example, when the methane price increased by $50 \%$ from $\$ 2.02 / \mathrm{GJ}$ to $\$ 3.01 / \mathrm{GJ}$, the maximum drop in the IRR was $3.9 \%$ absolute value for $\mathrm{MW}$-assisted process. In comparison, when the electricity price increased by $50 \%$, the drop in IRR was only $2.5 \%$ absolute value for conventional heating $700^{\circ} \mathrm{C}$ process. Similar to the methane sensitivity study, when the hydrogen price is the lowest, the IRR of MW-assisted process 
is about $0.7 \%$ (absolute value) lower than the conventional heating $800^{\circ} \mathrm{C}$ process. When the electricity price is $\$ 34.9 / \mathrm{GJ}$ corresponding to new England region, IRR of $15 \%$ can be achieved when the hydrogen selling price is approximately $\$ 3.4 / \mathrm{kg}, \$ 3.15 / \mathrm{kg}$, and $\$ 3.05 / \mathrm{kg}$ for conventional heating $750^{\circ} \mathrm{C}, 800^{\circ} \mathrm{C}$, and $\mathrm{MW}$-assisted heating process, respectively. Similarly, when electricity price is $\$ 17.5 / \mathrm{GJ}$ corresponding to Mid-Atlantic region, $15 \%$ IRR can be achieved with a hydrogen selling price of $\$ 3 / \mathrm{kg}, \$ 2.7 / \mathrm{kg}$, and $\$ 2.4 / \mathrm{kg}$ for conventional heating $750^{\circ} \mathrm{C}, 800^{\circ} \mathrm{C}$, and $\mathrm{MW}$-assisted heating process, respectively.
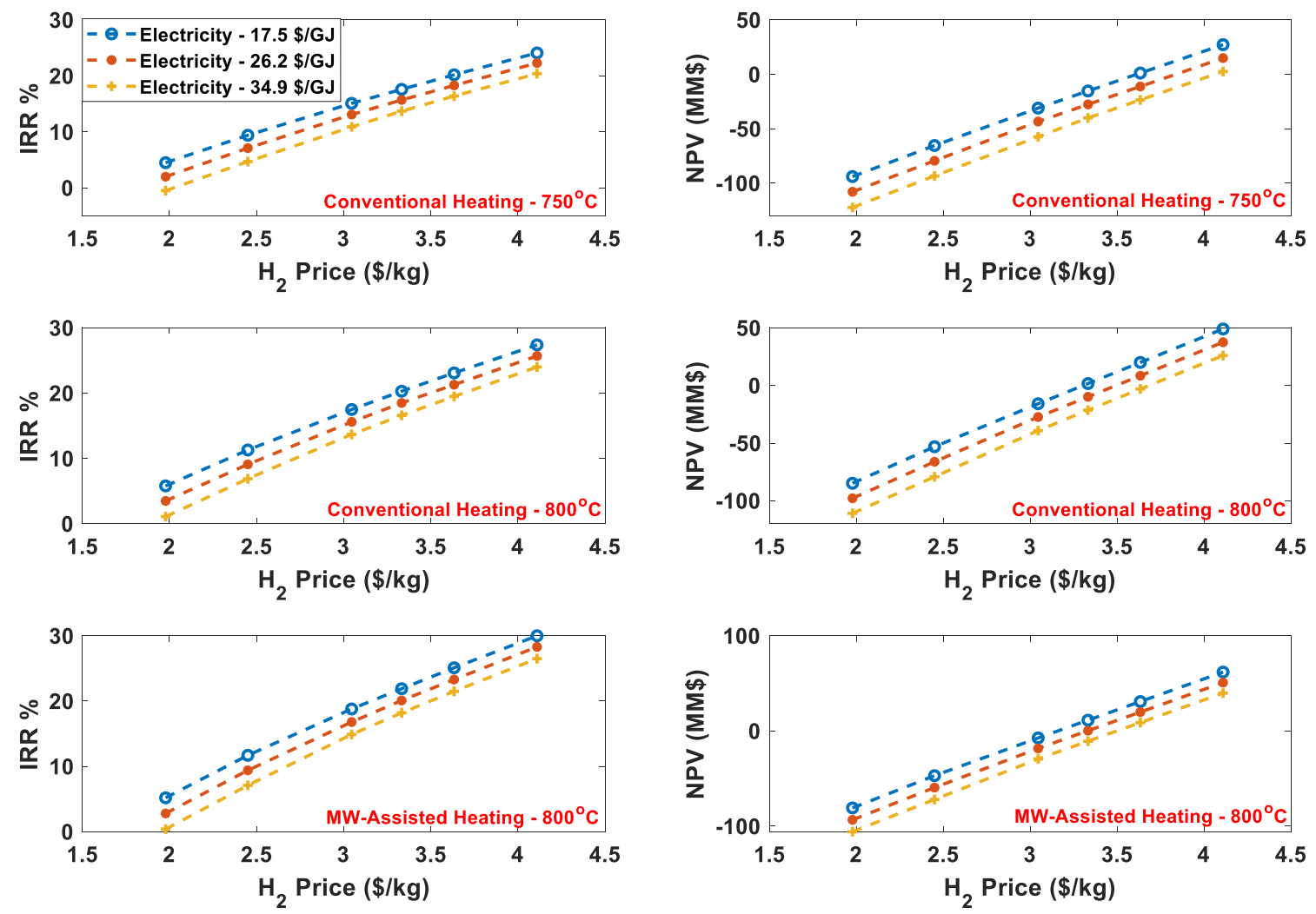

Figure 6.4: Effect of electricity and hydrogen price on IRR and NPV for methane DHA conventional heating process $\left(\mathrm{CH}_{4}\right.$ feed $\left.-19782 \mathrm{~kg} / \mathrm{h}, \mathrm{CH}_{4}-2.02 \$ / G J\right)$

\subsubsection{Sensitivity to Catalyst Variable Cost}

In methane DHA process, catalyst deactivation is very fast due to the deposition of the coke. Catalyst must be regenerated, and, in this step, there is a possibility for loss of the catalyst. So, fresh catalyst must be fed to maintain the same feed to catalyst mass ratio. Moreover, the operating temperature of reactor is high which can affect catalyst stability. Accessing the effect of this individual phenomena on process economics is not possible. So, a sensitivity study is performed by changing the catalyst cost and its impact on IRR and NPV is studied, as shown in Fig. 6.5. As 
mentioned earlier, a catalyst consumption rate of $0.01 \%$ per hour is assumed, which is then multiplied by the operating hours and catalyst cost to calculate the catalyst variable cost. In Fig. 6.5 , the catalyst cost is changed by $25 \%$ and $50 \%$ to mimic scenarios where the catalyst loss is more. Based on the analysis, increasing the catalyst cost by $50 \%$ reduces the IRR for MW-assisted process from $5.2 \%$ to $2.4 \%$ at the lowest hydrogen selling price. Similar, drop in IRR is seen for the conventional heating processes. Moreover, the IRR of MW-assisted case is slightly lower than the $800^{\circ} \mathrm{C}$ conventional heating process when the hydrogen price is the lowest. Between, electricity price, methane price, and catalyst variable cost, the later has the least impact on the process economics as compared to the former two.
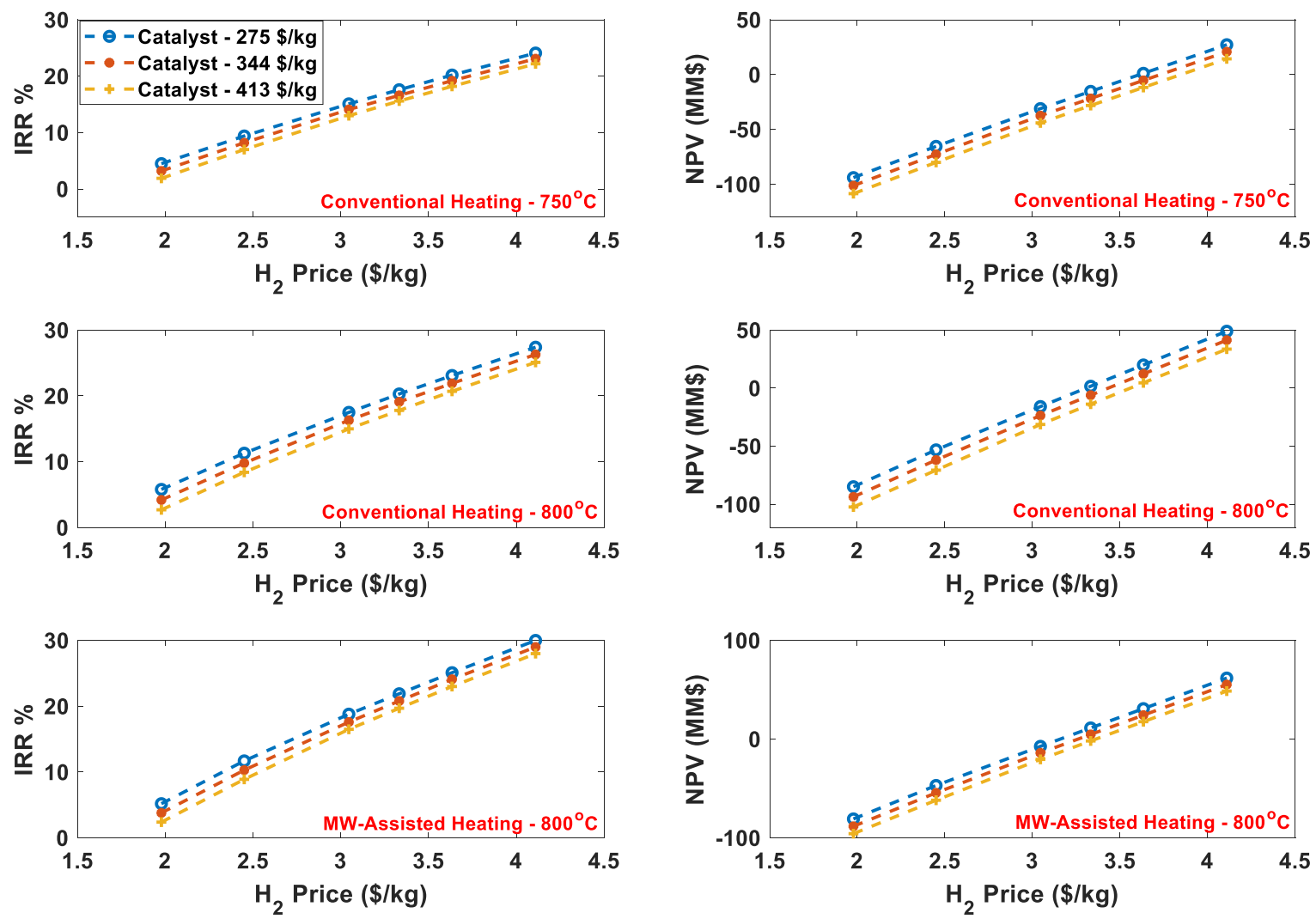

\section{Figure 6.5: Impact of catalyst cost and hydrogen price on IRR and NPV for methane DHA conventional heating process $\left(\mathrm{CH}_{4}\right.$ feed $-19782 \mathrm{~kg} / \mathrm{h}, \mathrm{CH}_{4}-2.02$ \$/GJ, Electricity- 17.5 $\$ / \mathbf{G J})$}

\subsubsection{MW Reactor Cost Variability}

MW reactor cost is not available in open literature. So, initially the cost is calculated based on inhouse information using the cost correlation shown in Table 6.6. There can still be considerable uncertainty in the MW reactor cost if it were to be used on a commercial scale. So, the sensitivity 
of change in MW reactor cost on the process economics is studied, as shown in Fig. 6.6. As seen, for hydrogen price of $\$ 1.98 / \mathrm{kg}$, increasing the MW reactor cost by $100 \%$ decreases the IRR from $5.2 \%$ to $4.2 \%$. Indicating that the process economics is relatively less sensitive to the MW reactor cost, as compared to other variables.
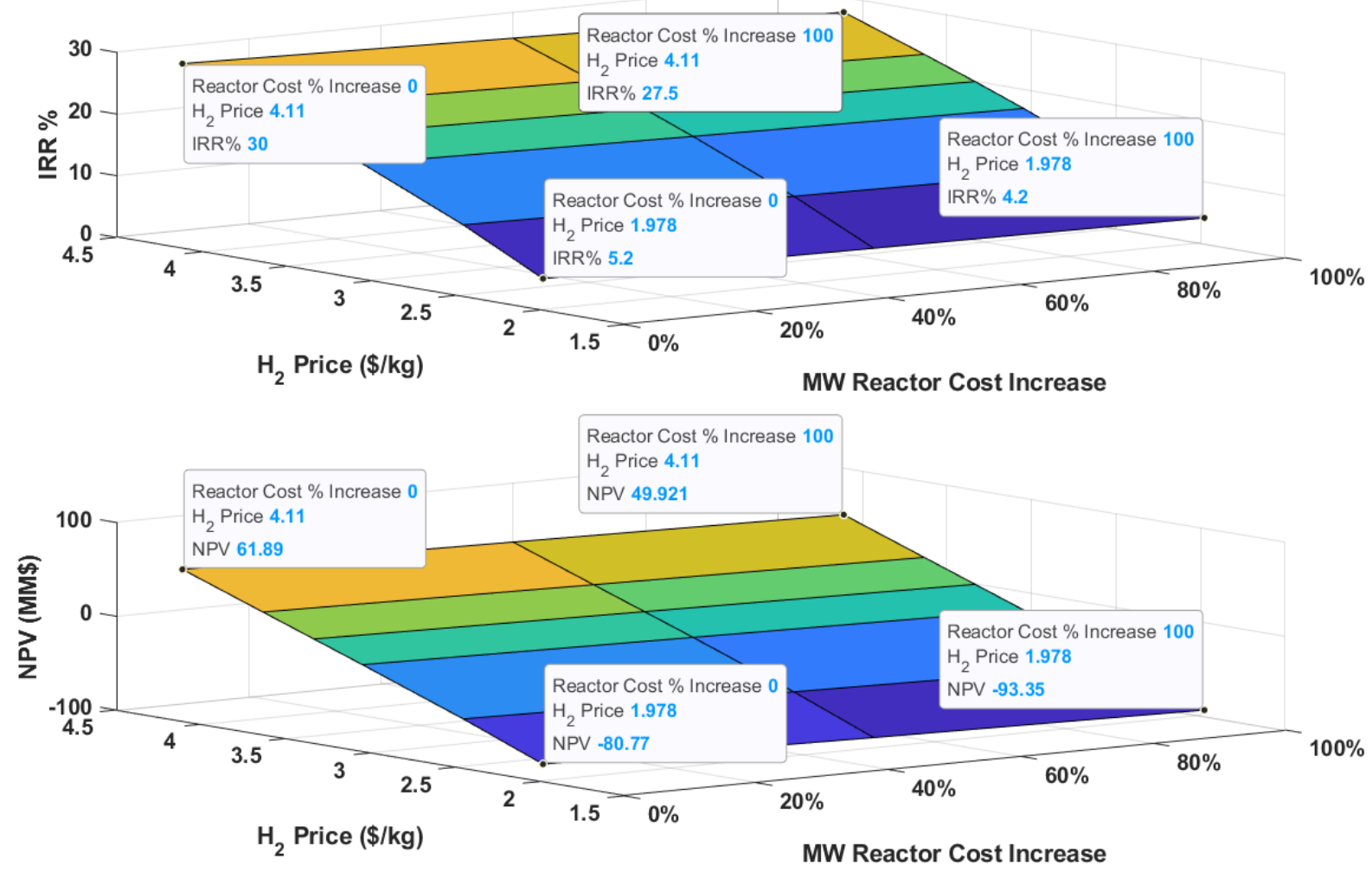

Figure 6.6: Impact of MW reactor cost on process economics parameter for $M W$-assisted process (scale - $19782 \mathrm{~kg} / \mathrm{h} \mathrm{CH}$ feed)

\subsubsection{Impact of Desired Rate of Return on Net Present Value}

Until now, desired rate of return (DROR) that was used for economic analysis was $20 \%$, for a 10 year period. Consideration of DROR will be based on the process capital investment, project operating life, products produced, location, and market conditions. Based on 20\% DROR, NPV was negative for all the process cases as shown in Table 6.11 because the rate of return is less than DROR. In this section, the impact of DROR on the process NPV for methane DHA cases is studied. Discounted cash flow diagram for MW-assisted case operating at $800^{\circ} \mathrm{C}$ is shown in Fig. 6.7. 

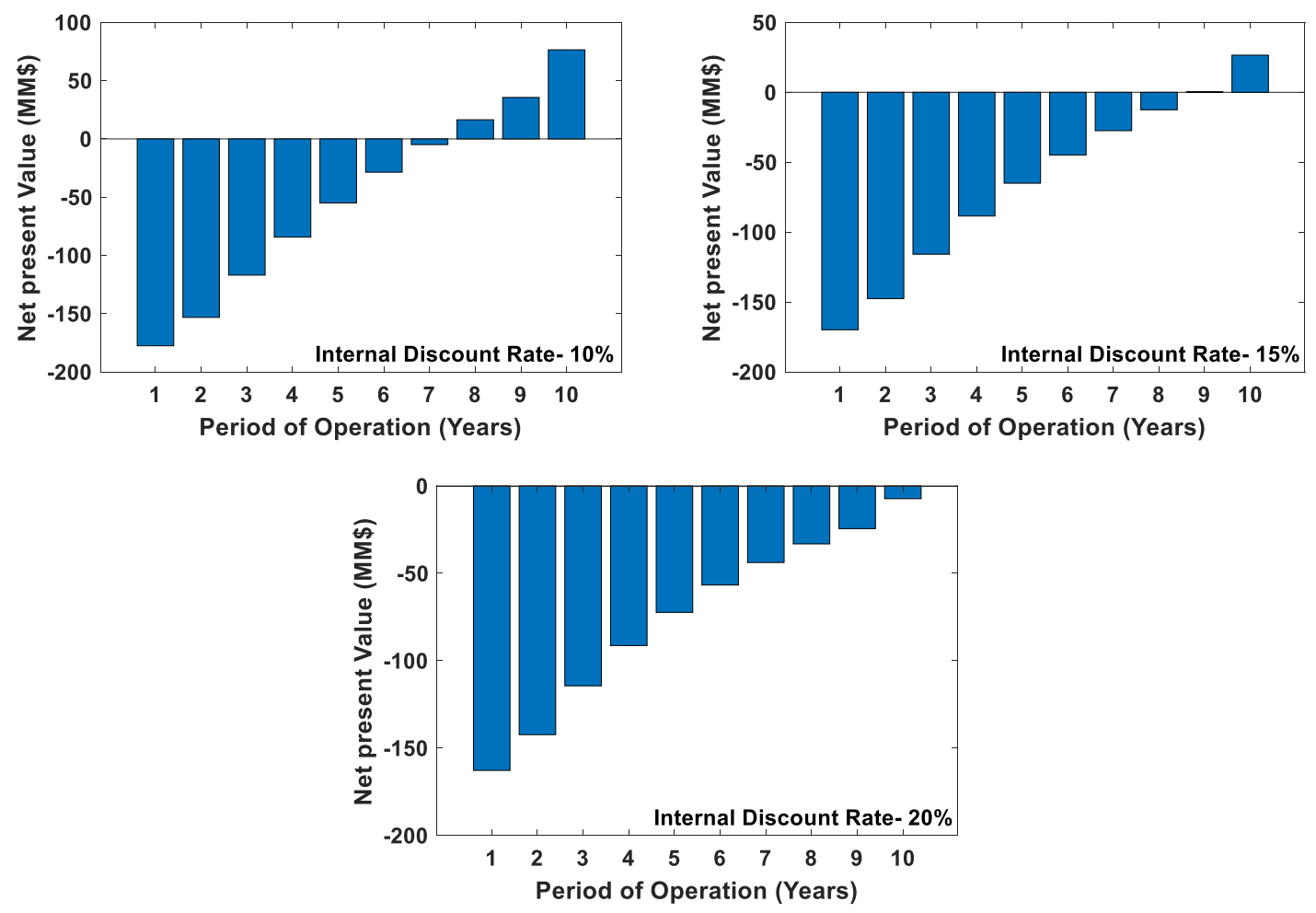

\section{Figure 6.7: Impact of DROR on NPV of MW-assisted heating process operating at $800^{\circ} \mathrm{C}$ $\left(\mathrm{CH}_{4}\right.$ Feed $\left.-19782 \mathrm{~kg} / \mathrm{h}\right)$}

With the increase in the internal discount or interest rate, the NPV of the process is decreasing. If the desired rate of return was set to $20 \%$, then the process would not be an acceptable investment because the NPV is negative. So, it is important to consider appropriately DROR while evaluating the economic feasibility of the process. Comparison between conventional and MW-assisted methane DHA heating processes at three different discount rate is shown in Table 6.12. As seen, for all cases with the increase in the DROR, the NPV is decreasing. Based on the analysis, DROR around $15 \%$ would be appropriate for all cases, with the MW-assisted case being the most attractive process. 


\section{Table 6.12: Comparison of NPV at different DROR for methane DHA cases $\left(\mathrm{CH}_{4}\right.$ Feed - $19782 \mathrm{~kg} / \mathrm{h}$ )}

Net Present Value (MM\$)

\begin{tabular}{cccc}
\hline $\begin{array}{c}\text { Desired Rate of } \\
\text { Return }\end{array}$ & $\begin{array}{c}\text { Conventional } \\
\text { Heating }\left(\mathbf{7 5 0}^{\circ} \mathbf{C}\right)\end{array}$ & $\begin{array}{c}\text { Conventional } \\
\text { Heating }\left(\mathbf{8 0 0}^{\circ} \mathbf{C}\right)\end{array}$ & $\begin{array}{c}\text { MW-Assisted } \\
\text { Heating }\left(\mathbf{8 0 0}^{\circ} \mathbf{C}\right)\end{array}$ \\
\hline $10 \%$ & 49 & 71 & 76 \\
$15 \%$ & 1.32 & 19 & 27 \\
$20 \%$ & -31 & -16 & -7 \\
\hline
\end{tabular}

\subsection{Conclusion}

In this Chapter, techno-economic analysis of conventional and MW-assisted methane DHA process is performed, and it is compared with the multi-step shale gas to aromatics via methanol synthesis process. Comparison between the methane DHA processes showed that the smaller scale (6594 kg/h CH 4 feed) conventional heating process operating at $800^{\circ} \mathrm{C}$ and $\mathrm{MW}$-assisted process had the lowest energy penalty of $0.539 \$ / \mathrm{kg}$. Moreover, the energy penalty of all small scale methane process cases was lower than the multi-step shale gas to aromatics via methanol synthesis production process. The electricity equivalent efficiency of conventional heating methane DHA process operating at $750^{\circ} \mathrm{C}$ was the highest at $69.2 \%$, while the $\mathrm{MW}$-assisted process had the lowest efficiency at $48.9 \%$. Comparison of IRR showed that the small scale MW-assisted process has an $11.2 \%$ IRR compared to $10 \%$ for large-scale multistep process. However, the NPV of both of these processes is negative, and a positive NPV is highly recommended for new investment. Impact of plant scale on the economic performance was also studied, and it showed that increasing the plant scale of methane DHA processes by three times to $19782 \mathrm{~kg} / \mathrm{h} \mathrm{CH} 4$ feed, increased the IRR of conventional heating $750^{\circ} \mathrm{C}, 800^{\circ} \mathrm{C}$, and $\mathrm{MW}$-assisted process to $15.2 \%, 17.5 \%$, and $18.8 \%$, respectively. While the IRR of the multi-step process was $0 \%$ at this plant scale. Sensitivity analysis of key process parameters showed that the hydrogen selling price has a huge impact on the economic feasibility of the process methane DHA process. In addition, methane price, electricity, and the catalyst variable cost do also have a considerable impact on the process economics, and MW reactor cost does not play a key role. While the methane DHA MW-assisted 
process seems to be like the most feasible option, further investigation would be required. In this study, all the solid products are classified as carbon. However, polyaromatics like naphthalene are also present which are not considered in this study because experimental data is not available due to the difficulty associated with quantifying it in real time. Moreover, more detail analysis of the catalyst regeneration would be required that would affect the reactor schedule operation and the productivity of the reactor. In any case, the methane DHA process is a promising technology compared to the multi-step aromatics production for a small to medium scale chemical plant. 


\section{Chapter 7. Final Remarks}

In this work, plant-wide modeling, and techno-economic optimization for direct and indirect conversion of shale gas to DME has been conducted. In addition, dynamic data reconciliation, parameter estimation, and multi-scale commercial scale reactor modeling has been undertaken for direct non-oxidative conversion of methane to aromatics. High-fidelity system-level and unit-level process models have been developed. using a multi-software platform that includes Aspen Plus Package, Aspen Custom Modeler, Exchanger Design and Rating, and Microsoft Excel. Using these models, economic analysis has been performed in Aspen Process Economic Analyzer to analyze the economic feasibility of the processes. The process and economic models have also been validated with literature and in-house experimental data, where possible.

For shale gas conversion to DME via direct and indirect synthesis routes, the following tasks have been performed and conclusions have been made: Plant-wide models for direct and indirect DME synthesis processes with integrated $\mathrm{CO}_{2}$ capture have been developed in Aspen Plus. A novel DME separation system has also been modeled for direct DME synthesis route. The binary interaction parameters for methanol-DME- $\mathrm{CO}_{2}-\mathrm{CO}-\mathrm{H}_{2} \mathrm{O}$ system are not available in Aspen library. So, they have been estimated using literature experimental data. Two $\mathrm{CO}_{2}$ capture technologies i.e. Rectisol and MDEA/PZ have been evaluated. Rectisol process is most energy efficient when the $\mathrm{CO}_{2}$ partial pressure in the feed is $\geq 6$ bar, while MDEA/PZ technology is preferable for lower $\mathrm{CO}_{2}$ partial pressure in the feed. For direct DME process routes, sensitivity of DME productivity to inlet syngas $\left(\mathrm{H}_{2} / \mathrm{CO}\right)$ ratios have shown that maximum DME productivity can be achieved when $\mathrm{H}_{2} / \mathrm{CO}$ $=1$. Similarly, for indirect DME synthesis route, it has been shown that a module $\left(\left(\mathrm{H}_{2}-\mathrm{CO}_{2}\right) /(\mathrm{CO}\right.$ $\left.+\mathrm{CO}_{2}\right)$ ) of $\sim 1.8$ results in maximum methanol production, which in turn can increase DME production. Plant level techno-economic optimization has been undertaken in Aspen Plus Equation Oriented Environment for maximizing the net present value (NPV). For this purpose, rigorous process models developed in Aspen plus are used, rather than reduced order models. Implementation of this optimization methodology can be useful in doing simultaneous process design and optimization. Economic analysis of optimized process shows that, even though the 
DME productivity of direct DME synthesis process is superior, the indirect DME process has a lower breakeven DME price than the direct synthesis route. This is mainly due to the increase in operating and capital.

For methane DHA process, a methodology has been developed for data reconciliation of dynamic reactor data that can applied to any other reaction system. Due to rapid coke formation, catalysts in the non-oxidative methane DHA reactors get deactivated. A model for the catalyst deactivation is proposed along with rate models for other DHA reactions. An algorithm is developed by coupling an iterative direct substitution approach with an optimization algorithm for optimal estimation of the initial state of the reactor and the kinetic parameters using the in-house experimental data. This algorithm can be easily applied to any other coking system. The catalyst deactivation model is in good agreement with experimental data. Analysis of methane DHA system shows that, benzene yield increases with temperature and catalyst deactivation also increases. Moreover, due to rapid deactivation, a cyclic parallel reactor operation needs to be considered if fixed bed reactor is used.

For the MW-assisted reactor, the amount of heat generated at specific catalyst sites has been modeled using Maxwell's equation. For integrating the Maxwell's equation within the process model, a reduced order model is developed. This reduce order model can be easily implemented in any other MW reactor modeling system, without any increase in the computational time. In addition, a multi-scale heterogenous industrial scale MW reactor model is developed by coupling the catalyst pellet level model with the reactor level model. Analysis show that large diameter reactors do not perform well when only MW-assisted heating is utilized because of the higher MW energy density near the center of the reactor as compared to surface. Either smaller diameter reactors or a furnace-MW hybrid heating system can be utilized for even temperature distribution and improving the performance of the MW reactor. Analysis between $2.45 \mathrm{GHz}$ and $915 \mathrm{MHz}$ frequency operation, the former has a higher MW absorption efficiency compared to later, and this results in better reactor performance. Techno-economic analysis of methane DHA processes showed that the MW-assisted process has a better economic performance compared to the conventional heating process and the multi-step aromatics production process. Plant scale would be one of the key parameter that needs to be considered for methane DHA process. Medium plant scale showed favorable economics, while on a small scale the process was economically unfavorable. However, further investigation needs to be done because polyaromatic hydrocarbons 
such as naphthalene is also formed in methane DHA system. Currently, it is not taken into consideration because of the lack of experimental data. Inclusion of valuable polyaromatics can positively affect the plant economics. 


\section{Chapter 8. Future Work}

In terms of DME production process, currently in this study $\mathrm{CO}_{2}$ is being recycled to the ATR reactor to reduce the $\mathrm{H}_{2} / \mathrm{CO}$ ratio. Other alternatives such as integration of reverse water gas shift (RWGS) reactor to the process, along with $\mathrm{CO}_{2}$ recycle to the ATR can be explored to study the impact on the economics of the process. RWGS can be operated at a lower pressure as compared to the ATR reactor, so integration of RWGS would help in reducing the compression duty associated with recycling $\mathrm{CO}_{2}$. In terms of techno-economic optimization, currently due to the software integration issue, APEA could not be utilized directly to perform plant-level technoeconomic optimization, instead cost equations with correction factors were used. Integration of Aspen plus with APEA should be explored for performing simultaneous process modeling and plan level optimization.

For methane DHA reaction system, the current rate model has been developed using the experimental data $1 \mathrm{~atm}$. Estimation using the experimental data at high pressures could not be performed due to technical issues with experimental equipment. So, the current rate model could be extended to higher pressure. This would be particularly helpful because usually the methane rich shale gas is available at high pressure from the site and the reactor outlet consists of light gases which have to be separated under high pressure separation system. So, extending the rate model to higher pressure and operating the reactor at high pressure would be beneficial for plant utility consumption. Real-time measurement for polyaromatic hydrocarbon is currently not available. So, all the unaccounted carbon is given to carbon-graphite. Exploration of new reaction schemes upon availability of the experimental data could increase the validity of the rate model. For MW-reactor system, currently there is uncertainty with the temperature measurement of the catalyst bed. If experimental data on the temperature distribution inside the bed is available, the rate model can be updated to increase its validity. The MW reactor model currently developed does not account for the absorption of MWs by the deposited coke. So, consideration of MW-coke interactions should be further explored to the understand the reasons behind higher methane conversion in the MW reactor system. Catalyst regeneration model can be developed using the experimental regeneration 
profile, upon availability. The catalyst regeneration model along with the current model can be useful in design of a cyclic reactor operation. Scheduling of the cyclic reactor operation can be formulated as a dynamic optimization problem with due consideration of regeneration cycle, catalyst deactivation, number of reactors, and cycle time. A hybrid MW-reactor model, where combination of MW pulsing and conventional heating is utilized should be explored because in industrial scale reactors simply utilizing MW-assisted heating will result in uneven temperature distribution inside the reactor. As a result, the reactor will not be operating at its optimum. Moreover, electricity is expensive than a furnace. So, having a hybrid reactor will help in maintaining relatively uniform temperature profiles inside the reactor. A second alternative is to have transmission lines embedded inside the catalyst bed through which MW propagates. This configuration could allow in more even heating of the catalyst bed. A third alternative is to have many smaller diameter reactors operating in parallel to which MW energy would be given through a single transmission line. This configuration could benefit from uniform heating of catalyst bed due to smaller reactor diameter. Alternatively, fluidized bed reactor with magnetrons attached on the sides is also a viable candidate. 


\section{Appendix A: Equilibrium Constant Coefficient and Estimated Kinetic Parameters for Direct DME Synthesis Reactions}

The adjusted equilibrium coefficient for the $4^{\text {th }}$ term in Eq. (2.2) is shown in Table A.1. Excel solver was used to do so. Note that the first three coefficients are the same as the work of Zhang et al. [75]. Fig. A.1 (a-c) shows the comparison between the original and the estimated equilibrium constant for reaction 9,10 and 12 .

Table A.1 Estimated equilibrium constant coefficients for DME synthesis

\begin{tabular}{cccccc}
\hline Reaction \# & A & B & C & \multicolumn{2}{c}{ D } \\
\hline \multicolumn{3}{c}{ Original } & & Original & Estimated \\
9 & 22.7 & 8975 & -7.694 & $3.92 \mathrm{E}-03$ & $4.10 \mathrm{E}-03$ \\
10 & 17.6 & 4213 & -5.752 & $-1.71 \mathrm{E}-03$ & $-4.16 \mathrm{E}-04$ \\
12 & -9.39 & 3205 & 0.836 & $2.35 \mathrm{E}-03$ & $1.43 \mathrm{E}-03$ \\
\hline
\end{tabular}
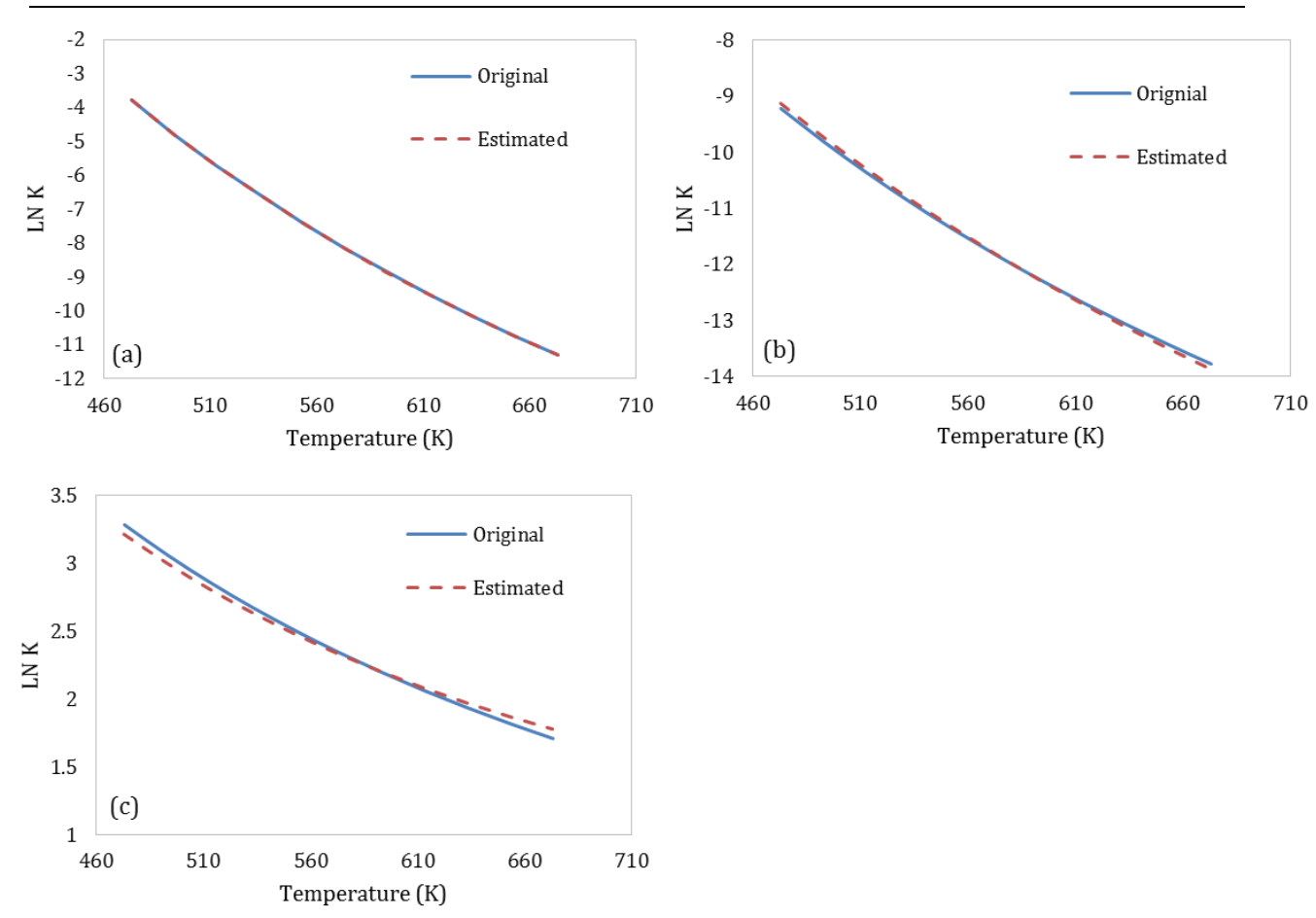

Fig. A.1. Comparison between original and estimated equilibrium constant of reaction 9 (Fig. A.1.a), reaction 10 (Fig. A.1.b) and reaction 12 (Fig. A.1.c)

Table A.2 shows the estimated kinetic rate parameters for the reactions occurring in direct syngas-to-DME reactor. 
Table A.2. Estimated Rate Parameters

\begin{tabular}{ccc}
\hline Reaction \# & Pre-Exponential Factor & Activation Energy $(\mathbf{k J} / \mathbf{k m o l})$ \\
\hline 9 & $1.537 \mathrm{~mol} / \mathrm{g} \mathrm{s} \mathrm{bar}^{3}$ & 62,915 \\
10 & $1.364 \mathrm{~mol} / \mathrm{g} \mathrm{s} \mathrm{bar}^{4}$ & 59,660 \\
12 & $0.301 \mathrm{~mol} / \mathrm{g} \mathrm{s} \mathrm{bar}$ & 42,765 \\
\hline
\end{tabular}

\section{Appendix B: Regressed Binary Interaction Parameters for DME-CO 2 , Methanol-CO $\mathrm{C}_{2}, \mathrm{DME}-\mathrm{H}_{2} \mathrm{O}$, and CO-DME}

The binary interaction parameters for NRTL-RK EOS were regressed using the experimental data as shown in Table B.

Table B. Regressed binary interaction parameters for NRTL-RK EOS

\begin{tabular}{|c|c|c|c|c|}
\hline & $\mathrm{CO}_{2}$ & & DME & $\mathrm{CO}$ \\
\hline Component $\mathbf{j}$ & DME & $\mathrm{CO}_{2}$ & $\mathrm{H}_{2} \mathrm{O}$ & DME \\
\hline $\mathrm{A}_{\mathrm{IJ}}$ & -2.17 & 15.90 & -60.70 & -17.22 \\
\hline $\mathrm{A}_{\mathrm{JI}}$ & 4.86 & 80.00 & -43.40 & -6.20 \\
\hline $\mathrm{B}_{\mathrm{IJ}}$ & 913.62 & -1221.13 & 3392.32 & 6079.49 \\
\hline $\mathrm{B}_{\mathrm{JI}}$ & -1703.00 & -2586.82 & 1009.65 & 1464.06 \\
\hline $\mathrm{C}_{\mathrm{IJ}}$ & 0.30 & 0.30 & 0.0012 & 0.30 \\
\hline $\mathrm{D}_{\mathrm{IJ}}$ & - & - & - & - \\
\hline $\mathrm{E}_{\mathrm{IJ}}$ & - & -2.00 & 9.065 & - \\
\hline $\mathrm{E}_{\mathrm{JI}}$ & - & -12.05 & 7.221 & - \\
\hline $\mathrm{T}_{\min }(\mathrm{K})$ & 273.15 & 230 & 293.15 & 288.1 \\
\hline $\mathrm{T}_{\max }(\mathrm{K})$ & 386.41 & 477 & 473 & 316.1 \\
\hline
\end{tabular}

The objective function used in estimating the binary interaction parameters is a maximum likelihood objective function given by Eq. (B.1).

$$
\begin{gathered}
f=\sum_{i=1}^{N}\left[\left(\left(T_{e, i}-T_{m, i}\right)^{T} \sigma_{T}^{-2}\left(T_{e, i}-T_{m, i}\right)\right)+\left(\left(P_{e, i}-P_{m, i}\right)^{T} \sigma_{P}^{-2}\left(P_{e, i}-P_{m, i}\right)\right)+\sum_{j=1}^{M}\left(\left(x_{e, i, j}-x_{m, i, j}\right)^{T} \sigma_{x, i, j}^{-2}\left(x_{e, i, j}-x_{m, i, j}\right)\right)\right. \\
\left.+\sum_{j=1}^{M}\left(\left(y_{e, i, j}-y_{m, i, j}\right)^{T} \sigma_{y, i, j}^{-2}\left(y_{e, i, j}-y_{m, i, j}\right)\right)\right]
\end{gathered}
$$

Here, $N, T, P, M, x, y, e, m, \sigma$ represent the number of data points in the data, temperature, pressure, number of components in the data, liquid mole fraction, vapor mole fraction, estimated data, 
measured data and standard deviation of the indicated quantity respectively. Figure B shows the fit for the liquid and vapor mole fractions. Experimental data are obtained from the open literature [76-83].
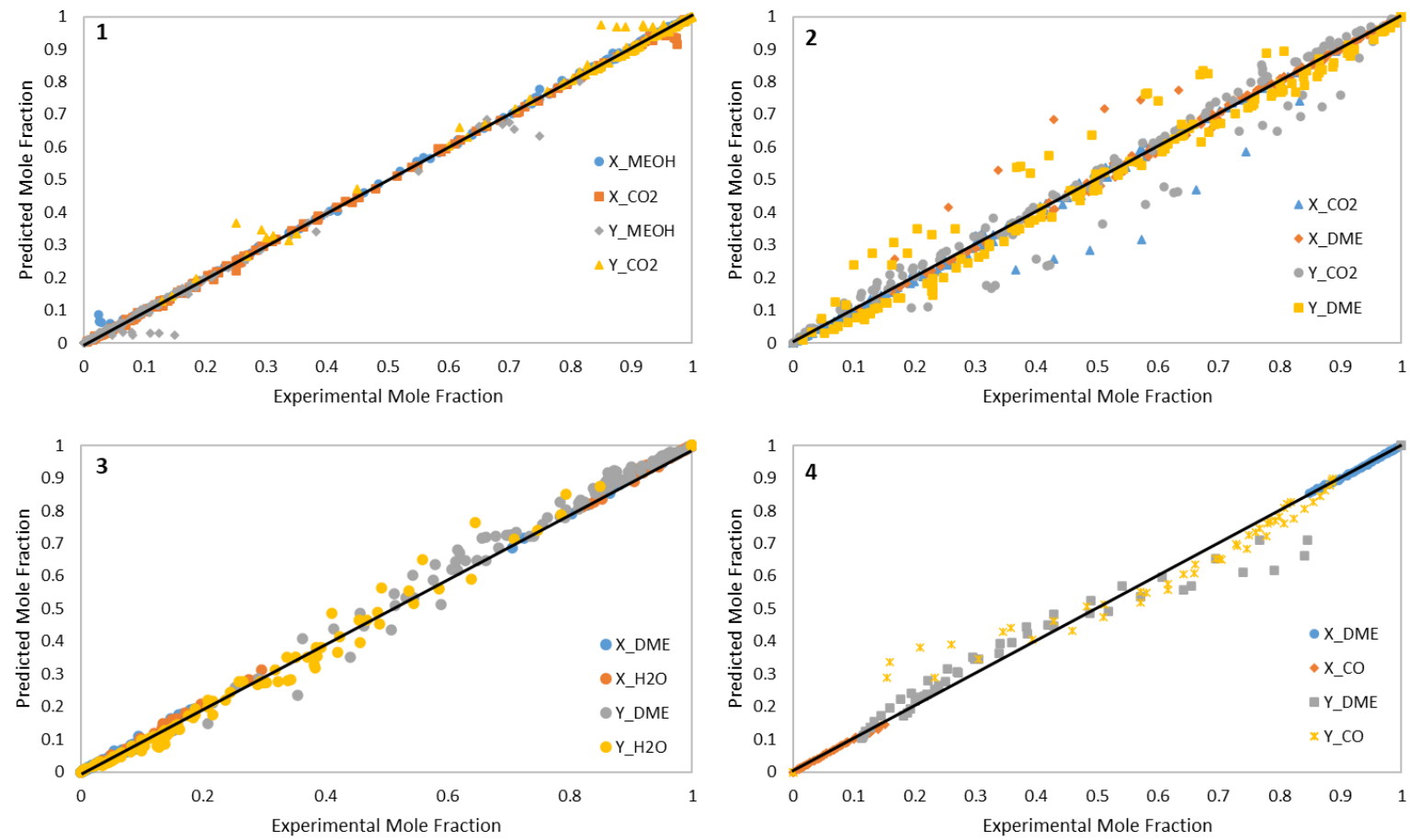

Fig. B. Comparison of predicted data with the experimental data; Fig. B.1- Methanol $\mathrm{CO}_{2}$; Fig. B.2- DME-CO2, Fig. B.3- DME-H2O, Fig. B.4- DME-CO Systems

\section{Appendix C: Validation of Methanol Dehydration Reactor Model}

Table C.1. Shows the model validation for the rate-based methanol dehydration reactor. As seen below, the predicted temperature and the methanol molar conversion by our model is in good agreement with Bercic and Levec [91].

Table C.1. Validation of Methanol Dehydration Reactor Model with Bercic \& Levec [91]

\begin{tabular}{cccc}
\hline Parameter & Inlet & Our model & Outlet \\
& & 407 & Reported \\
\hline Temperature $\left({ }^{\circ} \mathrm{C}\right)$ & 288 & - & 409 \\
Pressure (bar) & 2.1 & $\sim 80 \%$ & 2.099 \\
Methanol molar conversion & - & $81.38 \%$ \\
\hline
\end{tabular}


The rate based methanol dehydration reactor is also compared with the Gibbs free energy minimization model, as shown in Table C.2. The purpose of this test is to study that the rate model correctly calculates the equilibrium concentration. Reaction temperature is set to $250^{\circ} \mathrm{C}$ with an operating pressure of $10 \mathrm{bar}$ so that the reaction reaches equilibrium. The outlet concentration of the rate model at equilibrium is very close to the Gibbs free energy model.

Table C.2. Comparison of rate model with Gibbs free energy reactor

\begin{tabular}{cccc}
\hline & Inlet & \multicolumn{2}{c}{ Outlet } \\
& & Rate Model & Gibbs Free Energy \\
\hline Total Flow (kg/hr) & 147,600 & 147,600 & 147,600 \\
Total Flow (kmol/hr) & 4,615 & 4,615 & 4,615 \\
Mole Fraction & & & \\
$\mathrm{CH}_{3} \mathrm{OH}$ & 0.996 & 0.176 & 0.169 \\
$\mathrm{H}_{2} \mathrm{O}$ & & 0.414 & 0.418 \\
$\mathrm{C}_{2} \mathrm{H}_{6} \mathrm{O}$ & & 0.410 & 0.413 \\
\hline
\end{tabular}




\section{Appendix D: Equipment Details for Direct and Indirect DME Production Process}

List of major equipment in the direct and indirect shale gas to DME production process is shown in Table D.

Table D. Equipment details for direct and indirect DME synthesis production process

\begin{tabular}{|c|c|c|c|c|c|}
\hline \multirow[b]{2}{*}{ Equipment } & \multirow[b]{2}{*}{ \#Req } & \multirow[b]{2}{*}{ \# Spares } & \multicolumn{3}{|c|}{ Cost } \\
\hline & & & APEA Model & Source & Material \\
\hline \multicolumn{6}{|l|}{ Syngas Synthesis Section } \\
\hline Pre-Reforming reactor & 1 & 0 & QE & [124] & N/A \\
\hline Autothermal reforming reactor & 1 & 0 & QE & {$[125]$} & N/A \\
\hline \multicolumn{6}{|l|}{ Rectisol Process } \\
\hline $\mathrm{CO}_{2}$ absorber tower & 2 & 0 & TW Packed & Icarus & A $515,0.5 \mathrm{CIS}$ \\
\hline High pressure flash vessel & 2 & 0 & VT Cylinder & Icarus & CS \\
\hline Syngas feed compressor & 1 & 0 & GC Centrif & Icarus & CS \\
\hline Syngas recycle compressor & 2 & 0 & GC Centrif & Icarus & CS \\
\hline $\mathrm{CO}_{2}$ recycle compressor & 1 & 0 & GC Centrif & Icarus & CS \\
\hline Methanol circulation pump & 2 & 2 & CP Centrif & Icarus & CS \\
\hline Stripper- Condenser & 2 & 0 & HE Float Head & Icarus & $\mathrm{CS}, \mathrm{CS}$ \\
\hline Stripper- Condenser drum & 2 & 0 & HT Horiz Drum & Icarus & CS \\
\hline Stripper- Reboiler & 2 & 0 & HE Float Head & Icarus & $\mathrm{CS}, \mathrm{CS}$ \\
\hline Stripper- Reflux pump & 2 & 2 & CP Centrif & Icarus & CS \\
\hline Stripper-Tower & 2 & 0 & TW Trayed & Icarus & CS, A285C \\
\hline \multicolumn{6}{|l|}{ MDEA/PZ Process } \\
\hline $\mathrm{CO}_{2}$ absorber tower & 1 & 0 & TW Packed & Icarus & A 516, M107YC \\
\hline Pump around Heat Exchanger- Absorber & 5 & 0 & HE Float Head & Icarus & A $214, A 285 C$ \\
\hline Stripper- Condenser & 1 & 0 & HE Fixed TS & Icarus & TI50A, SS316 \\
\hline Stripper- Condenser drum & 1 & 0 & HT Horiz Drum & Icarus & A 516 \\
\hline Stripper- Reboiler & 1 & 0 & HE Float Head & Icarus & $304 L W$, SS316 \\
\hline Stripper-Reflux pump & 1 & 1 & CP Centrif & Icarus & SS316 \\
\hline Stripper-Tower & 1 & 0 & TW Packed & Icarus & 304L, M107YC \\
\hline Flash Vessel & 1 & 0 & VT Cylinder & Icarus & SS316 \\
\hline Solvent circulation pump & 1 & 1 & CP Centrif & Icarus & SS316 \\
\hline \multicolumn{6}{|l|}{ Direct DME Synthesis Production Section } \\
\hline Direct DME synthesis reactor & 1 & 0 & QE & {$[106]$} & N/A \\
\hline Absorber & 1 & 0 & TW Packed & Icarus & CS, M107YC \\
\hline $\mathrm{CO}_{2}$ separation column- Condenser & 1 & 0 & HE Float Head & Icarus & $304 S$, SS304 \\
\hline $\mathrm{CO}_{2}$ separation column- Condenser drum & 1 & 0 & HT Horiz Drum & Icarus & CS \\
\hline $\mathrm{CO}_{2}$ separation column- Reboiler & 1 & 0 & HE Float Head & Icarus & $\mathrm{CS}, \mathrm{CS}$ \\
\hline $\mathrm{CO}_{2}$ separation column- Reflux pump & 1 & 1 & CP Centrif & Icarus & CS \\
\hline $\mathrm{CO}_{2}$ separation column- Tower & 1 & 0 & TW Trayed & Icarus & CS, A285C \\
\hline DME purif. column- Condenser & 1 & 0 & HE Float Head & Icarus & CS, CS \\
\hline
\end{tabular}




\begin{tabular}{|c|c|c|c|c|c|}
\hline DME purif. column- Condenser drum & 1 & 0 & HT Horiz Drum & Icarus & CS \\
\hline DME purif. column- Reboiler & 1 & 0 & HE Float Head & Icarus & CS, CS \\
\hline DME purif. column- Reflux pump & 1 & 1 & CP Centrif & Icarus & CS \\
\hline DME purif. column- Tower & 1 & 0 & TW Trayed & Icarus & $C S, A 285 C$ \\
\hline Flash Vessel & 1 & 0 & VT Cylinder & Icarus & SS304 \\
\hline \multicolumn{6}{|l|}{ Indirect DME Synthesis Production Section } \\
\hline Methanol synthesis reactor & 1 & 0 & QE & [106] & $\mathrm{N} / \mathrm{A}$ \\
\hline Methanol dehydration reactor & 1 & 0 & QE & [126] & N/A \\
\hline Methanol purif. column- Condenser & 1 & 0 & HE Float Head & Icarus & CS, CS \\
\hline Methanol purif. column- Condenser drum & 1 & 0 & HT Horiz Drum & Icarus & CS \\
\hline Methanol purif. column- Reboiler & 1 & 0 & HE Float Head & Icarus & CS, CS \\
\hline Methanol purif. column- Reflux pump & 1 & 1 & CP Centrif & Icarus & CS \\
\hline Methanol purif. column- Tower & 1 & 0 & TW Trayed & Icarus & $C S, A 285 C$ \\
\hline DME separation column- Condenser & 1 & 0 & HE Float Head & Icarus & $\mathrm{CS}, \mathrm{CS}$ \\
\hline DME separation column- Condenser drum & 1 & 0 & HT Horiz Drum & Icarus & CS \\
\hline DME separation column- Reboiler & 1 & 0 & HE Float Head & Icarus & $\mathrm{CS}, \mathrm{CS}$ \\
\hline DME separation column- Reflux pump & 1 & 1 & CP Centrif & Icarus & $\mathrm{CS}$ \\
\hline DME separation column- Tower & 1 & 0 & TW Trayed & Icarus & CS, A285C \\
\hline Methanol-water column- Condenser & 1 & 0 & HE Float Head & Icarus & CS, CS \\
\hline Methanol-water column- Condenser drum & 1 & 0 & HT Horiz Drum & Icarus & CS \\
\hline Methanol-water column- Reboiler & 1 & 0 & HE Float Head & Icarus & $\mathrm{CS}, \mathrm{CS}$ \\
\hline Methanol-water column- Reflux pump & 1 & 1 & CP Centrif & Icarus & CS \\
\hline Methanol-water column- Tower & 1 & 0 & TW Trayed & Icarus & CS, A285C \\
\hline Air separation unit & 1 & 0 & QE & {$[40,121]$} & N/A \\
\hline Pressure swing absorption & 1 & 0 & QE & [127] & N/A \\
\hline HRSG \& SC & 1 & 0 & QE & [105] & $\mathrm{N} / \mathrm{A}$ \\
\hline
\end{tabular}

$Q E=$ Quoted Equipment

\section{Appendix E: Bare Module Cost Correlation between APEA and Cost Equations}

Fig. E shows the correlations developed between the bare module cost obtained from APEA and the bare module cost obtained using the simplified cost equations from Turton et al. [96]. Five major equipment types are considered: Packed distillation column, trayed distillation column, shell $\&$ tube heat exchanger, centrifugal multistage compressor, and centrifugal pump. The correction factor is not required for the reactors as their cost is estimated using correlation from literature. 

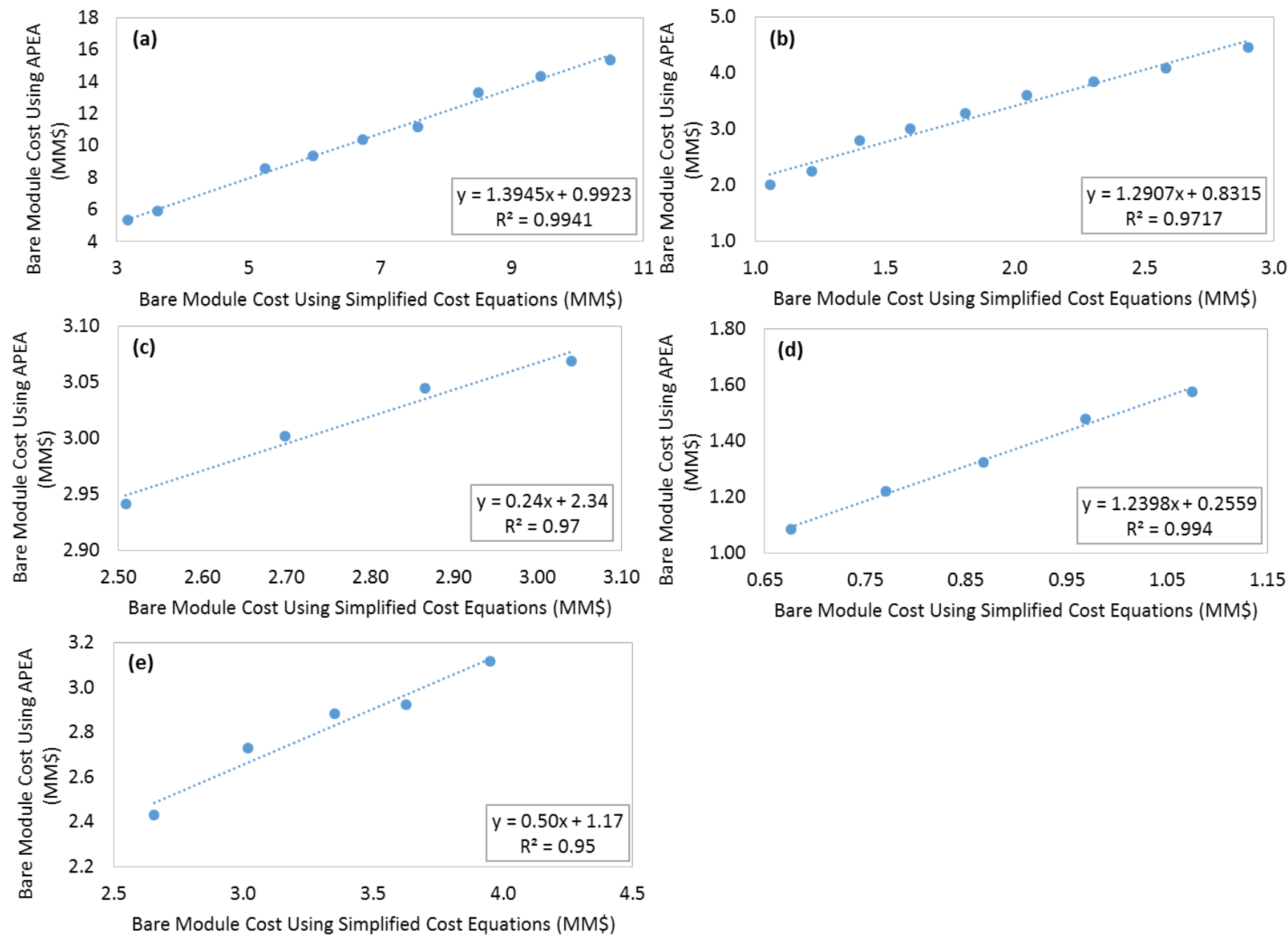

Fig. E. Correlation between the bare module cost and APEA cost for estimating the correction factor. (a) Packed Tower (b) Trayed Tower (c) Compressor (d) Heat Exchanger (e) Pump 


\section{Appendix F: Temperature Profile TGA Experiments}

Temperature profile for conducting the TGA experiment is shown in Figure F.

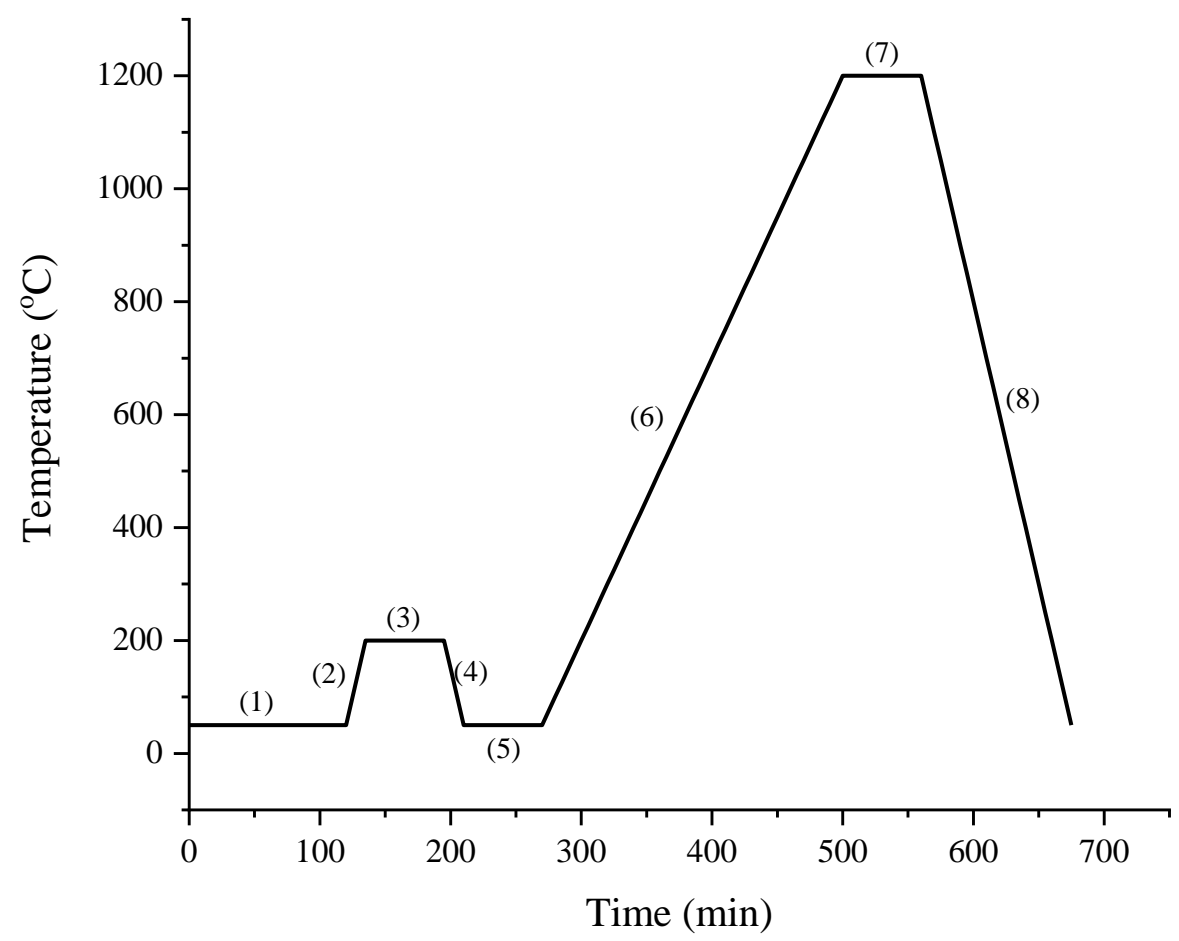

Figure F. Temperature profile of thermogravimetric analysis (TGA) experiments

The detail numerical reading for Figure 4.2 is shown in Table F.

Table F.: Detailed numerical reading of Figure 4.2

\begin{tabular}{ccccc}
\hline Samples & Initial Weight & $\begin{array}{c}\text { Weight at the End } \\
\text { of Step 6 }\end{array}$ & $\begin{array}{c}\text { Weight at the End } \\
\text { of Step 7 }\end{array}$ & $\begin{array}{c}\text { Total Weight Loss } \\
(\mathbf{m g})\end{array}$ \\
\hline a & 35.937 & 32.432 & 32.200 & 3.737 \\
b & 33.463 & 29.480 & 29.330 & 4.133 \\
c & 43.350 & 37.694 & 37.526 & 5.656 \\
d & 34.895 & 29.985 & 29.856 & 5.039 \\
\hline
\end{tabular}




\section{Appendix G: Methane DHA Conventional Heating- Data Reconciliation Plots for $725^{\circ} \mathrm{C}$ and $750{ }^{\circ} \mathrm{C}$}

Data reconciliation for $725^{\circ} \mathrm{C}$ and $750{ }^{\circ} \mathrm{C}$ temperature is shown in Figure G.
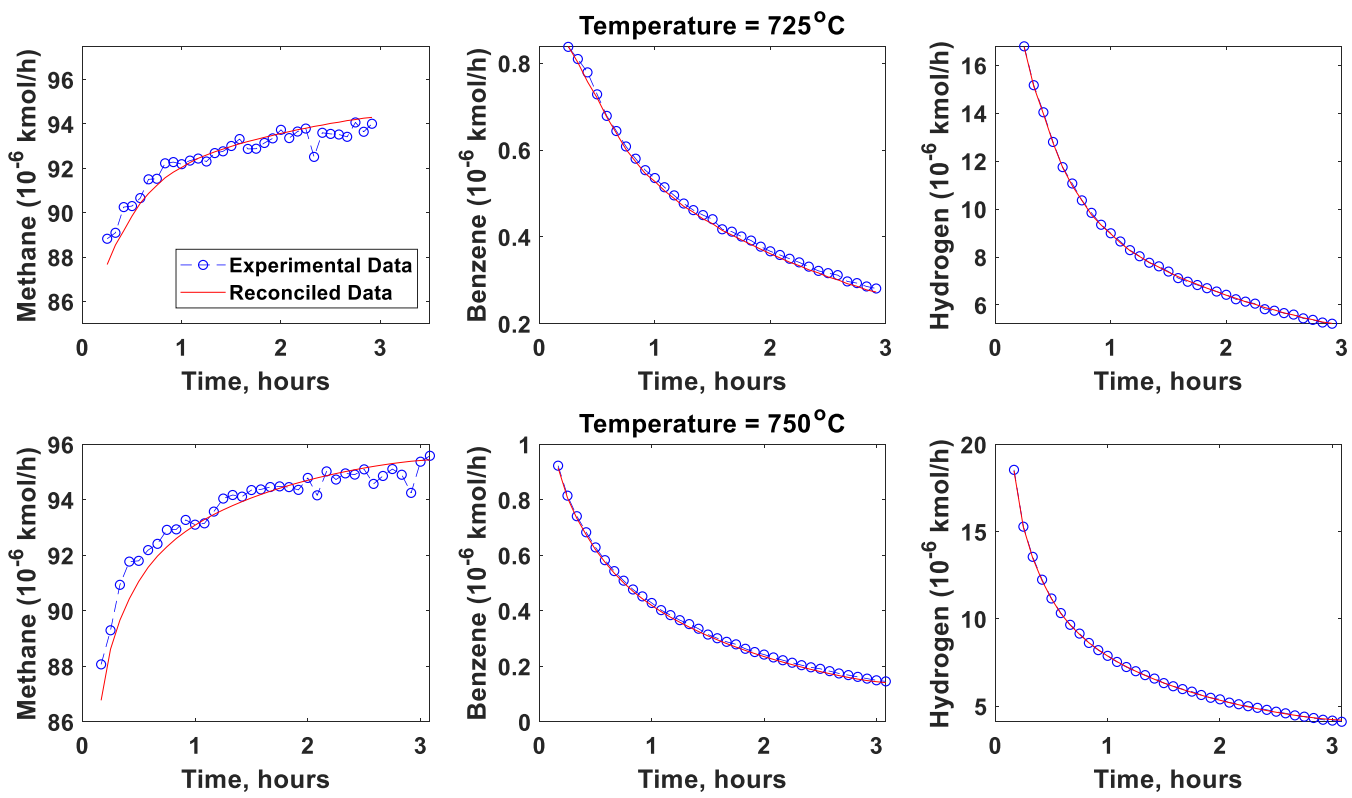

Figure G. Data reconciliation plots for $725^{\circ} \mathrm{C}$ and $750{ }^{\circ} \mathrm{C}$ temperature 


\section{Appendix H: Methane DHA Conventional Heating- Model Comparison with Experiment for $800^{\circ} \mathrm{C}$}

The comparison of parameter estimation model result with experimental data for $800{ }^{\circ} \mathrm{C}$ is shown in Figure $\mathrm{H}$.
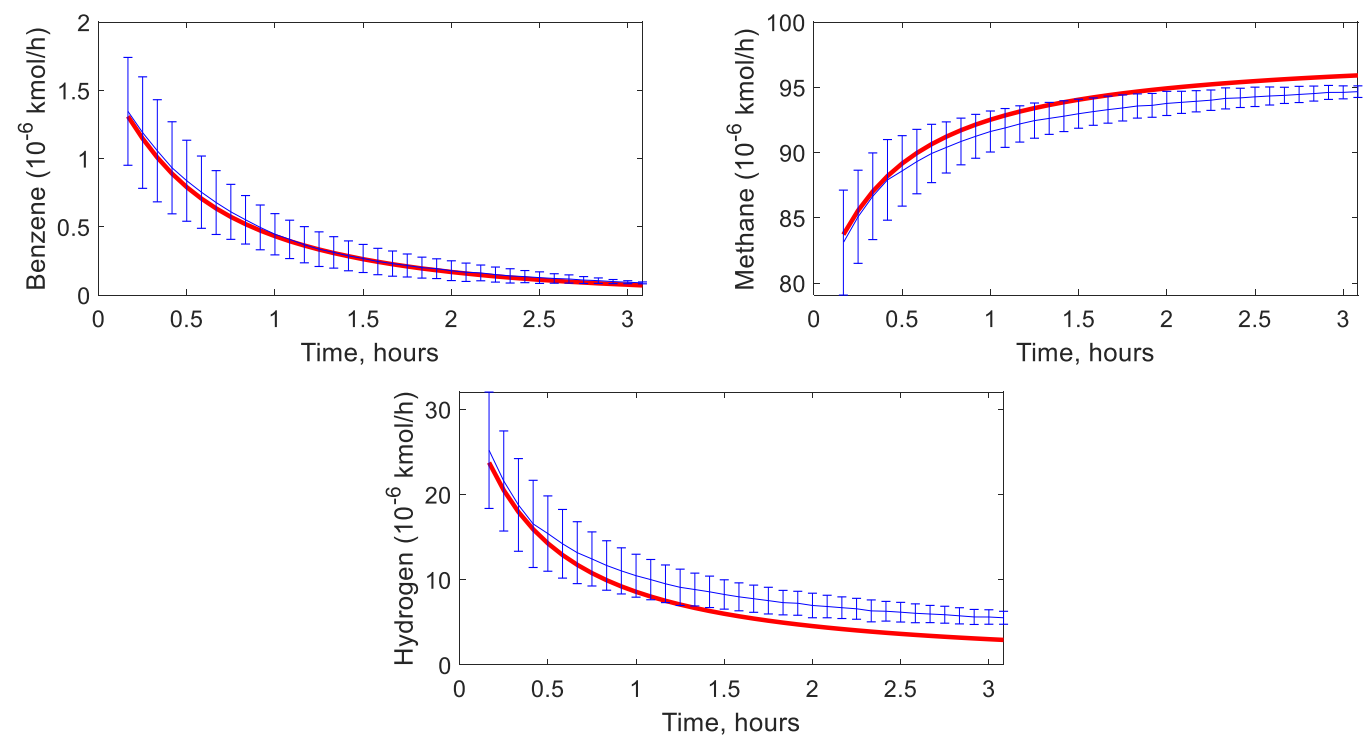

Figure H. Comparison of parameter estimation model with experimental data for $800{ }^{\circ} \mathrm{C}$

\section{Appendix I: Gantt Chart for 2-parallel Reactor Cyclic Operation}

Sample Gantt chart for 2 parallel reactor cyclic operation is shown in Figure I. The blue color indicates reactor undergoing methane DHA reaction, black color indicates catalyst regeneration, and green color indicates cooling/preparation time. It should be noted that this is not an optimized Gantt chart. Figure I show the Gantt chart for 2 parallel reactor cyclic operation. Here, the total number of reactors required is 4 for continuous operation, and at any given time 2 reactors are undergoing methane DHA reaction.

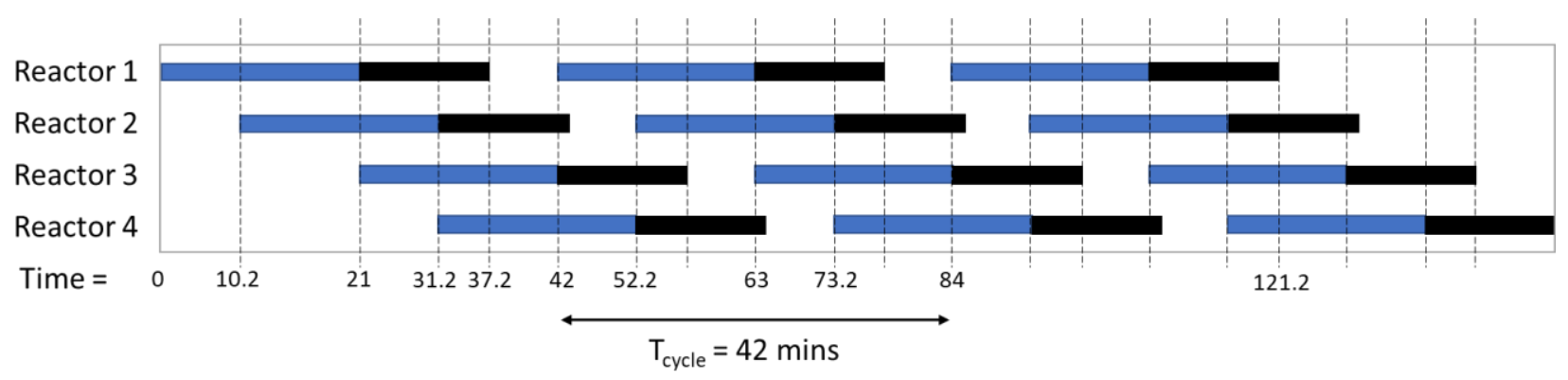

Figure I. Gantt chat for 2 parallel reactor cyclic operation 


\section{Appendix J: Derivation of Radiation Boundary Condition}

Derivation of the radiation boundary condition is shown in this section. The electric field outside the reactor travelling in opposite direct can be represented by waves travelling in opposite direction, as follows [202,204].

$E_{z}(r)=C_{1} H_{o}^{(1)}\left(\alpha_{o} r\right)+E_{o} H_{o}^{(2)}\left(\alpha_{o} r\right)$

Here, Hankel function $H_{o}^{(2)}$ and $H_{o}^{(1)}$ represents the incident and reflect field, respectively; $C_{1}$ is the constant to be evaluated. Evaluating Eq. J.1 at $r=R$ to calculate $C_{1}$, and taking the derivative gives the following radiation boundary condition,

at $r=R, \quad \frac{d E_{z}}{d r}+\alpha_{o} E \frac{H_{1}^{(1)}\left(\alpha_{o} R\right)}{H_{o}^{(1)}\left(\alpha_{o} R\right)}=\frac{-i 4 E_{o}}{\pi R H_{o}^{(1)}\left(\alpha_{o} R\right)}$

Making the following substitution in Eq. J.2 for $r$ and $E_{z}$,

$r^{*}=\frac{r}{R}$ and $u=\frac{E_{z}}{E_{0}}$

And representing the Hankel functions in terms of Bessel functions of first $\left(J_{m}(x)\right)$ and second kind $\left(Y_{m}(x)\right)$ as follows [204],

$H_{m}^{(1)}(x)=J_{m}(x)+i Y_{m}(x)$

Representing the electric field in terms of real and imaginary components i.e. $u=E_{R}+i E_{I}$. The following equation for electric field is obtained,

$\frac{E_{o}}{R} \frac{d\left(E_{R}+i E_{I}\right)}{d r^{*}}+\alpha_{o} \cdot E_{o} \cdot\left(E_{R}+i E_{I}\right) \cdot \frac{J_{1}\left(\alpha_{o} R\right)+i Y_{1}\left(\alpha_{o} R\right)}{J_{o}\left(\alpha_{o} R\right)+i Y_{o}\left(\alpha_{o} R\right)}=\frac{-i 4 E_{o}}{\pi R\left[J_{o}\left(\alpha_{o} R\right)+i Y_{o}\left(\alpha_{o} R\right)\right]}$

Eq. J.5 can also be represented as follows,

$\frac{d\left(E_{R}+i E_{I}\right)}{d r^{*}}+\alpha_{o} \cdot R \cdot\left(E_{R}+i E_{I}\right) \cdot \frac{J_{1}\left(\alpha_{o} R\right)+i Y_{1}\left(\alpha_{o} R\right)}{J_{o}\left(\alpha_{o} R\right)+i Y_{o}\left(\alpha_{o} R\right)}=\frac{-i 4}{\pi\left[J_{o}\left(\alpha_{o} R\right)+i Y_{o}\left(\alpha_{o} R\right)\right]}$

Taking the complex conjugate of the denominator of term 2 and right hand side of the equation, gives 


$$
\begin{array}{r}
\frac{d\left(E_{R}+i E_{I}\right)}{d r^{*}}+\alpha_{o} \cdot R \cdot\left(E_{R}+i E_{I}\right) \cdot \frac{\left[J_{1}\left(\alpha_{o} R\right)+i Y_{1}\left(\alpha_{o} R\right)\right]\left[J_{o}\left(\alpha_{o} R\right)-i Y_{o}\left(\alpha_{o} R\right)\right]}{J_{o}^{2}\left(\alpha_{o} R\right)+Y_{o}^{2}\left(\alpha_{o} R\right)} \\
=\frac{-i 4}{\pi} \frac{\left[J_{o}\left(\alpha_{o} R\right)-i Y_{o}\left(\alpha_{o} R\right)\right]}{J_{o}^{2}\left(\alpha_{o} R\right)+Y_{o}^{2}\left(\alpha_{o} R\right)}
\end{array}
$$

Multiplying the terms in the brackets and separating out the real terms from the imaginary terms gives equations for real and imaginary electric field components. Eq.J.8, will result in the boundary condition described by Eq. 5.25-5.30.

$J_{p}(x) Y_{p}^{\prime}(x)-Y_{p}(x) J_{p}^{\prime}(x)=\frac{2}{\pi x}$

\section{Appendix K: Estimated Constants for Reduced Order Microwave Power Absorption Model and Data Fitting Plots}

The constants estimated in section 5.4, Eq. 5.34-5.35, for $2.45 \mathrm{GHz}$ and $915 \mathrm{MHz}$ frequency is shown in Table K.

Table K. Estimated constants for reduced order model Eq. 5.34-5.35

\begin{tabular}{ccc}
\hline Constants & $\mathbf{f = 2 . 4 5 ~ G H z}$ & $\mathbf{f = 9 1 5 ~ M H Z}$ \\
\hline$a_{1}$ & $3.841 \cdot 10^{-6}$ & $6.933 \cdot 10^{-6}$ \\
$a_{2}$ & $-3.401 \cdot 10^{-9}$ & $-4.940 \cdot 10^{-9}$ \\
$b_{1}$ & $5.209 \cdot 10^{-7}$ & $1.084 \cdot 10^{-6}$ \\
$b_{2}$ & $-4.792 \cdot 10^{-10}$ & $-8.080 \cdot 10^{-10}$ \\
$b_{3}$ & 4.488 & 1.976 \\
$b_{4}$ & 0.852 & 0.897 \\
\hline
\end{tabular}

The MW power absorbed curve $\left(Q_{\text {Maxwell }}\right)$ generated using Eq. 5.22-5.32 and the data fitting $\left(Q_{R O M}\right)$ performed using Eq. $5.33-5.35$ for $650^{\circ}-750^{\circ} \mathrm{C}$ is shown in Figure $\mathrm{K}$. 

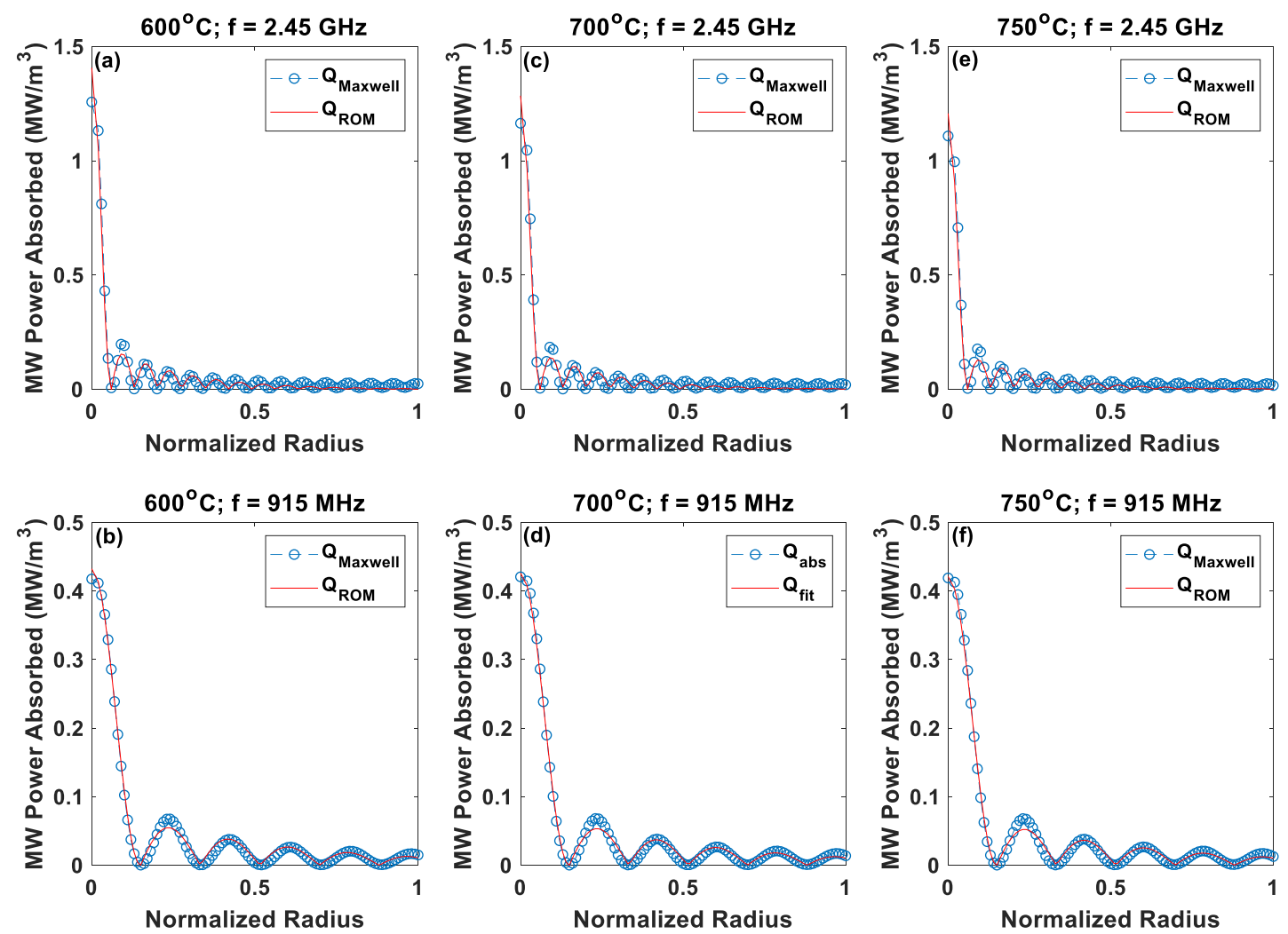

Figure K. MW power absorbed modeled using Maxwell's equation and reduced order model. $600^{\circ} \mathrm{C}$ - (a) $2.45 \mathrm{GHz}$ (b) $915 \mathrm{MHz} ; 7^{\circ} 0^{\circ} \mathrm{C}$ - (c) $2.45 \mathrm{GHz}$ (d) $915 \mathrm{MHz} ; 750^{\circ} \mathrm{C}-$ (e) 


\section{Appendix L: Reactor Performance for 915 MHz Frequency}

Area average values of reactor performance parameter for $915 \mathrm{MHz}$ frequency subjected to different input power is shown in Figure L. the reactor feed is $340 \mathrm{kmol} / \mathrm{h}\left(\mathrm{CH}_{4}-\right.$ 90 mol\%, balance $N_{2}$ ) at 2.1 bar and $800^{\circ} \mathrm{C}$.
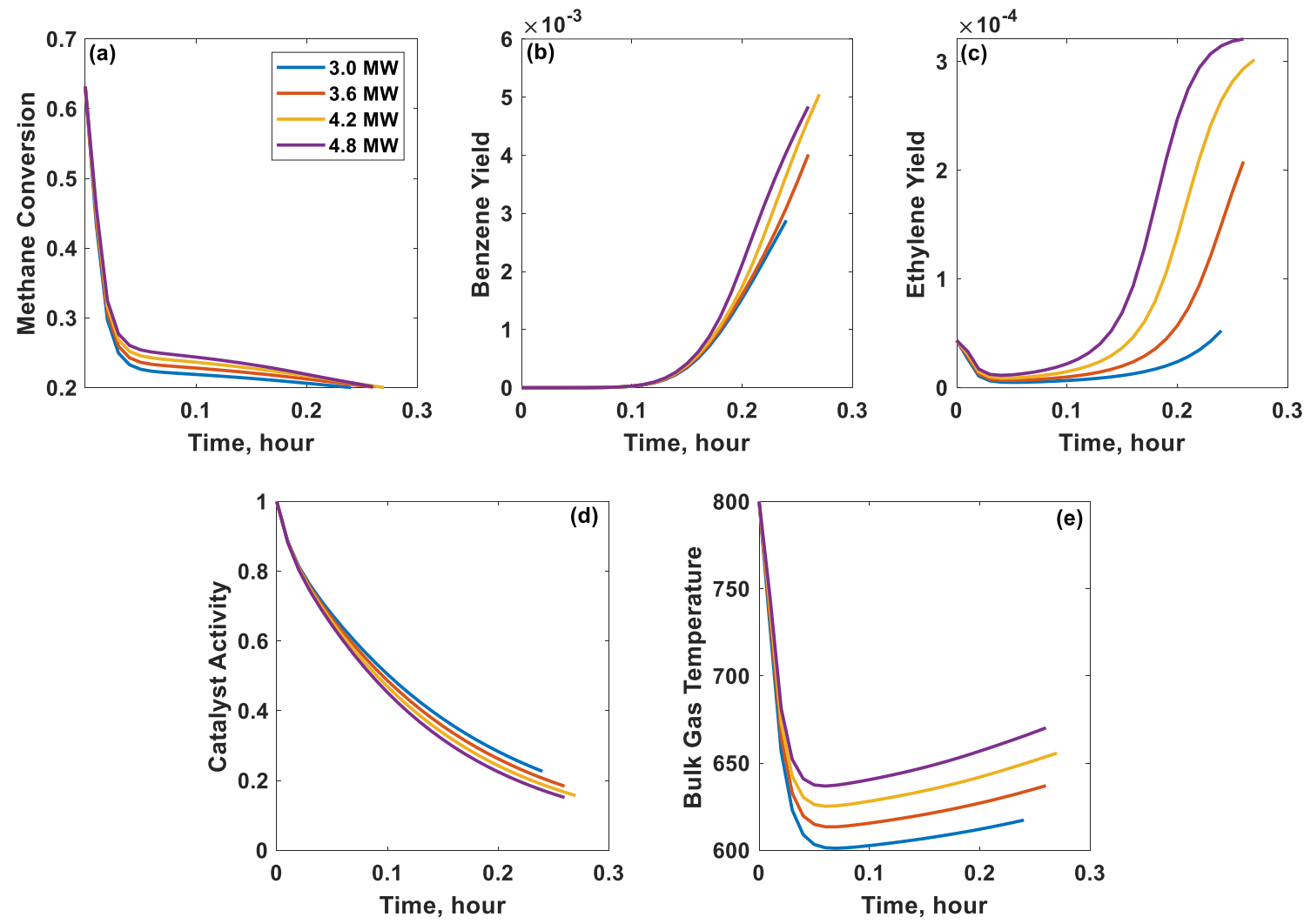

Figure L. Impact of MW input power on reactor performance parameters for $915 \mathrm{MHz}$ frequency. (a) methane conversion; (b) benzene yield; (c) ethylene yield; (d) catalyst activity; (e) bulk gas temperature 


\section{Appendix M: Time-Varying Profiles for Methane DHA Conventional Heating Reactor at $700^{\circ} \mathrm{C}, 7^{\circ} \mathrm{C}$, and $800^{\circ} \mathrm{C}$ and 1.2 bar pressure}

Profiles for methane DHA conventional heating reactor operating at $700^{\circ} \mathrm{C}, 750^{\circ} \mathrm{C}$, and $800^{\circ} \mathrm{C}$ and 1.2 bar pressure, is shown in Figure M. The total methane feed to be processed is about 1350 $\mathrm{kmol} / \mathrm{h}$. It is divided equally into 3 reactors operating parallelly in a cyclic operation. Profile for one of the reactors is shown below.
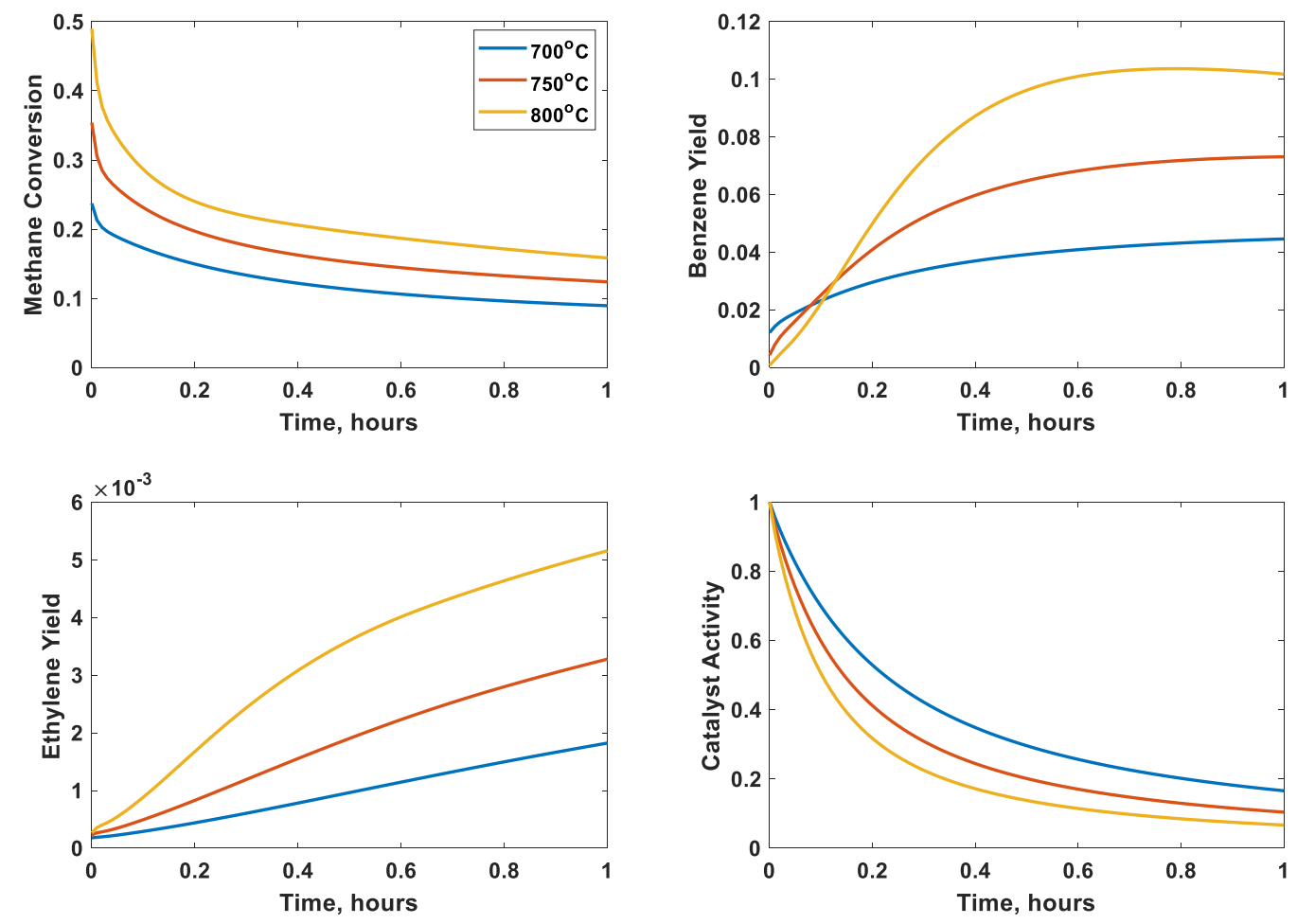

Figure M: Conversion, yield, and catalyst activity profile for methane DHA conventional heating reactor at $700^{\circ} \mathrm{C}, 750^{\circ} \mathrm{C}$, and $800^{\circ} \mathrm{C}$ 


\section{Appendix N: Shale Gas to Aromatics Via Methanol Synthesis Process- Products Throughput}

The production of key products for multi-step shale gas to aromatics via methanol synthesis process is shown in Table $\mathrm{N}$.

Table N. Production of key products for multi-step aromatics production Via methanol synthesis $\left(\mathrm{CH}_{4}\right.$ feed $\left.-98047 \mathrm{~kg} / \mathrm{h}\right)$

\begin{tabular}{cc}
\hline Components & Product Distribution (kg/h) \\
\hline$H_{2}$ & 1620 \\
$C_{2} H_{6} / C_{2} H_{4}$ & 6238 \\
$C_{3} H_{8} / C_{3} H_{6}$ & 4925 \\
$L P G$ & 5301 \\
$C_{6} H_{6}$ & 1442 \\
$C_{7} H_{8}$ & 6124 \\
$C_{8} H_{10}$ & 16884 \\
$C_{9} H_{12}$ & 16740 \\
\hline
\end{tabular}




\section{Appendix O: Publications and Presentations}

\section{$\underline{\text { Publications }}$}

1. Mevawala $\mathrm{C}$, Bhattacharyya $\mathrm{D}, \mathrm{Hu}$ J. Techno-economic analysis of direct non-oxidative conversion of methane to aromatics via thermo-catalytic and microwave $M W$ catalysis. Under Preparation.

2. Mevawala C, Bai X, Bhattacharyya D, Hu J. Dynamic Data Reconciliation, Parameter Estimation, and Multi-Scale, Multi-Physics Modeling of the Microwave-Assisted Methane Dehydroaromatization Process. Chemical Engineering Science, Submitted.

3. Mevawala C, Kotamreddy G, Bai X, Bhattacharyya D, Hu J. Dynamic data reconciliation, parameter estimation, and multi-scale reactor modeling of the direct non-oxidative methane dehydroaromatization process. Applied Energy. Submitted.

4. Mevawala C, Jiang Y, Bhattacharyya D. Techno-economic optimization of shale gas to dimethyl ether production processes via direct and indirect synthesis routes. Appl Energy 2019; 238:119-34.

5. Mevawala C, Jiang Y, Bhattacharyya D. Plant-wide modeling, and analysis of the shale gas to dimethyl ether (DME) process via direct and indirect synthesis routes. Appl Energy 2017; 204:163-80.

\section{$\underline{\text { Book Chapters }}$}

1. Mevawala C, Bhattacharyya D, Techno-Economic analysis of microwave-assisted conversion processes: Application to a direct natural gas-to-aromatics process. In: Hu J, Shekhawat D, (Eds.) Direct natural gas conversion to value added chemicals. CRC Press 2021.

\section{$\underline{\text { Presentations }}$}

1. Mevawala C, Bai X, Hu J, Abdelsayed v, Shekhawat D, Bhattacharyya D. Dynamic data reconciliation, parameter estimation, and plant-wide modeling of a microwave-assisted direct non-oxidative methane dehydroaromatization process. Paper 147d. AIChE Virtual Annual Meeting. November 16-20, 2020.

2. Mevawala C, Bai X, Hu J, Abdelsayed v, Shekhawat D, Bhattacharyya D. Direct non-oxidative conversion of shale gas to aromatics: Dynamic data reconciliation, parameter estimation, and dynamic modeling of a fixed bed reactor. Paper 734a. AIChE Virtual Annual Meeting. November 16-20, 2020. 
3. Mevawala $\mathrm{C}, \mathrm{Hu} \mathrm{J}$, Bhattacharyya $\mathrm{D}$. Techno-economic analysis of direct non-oxidative conversion of shale gas via non-thermal microwave plasma catalysis. Paper 570e, AIChE Annual Meeting. Pittsburgh, PA, USA, October 28-November 2, 2018.

4. Mevawala C, Jiang Y, Bhattacharyya D. Plant-wide modeling, techno-economic analysis and optimization of the shale gas to dimethyl ether process via direct and indirect synthesis route. Paper 578d. AIChE Annual Meeting. Minneapolis, MN, USA. October 29-November 3, 2017.

5. Mevawala C, Jiang Y, Bhattacharyya D. Techno-economic analysis of shale gas-to-dimethyl ether pross via direct synthesis. Paper 386c. AIChE Annual Meeting. San Francisco, CA, USA. November 13-18, 2016. 


\section{References}

[1] Sorrell S, Speirs J, Bentley R, Brandt A, Miller R. Global oil depletion: A review of the evidence. Energy Policy 2010;38:5290-5. https://doi.org/10.1016/j.enpol.2010.04.046.

[2] IEA. World energy outlook special report 2015: Energy and climate change. retrieved from: http://www.worldenergyoutlook.org/. 2015.

[3] Sources of greenhouse gas emissions. United States Environ Prot Agency 2018. https://www.epa.gov/ghgemissions/sources-greenhouse-gas-emissions (accessed February 20, 2020).

[4] Azizi Z, Rezaeimanesh M, Tohidian T, Rahimpour MR. Dimethyl ether: A review of technologies and production challenges. Chem Eng Process Process Intensif 2014;82:15072.

[5] Berg T. Volvo thinks the fuel of the future is DME - and it's almost here 2013. www.truckinginfo.com (accessed June 20, 2016).

[6] Mevawala C, Jiang Y, Bhattacharyya D. Plant-wide modeling and analysis of the shale gas to dimethyl ether (DME) process via direct and indirect synthesis routes. Appl Energy 2017;204:163-80.

[7] Dimethyl ether market worth 9.7 billion USD by 2020. Mark Mark 2016. http://www.marketsandmarkets.com/PressReleases/dimethyl-ether.asp (accessed April 15, 2016).

[8] Peng XD. Kinetic understanding of the syngas-to-DME reaction system and its implications to process and economics, Topical report, DE-FC22-94 PC93052. 2002.

[9] Cao Y, Gao Z, Jin J, Zhou H, Cohron M, Zhao H, et al. Synthesis gas production with an adjustable $\mathrm{H} 2 / \mathrm{CO}$ ratio through the coal gasification process: effects of coal ranks And methane addition. Energy \& Fuels 2008;22:1720-30.

[10] Peng XD, Wang AW, Toseland BA, Tijm PJA. Single-Step syngas-to-dimethyl ether processes for optimal productivity, minimal emissions, and natural gas-derived syngas. Ind Eng Chem Res 1999;38:4381-8.

[11] Zhu Y, Wang S, Ge X, Liu Q, Luo Z, Cen K. Experimental study of improved two step synthesis for DME production. Fuel Process Technol 2010;91:424-9.

[12] Park H-W, Ha J-K, Lee ES. Kinetic mechanism of dimethyl ether production process using syngas from integrated gasification combined cycle power plant. Korean J Chem Eng 2014;31:2130-5.

[13] Sweeney WA, Bryan PF. BTX Processing. Kirk-Othmer Encycl. Chem. Technol., 2007. https://doi.org/10.1002/0471238961.02202419230505.a01.pub2.

[14] Niziolek AM, Onel O, Floudas CA. Production of Benzene, Toluene, and Xylenes from Natural Gas via Methanol: Process Synthesis and Global Optimization. AIChE 2016;62:1531-56. 
[15] Treese SA, Pujadó PR, Jones DSJ. Handbook of petroleum processing. 2015. https://doi.org/10.1007/978-3-319-14529-7.

[16] Rostrup-Nielsen JR. Activity of nickel catalysts for steam reforming of hydrocarbons. J Catal 1973;31:173-99.

[17] Rostrup-Nielsen JR, Rostrup-Nielsen T. Large-Scale Hydrogen Production 2002.

[18] Nourbakhsh H, Rahbar Shahrouzi J, Zamaniyan A, Ebrahimi H, Jafari Nasr MR. A thermodynamic analysis of biogas partial oxidation to synthesis gas with emphasis on soot formation. Int J Hydrogen Energy 2018. https://doi.org/10.1016/j.ijhydene.2018.06.134.

[19] Aasberg-Petersen K, Dybkjaer I, Ovesen C V., Schjodt NC, Sehested J, Thomsen SG. Natural gas to synthesis gas - catalysts and catalytic processes. J Nat Gas Sci Eng 2011;3:423-59.

[20] Tian P, Wei Y, Ye M, Liu Z. Methanol to olefins (MTO): From fundamentals to commercialization. ACS Catal 2015. https://doi.org/10.1021/acscatal.5b00007.

[21] Olsbye U, Svelle S, Bjrgen M, Beato P, Janssens TVW, Joensen F, et al. Conversion of methanol to hydrocarbons: How zeolite cavity and pore size controls product selectivity. Angew Chemie - Int Ed 2012. https://doi.org/10.1002/anie.201103657.

[22] Schwach P, Pan X, Bao X. Direct Conversion of Methane to Value-Added Chemicals over Heterogeneous Catalysts: Challenges and Prospects. Chem Rev 2017;117:8497-520.

[23] Holmen A. Direct conversion of methane to fuels and chemicals. Catal Today 2009;142:2-8.

[24] Alvarez-Galvan MC, Mota N, Ojeda M, Rojas S, Navarro RM, Fierro JLG, et al. Direct methane conversion routes to chemicals and fuels. Catal Today2 2011;171:15-23.

[25] Zanthoff H, Baerns M. Oxidative Coupling of Methane in the Gas Phase. Kinetic Simulation and Experimental Verification. Ind Eng Chem Res 1990. https://doi.org/10.1021/ie00097a001.

[26] Chen Q, Couwenberg PM, Marin GB. Effect of pressure on the oxidative coupling of methane in the absence of catalyst. AIChE J 1994. https://doi.org/10.1002/aic.690400313.

[27] Ismagilov ZR, Matus E V., Tsikoza LT. Direct conversion of methane on Mo/ZSM-5 catalysts to produce benzene and hydrogen: Achievements and perspectives. Energy Environ Sci 2008. https://doi.org/10.1039/b810981h.

[28] Zeng JL, Xiong ZT, Zhang H Bin, Lin GD, Tsai KR. Nonoxidative dehydrogenation and aromatization of methane over W/HZSM-5-based catalysts. Catal Letters 1998. https://doi.org/10.1023/A:1019033201075.

[29] Julian I, Ramirez H, Hueso JL, Mallada R, Santamaria J. Non-oxidative methane conversion in microwave-assisted structured reactors. Chem Eng J 2019. https://doi.org/10.1016/j.cej.2018.08.150.

[30] Roussy G, Marchand C, Thiebaut J-M, Souiri M, Kiennemann A, Petit C, et al. Catalytic process for controlled oxidation of methane using microwaves for the synthesis of ethane 
and ethylene and catalysts used in this process. US5411649A, 1995.

[31] Ohno Y, Yagi H, Inoue N, Okuyama K, Aoki S. Slurry phase DME direct synthesis technology -100 tons/day demonstration plant operation and scale up study-. Stud Surf Sci Catal 2007; 167:403-8.

[32] Han Y, Zhang H, Ying W, Fang D. Modeling and simulation of production process on dimethyl ether synthesized from coal-based syngas by one-step method. Chinese J Chem Eng 2009;17:108-12.

[33] Shim HM, Lee SJ, Yoo YD, Yun YS, Kim HT. Simulation of DME synthesis from coal syngas by kinetics model. Korean J Chem Eng 2009;26:641-8.

[34] Chen HJ, Fan CW, Yu CS. Analysis, synthesis, and design of a one-step dimethyl ether production via a thermodynamic approach. Appl Energy 2013;101:449-56.

[35] Papari S, Kazemeini M, Fattahi M, Fatahi M. DME direct synthesis from syngas in a large-scale three-phase slurry bubble column reactor: transient modeling. Chem Eng Commun 2014;201:612-34.

[36] Papari S, Kazemeini M, Fattahi M. Modelling-based optimisation of the direct synthesis of dimethyl ether from syngas in a commercial slurry reactor. Chinese J Chem Eng 2013;21:611-21.

[37] Moradi F, Kazemeini M, Fattahi M. A three dimensional CFD simulation and optimization of direct DME synthesis in a fixed bed reactor. Pet Sci 2014;11:323-30.

[38] EG\&G Technical Services I. Fuel cell handbook. Fuel Cell, vol. 7 Edition, 2004, p. 8-23.

[39] Munch B, Elholm P, Stenseng M. From science to proven technology development of new topsoe pre-reforming catalyst AR-401. Nitrogen + Syngas Conf., 2007.

[40] Jiang Y, Bhattacharyya D. Process modeling of direct coal-biomass to liquids (CBTL) plants with shale gas utilization and $\mathrm{CO} 2$ capture and storage (CCS). Appl Energy 2017;183:433-48.

[41] Using an adiabatic pre-reformer. Ind Effic Technol Database 2016. http://ietd.iipnetwork.org/content/using-adiabatic-pre-reformer (accessed April 20, 2016).

[42] Huang X, Reimert R. Kinetics of steam reforming of ethane on Ni/YSZ (yttria-stabilised zirconia) catalyst. Fuel 2013;106:380-7.

[43] Sperle T, Chen D, Lodeng R, Holmen A. Pre-reforming of natural gas on a Ni catalyst. Criteria for carbon free operation. Appl Catal A Gen 2005;282:195-204.

[44] Jiang Y, Bhattacharyya D. Modeling and analysis of an indirect coal biomass to liquids plant integrated with a combined cycle plant and $\mathrm{CO} 2$ capture and storage. Energy \& Fuels 2015;29:5434-51.

[45] Adams II TA, Barton PI. High-efficiency power production from natural gas with carbon capture. J Power Sources 2010;195:1971-83.

[46] Adams II TA, Barton PI. Combining coal gasification and natural gas reforming for 
efficient polygeneration. Fuel Process Technol 2011;92:639-55.

[47] Akbari MH, Ardakani AHS, Tadbir MA. A microreactor modeling, analysis and optimization for methane autothermal reforming in fuel cell applications. Chem Eng $\mathbf{J}$ 2011;166:1116-25.

[48] Hoang DL, Chan SH. Modeling of a catalytic autothermal methane reformer for fuel cell applications. Appl Catal A Gen 2004;268:207-16.

[49] Scognamiglio D, Russo L, Maffettone PL, Salemme L, Simeone M, Crescitelli S. Modeling temperature profiles of a catalytic autothermal methane reformer with nickel catalyst. Ind Eng Chem Res 2009;48:1804-15.

[50] Simeone M, Salemme L, Allouis C. Reactor temperature profile during autothermal methane reforming on Rh/Al2O3 catalyst by IR imaging. Int J Hydrogen Energy 2008;33:4798-808.

[51] Kohl AL, Nielsen RB. Gas purification. Gas Purif., vol. 10, 1997, p. 731-865.

[52] Ogawa T, Inoue N, Shikada T, Inokoshi O, Ohno Y. Direct Dimethyl Ether (DME) synthesis from natural gas. Stud Surf Sci Catal 2004;147:379-84.

[53] Bhatt BL, Toseland BA, Peng XD, Heydorn EC. Catalyst and process development for liquid Phase DME synthesis. 17th Annu. Int. Pittsburgh Coal Conf., Pittsburgh, PA: 2000.

[54] Kabir KB, Hein K, Bhattacharya S. Process modelling of dimethyl ether production from Victorian brown coal-Integrating coal drying, gasification and synthesis processes. Comput Chem Eng 2013;48:96-104.

[55] Ding H. Shale gas treatment challenges and requirements. 13th U.S.- China oil Gas Ind. Forum, Xi'an, China: 2013.

[56] Xu J, Froment GF. Methane steam reforming, methanation and water-gas shift: I. Intrinsic kinetics. AIChE J 1989. https://doi.org/10.1002/aic.690350109.

[57] Numaguchi T, Kikuchi K. Intrinsic kinetics and design simulation in a complex reaction network; steam-methane reforming. Chem Eng Sci 1988. https://doi.org/10.1016/00092509(88)87118-5.

[58] De Smet CRH, De Croon MHJM, Berger RJ, Marin GB, Schouten JC. Design of adiabatic fixed-bed reactors for the partial oxidation of methane to synthesis gas. Application to production of methanol and hydrogen-for-fuel-cells. Chem Eng Sci 2001. https://doi.org/10.1016/S0009-2509(01)00130-0.

[59] Zyryanova MM, Snytnikov P V., Shigarov AB, Belyaev VD, Kirillov VA, Sobyanin VA. Low temperature catalytic steam reforming of propane-methane mixture into methane-rich gas: Experiment and macrokinetic modeling. Fuel 2014;135:76-82.

[60] Rafiq MH, Jakobsen HA, Hustad JE. Modeling and simulation of catalytic partial oxidation of methane to synthesis gas by using a plasma-assisted gliding arc reactor. Fuel Process Technol 2012;101:44-57. https://doi.org/10.1016/j.fuproc.2011.12.044.

[61] Christensen TS. Adiabatic prereforming of hydrocarbons - an important step in syngas 
production. Appl Catal A Gen 1996;138:285-309.

[62] Lee S. Methane and its derivatives. Can. J. Chem. Eng., 1997, p. 32-3.

[63] Bartholomew CH, Farrauto RJ. Fundamentals of industrial catalytic processes: second edition. Fundam. Ind. Catal. Process. Second Ed., 2010, p. 339-486.

[64] Halabi MH, de Croon MHJM, van der Schaaf J, Cobden PD, Schouten JC. Modeling and analysis of autothermal reforming of methane to hydrogen in a fixed bed reformer. Chem Eng J 2008;137:568-78.

[65] Jiang Y, Bhattacharyya D. Plant-wide modeling of an indirect coal-biomass to liquids (CBTL) plant with CO2 capture and storage (CCS). Int J Greenh Gas Control 2014;31:115.

[66] Rate based model of the CO2 capture process by methanol using Aspen Plus 2008:1-43. www.aspentech.com (accessed March 5, 2016).

[67] Yang S, Qian Y, Yang S. Development of a full CO2 capture process based on the rectisol wash technology. Ind Eng Chem Res 2016;55:6186-93.

[68] Gatti M, Martelli E, Marechal F, Consonni S. Review, modeling, heat integration, and improved schemes of Rectisol@-based processes for CO2 capture. Appl Therm Eng 2014.

[69] Berrouk AS, Ochieng R. Improved performance of the natural-gas-sweetening BenfieldHiPure process using process simulation. Fuel Process Technol 2014;127:20-5.

[70] Tobiesen FA, Svendsen HF, Mejdell T. Modeling of blast furnace CO2 capture using amine absorbents. Ind Eng Chem Res 2007;46:7811-9.

[71] Moradi G, Ahmadpour J, Nazari M, Yaripour F. Effects of feed composition and space velocity on direct synthesis of dimethyl ether from syngas. Ind Eng Chem Res 2008;47:7672-9.

[72] Jones D, Bhattacharyya D, Turton R, Zitney SE. Rigorous kinetic modeling and optimization study of a modified claus unit for an integrated gasification combined cycle (IGCC) power plant with CO2 capture. Ind Eng Chem Res 2012;51:2362-75.

[73] Kumar M, Srivastava VC. Simulation of a fluidized-bed reactor for dimethyl ether synthesis. Chem Eng Technol 2010;33:1967-78.

[74] Nie Z, Liu H, Liu D, Ying W. Intrinsic kinetics of dimethyl ether synthesis from syngas. J Nat Gas Chem 2005;14:22-8.

[75] Zhang H, Cao Y, Liu D, Fang D. Thermodynamic analysis for synthesis of dimethyl ether and methanol from synthesis gas. J East China Univ Sci Technol 2001;27:198-203.

[76] Jonasson A, Persson A, Fredenslund A. High pressure solubility of carbon dioxide and carbon monoxide in dimethyl ether. Chem Eng Data 1995;40:296-300.

[77] Tsang CY, Streett WB. Vapor-liquid equilibrium in the system carbon dioxide/dimethyl ether. J Chem Eng Data 1981;26:155-9.

[78] Katayama T, Ohgaki K, Maekawa G, Goto M, Nagano T. Isothermal vapor-liquid 
equilibria of acetone-carbon dioxide and methanol-carbon dioxide systems at high pressures. J Chem Eng Japan 1975;8:89-92.

[79] Semenova AI, Emelyanova EA, Tsimmerman SS, Tsiklis DS. Phase equilibria in the methanol + carbon dioxide system. Russ J Phys Chem 1979;53:2502-5.

[80] Hong JH, Kobayashi R. Vapor-liquid equilibrium studies for the carbon dioxide-methanol system. Fluid Phase Equilib 1988;41:269-76.

[81] Leu A-D, Chung SY-K, Robinson DB. The equilibrium phase properties of (carbon dioxide + methanol). J Chem Thermodyn 1991;23:979-85.

[82] Pozo ME, Streett WB. Fluid phase equilibria in the system dimethyl ether/water from 50 to $220 \mathrm{C}$ and pressures to 500 bar. Fluid Phase Equilib 1983;14:219-24.

[83] Song H, Zhang H, Ying W, Fang D. Study on vapor-liquid equilibrium for dimethyl ether/ water binary system. Nat Gas Chem Ind 2005;30:67-71.

[84] Van-Dal ÉS, Bouallou C. Design and simulation of a methanol production plant from CO2 hydrogenation. J Clean Prod 2013;57:38-45.

[85] Mignard D, Pritchard C. On the use of electrolytic hydrogen from variable renewable energies for the enhanced conversion of biomass to fuels. Chem Eng Res Des 2008;86:473-87.

[86] Vanden Bussche KM, Froment GF. A steady-state kinetic model for methanol synthesis and the water gas shift reaction on a Commercial $\mathrm{Cu} / \mathrm{ZnO} / \mathrm{Al} 2 \mathrm{O} 3$ catalyst. J Catal 1996;10:1-10.

[87] Tavan Y, Hosseini SH, Ghavipour M, Nikou MRK, Shariati A. From laboratory experiments to simulation studies of methanol dehydration to produce dimethyl ether Part I: Reaction kinetic study. Chem Eng Process Process Intensif 2013;73:144-50.

[88] Bercic G, Levec J. Intrinsic and global reaction rate of methanol dehydration over .gamma.-alumina pellets. Ind Eng Chem Res 1992;31:1035-40.

[89] Mollavali M, Yaripour F, Atashi H, Sahebdelfar S. Intrinsic kinetics study of dimethyl ether synthesis from methanol on $\gamma$-A12O3 catalysts. Ind Eng Chem Res 2008;47:326573.

[90] Diep BT, Wainwright MS. Thermodynamic equilibrium constants for the methanoldimethyl ether-water system. J Chem Eng Data 1987;32:330-3.

[91] Bercic G, Levec J. Catalytic dehydration of methanol to dimethyl ether. Kinetic investigation and reactor simulation. Ind Eng Chem Res 1993;32:2478-84.

[92] Bhattacharyya D, Turton R, Zitney SE. Steady-State Simulation and Optimization of an Integrated Gasification Combined Cycle Power Plant with CO 2 Capture. Ind Eng Chem Res 2011;50:1674-90. https://doi.org/10.1021/ie101502d.

[93] Baseline Design/Economics for Advanced Fischer- Tropsch Technology, DE-AC2291PC90027. San Fransciso: 1998. 
[94] Martelli E, Kreutz TG, Gatti M, Chiesa P, Consonni S. Design criteria and optimization of Heat Recovery Steam Cycles for high-efficiency, coal-fired, Fischer-Tropsch plants. Proc ASME Turbo Expo 2012;3:363-73. https://doi.org/10.1115/GT2012-69661.

[95] Steynberg AP, Nel HG. Clean coal conversion options using Fischer-Tropsch technology. Fuel, vol. 83, 2004, p. 765-70. https://doi.org/10.1016/j.fuel.2003.09.023.

[96] Turton R, Shaeiwitz JA, Bhattacharyya D, Whiting WB. Analysis, synthesis, and design of chemical processes. 5th ed. Prentice Hall; 2018.

[97] Historic rates for north customers. Direct Energy Regul Serv 2014. http://www.directenergyregulatedservices.com/GAS/Historic-Natural-Gas-Rates.aspx (accessed February 5, 2017).

[98] Yoon ES, Han C. A review of sustainable energy- Recent development and future prospects of dimethyl ether (DME). Comput Aided Chem Eng 2009;27:169-75.

[99] Fornell R, Berntsson T, Åsblad A. Techno-economic analysis of a kraft pulp-mill-based biorefinery producing both ethanol and dimethyl ether. Energy 2013;50:83-92. https://doi.org/10.1016/j.energy.2012.11.041.

[100] Trippe F, Fröhling M, Schultmann F, Stahl R, Henrich E, Dalai A. Comprehensive techno-economic assessment of dimethyl ether (DME) synthesis and Fischer-Tropsch synthesis as alternative process steps within biomass-to-liquid production. Fuel Process Technol 2013;106:577-86. https://doi.org/10.1016/j.fuproc.2012.09.029.

[101] Clausen LR, Elmegaard B, Houbak N. Technoeconomic analysis of a low CO2 emission dimethyl ether (DME) plant based on gasification of torrefied biomass. Energy 2010;35:4831-42. https://doi.org/10.1016/j.energy.2010.09.004.

[102] Clausen LR, Elmegaard B, Ahrenfeldt J, Henriksen U. Thermodynamic analysis of smallscale dimethyl ether (DME) and methanol plants based on the efficient two-stage gasifier. Energy 2011;36:5805-14. https://doi.org/10.1016/j.energy.2011.08.047.

[103] Zhou L, Hu S, Li Y, Zhou Q. Study on co-feed and co-production system based on coal and natural gas for producing DME and electricity. Chem Eng J 2008;136:31-40. https://doi.org/10.1016/j.cej.2007.03.025.

[104] Zhu Y, Tjokro Rahardjo S, Valkenburg C, Snowden-Swan L, Jones S, Machinal M. Techno-economic analysis for the thermochemical conversion of biomass to liquid fuels. US Dep Energy n.d.;COntract D:1-134. https://doi.org/PNNL-19009.

[105] Larson ED, Tingjin R. Synthetic fuel production by indirect coal liquefaction. Energy Sustain Dev 2003;7:79-102. https://doi.org/10.1016/S0973-0826(08)60381-6.

[106] Larson ED, Jin H, Celik FE. Gasification based fuels and electricity production from biomass, without and with carbon capture and storage. Princeton, NJ: 2005.

[107] Cocco D, Pettinau A, Cau G. Energy and economic assessment of IGCC power plants integrated with DME synthesis processes. Proc Inst Mech Eng Part A J Power Energy 2006;220:95-102. https://doi.org/10.1243/095765006X76027. 
[108] Tock L, Gassner M, Maréchal F. Thermochemical production of liquid fuels from biomass: Thermo-economic modeling, process design and process integration analysis. Biomass and Bioenergy 2010;34:1838-54. https://doi.org/10.1016/j.biombioe.2010.07.018.

[109] Omata K, Ozaki T, Umegaki T, Watanabe Y, Nukui N, Yamada M. Optimization of the temperature profile of a temperature gradient reactor for DME synthesis using a simple genetic algorithm assisted by a neural network. Energy and Fuels 2003;17:836-41. https://doi.org/10.1021/ef0202438.

[110] Hu Y, Nie Z, Fang D. Simulation and model design of pipe-shell reactor for the direct synthesis of dimethyl ether from syngas. J Nat Gas Chem 2008;17:195-200. https://doi.org/10.1016/S1003-9953(08)60051-1.

[111] Yasari, Shahrokhi, Abedini. Modeling, simulation and control of a tubular fixed-bed dimethyl ether reactor. Chem Biochem Eng Q 2010;24:415-23.

[112] Vakili R, Eslamloueyan R. Design and optimization of a fixed bed reactor for direct dimethyl ether production from syngas using differential evolution algorithm. Int $\mathrm{J}$ Chem React Eng 2013;11. https://doi.org/10.1515/ijcre-2012-0026.

[113] Khademi MH, Farsi M, Rahimpour MR, Jahanmiri A. DME synthesis and cyclohexane dehydrogenation reaction in an optimized thermally coupled reactor. Chem Eng Process Process Intensif 2011;50:113-23. https://doi.org/10.1016/j.cep.2010.12.004.

[114] Samimi F, Bayat M, Rahimpour MR, Keshavarz P. Mathematical modeling and optimization of DME synthesis in two spherical reactors connected in series. J Nat Gas Sci Eng 2014;17:33-41. https://doi.org/10.1016/j.jngse.2013.12.006.

[115] Farsi M, Jahanmiri A. Mathematical simulation and optimization of methanol dehydration and cyclohexane dehydrogenation in a thermally coupled dual-membrane reactor. Int $\mathbf{J}$ Hydrogen Energy 2011;36:14416-27. https://doi.org/10.1016/j.ijhydene.2011.08.019.

[116] Farsi M, Jahanmiri A, Eslamloueyan R. Modeling and Optimization of MeOH to DME in Isothermal Fixed-bed Reactor. Int J Chem React Eng 2010;8:1-14. https://doi.org/10.2202/1542-6580.2063.

[117] Asadi J, Jalali Farahani F. Optimization of dimethyl ether production process based on sustainability criteria using a homotopy continuation method. Comput Chem Eng 2018;115:161-78. https://doi.org/10.1016/j.compchemeng.2018.03.014.

[118] Shokrian M, High KA. An efficient multi criteria process optimization framework: Sustainable improvement of the Dimethyl Ether Process. Comput Chem Eng 2014;60:213-30. https://doi.org/10.1016/j.compchemeng.2013.09.011.

[119] Bîldea CS, Győrgy R, Brunchi CC, Kiss AA. Optimal design of intensified processes for DME synthesis. Comput Chem Eng 2017;105:142-51. https://doi.org/10.1016/j.compchemeng.2017.01.004.

[120] Kaewwisetkul P, Simasatitkul L, Arpornwichanop A. Design and optimization of dimethyl ether production from crude glycerol in a reactive distillation. Chem Eng Process Process Intensif 2017;117:80-8. https://doi.org/10.1016/j.cep.2017.03.019. 
[121] Jiang Y, Bhattacharyya D. Techno-economic analysis of a novel indirect coal-biomass to liquids plant integrated with a combined cycle plant and $\mathrm{CO} 2$ capture and storage. Ind Eng Chem Res 2016;55:1677-89.

[122] Pratapas J. Cost equations for industrial boilers, PEDCo Environmental, Inc., Contract no. 68-02-3074, Assignment 17 (PN 3400-Q). Research Triangle Park, North Carolina: 1980.

[123] Gollener JF, Shah V, Turner MJ, Kuehn NJ, Littlefield J, Conney G, et al. Analysis of natural gas-to liquid transportation fuels via fischer-tropsch, DOE report, DOE/NETL2013/1597. 2013.

[124] Spallina V, Pandolfo D, Battistella A, Romano MC, Van Sint Annaland M, Gallucci F. Techno-economic assessment of membrane assisted fluidized bed reactors for pure $\mathrm{H} 2$ production with CO2 capture. Energy Convers Manag 2016;120:257-73. https://doi.org/10.1016/j.enconman.2016.04.073.

[125] Baliban RC, Elia JA, Floudas CA. Novel Natural Gas to Liquids Processes: Process Synthesis and Global Optimization Strategies. AIChE J 2013;59:505-31. https://doi.org/10.1002/aic.13996.

[126] Jones SB, Zhu Y. Techno-economic analysis for the thermochemical conversion of lignocellulosic biomass to gasoline via methanol-to-gasoline (MTG) process. US Dep Energy 2009;PNNL-18483:1-46.

[127] Kreutz TG, Williams RH, Socolow RH, Chiesa P, Lozza G, Hall G. Production of hydrogen and electricity from coal with co 2 capture. System 2002:3-8.

[128] Kreutz TG, Larson ED, Liu G, Williams R. Fischer-Tropsch Fuels from Coal and Biomass. 25th Annu Int Pittsburgh Coal Conf 2008:1-81. https://doi.org/10.1016/j.egypro.2009.02.252.

[129] High temperature hydrogen attack (Decarburization) n.d. http://www.corrosionclinic.com/types_of_corrosion/high-temperature hydrogen attack_decarburization.htm (accessed January 22, 2016).

[130] Aspen icarus refernce guide. Aspen Technol Inc 2012. www.aspentech.com (accessed January 22, 2016).

[131] Henry hub natural gas spot price. US Energy Inf Adm 2017. https://www.eia.gov/dnav/ng/hist/rngwhhdd.htm (accessed October 31, 2016).

[132] Methanol pricing. Nat Gas Tech 2016. http://emsh-ngtech.com/methanol/methanolpricing/ (accessed October 31, 2016).

[133] Heavy duty gas turbines. GE Power Gener 2017. https://powergen.gepower.com/products/heavy-duty-gas-turbines.html (accessed September 6, 2016).

[134] STF-D650 steam turbine (reheat). GE Power Gener 2017. https://powergen.gepower.com/products/steam-turbines/stfd650-steam-turbine.html (accessed February 18, 2017). 
[135] Baseline design/economics for advanced fischer-tropsch technology. Quareterly report. Contract No. DE-AC22-91PC90027. Pittsburgh, PA: 1993.

[136] Seider WD, Seader JD, Lewin DR. Product \& Process Design Principles - Synthesis, Analysis \& Evaluation. 2003.

[137] Kelley L. Market outlook: Mega plants are the 1st phase of the methanol economy. ICIS Chem Bussiness 2014. https://www.icis.com/resources/news/2014/02/28/9758077/marketoutlook-mega-plants-are-the-1st-phase-of-the-methanol-economy/ (accessed August 20, 2018).

[138] Petroleum and other liquids. US Energy Inf Adm n.d. https://www.eia.gov/petroleum/gasdiesel/ (accessed April 20, 2018).

[139] Guo X, Fang G, Li G, Ma H, Fan H, Yu L, et al. Direct, nonoxidative conversion of methane to ethylene, aromatics, and hydrogen. Science (80- ) 2014;344:616-9. https://doi.org/10.1126/science.1253150.

[140] Su L, Liu L, Zhuang J, Wang H, Li Y, Shen W, et al. Creating mesopores in ZSM-5 zeolite by alkali treatment: A new way to enhance the catalytic performance of methane dehydroaromatization on Mo/HZSM-5 catalysts. Catal Letters 2003. https://doi.org/10.1023/B:CATL.0000007149.48132.5a.

[141] Wang L, Ohnishi R, Ichikawa M. Novel rhenium-based catalysts for dehydrocondensation of methane with CO/CO2 towards ethylene and benzene. Catal Letters 1999. https://doi.org/10.1023/A:1019022316715.

[142] Liu J-F, Jin L, Liu Y, QI Y-S. Methane Aromatization over Cobalt and Gallium Impregnated HZSM-5 Catalysts. Catal Letters 2008:352-8. https://doi.org/10.1007/s10562-008-9458-9.

[143] Tan PL, Au CT, Lai SY. Methane dehydrogenation and aromatization over $4 \mathrm{wt} \%$ Mn/HZSM-5 in the absence of an oxidant. Catal Letters 2006. https://doi.org/10.1007/s10562-006-0209-5.

[144] Borry RW, Kim YH, Huffsmith A, Reimer JA, Iglesia E. Structure and density of Mo and acid sites in Mo-exchanged H-ZSM5 catalysts for nonoxidative methane conversion. J Phys Chem B 1999. https://doi.org/10.1021/jp990866v.

[145] Kosinov N, Uslamin EA, Meng L, Parastaev A, Liu Y, Hensen EJM. Reversible Nature of Coke Formation on Mo/ZSM-5 Methane Dehydroaromatization Catalysts. Angew Chemie - Int Ed 2019. https://doi.org/10.1002/anie.201902730.

[146] Cui Y, Xu Y, Suzuki Y, Zhang ZG. Experimental evidence for three rate-controlling regions of the non-oxidative methane dehydroaromatization over Mo/HZSM-5 catalyst at 1073 K. Catal Sci Technol 2011. https://doi.org/10.1039/c1cy00083g.

[147] Razdan NK, Kumar A, Foley BL, Bhan A. Influence of ethylene and acetylene on the rate and reversibility of methane dehydroaromatization on Mo/H-ZSM-5 catalysts. J Catal 2020. https://doi.org/10.1016/j.jcat.2019.11.004.

[148] Sun K, Ginosar DM, He T, Zhang Y, Fan M, Chen R. Progress in Nonoxidative 
Dehydroaromatization of Methane in the Last 6 Years. Ind Eng Chem Res 2018. https://doi.org/10.1021/acs.iecr.7b04707.

[149] Kosinov N, Coumans FJAG, Uslamin E, Kapteijn F, Hensen EJM. Selective Coke Combustion by Oxygen Pulsing During Mo/ZSM-5-Catalyzed Methane Dehydroaromatization. Angew Chemie - Int Ed 2016. https://doi.org/10.1002/anie.201609442.

[150] Kosinov N, Coumans FJAG, Li G, Uslamin E, Mezari B, Wijpkema ASG, et al. Stable Mo/HZSM-5 methane dehydroaromatization catalysts optimized for high-temperature calcination-regeneration. J Catal 2017. https://doi.org/10.1016/j.jcat.2016.12.006.

[151] Dong X, Song Y, Lin W. A new way to enhance the coke-resistance of Mo/HZSM-5 catalyst for methane dehydroaromatization. Catal Commun 2007. https://doi.org/10.1016/j.catcom.2006.02.014.

[152] Li L, Borry RW, Iglesia E. Design and optimization of catalysts and membrane reactors for the non-oxidative conversion of methane. Chem Eng Sci 2002. https://doi.org/10.1016/S0009-2509(02)00314-7.

[153] Gao K, Yang J, Seidel-Morgenstern A, Hamel C. Methane Dehydro-Aromatization: Potential of a Mo/MCM-22 Catalyst and Hydrogene-Selective Membranes. ChemieIngenieur-Technik 2016. https://doi.org/10.1002/cite.201500139.

[154] Iliuta MC, Iliuta I, Grandjean BPA, Larachi F. Kinetics of methane nonoxidative aromatization over Ru-Mo/HZSM-5 catalyst. Ind Eng Chem Res 2003. https://doi.org/10.1021/ie030044r.

[155] Wong KS, Thybaut JW, Tangstad E, Stöcker MW, Marin GB. Methane aromatisation based upon elementary steps: Kinetic and catalyst descriptors. Microporous Mesoporous Mater 2012. https://doi.org/10.1016/j.micromeso.2012.07.002.

[156] I. Fayzullaev N. Kinetics and Mechanism of the Reaction of Catalytic Dehydroaromatization of Methane. Int J Oil, Gas Coal Eng 2017. https://doi.org/10.11648/j.ogce.20170506.11.

[157] Yao B, Chen J, Liu D, Fang D. Intrinsic kinetics of methane aromatization under nonoxidative conditions over modified Mo/HZSM-5 catalysts. J Nat Gas Chem 2008. https://doi.org/10.1016/S1003-9953(08)60027-4.

[158] Jeong J, Hwang A, Kim YT, Hong D-YY, Park M-JJ. Kinetic modeling of methane dehydroaromatization over a Mo2C/H-ZSM5 catalyst: Different deactivation behaviors of the Mo2C and H-ZSM5 sites. Catal Today 2019. https://doi.org/10.1016/j.cattod.2019.09.002.

[159] Karakaya C, Zhu H, Kee J. R. Kinetic modeling of methane dehydroaromatization chemistry on Mo/Zeolite catalysts in packed-bed reactors. Chem Eng Sci 2014;123:47486.

[160] Zhu Y, Al-ebbinni N, Henney R, Yi C, Barat R. Extension to multiple temperatures of a three-reaction global kinetic model for methane dehydroaromatization. Chem Eng Sci 2018;177:132-8. https://doi.org/10.1016/j.ces.2017.11.001. 
[161] Carrasco JC, Lima F V. An optimization-based operability framework for process design and intensification of modular natural gas utilization systems. Comput Chem Eng 2017. https://doi.org/10.1016/j.compchemeng.2016.12.010.

[162] Carrasco JC, Lima F V. Novel operability-based approach for process design and intensification: Application to a membrane reactor for direct methane aromatization. AIChE J 2017. https://doi.org/10.1002/aic.15439.

[163] Fouty NJ, Carrasco JC, Lima F V. Modeling and design optimization of multifunctional membrane reactors for direct methane aromatization. Membranes (Basel) 2017. https://doi.org/10.3390/membranes7030048.

[164] Carrasco JC, Lima F V. Nonlinear operability of a membrane reactor for direct methane aromatization. IFAC-PapersOnLine, 2015. https://doi.org/10.1016/j.ifacol.2015.09.055.

[165] Li L, Borry RW, Iglesia E. Reaction-transport simulations of non-oxidative methane conversion with continuous hydrogen removal - homogeneous-heterogeneous reaction pathways. Chem Eng Sci 2001;56:1869-81. https://doi.org/10.1016/S00092509(00)00465-6.

[166] Robinson B, Bai X, Samanta A, Abdelsayed V, Shekhawat D, Hu J. Stability of Fe- and Zn-Promoted Mo/ZSM-5 Catalysts for Ethane Dehydroaromatization in Cyclic Operation Mode. Energy and Fuels 2018. https://doi.org/10.1021/acs.energyfuels.8b01516.

[167] Ding W, Li S, Meitzner GD, Iglesia E. Methane conversion to aromatics on Mo/H-ZSM5: structure of molybdenum species in working catalysts. J Phys Chem B 2001. https://doi.org/10.1021/jp0030692.

[168] Tempelman CHL, Hensen EJM. On the deactivation of Mo/HZSM-5 in the methane dehydroaromatization reaction. Appl Catal B Environ 2015. https://doi.org/10.1016/j.apcatb.2015.04.052.

[169] Gheysens K. A top down approach on the kinetic modelling of methane aromatisation: from global kinetics to a bifunctional mechanism. Ghent University, n.d.

[170] Dumez FJ, Froment GF. Dehydrogenation of 1-Butene into Butadiene. Kinetics, Catalyst Coking, and Reactor Design. Ind Eng Chem Process Des Dev 1976. https://doi.org/10.1021/i260058a014.

[171] Acharya DR, Hughes R. Modelling of Butene-1 dehydrogenation in a fixed bed reactor Bed and Pellet Profiles. Can J Chem Eng 1990;68:89-96.

[172] Fogler HS. Elements of Chemical Reaction Engineering Fifth Edition. 2016.

[173] Froment GF, Bischoff KB, Wilde juray De. Chemical Reactor Analysis and Design. 3rd editio. John Wiley \& Sons, Inc.; 2011.

[174] Mobed P, Maddala J, Rengaswamy R, Bhattacharyya D, Turton R. Data reconciliation and dynamic modeling of a sour water gas shift reactor. Ind. Eng. Chem. Res., vol. 53, 2014, p. 19855-69. https://doi.org/10.1021/ie500739h.

[175] Adams TA, Barton PI. A dynamic two-dimensional heterogeneous model for water gas 
shift reactors. Int J Hydrogen Energy 2009;34:8877-91.

https://doi.org/10.1016/j.ijhydene.2009.08.045.

[176] Liu TL, Liu WR, Xu XH. Properties and heat transfer coefficients of four molten-salt high temperature heat transfer fluid candidates for concentrating solar power plants. IOP Conf. Ser. Earth Environ. Sci., 2017. https://doi.org/10.1088/1755-1315/93/1/012023.

[177] Satterfield CN, M.I.T. Mass Transfer Heterogeneous Catalysis. Bimetallic Nanostructures 2018. https://doi.org/10.1002/9781119214618.ch11.

[178] Penny C, Naylor D, Friedman J. Heat transfer to small cylinders immersed in a packed bed. Int J Heat Mass Transf 2010;53:5183-9. https://doi.org/10.1016/j.ijheatmasstransfer.2010.07.042.

[179] Jiao Y, Fan X, Perdjon M, Yang Z, Zhang J. Vapor-phase transport (VPT) modification of ZSM-5/SiC foam catalyst using TPAOH vapor to improve the methanol-to-propylene (MTP) reaction. Appl Catal A Gen 2017. https://doi.org/10.1016/j.apcata.2017.07.036.

[180] Xu Y, Song Y, Liu X, Zhang ZG. Effect of Bed Height on the Performance of a Fixed Mo/HZSM-5 Bed in Direct Aromatization of Methane. Chem Eng Technol 2016. https://doi.org/10.1002/ceat.201600178.

[181] Lidström P, Tierney J, Wathey B, Westman J. Microwave assisted organic synthesis - A review. Tetrahedron 2001. https://doi.org/10.1016/S0040-4020(01)00906-1.

[182] Conde LD, Suib SL. Catalyst nature and frequency effects on the oligomerization of methane via microwave heating. J Phys Chem B 2003. https://doi.org/10.1021/jp022523u.

[183] Conde LD, Marún C, Suib SL. Oligomerization of methane via microwave heating using Raney nickel catalyst. J Catal 2003. https://doi.org/10.1016/S0021-9517(03)00083-6.

[184] Conde LD, Marún C, Suib SL, Fathi Z. Frequency effects in the catalytic oligomerization of methane via microwave heating. ACS Div. Fuel Chem. Prepr., 2002.

[185] Marún C. Catalytic oligomerization of methane via microwave heating. J Phys Chem A 1999. https://doi.org/10.1021/jp984671j.

[186] Lu YH, Li K, Lu YW. Microwave-assisted direct synthesis of butene from high-selectivity methane. R Soc Open Sci 2017. https://doi.org/10.1098/rsos.171367.

[187] Gerasev AP. Emergence of traveling wave endothermic reaction in a catalytic fixed bed under microwave heating. Energy 2017. https://doi.org/10.1016/j.energy.2016.11.042.

[188] Cherbański R. Numerical simulations of heat transfer in a packed column: comparison of microwave and convective heating. Heat Mass Transf Und Stoffuebertragung 2015. https://doi.org/10.1007/s00231-014-1447-5.

[189] Haneishi N, Tsubaki S, Abe E, Maitani MM, Suzuki E ichi, Fujii S, et al. Enhancement of Fixed-bed Flow Reactions under Microwave Irradiation by Local Heating at the Vicinal Contact Points of Catalyst Particles. Sci Rep 2019. https://doi.org/10.1038/s41598-01835988-y.

[190] Haneishi N, Tsubaki S, Maitani MM, Suzuki E, Fujii S, Wada Y. Electromagnetic and 
Heat-Transfer Simulation of the Catalytic Dehydrogenation of Ethylbenzene under Microwave Irradiation. Ind Eng Chem Res 2017. https://doi.org/10.1021/acs.iecr.7b01413.

[191] Bhattacharya M, Basak T, Senagala R. A comprehensive theoretical analysis for the effect of microwave heating on the progress of a first order endothermic reaction. Chem Eng Sci 2011. https://doi.org/10.1016/j.ces.2011.08.003.

[192] Bhattacharya M, Basak T. A theoretical study on the use of microwaves in reducing energy consumption for an endothermic reaction: Role of metal coated bounding surface. Energy 2013. https://doi.org/10.1016/j.energy.2013.03.016.

[193] Muley PD, Nandakumar K, Boldor D. Numerical modelling of microwave heating of a porous catalyst bed. J Microw Power Electromagn Energy 2019. https://doi.org/10.1080/08327823.2019.1569900.

[194] Bai X, Robinson B, Killmer C, Wang Y, Li L, Hu J. Microwave catalytic reactor for upgrading stranded shale gas to aromatics. Fuel 2019. https://doi.org/10.1016/j.fuel.2019.01.147.

[195] Robinson B, Caiola A, Bai X, Abdelsayed V, Shekhawat D, Hu J. Catalytic direct conversion of ethane to value-added chemicals under microwave irradiation. Catal Today 2020. https://doi.org/10.1016/j.cattod.2020.03.001.

[196] Priecel P, Lopez-Sanchez JA. Advantages and Limitations of Microwave Reactors: From Chemical Synthesis to the Catalytic Valorization of Biobased Chemicals. ACS Sustain Chem Eng 2019. https://doi.org/10.1021/acssuschemeng.8b03286.

[197] Hossan MR, Byun D, Dutta P. Analysis of microwave heating for cylindrical shaped objects. Int J Heat Mass Transf 2010. https://doi.org/10.1016/j.ijheatmasstransfer.2010.07.051.

[198] Durka T. Microwave effects in heterogeneous catalysis : Application to gas-solid reactions for hydrogen production. 2013.

[199] Harrison A, Whittaker AG. Microwave Heating. Compr Coord Chem II 2003:741-5. https://doi.org/10.1016/B0-08-043748-6/01162-2.

[200] Oliveira MEC, Franca AS. Microwave heating of foodstuffs. J Food Eng 2002. https://doi.org/10.1016/S0260-8774(01)00176-5.

[201] Basak T. Theoretical analysis on the role of annular metallic shapes for microwave processing of food dielectric cylinders with various irradiations. Int J Heat Mass Transf 2011. https://doi.org/10.1016/j.ijheatmasstransfer.2010.09.047.

[202] Pangrle BJ, Ayappa KG, Davis HT, Davis EA, Gordon J. Microwave thawing of cylinders. AIChE J 1991. https://doi.org/10.1002/aic.690371204.

[203] Sun J, Wang W, Yue Q. Review on microwave-matter interaction fundamentals and efficient microwave-associated heating strategies. Materials (Basel) 2016. https://doi.org/10.3390/ma9040231.

[204] Balanis CA. Advanced Engineering Electromangetics. 2nd ed. John Wiley \& Sons, Inc.; 
2012.

[205] Yang HW, Gunasekaran S. Comparison of temperature distribution in model food cylinders based on Maxwell's equations and Lambert's law during pulsed microwave heating. J Food Eng 2004. https://doi.org/10.1016/j.jfoodeng.2003.08.016.

[206] Julian I, Pedersen CM, Achkasov K, Hueso JL, Hellstern HL, Silva H, et al. Overcoming stability problems in microwave-assisted heterogeneous catalytic processes affected by catalyst coking. Catalysts 2019. https://doi.org/10.3390/catal9100867.

[207] Ostace A, Kocan KX, Mebane DS, Schmal JP, Bhattacharyya D. Probabilistic Model Building with Uncertainty Quantification and Propagation for a Dynamic Fixed Bed CO2 Capture Process. Energy and Fuels 2020. https://doi.org/10.1021/acs.energyfuels.9b03250.

[208] Collier AR, Hayhurst AN, Richardson JL, Scott SA. The heat transfer coefficient between a particle and a bed (packed or fluidised) of much larger particles. Chem Eng Sci 2004. https://doi.org/10.1016/j.ces.2004.07.029.

[209] Samanta A, Bai X, Robinson B, Chen H, Hu J. Conversion of light alkane to value-added chemicals over ZSM-5/metal promoted catalysts. Ind Eng Chem Res 2017. https://doi.org/10.1021/acs.iecr.7b02095.

[210] Hasnan NSN, Timmiati SN, Lim KL, Yaakob Z, Kamaruddin NHN, Teh LP. Recent developments in methane decomposition over heterogeneous catalysts: an overview. Mater Renew Sustain Energy 2020. https://doi.org/10.1007/s40243-020-00167-5.

[211] Srilatha K, Bhagawan D, Shiva Kumar S, Himabindu V. Sustainable fuel production by thermocatalytic decomposition of methane - A review. South African J Chem Eng 2017. https://doi.org/10.1016/j.sajce.2017.10.002.

[212] Yang M, You F. Modular methanol manufacturing from shale gas: Techno-economic and environmental analyses of conventional large-scale production versus small-scale distributed, modular processing. AIChE J 2018. https://doi.org/10.1002/aic.15958.

[213] Corredor EC, Chitta P, Deo MD. Techno-economic evaluation of a process for direct conversion of methane to aromatics. Fuel Process Technol 2019. https://doi.org/10.1016/j.fuproc.2018.05.038.

[214] Pérez-Uresti S, Adrián-Mendiola J, El-Halwagi M, Jiménez-Gutiérrez A. TechnoEconomic Assessment of Benzene Production from Shale Gas. Processes 2017. https://doi.org/10.3390/pr5030033.

[215] Huang K, Miller JB, Huber GW, Dumesic JA, Maravelias CT. A General Framework for the Evaluation of Direct Nonoxidative Methane Conversion Strategies. Joule 2018. https://doi.org/10.1016/j.joule.2018.01.001.

[216] Gasparini. Metals and materials for low temperature cryogenic operation n.d. https://www.gasparini.com/en/blog/metals-and-materials-for-low-temperatures/.

[217] Phillips SD, Tarud JK, Biddy MJ, Dutta A. Gasoline from Wood via Integrated Gasification, Synthesis, and Methanol-to-Gasoline Technologies. 2011. 
https://doi.org/10.2172/1004790.

[218] Mevawala C, Jiang Y, Bhattacharyya D. Techno-economic optimization of shale gas to dimethyl ether production processes via direct and indirect synthesis routes. Appl Energy 2019;238:119-34. https://doi.org/10.1016/J.APENERGY.2019.01.044. 